\title{
Structure and Mechanics of the Subducted Gorda Plate: Constrained by Afterslip Simulations and Scattered Seismic Waves
}

\author{
by \\ Jianhua Gong
}

B.S., Peking University (2012)

M.S., Peking University (2015)

Submitted to the Department of Earth, Atmospheric, and Planetary Sciences in partial fulfillment of the requirements for the degree of

Doctor of Philosophy

at the

\section{MASSACHUSETTS INSTITUTE OF TECHNOLOGY and the}

\section{WOODS HOLE OCEANOGRAPHIC INSTITUTION}

February 2021

(C) 2021 Jianhua Gong. All rights reserved.

The author hereby grants to MIT and WHOI permission to reproduce and to distribute publicly paper and electronic copies of this thesis document in whole or in part in any medium now known or hereafter created.

Author

Department of Earth, Atmospheric, and Planetary Sciences Massachusetts Institute of Technology $\&$ Woods Hole Oceanographic Institution January 4, 2021

Certified by

Dr. Jeffrey Joseph McGuire Research Geophysicist, Earthquake Science Center United States Geological Survey Thesis Supervisor

Certified by

Dr. Daniel Lizarralde

Associate Scientist with Tenure, Department of Geology \& Geophysics Woods Hole Oceanographic Institution Thesis Supervisor

Accepted by

Dr. Oliver Jagoutz

Professor of Geology, Department of Earth and Planetary Sciences Massachusetts Institute of Technology Chair, Joint Committee for Marine Geology \& Geophysics 


\title{
Structure and Mechanics of the Subducted Gorda Plate: Constrained by Afterslip Simulations and Scattered Seismic Waves
}

\author{
by \\ Jianhua Gong \\ Submitted to the Department of Earth, Atmospheric, and Planetary Sciences \\ Massachusetts Institute of Technology \\ \& Woods Hole Oceanographic Institution \\ on January 4, 2021, in partial fulfillment of the \\ requirements for the degree of \\ Doctor of Philosophy
}

\begin{abstract}
Subduction zones host the greatest earthquakes on earth and pose great threat to human society. The largest slip in megathrust earthquakes often occurs in the 10-50 km depth range, yet seismic imaging of the material properties in this region has proven difficult. This thesis focuses on developing methods to utilize high frequency (2-12 Hz) seismic waves scattered from the megathrust plate interface to constrain its fine-scale velocity structures and to investigate the relationship between velocity structures and megathrust slip behaviors. Chapter 2 investigates the locking condition of the subducted Gorda plate by simulating afterslip that would be expected as a result of the stress changes from offshore strike-slip earthquakes. Chapter 3 develops array analysis methods to identify P-to-S and S-to-P seismic converted phases that convert at the subducted Gorda plate interface from local earthquakes and uses them to constrain the geometry and material properties of the plate boundary fault of the subducted Gorda plate between 5-20 km depth. Chapters 4 and 5 use a dense nodal array and numerical modeling methods to study the seismic guided waves that propagate along the thin low velocity layer at the boundary of the subducted Gorda plate. Taken together, our results indicate that material properties of the subduction plateboundary fault is highly heterogeneous and the plate-boundary fault is potentially contained in a low velocity layer with significant porosity and fluid content at seismogenic depths.
\end{abstract}

Thesis Supervisor: Dr. Jeffrey Joseph McGuire

Title: Research Geophysicist, Earthquake Science Center

United States Geological Survey

Thesis Supervisor: Dr. Daniel Lizarralde

Title: Associate Scientist with Tenure, Department of Geology \& Geophysics

Woods Hole Oceanographic Institution 


\section{Acknowledgments}

Coming to the United States for a $\mathrm{PhD}$ is a big adventure. There are many people who helped me to get to this point and supported me both academically and emotionally. I am grateful to all of you.

First and foremost, I thank my advisor, Jeff McGuire, without whom this thesis would not be possible. Jeff provided the key ideas for each chapter of this thesis and offered me many opportunities for field works, research cruises, conferences and workshops that helped me to see a bigger picture of a research project and to communicate my work with other people. He taught me to study earthquakes from both the seismological and the geodetic perspectives. Over the past 5.5 years, he has given me endless encouragement to help me overcome the hard times. I will always appreciate him spending his spare time working on my writing. I will never forget the whiteboard in his office on which we laid out the structure of each chapter, and which is also too high that I could never reach the top. I have many things I want to thank Jeff for. But most of all, I thank him for bringing me to the Joint Program. In his career, Jeff has collaborated with many Chinese scholars including several from my alma mater. It is the excellent researchers before me built his trust, and I hope one day I could become one of them!

Second, I thank my co-advisor Dan Lizarralde. I could still remember the time when we met in the parking lot one day in the morning and you said to me: "we need to find you a co-advisor at WHOI", and then "I am happy to do that". I was thinking to ask you to be my co-advisor at the similar time, but you asked me first! Thank you for your constant checking in through the COVID time. The last few months towards my graduation wouldn't have been smooth without your encouragement and support.

I am grateful to my other committee members - John Collins, Matej Pec and Rob Evans - for giving me support and sharing their expertise. I thank John for giving me a tour to the OBS lab that I had wished for a long time, introducing me to the wavefield decomposition method that is used in the third chapter and the discussions on OBS instrument response and tilting. I thank Matej Pec for the imaging short course at MIT and the discussion of the mélange shear zones. I thank Rob for the EM workshop at Woods Hole and his knowledge of fluids in subduction zones from the EM data.

Chapters 3-5 of this thesis would not have been possible without the help from Hao Guo, Wenyuan Fan and Marleen Nyst. I thank Hao Guo for providing the tomography and earthquake location results near the Mendocino Triple Junction, the study area of this thesis. The method developed in Chapter 3 highly relies on the high-resolution $\mathrm{P}$ and $\mathrm{S}$ wave velocity models and the accurate earthquake locations from his work. I thank Wenyuan Fan and Marleen Nyst for the design and deployment of the nodal array in Northern California that collects data for Chapters 4 and 5. Thank you for climbing up and down the hills with the heavy nodes and making it a successful experiment.

I am grateful to Professor Brian Evans for guiding me through the second general project and allowing me to muck around in his lab. I feel lucky that I could learn the concept of permeability in such a hands-on way. I thank Professor Evans for his kindness, patience and 
tolerance. I also thank EAPS graduate student Ekaterina Bolotskaya for conducting the experiments together and ERL students and researchers-Chen $\mathrm{Gu}$, Wenlian Xiao, Saied Mighani, Ulrich Mok, Yves Bernabé and Stephen Brown - for various discussions and guidance through the project.

Going on research cruise is an advantage of studying at WHOI. I thank Jessica Warren and Mark Behn for leading a successful cruise to the Gofar transform fault. I thank the OBS team-Alan Gardner, Dan Knot and Martin Rapa - for letting me operate the transponder. I thank all the graduate students and postdocs on the cruise for their delightful science talks and friendship!

I greatly appreciate many WHOI scientists through their teaching and support. I thank Ralph Stephen for his two-student seismology class. I thank Dan Lizarralde, Adam Soule, Olivier Marchal and Liviu Giosan for a really broad Geological Oceanography. I thank Veronique Le Roux and Virginia Edgcomb for a practical presentation training course. I thank Mark Behn and Veronique Le Roux for organizing the special seminar on oceanic crust and leading the SCARF cruise. I thank Pablo Canales for chairing my defense.

I am also thankful for the wonderful and challenging classes and seminars I took at MIT and Harvard by Tom Herring, Brian Evans, Brad Hager, Laurent Demanet, Florent Brenguier and Miaki Ishii.

I thank Andrew Daly for organizing the geodynamic seminar and the field trip to Josephine Ophiolite and Henry Dick and Professor Tim Grove's instruction of the geology of western US. Even though I was confused looking at those rocks in the field, it turned out to be very helpful when I read papers on the geology of the Mendocino Triple Junction after we came back.

I appreciate the support from the Academic Programs Office. Especially, I would like to thank Meg Tivey and Delia Oppo for the caring meetings with me after Jeff moved to USGS; Julia Westwater and Lea Fraser for many emails on classes, registrations and event scheduling; Valerie Caron and Martha Bridgers for maintaining the tidiness of Oyster Pond complex where I had stayed for 2.5 years; Kris Kipp for booking rooms and all the chats on the 8th floor; and to many who work behind-the-scenes that I don't really know about.

I thank the G\&G department admins, in particular Sally Houghton and Christina Cuellar, for their prompt help with any office issue. As an international student, our study wouldn't be smooth without the support from MIT International Student Office. I thank Janka Moss for many emails and several zoom meetings for helping me with the immigration related procedure towards graduation.

I would like to thank my Master's advisor Zengxi Ge for being the first role model as a researcher and other faculty members at the Geophysics Department of Peking University who opened the door for me to seismology.

My life at Falmouth wouldn't be so colorful without my fellow students in the Joint Program. I thank Lizzie Wallace for the softball games, being roommates at OP, many chats in the office and lots of favors; Billy Shinevar for sharing an office, the Wednesday night 
reading club and writing the SCARF paper; Emmanuel Codillo for being always encouraging and answering many questions; Hannah Mark, Megan Jones and Laura Stevens for being excellent role models next to my office; Ben Urann for driving during the geodynamic trip; Tianyi Huang for being roommates both at WHOI and MIT; Fiona Clerc, Rose Palermo, Emmanuel Codillo, Paris Smalls for being together on the student search committee and teaching me a lot of things; Laura Fleming, Genevieve Flaspohler, Astrid Pacini, Julia Middleton and Marianne Acker for sharing rooms at OP for no matter short or long; Astrid Pacini and Mara Freilich for leading the student cruise; Ning Zhao for help, advice and pick-ups during my initial stay at Woods Hole.

I also thank students on the 2nd, 5th and 6th floor at EAPS for their companionship and help during my first 2.5 years in Boston. I thank Shujuan Mao, Harry Matchette-Downes, Hongyu Sun, Eric Beaucé, Eva Golos, Min Ding, Chen Gu and Chunquan Yu. I thank Shujuan Mao for being two years' of roommate when I was in Boston and Harry MatchetteDownes for sharing an office WHOI and the delightful chats at lunch. I thank Professor Robert van der Hilst for letting me stay in the office of his group.

I thank Nathan Miller for sharing his noise correlation code with me on an ambient noise project. I thank Duo Li and Haoran Meng for being guest students in my group and their short companionship at Woods Hole.

Many Chinese friends both here and in China have brought me a lot of happiness during the last 5.5 years. I thank Hanchao Jian, Menghe Guo, Tingting Zheng, Chuanxu Chen for the happy parties. I thank my Chinese friends who have visited me, Qianyun Lu, Yue Zhang, Shilu Zhang, Hanwen Wu and Minghao Sun, Jinghua Yang, Linxi Zhang. And I thank my old friends in China-Shuxian Zhao, Jiaying Yang, Luqing Cao, Yi Deng, Changhong Li, Xue Liu, Yuxuan Li, and my 13 "siblings" in the Cycling Association of Peking University — for keeping in touch, entertaining me and feeding me every time I came back.

I thank my English tutor Jackie Webster for chatting with me and Hanchao about the news on Falmouth Enterprise. I thank my housemates Collin Dobson and Charlotte Rivard and my landlord Scott Bressoud and Elizabeth Beardshaw for having me in the house and making my life at Falmouth smooth and calm.

I thank Talon Chandler for all the interesting books, lots of trivia and songs of different genres.

Finally, I thank my parents, Lijun Gou and Suhe Gong, for your endless support. Skyping with you became a daily routine after the start of COVID pandemic. I know your concern and longing for me all the time. I hope to come back to see you soon!

Funding for this research was provided by National Science Foundation Division of Earth Sciences (EAR) award \#1520690 and the WHOI Academic Programs Office. 


\section{Contents}

$\begin{array}{ll}\text { Abstract } & 3\end{array}$

Acknowledgments $\quad 5$

$\begin{array}{ll}\text { List of Figures } & 13\end{array}$

$\begin{array}{ll}\text { List of Tables } & 17\end{array}$

1 Introduction $\quad 19$

1.1 Tectonic and geologic setting of the Mendocino Triple Junction . . . . . . . . 20

1.1.1 Tectonic and geologic overview . . . . . . . . . . . . . 20

1.1.2 Faults and seismicity near MTJ . . . . . . . . . . . . . . . 21

1.1.3 Deformation and stress near MTJ . . . . . . . . . . . . . 25

1.1.4 Seismic imaging and tomography near MTJ . . . . . . . . . . . 26

1.2 Structural geology and rock physics studies of subduction plate interface material properties at seismogenic depths . . . . . . . . . . . . . . 28

1.2.1 Structural geology study of mélange shear zones . . . . . . . . . . . 28

1.2.2 Rock physics study of frictional properties of subduction plate interface 30

1.3 Seismic imaging of the subduction plate-boundary faults at seismogenic depths 31

1.3.1 Active source . . . . . . . . . . . . . . . . . . . . 31

1.3.2 Receiver functions . . . . . . . . . . . . . . . . . 33

1.3.3 Direct observations of seismic scattering phases . . . . . . . . . . 33

1.3 .4 Tomography . . . . . . . . . . . . . . . . . . . . 34

1.3.5 Summary . . . . . . . . . . . . . . . . . . . 35

1.4 Subduction zone megathrust earthquakes and physical properties of forearc

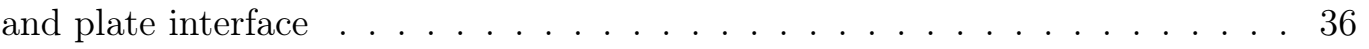


1.4.1 Structure and stress of the overriding plate . . . . . . . . . 36

1.4.2 Thermal and petrological controlled frictional properties . . . . . . . 37

1.4.3 Stress, strength and pore pressure of the plate-boundary faults . . . . 38

1.4.4 Faulting in the subducted slab . . . . . . . . . . . . . . 40

1.4.5 Roughness of plate interface and the role of subducted sediments . . . 40

1.4 .6 Summary . . . . . . . . . . . . . . . . . . . . . . 42

1.5 Thesis structure . . . . . . . . . . . . . . . . . . . . . . 42

2 Interactions Between Strike-slip Earthquakes and the Subduction Interface near the Mendocino Triple Junction 45

2.1 Introduction . . . . . . . . . . . . . . . . . . 45

2.2 Data and resources . . . . . . . . . . . . . . . . . . . 47

2.3 Second moments inversion . . . . . . . . . . . . . . . . . . 49

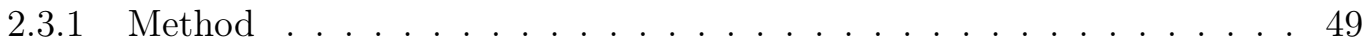

2.3.2 EGF deconvolution . . . . . . . . . . . . . . . . . . 51

2.3 .3 Inversion result $\ldots \ldots \ldots \ldots \ldots$

2.4 Coseismic Coulomb stress change . . . . . . . . . . . . . . 55

2.5 Afterslip simulation . . . . . . . . . . . . . . . 56

2.6 Discussion . . . . . . . . . . . . . . . . . . . 60

3 Constraints on the Geometry of the Subducted Gorda Plate from Converted Phases Generated by Local Earthquakes $\quad 63$

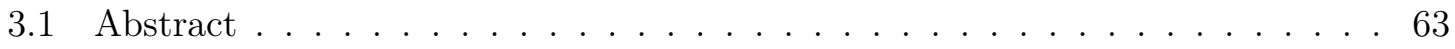

3.2 Introduction . . . . . . . . . . . . . . . . . . 64

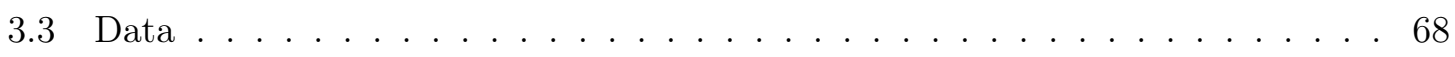

3.4 Methods . . . . . . . . . . . . . . . . . . 70

3.4 .1 Raytracing . . . . . . . . . . . . . . . 70

3.4.2 Source side beamforming . . . . . . . . . . . . . . . 72

3.4 .3 Wavefield decomposition . . . . . . . . . . . 76

3.5 Results. . . . . . . . . . . . . . . . . . . . 78

3.5.1 Northern onshore stations with SP phases . . . . . . . . . 78

3.5.2 Southern onshore stations with $\mathrm{SP}$ arrivals . . . . . . . . . . 80

3.5.3 Eastern onshore stations with Ps arrivals . . . . . . . . . . . . . 82 
3.6 Discussion . . . . . . . . . . . . . . . . . . . . . . 84

3.6.1 Implications for slab geometry . . . . . . . . . . . . . . . . 84

3.6.2 Estimation of velocity contrast . . . . . . . . . . . . . . 88

3.6.3 Single station variability in converted phase amplitudes . . . . . . . . 93

3.6.4 Spatial variations in the converted phases observations . . . . . . . . 94

3.7 Conclusions . . . . . . . . . . . . . . . . . . . 96

3.8 Acknowledgement . . . . . . . . . . . . . . . . . . . . . . . 98

4 Observations of Guided Waves from Slab Interface Earthquakes 99

4.1 Introduction . . . . . . . . . . . . . . . . . . . . 99

4.2 Cascadia Initiative observations . . . . . . . . . . . . . . . . . . . 103

4.3 Design of nodal array experiment . . . . . . . . . . . . . 106

4.4 Nodal array experiment data . . . . . . . . . . . . . . . . . . 108

4.5 Array analysis . . . . . . . . . . . . . . . . . . 109

4.5.1 Method ... . . . . . . . . . . . . . . 109

4.5.2 Data processing . . . . . . . . . . . . . . . . . 111

4.5 .3 Results . . . . . . . . . . . . . . . . . . . 112

4.6 Summary . . . . . . . . . . . . . . . . . . . . . . 115

5 Numerical Simulations of Guided Waves from Earthquakes Located near the Slab Interface $\quad 119$

5.1 Introduction . . . . . . . . . . . . . . . . . . . . . 119

5.2 Model setup . . . . . . . . . . . . . . . . . . . . . . . 124

5.3 Simulation results . . . . . . . . . . . . . . . . . . 127

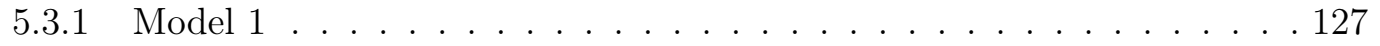

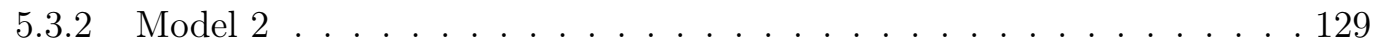

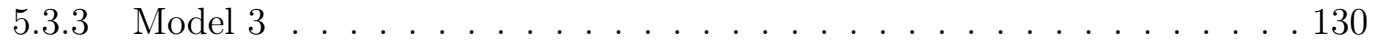

5.4 Discussion . . . . . . . . . . . . . . . . . . . . . . 131

$5.4 .1 \mathrm{~S} 1, \mathrm{~S} 2$ phases and Model 1. . . . . . . . . . . . 131

5.4 .2 S coda and Model $3 \ldots \ldots$. . . . . . . . . . . . . . . . . . . . .

5.4 .3 Geological Implications: LVZ on top of the crust . . . . . . . . . . . 132

5.4.4 Geological Implications: Heterogeneity of the plate boundary zone . . 136 
5.4.5 Geological Implications: Pore pressure and stress state of the plate boundary faults . . . . . . . . . . . . . . . . 137

5.4.6 Additional properties of the S-wave at KCT . . . . . . . . . . . 138

5.5 Conclusions . . . . . . . . . . . . . . . . . . . . . . 139

6 Conclusions and Future Directions $\quad 143$

6.1 Thesis summary . . . . . . . . . . . . . . . . . . . 143

6.2 Future directions . . . . . . . . . . . . . . . . . . . . 146

6.2.1 Numerical simulation of wave propagation in subduction zones . . . . 146

6.2 .2 Dense arrays . . . . . . . . . . . . . . . . . 146

6.2 .3 Advanced imaging methods . . . . . . . . . . . . . . . 147

A Appendix for "Constraints on the Geometry of the Subducted Gorda Plate from Converted Phases Generated by Local Earthquakes" 149

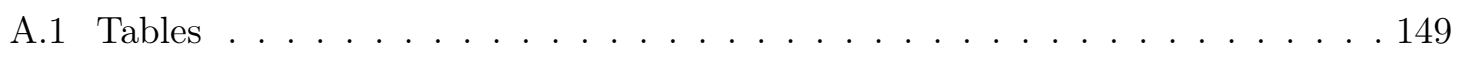

A.2 Ray tracing validation . . . . . . . . . . . . . . . . . . . . 149

A.3 Effects of dipping slab . . . . . . . . . . . . . . . . . 154

A.4 Additional results . . . . . . . . . . . . . . . . . . . . 155

A.4.1 Central onshore stations with Ps arrivals . . . . . . . . . 155

A.4.2 OBS stations with $\mathrm{SP}$ and Ps arrivals . . . . . . . . . 156

A.5 Figures. . . . . . . . . . . . . . . . . . . . 158

B Appendix for "Observations of Guided Waves from Slab Interface Earthquakes" 163

B.1 Recurrence rate of the five clusters . . . . . . . . . . . . . . . 163

B.2 Sensor rotate . . . . . . . . . . . . . . . . . . 164

B.3 Near surface velocity . . . . . . . . . . . . . . . . . . . . 164

B.4 Polarization analysis . . . . . . . . . . . . . . . 166

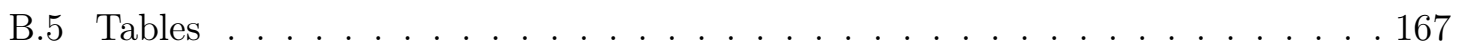

B.6 Figures. . . . . . . . . . . . . . . . . . . . . 168

$\begin{array}{ll}\text { Bibliography } & 175\end{array}$ 


\section{List of Figures}

1-1 Simplified geologic map of northern coastal California. . . . . . . . . . . . . 21

1-2 Inter- and intraplate faults near MTJ. . . . . . . . . . . . . . . 22

1-3 Seismicity near MTJ. . . . . . . . . . . . . . . . . . 24

2-1 Map of the study area near the MTJ. . . . . . . . . . . . . . . . 48

$2-2$ WHOI Keck OBS. . . . . . . . . . . . . . . . . . . . 49

2-3 EGF deconvolution and ASTF. . . . . . . . . . . . . . . 53

2-4 Apparent duration. . . . . . . . . . . . . . . . . 54

2-5 Geometry setup for afterslip simulation. . . . . . . . . . . . . . . 55

2-6 Coseismic Coulomb stress changes on the plate interface. . . . . . . . . . . 56

2-7 Accumulated afterslip on the slab interface and corresponding GPS displace-

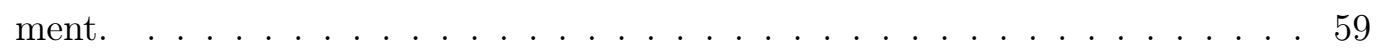

2-8 Predicted accumulated afterslip signal on the seafloor. . . . . . . . . . . 60

3-1 Map of the study area. . . . . . . . . . . . . . . . . . . . 69

$3-2$ Raytracing results. . . . . . . . . . . . . . . . . . . 71

3-3 Waveform section and source side 3D beamforming results. . . . . . . . . . 73

3-4 Wavefield decomposition results. . . . . . . . . . . . . . 77

3-5 SP converted phases at stations in the north. . . . . . . . . . . . . . 79

3-6 SP converted phases at stations in the south. . . . . . . . . . 80

3-7 Shallow SP converted phases at station B047. . . . . . . . . . . . . . 81

$3-8$ Ps converted phases at stations in the east. . . . . . . . . . . . 83

3-9 Comparison between the Slab1.0 and Slab2 models. . . . . . . . . . . . . . . . 85

3-10 Velocity models for calculating synthetic seismograms. . . . . . . . . . . . 89

3-11 Amplitude ratio measurements from synthetic seismograms and real data. . . 90 
3-12 Mapview of conversion points on the Slab1.0 interface from onshore stations.

4-1 CI experiment and five near slab-interface clusters. . . . . . . . . . . . 103

4-2 Earthquakes in the below cluster C1. . . . . . . . . . . . . . 105

4-3 Comparison between waveforms of events from cluster $\mathrm{C} 1$ and events below cluster C1. . . . . . . . . . . . . . . . . . . 107

4-4 Time frequency analysis of waveforms of an event from C1. . . . . . . . 108

$4-5 \quad$ Nodal array experiment. . . . . . . . . . . . . . . . . . . . 109

$4-6$ Candidate events. . . . . . . . . . . . . . . . . . . . . . 110

$4-7 \quad$ Waveforms of Candidate $2 \ldots \ldots \ldots \ldots \ldots 11$

4-8 Running window beamforming results on $\mathrm{P}$ wave. . . . . . . . . . . . . . 112

4-9 Running window beamforming results on $\mathrm{S}$ wave. . . . . . . . . . . . . . 113

4-10 Events that show double $\mathrm{P}$ and double S arrivals. . . . . . . . . . . . . . 114

4-11 Partition of $\mathrm{P}$ and $\mathrm{S}$ waves. . . . . . . . . . . . . . . . 115

5-1 The 3 different 2D seismic models utilized in the synthetic waveform simulations. 126

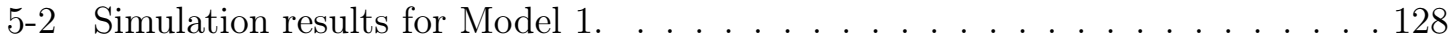

5-3 Wave propagation snapshot for Model 2. . . . . . . . . . . . . . . . . . 129

5-4 Waveform sections from Model 2. . . . . . . . . . . . . . . . . 130

$5-5$ Simulation results for Model 3. . . . . . . . . . . . . . . . . . 131

5-6 Ray parameters of $\mathrm{P}, \mathrm{S}$ and $\mathrm{PmP}$ and $\mathrm{SmS}$ phases. . . . . . . . . . . . . 132

5-7 Velocity waveform comparisons between the 3 models and real record on station KCT. . . . . . . . . . . . . . . . . . . . . 133

$5-8$ Summary of simulations . . . . . . . . . . . . . . . . . 141

A-1 Raypaths for simple layer models. . . . . . . . . . . . . . . . . . 151

A-2 Velocity models used for 2D wave propagation simulation and raytracing. . . 152

A-3 2D wave propagation simulation. . . . . . . . . . . . . . 153

A-4 Transmission/reflection coefficients as a function of incident angle. . . . . . 154

A-5 Ps converted phases at stations in the middle of the array. . . . . . . . 156

A-6 Ps and SP converted phases on OBS station FS13D near the deformation

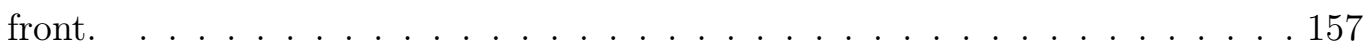

A-7 Ps and SP converted phases on OBS stations. . . . . . . . . . . 158 
A-8 Schematic plots of SP converted phase raypaths for B047 synthetic waveforms.159

A-9 Comparison between real data and synthetic data for station CM03A. . . . . 159

A-10 Examples of amplitude ratio variations for clustered events at station CM01A.160

A-11 Examples of amplitude ratio variations for common events. . . . . . . . . . . 161

A-12 Amplitude ratio variations on single station. . . . . . . . . . . . . . . . 161

B-1 Recurrence rate of events in cluster C1. . . . . . . . . . . . . . 163

B-2 3D beamforming. . . . . . . . . . . . . . . . . 165

B-3 Polarization analysis of the master event. . . . . . . . . . . . 166

B-4 Waveforms of events in and below cluster C2. . . . . . . . . . . . . 168

B-5 Comparison of waveforms from the five clusters. . . . . . . . . . . . . . 169

B-6 Instrument response of the node. . . . . . . . . . . . . . . . . . . . 169

B-7 Running window beamforming results on $\mathrm{S}$ wave. . . . . . . . . . . . . . . 170

B-8 Double P arrivals from events north of KCT. . . . . . . . . . . . . . . . 171

B-9 Double S arrivals from events north of KCT. . . . . . . . . . . . . . . . . 172

B-10 Double S arrivals from events north of KCT (continued) . . . . . . . . . . . . 173

B-11 Waveforms from event 84 south of KCT. . . . . . . . . . . . . . . . . 174 


\section{List of Tables}

2.1 Information of 2015 earthquake. . . . . . . . . . . . . . . . . . 47

2.2 Second moments estimates. . . . . . . . . . . . . . . . . 53

5.1 Parameters for wave propagation simulation. . . . . . . . . . . . 127

A.1 Summary of beamforming results. . . . . . . . . . . . . . . . . . 150

A.2 Station parameters for FK simulation. . . . . . . . . . . . . . 150

A.3 Ray parameter range for the different type of waves shown in Fig. A-1. . . . . 151

B.1 Rotation angle estimates. . . . . . . . . . . . . . . . . 164

B.2 Summay of five slab interface earthquake clusters . . . . . . . . . . . 167

B.3 Summay of slowness analysis of events north of station KCT. . . . . . . . . 167 


\section{Chapter 1}

\section{Introduction}

This thesis uses high-frequency $(2-12 \mathrm{~Hz})$ scattered seismic waves (converted phases and guided waves) to image subduction plate-boundary faults at seismogenic depths and to understand the relationships between the velocity structure of the plate-boundary faults zone, the interseismic locking conditions, and the seismogenic behaviors on these faults. We use seismic data from an amphibious seismic array near the Mendocino Triple Junction (MTJ) from the Cascadia Initiative experiment (Toomey et al., 2014), one of the densest onshore-offshore seismic datasets in the world, to image the plate interface of the subducted Gorda plate at the southern end of the Cascadia subduction zone.

We begin by introducing the tectonic and geologic setting of the Mendocino Triple Junction, use seismicity to delineate inter- and intra-plate faults, discuss deformation patterns near the triple junction, and review previous imaging results in this area. Second, we briefly summarize structural geology observations of subduction mélange shear zones, that represent previously active subduction plate boundaries that have been exhumed from depth, interpretations of their material properties and deformation mechanisms, and our understanding of the thermodynamic and petrology controlled frictional properties of subduction plateboundary faults. Next, we summarize previous seismic imaging results of the subduction plate boundary from various methods including active source, receiver function, scattering phases, and tomography with a focus on those experiments that penetrate into the seismogenic part of the subducted slab. Fourth, we discuss major physical properties of the forearc and subduction plate interface that affect interseismic locking and megathrust earthquakes that have been proposed in literature, their corresponding geophysical observations, 
controversies and limitations. Finally, we outline the structure of the thesis.

\subsection{Tectonic and geologic setting of the Mendocino Triple Junction}

\subsubsection{Tectonic and geologic overview}

The Mendocino triple junction is where the Gorda, Pacific and North American plates meet (Fig. 1-1). North of the MTJ, the young ( $5 \mathrm{Ma}$ ) Gorda plate subducts obliquely beneath the North American plate along the Cascadia subduction zone. South of the MTJ, the tectonics are governed by the transform boundary between the Pacific and North American plates, the San Andreas fault (SAF) system. Offshore, west of the MTJ, the Mendocino transform fault juxtaposes the Gorda plate with older ( $\sim 26 \mathrm{Ma})$ Pacific plate lithosphere. The triple junction initiated at 25-29 Ma when the Pacific spreading center collided with the North American continent (Atwater, 1970; Dickinson and Snyder, 1979; Furlong and Schwartz, 2004). The Juan de Fuca-Pacific plate boundary then migrated northward relative to North America, forming the San Andreas fault system.

The Gorda plate is a nonrigidly deforming tectonic plate. At present, the half-spreading rates of the Gorda Ridge are $26 \mathrm{~mm} / \mathrm{yr}$ at the northern end of the ridge near the Blanco Fracture Zone and $12.5 \mathrm{~mm} / \mathrm{yr}$ near the Mendocino Fracture Zone (Wilson, 1989). Compression from the Pacific plate combined with the variable spreading rate along the Gorda ridge result in the strong internal deformation of the Gorda plate (Chaytor et al., 2004).

Onshore, basement rocks in the vicinity of the MTJ primarily consist of the Franciscan Complex, formed by offscraping and tectonic underplating of rocks (subduction accretion) from an east-dipping subducting plate during the Mesozoic to Cenozoic (160-20 Ma) (Dickinson, 1981; Blake et al., 1982; Blake Jr et al., 1985; Wakabayashi, 1992). The Franciscan is well known for its high-pressure-low-temperature (HP-LT) metamorphism (Ernst, 1970). The Franciscan Complex has been divided into three parallel belts based on differences in lithology, structural fabric, and the degree of metamorphism with increasing rock age and metamorphic grade from west to east (Blake Jr et al., 1985; Furlong and Schwartz, 2004; Wakabayashi, 2011). The three belts are named Coastal, Central, and Eastern Belts (Fig. 1-1). The zeolite-facies Coastal Belt consists of mostly intact but folded and imbricated sandstones and shales from late Cretaceous to early Cenozoic; the Central Belt is 


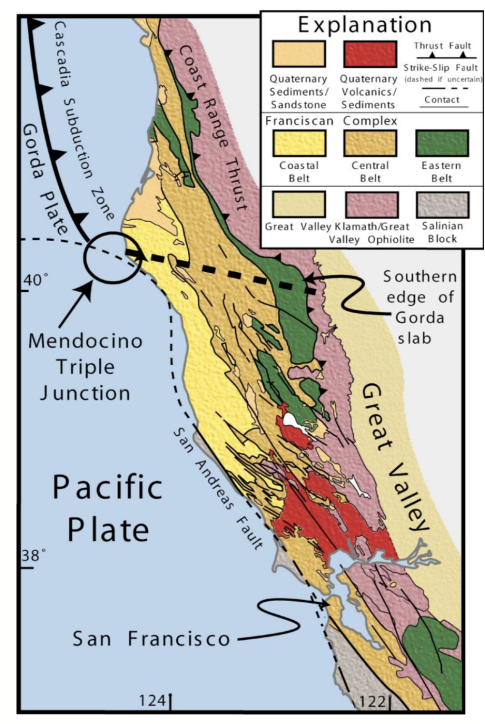

Figure 1-1: Simplified geologic map of northern coastal California from Furlong and Schwartz (2004).

chiefly mélange with prehnite pumpellyite facies matrix of Early Jurassic to Tertiary age; and the Eastern Belt mainly comprises coherent blueschist-facies thrust sheets of Jurassic to Cretaceous age. The Eel River basin overlay the Coastal and Central belt with up to $4 \mathrm{~km}$ of Miocene and younger sedimentary rocks (Clarke and Carver, 1992). North of the MTJ, the Franciscan belts are overlain by the Klamath terrane, composed of arc-related rocks of Paleozoic to Late Jurassic age (Harper, 1980). South of MTJ and the Klamath belt, the Franciscan is attached to the older Great Valley forearc basin and its ophiolitic basement (Godfrey et al., 1997; Beaudoin et al., 1998).

\subsubsection{Faults and seismicity near MTJ}

The Mendocino triple junction area is one of the most seismic active areas in North America with frequent large magnitude earthquakes and abundant microseismicity. Here we use the fault planes of previous $M \geqslant 5.9$ earthquakes, locations of microseismicity and suface mapped Quaternary faults to characterize major plate boundaries between the 3 plates and multiple intraplate faults near the MTJ.

Since 1976, $22 \mathrm{M} \geqslant 5.9$ earthquakes have occurred near MTJ. Hypocenters and fault planes of these earthquakes are shown in Fig. 1-2(a). They are named A to V in chronological order. Events A to T are the same as in Rollins and Stein (2010) between year 1976 and 2010. 

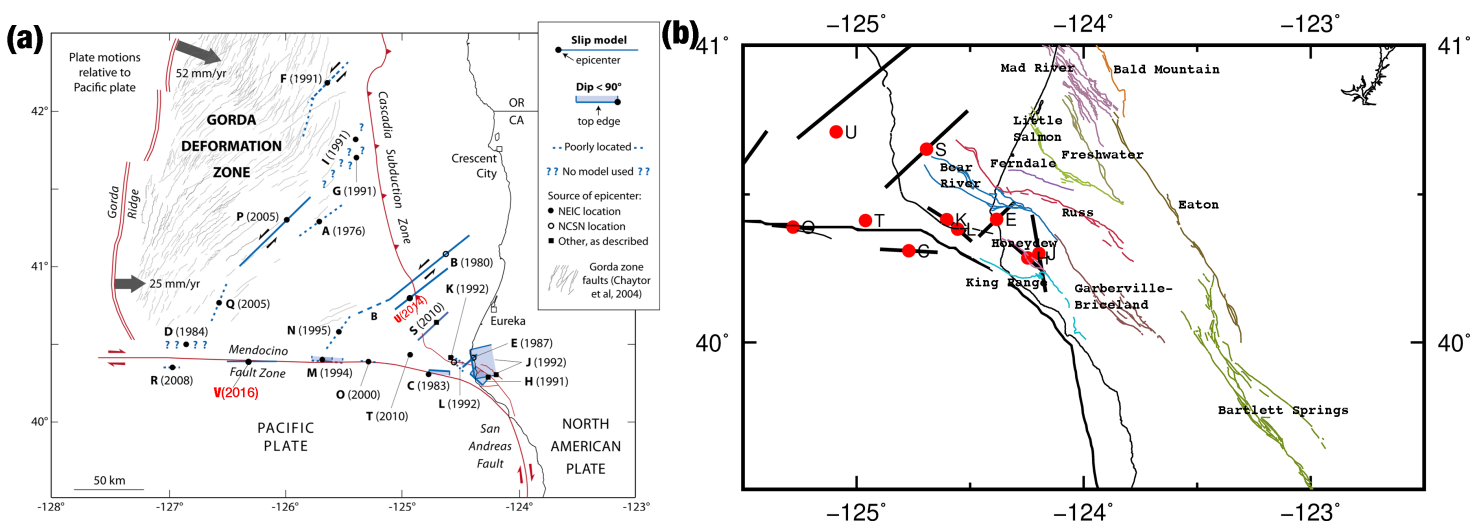

Figure 1-2: Inter- and intraplate faults near MTJ. (a) Tectonic configuration of the Gorda deformation zone and locations and source models for $\mathrm{M} \geqslant 5.9$ earthquakes since 1979. Letters designate chronological order of earthquakes. Original figure is from Rollins and Stein (2010). Events U and V are newly added to the original figure, which represent the 2014-03-05 M6.9 and 2016-12-08 M6.5 earthquakes. Plate motion vectors relative to the Pacific Plate (gray arrows in main diagram) are from Wilson (1989), with Cande and Kent (1995) timescale correction. (b) USGS Quaternary Faults near MTJ.

Events U and V are the 2014-03-05 M6.9 and the 2016-12-08 M6.5 earthquakes respectively. These earthquakes can be separated into three groups: strike-slip earthquakes along the Mendocino transform fault (events C, D, M, O, R, T, V), strike-slip earthquakes inside the Gorda plate (events A, B, E, F, G, I, K, L, N, P, Q, S, U), and thrust earthquakes inside the overriding North American plate (events E, H and J). Events on the transform fault clearly mark the boundary between the Gorda plate and the Pacific plate. These large magnitude earthquakes show interesting triggering relations. For example, events G, H, I occurred on 2 successive days (Table 1 in Rollins and Stein (2010)), and the 1992 Cape Mendocino earthquake (event J) triggered two strike-slip earthquakes in the mantle of Gorda plate (event K and L) on the next day (Oppenheimer et al., 1993; Ammon et al., 1993). Inside the Gorda plate, several strike-slip events appear to be pairwise, such as I and G, A and $\mathrm{P}, \mathrm{B}$ and $\mathrm{U}, \mathrm{K}$ and $\mathrm{L}$. These events indicate the strong internal deformation of the Gorda plate, and many of the faults are operating under critical stress conditions.

Onshore, many shallow strike-slip and thrust faults have developed near MTJ (Fig. 12(b)). Locations of these faults are from USGS Quaternary Faults database. These faults are mostly identified through surface mapping. Trenching studies of these faults have shown that there were $M>6$ earthquakes occurring on these faults in the past a few thousand years, such as on the Mad River fault zone and the Little Salmon fault zone (Carver and Burke, 
1988; Clarke and Carver, 1992) indicating potential seismic hazards on these faults.

Microseismicity provides a more accurate way to delineate plate boundaries and intraplate faults at depth. Fig. 1-3 shows the distribution of microseismicity from Guo et al. (2019) in map view and depth profile. Microseismicity associated with the 1992 Cape Mendocino earthquake aftershocks, Mendocino transform fault, offshore strike-slip faults and those apparently above the subduction slab are highlighted in Fig. 1-3(b)-(e).

The aftershocks of the 1992 Cape Mendocino earthquake are mainly located on an eastward dipping fault at $\sim 10 \mathrm{~km}$ depth (Fig. 1-3(b)). Part of the aftershocks overlap with the projection of the Mendocino transform fault.

For the earthquakes along the Mendocino transform fault, the locations of the events west of $-125^{\circ}$ are not well constrained (Fig. 1-3(c)). There are two places with concentrated seismicity: one between $-124.75^{\circ}$ to $-124.25^{\circ}$ at 20 to $25 \mathrm{~km}$ depth, the other between $-124.5^{\circ}$ to $-124.25^{\circ}$ at 10 to $15 \mathrm{~km}$ depth. The background seismicity is $\sim 5 \mathrm{~km}$ deeper than the former group. The latter group shares similar locations as the southern part of the 1992 earthquake aftershocks. East of $-124.25^{\circ}$, two clusters of seismicity are visible. One is near $-124.2^{\circ}$ at $15 \mathrm{~km}$ depth and the other one is near $-123.75^{\circ}$ below $20 \mathrm{~km}$ depth, seemingly on top of the subducted oceanic crust. However, whether these two clusters represent onshore extension of the Mendocino transform fault or mark the southern boundary of the subducted Gorda plate cannot be decided as there is a thin wedge shape area with a lack of seismicity between these two clusters and the bulk seismicity to the north.

Two strike-slip faults inside the mantle of the subducted Gorda plate are shown in Fig. 13(d). The green dots denote the trace of a linear fault (discussed in Chapter 3) orientated in the NW-SE direction and the red dots denote the location of the NE-SW oriented 2010 M6.5 earthquake (event S in Fig. 1-2) (Wei and McGuire, 2014).

In Fig. 1-3(e), events that are above the subducted oceanic crust are highlighted in dark brown. This shallow seismicity is not evenly distributed with many earthquakes located offshore along the coastline and several cluters onshore. The rest of the seismicity in grey are mostly associated with the subducted oceanic crust and upper mantle. There are several clusters near the top of the subducted oceanic crust (discussed in Chapter 4). However, we don't observe double seismic zones inside the subducted Gorda plate as in Wang and Rogers (1994); McCrory et al. (2012). The seismicity rate is also higher between $-124.5^{\circ}$ and $-124.0^{\circ}$ at depth of 15 to $30 \mathrm{~km}$, indicating intense deformation at the core of the triple 

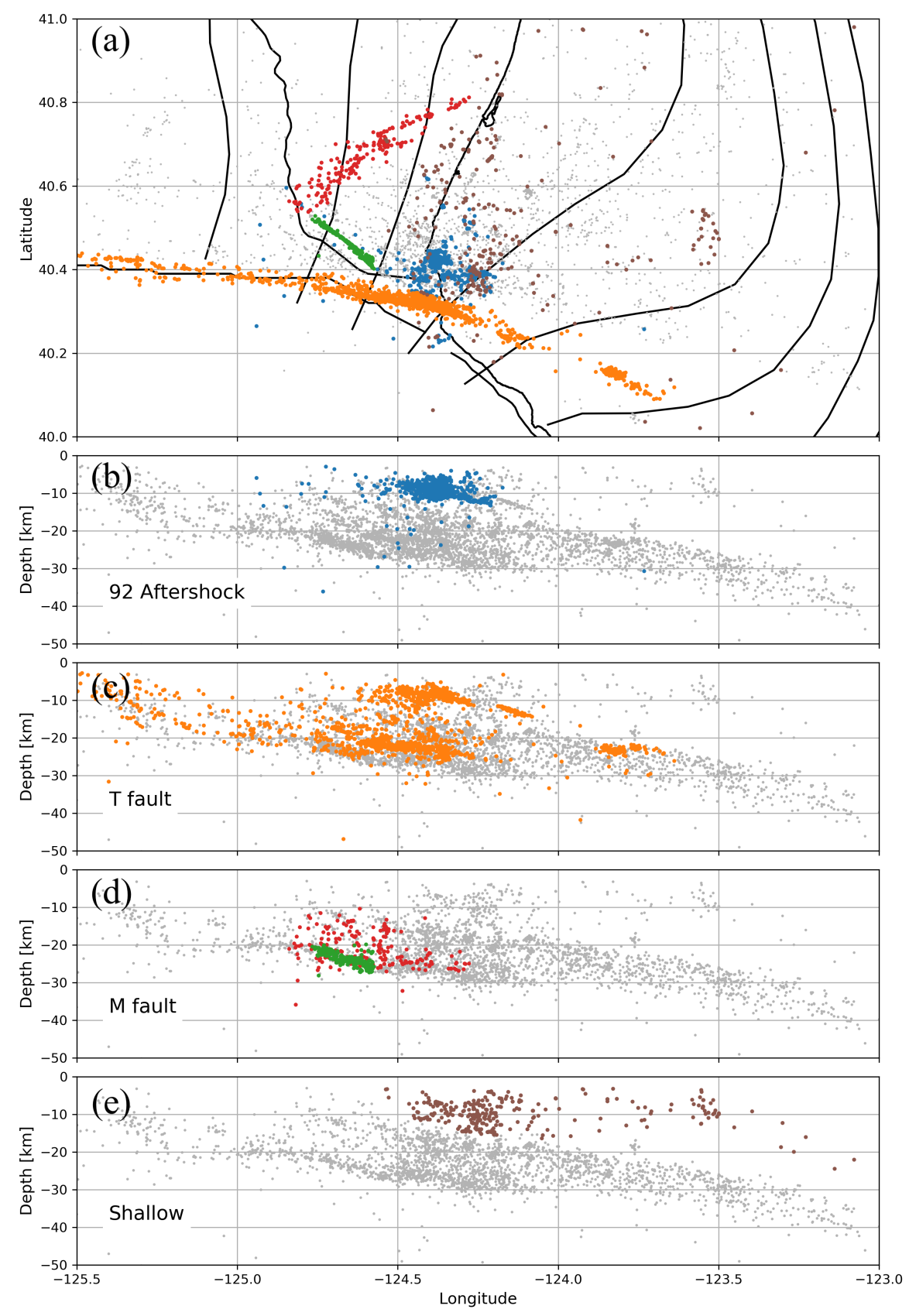

Figure 1-3: Seismicity near MTJ in map view (a) and depth profiles (b)-(e). (b)-(e) highlight the earthquakes from 1992 M7 Cape Mendocino earthquake aftershocks, Mendocino transform fault, faults inside the mantle of the subducted Gorda plate, and above the subducted slab. Each plot has all the previously highlighted events removed. 
junction.

\subsubsection{Deformation and stress near MTJ}

Interactions between the three plates results in complex deformation patterns near the MTJ. On the surface, in the vertical direction, the MTJ undergoes rapid uplift (McCrory, 1989; Lajoie et al., 1991; McCrory, 1996; Merritts, 1996). In the horizontal direction, surface deformation changes from dextral shear south of MTJ to SW-NE convergence north of MTJ. This rotation in surface displacement is the most characteristic feature of MTJ and is accomplished by the San Andreas Fault to the megathrust transition, as well as the change in faulting style from dextral slip on the Garberville/Maacama faults plus Eaton Roughs/Lake Mountain/Bartlett Springs faults to primarily dip slip on the Little Salmon fault and Mad River fault zone (Williams et al., 2006; Pollitz et al., 2008). On the thrust interface between the Gorda plate and the North America plate, geodetic studies have inferred strong interseismic coupling above $20 \mathrm{~km}$ depth (Pollitz et al., 2008; Michel et al., 2019). At the transient zone between the seismogenic zone and the episodic tremor and slow-slip (ETS) zone, coupling can be potentially modulated by stress perturbation induced by offshore large earthquakes (Materna et al., 2019). Along the Mendocino transform fault, over the past 40 years, $M \geqslant 5.9$ earthquakes have ruptured successive parts of the faults (Fig. 1-2(a)). Although not accurately quantified, a certain amount of aseismic slip is expected along the transform fault (Boettcher and Jordan, 2004; Materna et al., 2018).

The transition from SAF-generated dextral shear to WSW-ENE contraction along the Cascadia megathrust through the MTJ and the strain partitioning among the three plates are still not well understood (Pollitz et al., 2008; McCrory, 2000). Several uncertain factors impede our understanding of these questions, such as knowledge of the actual convergence rate between Gorda plate and North America plate (Bartlow, 2020), the degree of internal deformation inside the Gorda plate, the slip rates and directions of the crustal faults in Northern California, and the interseismic coupling on the Mendocino transform fault and the subducted Gorda plate interface. Moreover, for a tectonic region as complex as MTJ, understanding surface deformation is not merely a geodetic problem but rather a geodynamic problem. Structure of the three plates at depth and rheology of crust and upper mantle are also important factors that need to be understood (Barbot, 2020).

The stress field near MTJ is mostly constrained by focal mechanisms of local earthquakes. 
By inverting earthquake focal mechanisms, Schwartz and Hubert (1997) and Wada et al. (2010) infer that stresses in the Gorda plate are dominated by north-south compression down to about $20 \mathrm{~km}$ depth, consistent with a strong push by the Pacific plate from south of the Mendocino transform fault. Deeper parts of the slab show downdip-tension. Deviatoric stresses in the Gorda slab appear to be very low, resulting in very low intraslab seismicity further north of the MTJ (Wang and Rogers, 1994). A maximum compressive stress direction nearly parallel to strike of the Cascadia subduction zone implies very low resolved shear stress across this plate boundary. Recent work by Li et al. (2018a) using stress tensor inversions from focal mechanisms solutions of earthquakes near the subducted Gorda plate interface demonstrated that the plate interface is operating at a relatively low shear stress with a fluid pore pressure approaching $70 \%$ of lithostatic at $\sim 15-20 \mathrm{~km}$ depth.

\subsubsection{Seismic imaging and tomography near MTJ}

Constraints on crustal and lithospheric structure near the MTJ come principally from seismic refraction-reflection profiles carried out during the 1993-1994 Mendocino Triple Junction seismic experiment (Trehu and Mendocino Working Group, 1995; Beaudoin et al., 1994, 1996, 1998; Hole et al., 1998, 2000; Henstock et al., 1997; Henstock and Levander, 2000, 2003; Gulick et al., 1998, 2001; Gulick and Meltzer, 2002; Godfrey et al., 1998; Levander et al., 1998), tomographic inversion of local earthquake arrival times (Verdonck and Zandt, 1994; Levander et al., 1998; Thurber et al., 2009; Liu et al., 2012; Guo et al., 2019), anisotropy from SKS splitting analysis (Hartog and Schwartz, 2000; Eakin et al., 2010), and teleseismic receiver function analysis (Hayes and Furlong, 2007; Tauzin et al., 2013, 2016, 2017; Cheng et al., 2017). Most of the studies before 2000 were initiated by the 1992 Cape Mendocino earthquake to understand crust and lithosphere both onshore and offshore near MTJ. Here we focus on the results that are related to the subducted Gorda plate, which is more relavant to this thesis.

Structures of the subducted Gorda plate near the deformation front were imaged by several multi-channel seismic surveys (Gulick et al., 1998, 2001). The incoming sediments have a thickness of $1.5-3.5 \mathrm{~km}$, but only a thin décollement of 250-600 m thick is developed at the base of the sediment layer (Gulick et al., 1998). Wedge taper analysis shows the prism has low basal shear stress (Gulick et al., 1998). Pervasive high-angle faults exist at the base of the sediments and penetrate into the upper crust (Gulick et al., 2001). 
Larger offset faults appear to divide crust into blocky crustal regions. Strike of these faults are dominantly northeast-southwest oriented, consistent with the north-south compression across the Gorda-Pacific plate boundary. In contrast, in the overlying accretionary prism, many northwest-southeast-trending structures exist. Gulick et al. (2001) explained it as an indication of partial decoupling between the Gorda plate and the North American plate. However, many of the northwest-southeast-trending fault traces in the accretionary prism are offshore extensions of the low angle thrust faults onshore, which slip in the northeastsouthwest direction. Therefore, a strong coupling might exist between Gorda and North American plate alternatively.

Structures of Gorda plate below $14 \mathrm{~km}$ depth were studied by a few onshore wideangle reflection/refraction experiments (Beaudoin et al., 1994, 1998). Beaudoin et al. (1994) imaged the subducted Gorda crust near the coast between $40.5^{\circ} \mathrm{N}$ to $42^{\circ} \mathrm{N}$. The top of the subducted plate locates at approximately $14 \mathrm{~km}$ depth. The subducted crust is characterized by $\mathrm{P}$-wave velocity discontinuities at its top and bottom, each of which has $\sim 10-15 \%$ velocity increase. No clear evidence for the expected low velocity layer that possibly represents the subducted sediment is found on top of the crust. The reflectivity of the top of the Gorda plate is weak under the Eel river base in the middle, but is stronger on the two sides. Beaudoin et al. (1998) imaged the subducted Gorda plate at 20-30 km depth with two survey lines. One oriented in the NNW-SSE direction between $39^{\circ} \mathrm{N}$ to $40.5^{\circ} \mathrm{N}$ and the other one oriented in the NWW-SEE direction at around $40.6^{\circ} \mathrm{N}$. Sharp reflections from the top of the oceanic crust only exist at sparse locations, while the rest of the top of the oceanic crust is characterized by intermittent high reflection patches with a few hundred meters thick. Sharp reflections from the Moho of the subducted crust is more continuous. These observations indicate that between $15-30 \mathrm{~km}$ material properties of the plate-boundary faults between the suducted Gorda plate and North America plate can have large variations in both the along-strike and the along-dip directions.

Tauzin et al. (2017) conducted receiver function (RF) studies using the data from Flexible Array Mendocino Experiment deployed in northern California from July 2007 to June 2009. The benefit of the RF study is that it is more sensitive to shear wave velocity than an active source experiment. They found that, below $20 \mathrm{~km}$ depth, the receiver function could be best modeled with a subducted slab dipping $6^{\circ}$ to the east and having $5 \%$ velocity reduction in shear wave velocity. A clear interface at $\sim 10 \mathrm{~km}$ depth exists inside the overriding North 
American plate between the coast and $123^{\circ} \mathrm{W}$ and is interpreted as the Conrad interface.

All of the above seismic studies near MTJ either focus on the deformation front or only use land stations, so there is still a gap between the 5-15 km depth where no seismic image of the subducted Gorda plate is available. (Guo et al., 2019) took advantage of a dense onshore-offshore array deployed near MTJ during the Cascadia Initiative project (Toomey et al., 2014) and were able to create a continuous image of the subducted Gorda plate from the deformation front down to $40 \mathrm{~km}$ depth. The subducted slab is clearly imaged as a $\sim 6$ $\mathrm{km}$ thick layer with high $\mathrm{Vp} / \mathrm{Vs}$ ratio $(\sim 1.9)$ compared to the subducted ocean mantle and the overriding North America crust. It is so far the highest resolution tomography image near MTJ. Chapters 2-4 of this thesis are built upon the $\mathrm{P}$ and $\mathrm{S}$ velocity models and earthquake location results from this work.

\subsection{Structural geology and rock physics studies of subduction plate interface material properties at seismogenic depths}

\subsubsection{Structural geology study of mélange shear zones}

The subduction plate boundary is not an idealized planar interface, but is instead volume mixture of materials that contains highly sheared, fluid-saturated trench-fill sediments intermingled with fragments of oceanic crust (Fagereng and Sibson, 2010). Subduction-related mélange shear zones exposed on the Earth's surface are inferred to be the exhumed rock assemblages of the shear zones along the previous active subduction plate boundary (Silver

and Beutner, 1980; Kimura et al., 2012b). They provide direct insights into mechanics of the plate-boundary faults and their relationship to subduction zone earthquakes (Kimura et al., 2012b).

Mélange shear zones have been identified at several places on Earth. Among them, locations thought to represent plate-boundary zones at seismogenic depths include: the Shimanto accretionary complex (Kimura and Mukai, 1991), the Franciscan Complex (Wakabayashi, 2011), Kodiak Island (Rowe et al., 2005), the Chrystalls Beach Complex (Fagereng, 2011) and the Northern Apennines (Remitti et al., 2007). Although thickness of the whole exhumed accretionary complex can be a few kilometers wide, a single intensively sheared mélange strand is only tens of meter thick (Rowe et al., 2005; Fagereng, 2011; Kimura et al., 2012b). Several simultaneously active strands are thought to constitute the subduction 
plate-boundary faults and host earthquake ruptures. Rowe et al. (2013) compiled data of mélange shear zones across the world and found that such simultaneously active strands are 100-350 m thick and this thickness is maintained down to $15 \mathrm{~km}$ depth in the subduction zone.

The mélange shear zones are characterized by block-in-matrix texture and are mixtures of materials with diverse viscosity. The materials with higher viscosity are referred to as competent component, such as chert, sandstone and metabasalt, and the materials with lower viscosity are referred to as incompetent component, such as mudstone and shale (Fagereng and Sibson, 2010).

The rheology of the plate boundary shear zone depends critically on the ratio of the competent and incompetent components (Fagereng and Sibson, 2010). Subduction plateboundary faults can accommodate deformation with strain rates that span several orders of magnitude from earthquake displacements occurring at $\mathrm{m} / \mathrm{s}$ to plate convergence occurring at $\mathrm{cm} /$ year. Records of mixed continuous-discontinuous deformations can be found in the mélange shear zones. The discontinuous deformations, which concentrate near lithology boundaries, are interpreted as slips from micro earthquakes or small aftershocks. The continuous deformations, which are distributed in the block matrix, are interpreted as afterslip and plate convergent (Fagereng and Sibson, 2010; Rowe et al., 2011; Kimura et al., 2012b). The mixture of competent and incompetent components inside the mélange shear zone allows the plate-boundary faults to host both seismic and aseismic deformation at the same place (Rowe et al., 2011).

Although small scale (cm scale) discontinuous type of deformations are identified inside mélange shear zones, less evidence is available for large-scale fast earthquake ruptures. Pseudotachylyte is considered the clearest record of ancient seismicity in the rock formed by frictional melting due to fast slip along faults (Sibson, 1975). Pseudotachylytes have been found in several mélange shear zones and are interpreted as evidences of paleoearthquakes (Ikesawa et al., 2003; Austrheim and Andersen, 2004; Rowe et al., 2005). However, recent structural geology observations and rock deformation experiments have shown that frictional melt is not the only way of creating pseudotachylyte (White, 2012; Peč et al., 2012). Therefore, how rupture propagates hundreds of kilometers inside the mélange shear zones during megathrust earthquakes remains a fundamental problem in earthquake seismology and rock mechanics. 


\subsubsection{Rock physics study of frictional properties of subduction plate in- terface}

In traditional rock physics, earthquake slip is consider as frictional instability of the gouge materials due to stress loading. The rate and state friction law (Dieterich, 1979, 1981; Ruina, 1983; Rice and Ruina, 1983; Marone, 1998) revolutionized our understanding of earthquakes and various transient slips on the faults. This theory successfully explains the first-order observations of slip behaviors along the dipping direction of the subduction plate interface, where frictional parameters of the subduction plate interface change from velocity strengthening to velocity weakening to velocity strengthening from trench to the seismogenic zone to the steady creeping zone at depth (Hyndman et al., 1997; Scholz, 1998). Earthquakes can only nucleate in velocity weakening areas, while transient slip mostly occurs in the transitions and in nominally velocity strengthening areas.

The seismogenic zone on the megathrust is roughly bounded by the $150^{\circ} \mathrm{C}$ and $350^{\circ} \mathrm{C}$ isotherms (Blanpied et al., 1991; Hyndman et al., 1997) where the $\sim 150^{\circ} \mathrm{C}$ isotherm corresponds to the temperature where dehydration of stable sliding clays become velocityweakening, and the $\sim 350^{\circ} \mathrm{C}$ isotherm is estimated by frictional sliding experiments done on crustal rocks (Blanpied et al., 1991). However, this is a very simplied model and the actual frictional stability of the gauge material depends on mineral composition (den Hartog and Spiers, 2013), pressure-temperature conditions (Hyndman et al., 1997; den Hartog et al., 2012), strain rate (Niemeijer and Spiers, 2006) and hydrothermal conditions (Blanpied et al., 1991).

Frictional coefficient is an important parameter controlling earthquake rupture, as low frictional coefficient will make earthquake rupture easier. In-situ temperature measurement at subduction zones and fast shear experiments using subduction fault zone samples have shown that the coseismic frictional coefficient can be as low as $\sim 0.08-0.24$ (Fulton et al., 2013; Ikari et al., 2015; Brodsky et al., 2020) for clay materials, while experiments with granite, gabbro and altered basalt have shown normal Byerlee frictional coefficient of $\sim 0.6-0.7$ under higher temperature and pressure conditions (Blanpied et al., 1991; He et al., 2006; Phillips et al., 2020). 


\subsection{Seismic imaging of the subduction plate-boundary faults at seismogenic depths}

Seismic imaging is one of the most important geophysical methods to investigate the geometry and the mechanical properties of subduction plate-boundary faults. One of the key questions for seismic imaging in subduction zone is whether a low velocity layer exists on top of the subducted oceanic crust, as a low velocity layer implies a weaker plate boundary and has great implications for the rupture dynamics of megathrust earthquakes. Numerous seismic imaging studies have been conducted in subduction zones worldwide. Here we discuss four different methods often applied for imaging subduction slabs and focus on studies that are able to image the seismogenic part of the subduction plate boundary.

\subsubsection{Active source}

Active source reflection and refraction experiments provide the most continuous and the highest resolution images of subducted slabs. Due to the difficulties in imaging velocity structures at greater depth with controlled sources, only a few active source experiments have penetrated to the seismogenic zone of the subduction slab. Their imaging results of the subduction plate boundaries at seismogenic depths are summarized below.

Christeson et al. (1999) imaged the subducted slab offshore Nicoya Peninsula. The top of the subducted slab is well resolved. A low-velocity zone $<400 \mathrm{~m}$ thick is inferred on top of the subducted oceanic crust between $5-15 \mathrm{~km}$ depth. Layer 2 of the subducted slab has

a significantly lower $\mathrm{P}$ wave velocities than normal oceanic crust with the same age. The anomalous velocities support the model of a permeable $1 \mathrm{~km}$ thick hydrothermally cooled zone at the top of the subducting crust with increased porosity that likely contains the plate-boundary faults.

A series of active source experiments were conducted offshore Japan with the goal of investigating the downdip limit of the seismogenic zone and the spatial relationship between forearc crustal models and the coseismic rupture zones of offshore earthquakes (Kodaira et al., 2002; Nakanishi et al., 2002, 2004; Takahashi et al., 2004; Miura et al., 2005). From northern Japan where a cold slab subducts to Nankai Japan where a warm slab subducts, these experiments show consistent results of a $\sim 1-2 \mathrm{~km}$ thick LVZ ( $\mathrm{P}$ wave) at the plate boundary beneath the island arc crust below $\sim 15 \mathrm{~km}$ depth. The LVZ is interpreted as layer 
2, the basalt and sheeted dike layer of the oceanic crust. Clear reflection phases are observed from the top of layer 2, layer 3 and the Moho of the subducted oceanic crust. However, no thin LVZ above the subducted oceanic crust is inferred or clearly imaged from these models at seismogenic depths. Only Nakanishi et al. (2004) observed a high-reflectivity layer updip of the seismogenic zone of the 1973 Nemuro-Oki earthquake, which indicates potential LVZ at the plate boundary updip of the seismogenic zone.

Nedimović et al. (2003) created the first continuous seismic image of the subduction plate-boundary faults from the trench down to the episodic tremor and slow-slip (ETS) zone offshore Vancouver Island in northern Cascadia. The imaging results indicate a continuous sediment layer throughout the locked zone into the ETS zone. Within the seismogenic depth range $(\sim 10-20 \mathrm{~km})$ the plate-boundary zones are characterized by a $2 \mathrm{~km}$ wide (or less) zone of sediments, while at the depths of ETS events the plate-boundary zones expand to a width of over $4 \mathrm{~km}$. This wide zone is shown on the seismic migration images as a thick band of reflections that are named E-reflections. The broadening of the plate-boundary zones at the ETS depth range is explained to be related to both shearing and fluids and facilitates stable sliding and slow slip events on the megathrust interface.

Singh et al. (2008) conducted an active-source seismology experiment near the epicenter of the 2004 Sumatra earthquake down to $40 \mathrm{~km}$ depth. The seismic data reveals that the subducting crust and oceanic Moho - the crust-mantle boundary - are broken and displaced by landward-dipping thrust ramps, suggesting that the megathrust now lies in the oceanic mantle.

Großet al. (2008) conducted an active-source seismology experiment across the seismogenic and high interseismic coupling zone of the south central Chilean subduction zone above the epicenter of the 1960 M9.5 Valdivia earthquake. A high reflectivity layer with a varying thickness of 2-5 km are imaged between $25-35 \mathrm{~km}$ depth at the plate interface, which is inferred as the subduction channel. While further downdip along the seismogenic coupling zone, the reflectivity decreases in the area of the presumed 1960 Valdivia earthquake hypocenter at about $40 \mathrm{~km}$ depth.

Li et al. (2015) imaged the subduction plate boundary offshore Alaska Peninsular from 5-60 km depth and found that at seismogenic depth between 20 and $30 \mathrm{~km}$, the plate boundary is a $\sim 100-250 \mathrm{~m}$ thick layer with strong attenuation. The thin reflection band is located at the center of the $1938 \mathrm{Mw} 8.2$ Semidi earthquake and is interpreted as a compacted 
sediment layer.

Comparing imaging results from different subduction zones, the subduction plate-boundary faults show large variations in their continuity, thickness and reflectivity. If these results are true and the variations are not related to differences in data processing methods and data quality, it means that structures of subduction plate-boundary faults can vary dramatically from one subduction zone to the other and their detailed structures could affect rupture characteristics in each subduction zone.

\subsubsection{Receiver functions}

Receiver function (RF) method is one of the most popular and stable methods to image subsurface velocity discontinuities (Langston, 1979). Recent progress in passive seismic monitoring in offshore regions has offered more opportunities to conduct RF analysis using data of ocean bottom seismometer (OBS) (Audet, 2016). The application of RF analysis to OBS data suffers from several limiting factors, such as instrument coupling with the ground, pressure reverberations from the water column and the effects of a layer of lowvelocity marine sediments. Recently several methods have been developed to account for these problems including transfer function modelling (Audet, 2016), inverse water-layer filter (Akuhara and Mochizuki, 2015; Akuhara et al., 2016) and transdimensional inversion (Akuhara et al., 2019).

Akuhara et al. (2017) applied inverse water-layer filter to OBS stations located in the Nankai trough and found the presence of a thin low-velocity zone (LVZ) of a thickness of $0.2-1.2 \mathrm{~km}$ with a $\mathrm{S}$ wave velocity of $0.7-2.4 \mathrm{~km} / \mathrm{s}$ along the plate interface at $15-20 \mathrm{~km}$ depth. Using the transdimensional inversion method, Akuhara et al. (2020) also found a LVZ $\sim 1 \mathrm{~km}$ thick at the plate interface at $\sim 6 \mathrm{~km}$ depth in the shallow part of Nankai trough forearc. With more OBS stations being available in subduction zones globally, RF will become a more promising method for imaging the subduction plate interface, especially at deeper depths.

\subsubsection{Direct observations of seismic scattering phases}

Seismic scatterred waves are generated when seismic waves encounter obstacles, such as discontinuities and other velocity anomalies in the Earth. Seismic energy is then radiated in all possible directions by these obstacles and creates scattering. S-to-P and P-to-S scattering 
phases generated by local earthquakes in the mantle of the downgoing plate and converted in the vicinity of the slab interface carry direct information of the fault structure and can be used to constrain the geometry and material properties of the plate-boundary zones. These scattering phases have frequencies of $1-10 \mathrm{~Hz}$, and can image the subduction plate boundary with much higher resolution than traditional RF method.

Matsuzawa et al. (1986) pioneered the study of Ps and Sp converted phases in Tohoku and imaged clear slab interface between 50-100 km depth. Since then, seismic scattering phases have been used for imaging the structure of subducted slabs in a number of regions including: Japan (Matsuzawa et al., 1990; Obara and Sato, 1988; Nakamura et al., 1998; Ohmi and Hori, 2000; Horleston and Helffrich, 2012), New Zealand (Eberhart-Phillips and Reyners, 1999; Reading et al., 2001), Mexico (Lomnitz, 1982; Song et al., 2009; Song and Kim, 2011), Alaska (Stephens et al., 1990) and Cascadia (Nowack and Bostock, 2013; Merrill and Bostock, 2019). Among these studies, Eberhart-Phillips and Reyners (1999) observed a 1-2 km thick low velocity layer at the plate interface with a $\mathrm{Vp} / \mathrm{Vs}$ higher than 2.5 offshore New Zealand at $\sim 15 \mathrm{~km}$ depth.

Most of these studies rely on the observation of the scattering phase from only a few earthquakes or on a few stations, which limits the imaging scale and resolution. But with more dense arrays deployed in the subduction zones, these scattering phases could be utilized for imaging large dimension structures of the subduction plate-boundary faults.

\subsubsection{Tomography}

Traveltime tomography has been widely used to image subduction zones worldwide. However, previous studies using only land stations have poor constraints on the seismogenic parts of the subducted slab since they are located primarily offshore. Two recent studies using onshore-offshore seismic arrays prove that offshore OBS stations are necessary for improving the resolution of the subducted slab, especially at the seismogenic depths (Moreno et al., 2014; Guo et al., 2019). Continuous and extensive spatial coverage of images allow the investigation of the relationship between velocity structures around a slab interface and its seismogenic behavior.

Moreno et al. (2014) used an onshore-offshore seismic array deployed in the central Chile subduction zone over the rupture area of the 2011 M8.8 Maule earthquake to image velocity structure near the plate interface. They found that high $\mathrm{Vp} / \mathrm{Vs}$ domains of the plate- 
boundary zones correlate spatially with parts that are poorly locked and slip aseismically, while low $\mathrm{Vp} / \mathrm{Vs}$ domains correlate with locked parts of the plate interface where unstable slip and earthquakes occur. Elevated pore-fluid pressures are inferred in the high $\mathrm{Vp} / \mathrm{Vs}$ domains that reduce locking and promote aseismic slip on the subduction plate interface.

Guo et al. (2019) is another example showing the importance of OBS for imaging a continuous slab structure across the coastline. The details of the imaging results are discussed in Section 1.1.4. Comparing the imaging results with the surface geodetic observations, both the locked and the slow slip zones show evidence of high fluid content implying a significant porosity, yet the intervening transition zone shows an order of magnitude lower porosity. These strong variations are consistent with models that contain a ductile region between the earthquake rupture and ETS zones that would inhibit significant onshore propagation of large ruptures and hence reduce seismic hazard.

\subsubsection{Summary}

Active source experiments show that the subduction plate-boundary faults have large variations in continuity, thickness and reflectivity. It is so far the most effective way to image the subduction plate boundary over a large depth range. However, such experiments are expensive and are only available at limited places in the world. Traveltime tomography also can generate continuous and large spatial coverage image of the subduction slab, albeit with lower resolution. With the advent of dense OBS networks, two recent tomography studies of the subduction slab have shown promising evidence of the correlations between velocity structure of the subduction plate interface and its seismogenic behavior. RF and scattering phases methods, with their much higher sensitivity to velocity discontinuities, will be more valuable for imaging subduction plate-boundary faults when dense seismic array across the subduction zone is available in the future. Moreover they allow for the possibility of monitoring temporal variations in plate boundary properties similar to studies using guided waves in terrestrial fault zones. 


\subsection{Subduction zone megathrust earthquakes and physical prop- erties of forearc and plate interface}

Subduction zones host the most devasting earthquakes on Earth, however, the physical or structural characteristics that control megathrust coupling, earthquake rupture extents and the amplitude of slip are still not clear. Several factors have been proposed in the literature that range from large scale forearc and backarc structures to detailed geometry and material properties on the megathrust interface. Here, the major controlling factors are summarized and their corresponding observations and limitations are discussed.

\subsubsection{Structure and stress of the overriding plate}

Structure and stress of the overriding plate are inferred to control megathrust coupling and seismogenic behavior in large spatial scale and in long geological time scale. Song and Simons (2003) investigated trench-parallel gravity anomaly (TPGA) over the locations of the subduction plate interface where large-thrust earthquakes occur and found that great earthquakes occur predominantly in regions with a strongly negative TPGA, whereas regions with strongly positive TPGA are relatively aseismic. These observations suggest that spatial variations of seismogenic behavior are primarily linked to the geological structure of the forearc. Such geological structure causes spatial variations in frictional properties on the plate interface, and control trench-parallel variations in forearc topography, gravity, and seismogenic behavior. Similar correlations between gravity anomaly and seismogenic behavior of the subduction plate interface are found in northeast Japan (Bassett et al., 2016), Sunda-Andaman subduction zone (Grevemeyer and Tiwari, 2006) and Cascadia (Wells et al., 2003).

Seismic tomography studies also indicate that the seismogenic behavior of the megathrust correlates with geological structures of the forearc. Liu and Zhao (2018) used traveltime tomography to image the Tohoku forearc and found the 2011 Tohuko-Oki earthquake nucleated in an area with high seismic velocity, low seismic attenuation, and strong seismic coupling. Strong coseismic high-frequency radiation also occurred in high-velocity patches, whereas large afterslip took place in low-velocity areas. These structural heterogeneities in and around the Tohoku megathrust originate from both the overriding and subducting plates, which influenced the nucleation and rupture processes of the 2011 Tohoku-oki 
earthquake.

Lateral variations in interseismic coupling could also be influenced by topographic character in the overriding plate. Béjar-Pizarro et al. (2013) find that the base of the strongly coupled seismogenic zone in North Chile seismic gap has an unambiguous relationship with the line of the surface coastal scarp, a crustal-scale fault structure in the overriding plate. Heuret et al. (2011) compiled global earthquake catalogs and geometrical and mechanical parameters of global subduction zones and find that the subduction velocity is the firstorder controlling parameter for variations in the physical characteristics of plate interfaces, determining both the geometry and mechanical behavior and large lateral ruptures should be promoted in neutral subduction zones due to moderate compressive stresses along the plate interface that allow the rupture to propagate laterally.

In general, gravity anomaly, velocity and crustal structure of the overriding plate, convergent rate and backarc strain all show possible correlations with segmentations in interseismic coupling and seismogenic behavior along the subduction plate interface. However, these observations are of low resolution, and they don't provide unambiguous physical mechanisms that explain these correlations and hence cannot be used to explain the ruptures details of an individual megathrust earthquake.

\subsubsection{Thermal and petrological controlled frictional properties}

Thermal and petrologically controlled frictional properties are another important factor governing the slip behaviors of the subduction plate interface (Hyndman et al., 1997). The classic frictional model of a subduction zone thrust fault from top to bottom involves threelayers (Scholz, 1998) where the top rate-strengthening layer slides stably and has important implications for tsunami generation; the middle rate-weakening layer, often referred to as the locked zone during the interseismic period, fails during great megathrust earthquakes; and the bottom rate strengthening layer creeps stably as afterslip following great earthquakes and continuously during the interseismic period, it also slips episodically during ETS events. The two transition zones between velocity weakening and strengthening often produce tremor and slow slip events that relieve small amounts of stress regularly (Scholz, 1998; Schwartz and Rokosky, 2007; Peng and Gomberg, 2010; Obara and Kato, 2016).

However, seismological and geodetic observations also show more complex phenomena than the theory predicts (Scholz, 1998). The 2011 Mw9.0 Tohoku-Oki earthquake challenged 
this traditional view because earthquake rupture penetrated into the shallow creeping regions on the fault (Ide et al., 2011; Noda and Lapusta, 2013). Moreover, geodetic observations have discovered that afterslip following the Maule earthquake occurred on patches that overlap with the seismic rupture area and with the interseismically locked zone (Bedford et al., 2013). Subduction plate-boundary faults hardly achieve $100 \%$ locking at the seismogenic zone, indicating that it could accomodate both seismic and aseismic slip at the same region. In the Cascadia subduction zone, there exists a wide transition zone between the seismogenic part of the plate interface and the slow-slip part at deeper depth (Liu, 2013).

Overall, these seismological and geodetic observations indicate that rheology of the subduction plate interface is perhaps more heterogeneous than previously expected and stable and instable slip can switch or coexist at the same portion of the plate-boundary faults. Fault slip is likely governed by more sophisticated physical laws and more complex rheological properties.

\subsubsection{Stress, strength and pore pressure of the plate-boundary faults}

Stress and strength of the subduction plate-boundary faults are indisputably important parameters controlling earthquake rupture along the megathrust interface. However, they are extremely hard to measure and only at shallow part of the Japan trench, where the 2011 Mw 9.1 Tohoku earthquake occurred, has it been possible to acquire the state of stress on the fault before, during, and after a major earthquake, thanks to the intense and integrated geological, rheological, and geophysical data acquisitions (Brodsky et al., 2020).

At present, no method is available to directly measure stress on the subduction plate interface at seismogenic depths. The stress condition is mostly inferred by indirect measurements, while results from different methods provide different views on the peak shear stress levels within the seismogenic zone. Based on the force balance between the shear stress at seismogenic megathrust and the lithostatic pressure, Lamb (2006) and Seno (2009) estimate that shear stress at the subducted plate interface is only $\sim 10 \mathrm{MPa}$ averaged over the full depth range of plate coupling $(\sim 0-50+\mathrm{km})$. Models that match the available heat-flow data, which represents an integrated effect of frictional heating over many earthquake cycles, show that shear stress on the megathrust interface is $\sim 40-70 \mathrm{MPa}$ (Von Herzen et al., 2001; Gao and Wang, 2014).

A variety of studies have demonstrated that subduction plate-boundary faults are weak 
due to high pore fluid pressures (Saffer and Tobin, 2011) and low friction coefficients (Fulton et al., 2013). Bilek and Lay $(1998,1999)$ analyzed stress drops of earthquakes from several subduction zones and find that most of these earthquakes have stress drops $<10 \mathrm{MPa}$, indicating low background stress conditions within the subduction plate-boundary faults. Focal mechanism studies of the aftershocks of the 1968 Tokachi-Oki earthquake show that the minimum principal stress acts approximately perpendicular to the main-shock thrust plane which implies low resolved shear stresses on the interplate thrust fault as well as low frictional fault strength (Magee and Zoback, 1993). In contrast, Hardebeck (2015) conducted a global investigation of stress orientations in subduction zones and found that the maximum compressive stress axis consistently making an angle of $45^{\circ}$ to $60^{\circ}$ with respect to the subduction megathrust fault. These angles indicate that the fault has comparable strength with the overriding plate.

Fluid plays an important yet enigmatic role in controlling earthquake rupture in subduction zones, especially at deeper depth, as our understanding of it is still very limited. There are two ways for fluids to enter subduction zones: as pore water in the sediments and igneous crust, or as bound water within hydrous minerals (Saffer and Tobin, 2011). Pore fluid is mostly released by dewatering due to burial and lateral tectonic loading at the first 3-7 km depths (Bray and Karig, 1985; Bekins and Dreiss, 1992). Bound water is released by mineral dehydration process, such as the smectite to illite transformation near the updip of the seismogenic zone (Bethke, 1986; Meunier, 2005).

Various studies, including seismic tomography (Moreno et al., 2014; Guo et al., 2019), receiver function (Audet and Schwartz, 2013; Janiszewski and Abers, 2015; Audet and Schaeffer, 2018) and magnetotelluric imaging (Heise et al., 2012; McGary et al., 2014; Wannamaker et al., 2014; Evans et al., 2014; Pommier and Evans, 2017; Heise et al., 2017), have shown that plate-boundary faults and the subducted oceanic crust perhaps contain a significant volume of fluid content at seismogenic depths. At the shallow portion of the subduction zone, fluid flow along the plate-boundary faults could be measured directly with borehole instruments or use seismic reflectivity as a proxy for the presence of fluid. Borehole measurements and seismic reflectivity indicate that fluid flow along plate-boundary faults is both transient (Saffer and Bekins, 1999; Spinelli et al., 2006; Chaves and Schwartz, 2016) and spatially heterogeneous (Bangs et al., 1999; Ranero et al., 2008; Bangs et al., 2015). Fewer results of fluid flow are available for plate-boundary faults at seismogenic depth. 
Much is unknown about the stress, strength and pore pressure of subduction plateboundary faults at seismogenic depth. More comprehensive geophysical observations are needed both onshore and offshore to better infer the values of these three parameters and improve the spatial and temporal resolutions of their variations on the faults.

\subsubsection{Faulting in the subducted slab}

Normal faults are often imaged in the sediment, crust or upper mantle of both the incoming and subducted slab. These faults may be generated at the mid-ocean ridge or be created due to plate bending during subduction. They carry water into the subduction zone and affect the dehydration process and seismogenic behavior of the subducted slab at depth.

Offshore Alaska Peninsular, Shillington et al. (2015) find that along-strike variations in bending faulting and hydration correlate with variations in the abundance of interplate and intermediate-depth earthquakes. The Shumagin segment is characterized by much more abundant intermediate-depth and interplate seismicity than the Semidi segment. Outboard of the Shumagin Gap, pronounced bending faulting is present, whereas outboard of the Semidi segment the downgoing plate exhibits much less bend-related faulting. Similar correlations are found in Cascadia (Han et al., 2016). Canales et al. (2017) also infer that the lack of interplate and intraplate seismicity in Cascadia is related to the limited bend faulting inside the subducted Juan de Fuca plate which limits slab access to water and results in a dry slab subducting.

\subsubsection{Roughness of plate interface and the role of subducted sediments}

Roughness of the subducting seafloor is another important factor affecting subduction earthquakes (Bilek et al., 2003; Wang and Bilek, 2014; van Rijsingen et al., 2018). Seismic and geodetic studies of megathrust locking/creeping state find that creeping is the predominant mode of subduction in areas of extremely rugged subducting seafloor (Uyeda and Kanamori, 1979; Chlieh et al., 2008; Wallace et al., 2009b,a; Chlieh et al., 2011; Hsu et al., 2012; Feng et al., 2012), while mega-earthquakes tend to rupture flat and smooth megathrusts (Contreras-Reyes et al., 2010; Bletery et al., 2016). Large topographic features such as subducted ridges, fracture zones and seamounts often promote creep and stop the propagation of large ruptures (Wang and Bilek, 2011; Contreras-Reyes and Carrizo, 2011).

Recent three-dimensional (3D) seismic experiments have focused on small scale (a few 
kilometer) roughness and its impact on earthquake rupture characteristics (Edwards et al., 2018; Kirkpatrick et al., 2020). Using 3D seismic reflection data located offshore Costa Rica, Kirkpatrick et al. (2020) quantified spatial variability in the megathrust roughness, overburden and rock physical properties. They found that heterogeneity in the megathrust roughness exists at length scales of a few kilometers and spatial variations in the rock physical properties are characterized by correlation length scales of hundreds of meters. Spatial variations in fault roughness, lithostatic load and physical properties define asperities and imply heterogeneous effective stress on the Costa Rica subduction plate interface.

Subducted sediments play an important role in developing a smooth, homogeneous plate interface that allows broad areas of strong plate locking and large strain accumulation (Ruff, 1989; Heuret et al., 2012; Scholl et al., 2015). The thick (>1 km) sediments subducting in southern Chile cover the rough slab interface with several fracture zones and to allow the 1960 M9.6 Valdivia earthquake, the largest earthquake ever recorded, to rupture $1000 \mathrm{~km}$ along the subducted Nazca plate.

Consolidation state is another property of the subducted sediments that determines the strength of the plate-boundary faults and affects interseismic coupling (Han et al., 2017). However, three recent seismic imaging results using similar analysis methods draw contradictory conclusions about the relationship between subducted sediment properties and the locking state on the megathrust fault. Along the Cascadia subduction zone, Han et al. (2017) found offshore Washington where the megathrust is inferred to be strongly locked, the sediments near the deformation front are over-consolidated and are incorporated into a strong outer wedge, with little sediment subducted. In contrast, offshore Central Oregon where reduced locking is inferred, a thick under-consolidated sediment sequence is subducting. Offshore Alaska Peninsular, Li et al. (2018b) found that, in the Semidi segment where interseismic locking is strong, sediments subducting in Semidi segment corresponded to a thicker layer of high-porosity sediments with lower effective stress. In contrast, in the Shumagin Gap, where interseismic locking is weak, they found thinner sediments and higher effective stress. Along the southern Chile subduction zone, Olsen et al. (2020) observed a strong, well-drained, thick sediment layer which is likely a determining factor for developing a smooth plate interface located well above the subducted crust topography and generates particularly large earthquakes along the south central Chile margin. These three studies show that the stronger locking part of the subducted slab interface corresponds to a thin 
and stronger, thick and weaker and thick and stronger sediment layer in Cascadia, Alaska and southern Chile subduction zones respectively. These studies also imply that more complex relations between subducted sediments and interseismic coupling and seismogenic properties of the subducted slab might exist, especially at deeper depth of the subduction zone.

\subsubsection{Summary}

Many factors determine where and how megathrust earthquakes occur. However, a criteria applied to one subduction zone might not be applicable to others. "Long wavelength factors", such as large-scale geological structure of the forearc and thermally controlled frictional properties on the plate-boundary faults, will, over time scales up to 1 million years, get stationary spatial variations of seismogenic behavior within a given subduction zone (Song and Simons, 2003) and are the dominant factor in the sense of long term statistics. "Short wavelength factors", such as roughness, faulting and sediment layer, play more important roles in controlling the detailed rupture characteristic of each individual earthquake (Harris and Day, 1997; Sagy et al., 2007; Huang et al., 2014; Frankel et al., 2018; Wirth et al., 2018; Idini and Ampuero, 2020). From seismic hazard point of view, such short wavelength factors are more important as it will affect rupture directivity, rupture extend, amplitude of slip and stress drop, all of which will determine the intensity of shaking on the ground.

One major challenge to resolve "short wavelength factors" along the subduction plate interfaces is the difficulty for imaging the fine-scale structure of the subduction plate boundary at seismogenic depth, typically between $10-50 \mathrm{~km}$. The main goal of this thesis is to develop methods for imaging fine-scale plate-boundary faults structure using high frequency (2-12 Hz) scattering phases from local earthquakes. In the following chapters, I will show that seismic waves scattered from the subduction plate-boundary faults can be utilized to infer kilometre-scale structural heterogeneities on the fault and will be able to shed light on the physical controls on seismogenic behavior of the megathrust.

\subsection{Thesis structure}

In Chapter 2, I combine both seismic and geodetic observations near MTJ to constrain locking conditions on the subducted Gorda slab. Rupture properties of the January 28, $2015 \mathrm{Mw} 5.7$ earthquake which occurred on the Mendocino transform fault was studied. 
The frictional state of the subduction interface is investigated by simulating the afterslip that would be expected there as a result of the stress changes from the 2015 earthquake and the $2010 \mathrm{Mw} 6.5$ intraplate earthquake within the subducted Gorda plate.

In Chapter 3, I develop array analysis methods to use high frequency P-to-S and P-to-S seismic scattering phases to image the plate-boundary faults of the subducted Gorda plate at seismogenic depth. Their arrival times and amplitudes are used to infer the location of the top and bottom of the subducted crust as well as the velocity contrasts across these discontinuities.

In Chapters 4 and 5, I study seismic guided waves that propagate along a thin low velocity layer at the subduction plate boundary near MTJ. A dense nodal array was deployed near MTJ to investigate the origin of such waves. Various structure models are tested in 2D wave propagation simulations to replicate the observed signal to infer structural properties of the thin low velocity layer. 


\section{Chapter 2}

\section{Interactions Between Strike-slip}

\section{Earthquakes and the Subduction}

\section{Interface near the Mendocino Triple}

\section{Junction}

This chapter was originally published as: Gong, J. and McGuire, J.J., 2018. Interactions between strike-slip earthquakes and the subduction interface near the Mendocino Triple Junction. Earth and Planetary Science Letters, 482, pp.414-422. Used with permission as granted in the original copyright agreement.

\section{$2.1 \quad$ Introduction}

The classic synoptic frictional model of a subduction zone thrust fault from top to bottom involves three-layers (Scholz, 1998; Obara and Kato, 2016) where the top rate-strengthening layer coincides with the accretionary wedge and has important implications for tsunami generation; the middle rate-weakening layer, often referred to as the locked zone during the interseismic period, fails during great megathrust earthquakes; and the bottom rate strengthening layer creeps stablely as afterslip following great earthquakes and continuously during the interseismic period, it also slips episodically during ETS events. The two transition zones between velocity weakening and strengthening often produce tremor and slow 
slip events that relieve small amounts of stress regularly (Scholz, 1998). In terms of earthquake hazard assessment, determining the spatial variations in the locking state on the interface and the downdip and updip limits of the locked zone are important for estimating the potential rupture areas of future earthquakes.

In the Cascadia subduction zone (CSZ), the spatial variations in interseismic locking and particularly the downdip and updip limits of the locked zone remain unclear. The low rate of interplate earthquakes (Obana et al., 2015; Morton and Bilek, 2015) and the uplift of the West Coast (McCaffrey et al., 2007) indicate the interface is largely locked at depths shallower than $20 \mathrm{~km}$. Several studies have inverted geodetic data for the spatial distribution of the locking along the interface (McCaffrey et al., 2000, 2007; Burgette et al., 2009; Schmalzle et al., 2014; Pollitz and Evans, 2017). However, owing to the lack of offshore geodetic observations, there is little resolution of locking near the trench. Moreover, different modeling assumptions can produce significantly different results even in the 10-30 km depth range where great earthquake slip is expected to be largest (Schmalzle et al., 2014; Pollitz and Evans, 2017). While in general episodic tremor and slow slip may mark the updip and downdip margins of the locked zone (Obara and Kato, 2016), in Cascadia, there may be a large spatial gap between the downdip edge of the locked zone and the well constrained tremor region (Liu, 2013). Additionally, no studies have yet reported transient slip or low frequency earthquake at the updip edge of the locked zone, e.g., within the accretionary wedge, adding to the uncertainty of the locking state near the trench (Wang and Tréhu, 2016).

Near the MTJ, the locking state of the southernmost part of the megathrust interface has only been estimated in the two most recent geodetic inversion studies (Schmalzle et al., 2014; Pollitz and Evans, 2017). The locking fraction in the models of Schmalzle et al. (2014) ranges from $\sim 0.5$ to $\sim 1.0$ depending on the regularizaiton and other assumptions. Similarly, the locking rate in the models of Pollitz and Evans (2017) ranges from 0 to $30 \mathrm{~mm} / \mathrm{yr}$ in models with different assumed rheologies for the surrounding region. Thus it remains an important goal to better constrain the expected rupture area in this region where the great earthquake recurrence interval is the shortest among the various segments along the Cascade megathrust (Goldfinger et al., 2008).

The goal of this paper is to evaluate an alternative method for probing the locking state on the subduction plate which takes advantage of the frequent moderate earthquakes on 
the nearby faults in the MTJ region. These earthquakes will cause Coulomb stress changes that could possibly generate transient aseismic fault slip, typically referred to as afterslip, on the thrust interface (Wallace et al., 2016). Afterslip is very common following large subduction earthquakes and delineates parts of the fault with velocity strengthening friction (Perfettini and Ampuero, 2008). Geodetic recordings of afterslip have been used to probe the frictional state of fault interface by analyzing its temporal evolution (Miyazaki et al., 2004; Hsu et al., 2006; Thomas et al., 2017). Similarly, velocity strengthening regions of crustal faults are often observed to undergo triggered afterslip following nearby earthquakes resulting from both static and dynamic stress changes (Wei et al., 2015a). We determine the rupture area of a $M_{w} 5.7$ earthquake on the Mendocino transform fault and use the coseismic slip distribution from it and an intraplate earthquake within the subducting Gorda plate to calculate Coulomb stress changes on the thrust interface. We then simulate the afterslip and corresponding displacement signals at onshore GPS sites. We model different downdip limits of the locking zone and compare the simulated GPS series with the GPS observations to estimate a minimum depth of the downdip limit of the locking zone near MTJ.

\subsection{Data and resources}

\begin{tabular}{llll}
\hline \hline Time (UTC) & Lat/Lon & Depth & Strike/Dip/Rake \\
\hline $2015-01-28$ & $40.3178^{\circ} \mathrm{N}$ & $17.2 \mathrm{~km}$ & Plane 1: $105^{\circ} / 87^{\circ} / 178^{\circ}$ \\
$21: 08: 53$ & $124.6067^{\circ} \mathrm{W}$ & & Plane 2: $194^{\circ} / 85^{\circ} / 9^{\circ}$ \\
\hline
\end{tabular}

Table 2.1: Information of 2015 earthquake.

Two earthquakes near MTJ are used as sources that generate stress perturbations on the slab surface. They are the Jan 10, $2010 M_{w} 6.5$ earthquake and the Jan 28, $2015 M_{w} 5.7$ earthquake (Figure 1). The 2010 earthquake is the only earthquake that has a published finite fault inversion model near MTJ since the $1992 M_{w} 7.1$ Cape Mendocino earthquake (Wei and McGuire, 2014; Rollins and Stein, 2010). We use the coseismic slip model from Wei and McGuire (2014) for the 2010 earthquake. For the 2015 earthquake, we apply the second moments inversion method (McGuire, 2004) to determine its rupture area and simulate it with a simple uniform slip model.

The $M_{w} 5.7$ earthquake occurred at 21:08:53, January 28, 2015 UTC about $27 \mathrm{~km}$ offshore at on the Mendocino transform fault (See Table 1 and IRIS Event Page, http://ds . 


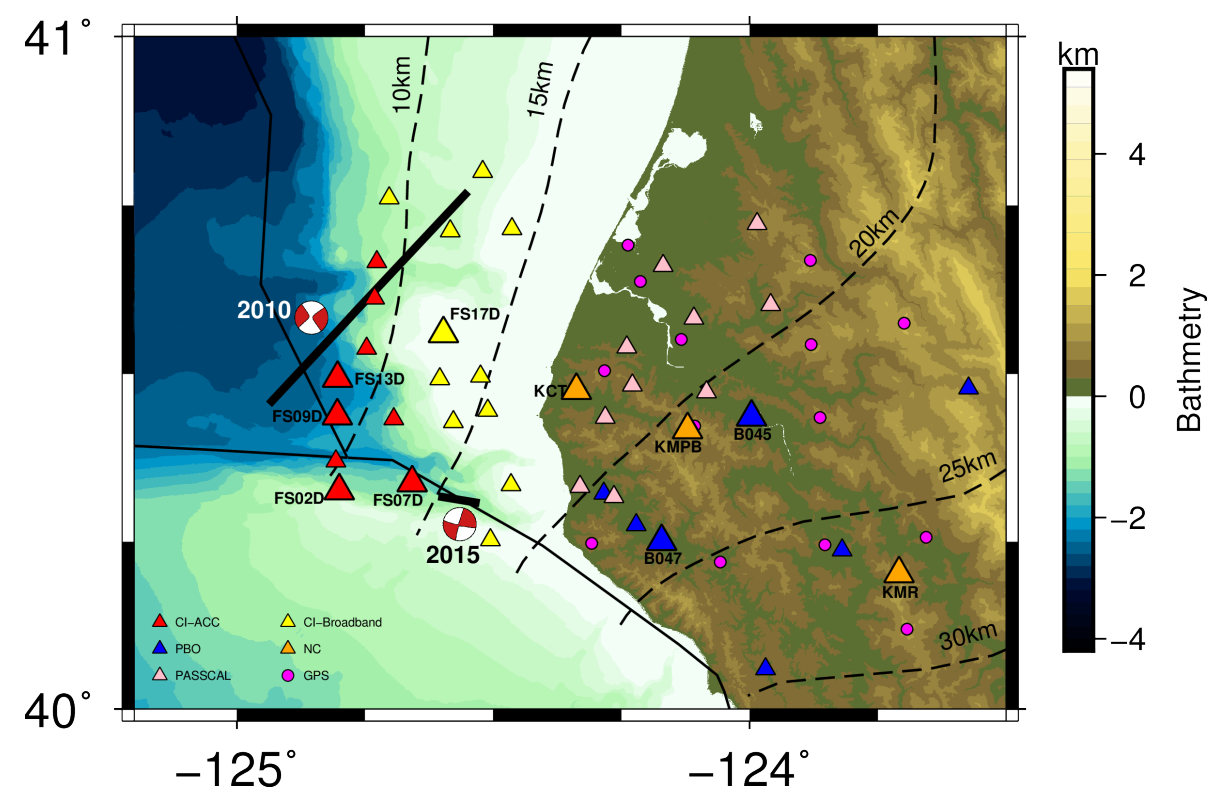

Figure 2-1: Map of the study area near the MTJ. Triangles are seismic stations. Offshore stations are from Cascadia Initiative experiment with yellow triangles representing broadband OBS from LDEO and SIO and red triangles representing broadband and accerlerometer stations from WHOI. Onshore, orange triangles are broadband and accerlerometer stations from the NCSN, pink triangles are short-period stations from PASSCAL, blue triangles are borehole short-period stations from the PBO and magenta circles are GPS stations from the PBO. Stations used in the second moment inversion are shown by larger triangles with station names labeled. Bold black straight lines and beach balls denote location and Global CMT mechanisms of the 2010 and 2015 earthquakes (ANSS (Advanced National Seismic System) Composite Catalog event ID numbers are 71338066 and 72387946 for 2010 and 2015 earthquakes). Dashed lines show subduction slab depth contours (McCrory et. al., 2012). Solid black lines are plate boundaries between Pacific, Gorda and North America plates from USGS Tectonic Plate Boundaries. Topography data is from NOAA.

iris.edu/ds/nodes/dmc/tools/event/5003592). The earthquake was recorded by a dense onshore/offshore seismic array with 45 stations within $80 \mathrm{~km}$ of the epicenter (Figure 1). The offshore stations were from the Cascadia Initiative (CI network) Year 4 experiment (Toomey et al., 2014) that contained 20 stations with ocean bottom seismometers (OBS) from the Lamont-Doherty Earth Observatory (LDEO), the Scripps Institution of Oceanography (SIO) and the Woods Hole Oceanographic Institution (WHOI). The LDEO and SIO stations were broadband OBSs sampled at $125 \mathrm{~Hz}$ and $100 \mathrm{~Hz}$ respectively. The WHOI stations were equipped with both a broadband OBS and a strong motion accelerometer (Figure 2) sampled at $50 \mathrm{~Hz}$. The onshore stations were from the Northern California Seismic Network (NCSN), the Plate Boundary Observatory (PBO) and a temporary deployment of IRIS-Portable Array Seismic Studies of the Continental Lithosphere (PASSCAL) sensors. 3 stations from the 


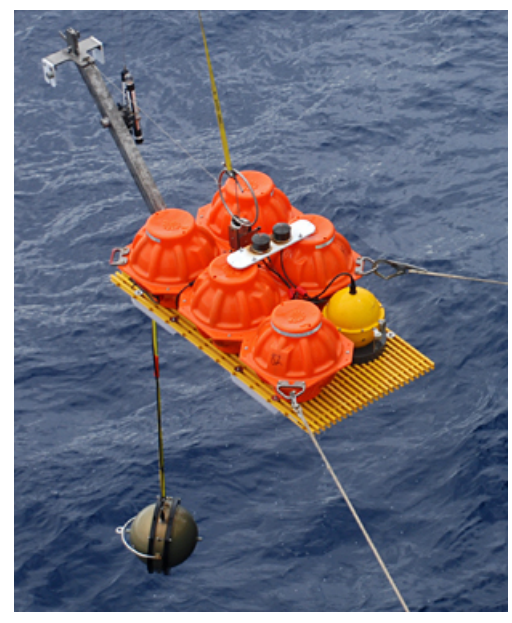

Figure 2-2: WHOI Keck ocean bottom seismograph instrument during recovery. The gray sphere hanging beneath the frame is the pressure housing that contains a broadband Guralp CMG-3T seismometer. The yellow ball contains a Kinemetrics strong motion Episensor accelerometer.

NCSN had both broadband seismometers and accelerometers installed; the 6 stations from the PBO were short period borehole seismometers and the 10 stations from PASSCAL are short period temporary stations. Offshore, the strong ground motions were recorded on scale by the 9 WHOI ocean bottom accelerometers and a few broadband OBSs located $>30$ $\mathrm{km}$ from the epicenter (Figure 3). Onshore, the strong ground motion waveforms were only recorded on scale by the 3 NCSN accelerometers and the 6 PBO borehole seismometers while the other PASSCAL and NCSN broadband and short-period seismometers were clipped.

\subsection{Second moments inversion}

\subsubsection{Method}

The second moments of an earthquake's rupture are the second order space and time moments of the normalized moment-rate distribution function $\dot{f}(\underline{r}, t)$ (McGuire, 2004). We use azimuthal variations in the duration of apparent source time functions (ASTF) to invert the second moments which provide estimates of the rupture dimension, duration and directivity. 
The second moments are given by:

$$
\begin{aligned}
& \underline{\underline{\mu}}^{(2,0)}=\iint \dot{f}(\underline{r}, t)\left(\underline{r}-\underline{r}_{0}\right)\left(\underline{r}-\underline{r}_{0}\right) d V d t \\
& \mu^{(0,2)}=\iint \dot{f}(\underline{r}, t)\left(t-t_{0}\right)\left(t-t_{0}\right) d V d t \\
& \underline{\mu}^{(1,1)}=\iint \dot{f}(\underline{r}, t)\left(\underline{r}-\underline{r}_{0}\right)\left(t-t_{0}\right) d V d t,
\end{aligned}
$$

where $\dot{f}(\underline{r}, t)$ satisfies:

$$
\underline{\underline{M}}(\underline{r}, t)=\underline{\underline{M}} \dot{f}(\underline{r}, t)
$$

Here, $\underline{\underline{M}}(\underline{r}, t)$ is the moment-rate distribution function at position $\underline{r}$ and time $t$ in the source region, $\underline{\underline{M}}$ is the seismic moment tensor, and $\underline{r}_{0}$ and $t_{0}$ are the centroid location and time. $\underline{\underline{\mu}}^{(2,0)}$ is a $3 \times 3$ tensor related to the spatial extent of the source. $\underline{\underline{\mu}}^{(0,2)}$ is a scalar related to the duration of the rupture. $\underline{\mu}^{(1,1)}$ is a $3 \times 1$ vector related to the rupture propagation.

Characteristic rupture properties of an earthquake, such as the characteristic dimension of the rupture $x_{c}(\underline{\hat{n}})$ in direction $\underline{\hat{n}}$, the characteristic duration $\tau_{c}$, the characteristic rupture velocity $v_{c}$ and the instantaneous centroid velocity $v_{0}$, can be estimated based on the second moments (Silver, 1983; McGuire et al., 2001). They are defined as:

$$
\begin{array}{ll}
x_{c}(\underline{\hat{n}})=2 \sqrt{\underline{\hat{\underline{\hat{n}}}}^{T} \underline{\underline{\mu}}^{(2,0)} \underline{\hat{n}}}, & \tau_{c}=2 \sqrt{\mu^{(0,2)},} \\
\underline{v}_{0}=\underline{\mu}^{(1,1)} / \mu^{(0,2)}, & v_{c}=L_{c} / \tau_{c},
\end{array}
$$

where the characteristic rupture length $L_{c}$ is the maxiumum value of $x_{c}(\underline{\hat{n}})$, corresponding to the largest eigenvalue of $\underline{\mu}^{(0,2)}$. A characteristic rupture width $W_{c}$ can also be estimated by using the second largest eigenvalue of $\underline{\underline{\mu}}^{(2,0)}$. The directivity ratio is defined by $\left|\underline{v}_{0}\right| / v_{c}$. A ratio $<0.5$ indicates a predominately bilateral rupture while a ratio $>0.5$ indicates a predominately unilateral rupture (McGuire et al., 2002).

The relative distortion of the ASTFs observed at stations located at different azimuths reflects the finiteness of an earthquake. The variance of the ASTF is linearly related to the second moments through slowness vector at the source (McGuire, 2004; Doornbos, 1982; Silver, 1983):

$$
\mu_{s}^{(0,2)} \approx \mu^{(0,2)}-2 \underline{s} \cdot \underline{\mu}^{(1,1)}+\underline{s}^{T} \cdot \underline{\underline{\mu}}^{(2,0)} \cdot \underline{s},
$$


where $\mu_{s}^{(0,2)}$ is the variance of the ASTF and $\underline{s}$ is the slowness vector of a particular seismic phase at the source. Additionally, we enforce the physical constraint that the source region has non-negative volume (Das and Kostrov, 1997; McGuire et al., 2001) using the linear matrix inequality:

$$
\left[\begin{array}{ll}
\mu^{(0,2)} & \underline{\mu}^{(1,1) T} \\
\underline{\mu}^{(1,1)} & \underline{\mu}^{(2,0)}
\end{array}\right] \geq 0,
$$

Equation (4) together with the constraint (5) can be solved using convex optimization techniques (McGuire, 2017; Vandenberghe and Boyd, 1996) to obtain the second moments and then the characteristic rupture dimensions. The number of unknown parameters can be reduced from ten to six if a double couple source model is assumed and the fault plane is known apriori.

\subsubsection{EGF deconvolution}

To estimate the ASTFs we utilize an empirical Green's function (EGF) deconvolution method to remove the propagation effects between the earthquake and the seismic stations. A nearby magnitude 2.5 earthquake 1 hour after the mainshock is selected as the EGF. P and S phases are bandpass filtered between 0.5 and $10 \mathrm{~Hz}$ and are integrated to velocity for the acceleration records. We use the Projected Landward Deconvolution (PLD) algorithm of Bertero et al. (1997) and Lanza et al. (1999) to deconvolve the aftershock waveforms from the mainshock. The PLD algorithm provides an objective determination of the duration of ASTF by calculating ASTF for a series of increasing length intervals and generating a trade-off curve showing the reduction of misfit with the increase in the ASTF duration.

We obtain 14 acceptable ASTFs on 10 stations (5 offshore and 5 onshore, $10 \mathrm{~S}$ phases

and $4 \mathrm{P}$ phases) for this earthquake (Figure 3). The reasons that other stations and phases are not used include clipped mainshock waveforms, EGF waveforms with poor signal to noise ratios, and mainshock $\mathrm{S}$ waves on a few OBS accelerometers that appear unusually complex possibly due to reverberations in the sediments or poor coupling. The duration of the ASTFs were determined based on the trade-off curves (Figure 3(A)). We pick the maximum duration of the ASTF where the trade-off curve flattens out or at a significant downward step. This is a challenging earthquake to apply the PLD method to because no 
A)

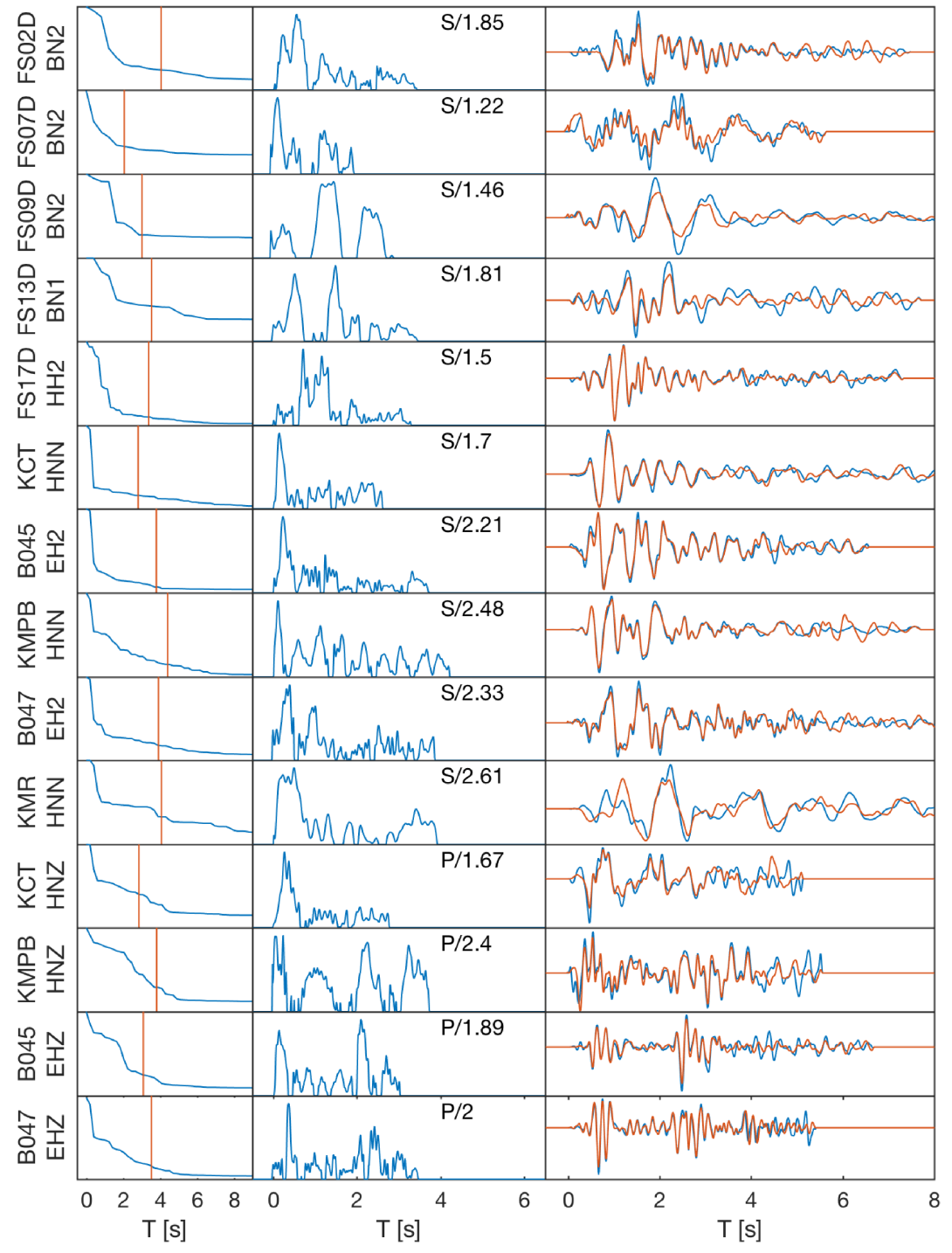

B)

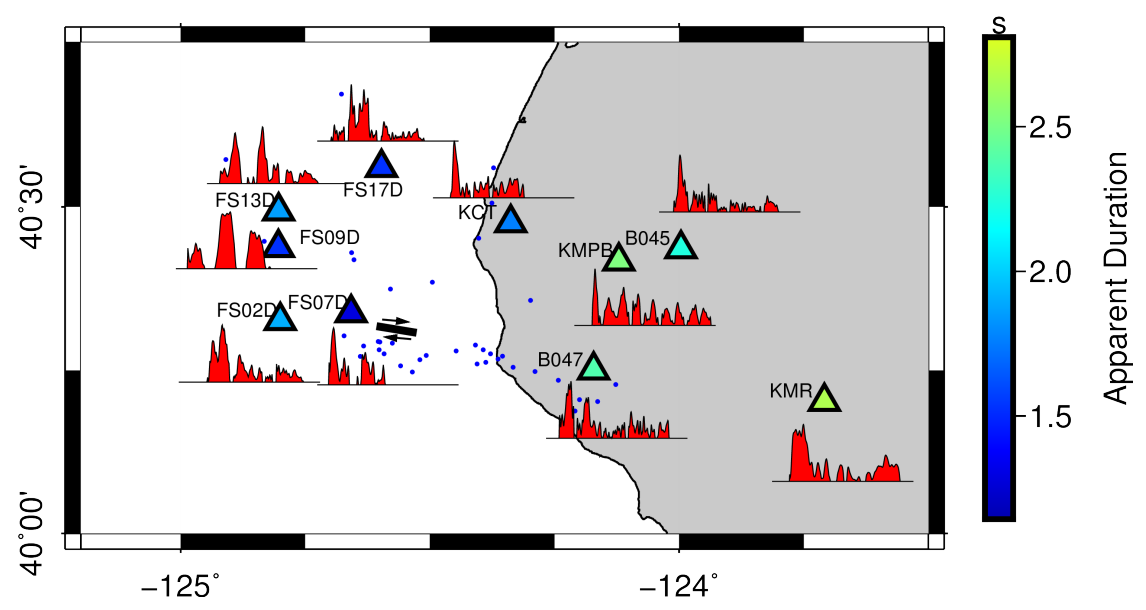


single subevent dominates the time function and it does not end abruptly. Both features make the picking of the ASTF duration difficult. We identified the most robust stations based on their sharply declining tradeoff curves (e.g. FS09D, B045) and the clear need for long ASTFs at a few onshore stations (e.g. KMR, KMPB). For stations with low misfits but no significant downward steps, we picked the duration to be similar to nearby stations with clearer durations (e.g. B047 and B045). The duration of the ASTF can be quantified by its

variance $\mu_{s}^{(0,2)}$ and the associated apparent characteristic duration $2 \sqrt{\mu_{s}^{(0,2)}}$. The rupture directivity can be observed by the relatively broadening or shortening of the ASTFs at stations of different azimuths. Figure 3(B) shows the map view of the employed stations with their ASTFs. The ASTF durations are shorter at offshore stations than onshore stations, indicting a directivity to the west.

\subsubsection{Inversion result}

\begin{tabular}{llllll}
\hline \hline $\mathrm{tt}\left(\mathrm{sec}^{2}\right)$ & $\mathrm{tx}(\mathrm{km} \cdot \mathrm{sec})$ & $\mathrm{ty}(\mathrm{km} \cdot \mathrm{sec})$ & $\mathrm{xx}\left(\mathrm{km}^{2}\right)$ & $\mathrm{yy}\left(\mathrm{km}^{2}\right)$ & $\mathrm{xy}\left(\mathrm{km}^{2}\right)$ \\
\hline 0.68 & -0.50 & -1.15 & 7.67 & 2.62 & 2.12 \\
\hline
\end{tabular}

Table 2.2: Second moments estimates in the Along-Strike (x), Downdip (y), and Time (t) Coordinate System.

We invert the apparent duration measurements in Figure 3 for the second moments assuming a two-dimensional fault plane source. To calculate the slowness vector for each measurement, we use the location and the focal mechanism listed in Table 1 and the $\mathrm{P}$ wave velocity model of Hole et al. (2000). For S-waves we assumed a constant $V_{p} / V_{s}$ ratio of 1.73 . We performed the inversion for each of the two conjugate focal planes. The E-W striking

Figure 2-3 (preceding page): A) EGF deconvolution result using PLD method. The first column shows the normalized squared misfit between the mainshock waveform and the synthetic waveform. The red line marks the time where misfit curve flattens. The second column is the ASTF produced by deconvolving EGF from the mainshock waveform. The phase ( $\mathrm{P}$ or $\mathrm{S}$ ) and the apparent duration of the ASTF are marked at the top right corner in each panel. The third colomn shows the mainshock waveform (blue line) and synthetic waveform (red line) produced by convolving the EGF with ASTF. B) Apparent source time functions. Triangles denote the location of the stations used in this study. ASTFs are plotted next to the stations. The straight line under each ASTF is $5 \mathrm{~s}$ time scale bar. The triangles are color coded to represent the apparent duration of the ASTFs. Bold black line denotes the location of the 2015 earthquake and arrows are the slip direction on two sides of the fault. Blue dots are aftershock distribution of this earthquake from. 


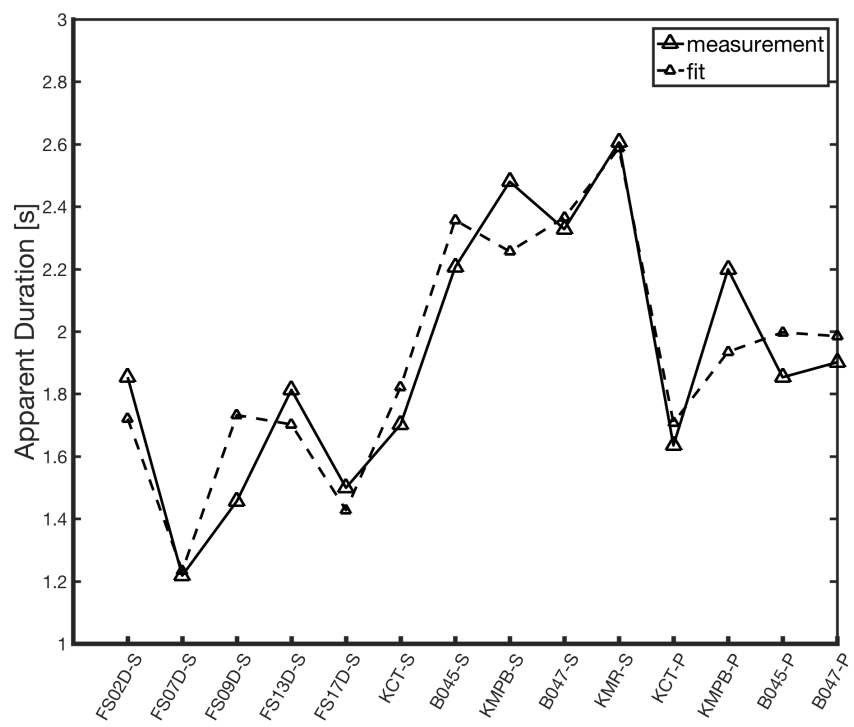

Figure 2-4: Solid line is the apparent duration calculated from ASTF of each station shown in Figure 3. Dashed line is the synthetic apparent duration calculated from equation (4) using the inverted second moments.

plane allows a better fit to the apparent durations indicating that the earthquake did indeed rupture the Mendocino transform fault. The estimated values of the second moments are listed in Table 2. The inversion results correspond to an $L_{c}$ of $5.8 \pm 0.2 \mathrm{~km}, W_{c}$ of $2.7 \pm 0.8$ $\mathrm{km}, \tau_{c}$ of $1.7 \pm 0.04 \mathrm{~s}, v_{c}$ of $3.5 \pm 0.1 \mathrm{~km} / \mathrm{s}, v_{0}$ of $1.85 \pm 0.5 \mathrm{~km} / \mathrm{s}$ and a directivity ratio of 0.5 . Figure 4 shows the fit of the measured apparent durations by the values predicted using Equation (4). The jackknife method is used to estimate the uncertainties. In each resampled dataset for the jackknife, we leave out the (2 or 3 ) stations within a $45^{\circ}$ azimuth bin (McGuire et al., 2001). Given the moment magnitude of 5.7 and the rupture area of 5.8 $\mathrm{km}$ by $2.7 \mathrm{~km}$, average slip distance is about $0.6 \mathrm{~m}$ and the stress drop is approximately 4 MPa assuming an elliptical crack model (Kaneko and Shearer, 2015; McGuire and Kaneko, 2017). The aftershock distribution extends for about $50 \mathrm{~km}$ along the Mendocino transform fault (Figure 3). The events that were large enough for focal mechanism estimation all had the expected strike-slip solutions indicating that aftershocks were primarily triggered along the Mendocino transform fault, not the thrust interface ( $\mathrm{Li}$ et al., 2018a). 


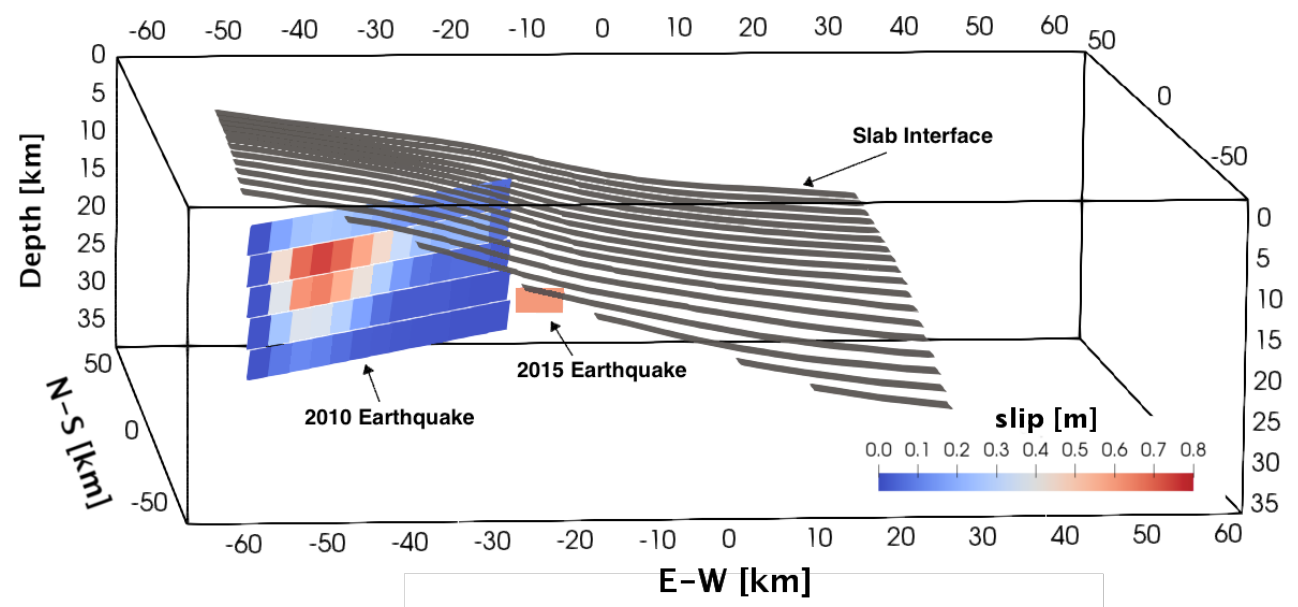

Figure 2-5: Locations of the subduction slab interface and the 2010 and 2015 earthquakes with their slip distributions. Slip distribution for the 2010 earthquake is from (Wei and McGuire, 2014). The geometry of slab surface is from (McCrory et al., 2012). The origin in horizontal coordinates is at the 2015 earthquake epicenter

\subsection{Coseismic Coulomb stress change}

Earthquakes within and adjacent to the subducting plate can build stress on the thrust interface and potentially trigger aftershocks or afterslip there. We calculate the coseismic static Coulomb stress changes $(\Delta \mathrm{CFS})$ on the slab surface induced by the 2010 and 2015 earthquakes. For the 2010 earthquake, we use the L2-norm coseismic slip model from Wei and McGuire (2014). For the 2015 earthquake, we use a $5.8 \mathrm{~km}$ by $2.7 \mathrm{~km}$ fault patch with uniform slip of $0.6 \mathrm{~m}$ obtained from the second moments solution above. Figure 5 shows the relative locations of these two earthquakes and the slab surface. The geometry of the slab surface is from McCrory et al. (2012). To calculate $\Delta$ CFS we mesh the slab surface into $\sim 1.1 \mathrm{~km}$ by $0.85 \mathrm{~km}$ subfaults and $\sim 0.28 \mathrm{~km}$ by $0.42 \mathrm{~km}$ subfaults for the 2010 and 2015 earthquake respectively following the curvature of the slab. We assume the strike of all of the subfaults is $0^{\circ}$ and the rake is $90^{\circ}$ for pure thrust slip. $\triangle \mathrm{CFS}$ is given by:

$$
\Delta \mathrm{CFS}=\Delta \tau-\mu \Delta \sigma
$$

where $\Delta \tau$ is the change in shear stress along the dip direction on the fault (positive for updip direction), $\Delta \sigma$ is the change in normal stress (positive for compression), and $\mu$ is the coefficient of friction which is set to be 0.2 in this study (Li et al., 2018a). For each 
A)

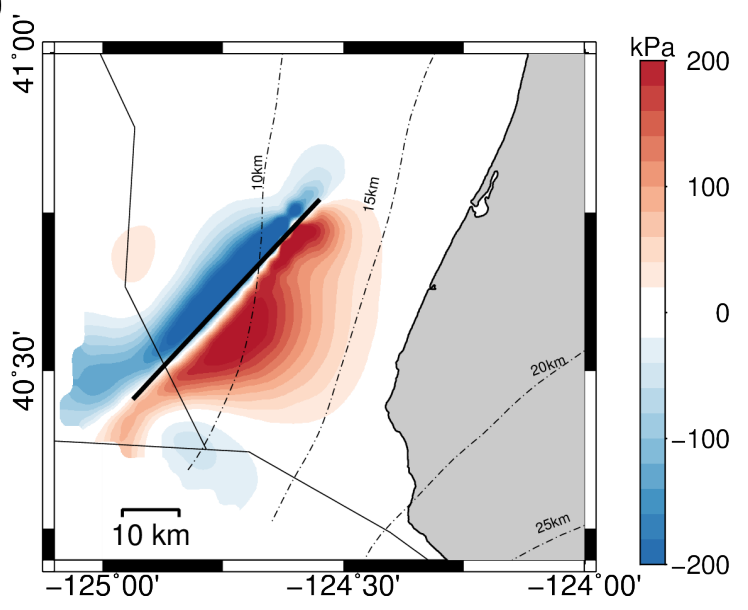

B)

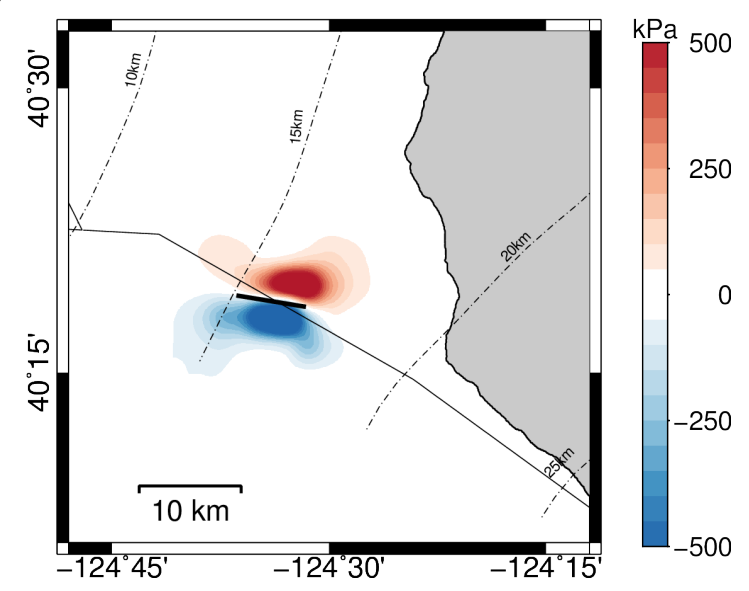

Figure 2-6: (A) 2010 earthquake. (B) 2015 earthquake. Dashed and solid lines denote slab depth contours and plate boundaries as in Figure 1. The negative Coulomb stress changes south of the 2015 earthquake are unrealistic as the subduction thrust fault likely does not extend south of the Mendociono transform fault.

subsurface, $\Delta \tau$ and $\Delta \sigma$ are calculated using Okada (1992) solution.

The $\Delta$ CFS results are shown in Figure 6. The 2010 earthquake caused a $\sim 0.1 \mathrm{MPa}$ coseismic Coulomb stress increase in an area of about $430 \mathrm{~km}^{2}$ between the depth of 5 $\mathrm{km}$ and $15 \mathrm{~km}$ on the interface. Similarly, the 2015 earthquake generated a $\sim 0.1 \mathrm{MPa}$ Coulomb stress increase in an area of about $77 \mathrm{~km}^{2}$ between the depth of $15 \mathrm{~km}$ and $20 \mathrm{~km}$. The negative Coulomb stress changes south of the 2015 earthquake are unrealistic as the subduction thrust fault likely does not extend south of the Mendocino transform fault as it does by a few $\mathrm{km}$ in the interface geometry model.

\subsection{Afterslip simulation}

To evaluate the frictional conditions and related locking state on the thrust interface, we build models of the postseismic response of the thrust interface following the two earthquakes by assuming that velocity strengthening frictional behavior starts at different depths on the slab interface. The Coulomb stress increases for the two earthquakes occur primarily in the 10-17 km depth range, and thus we test models where the downdip limit of the locked zone (e.g. start of velocity strengthening) occurs in this depth range.

We perform the modeling with the open source software Relax (Barbot and Fialko, 2010a,b). Afterslip on the deeper part of the plate interface obeys a generalized version of 
the velocity-strengthening friction law (Rice et al., 2001; Barbot and Fialko, 2010b):

$$
V=2 \dot{\gamma}_{0} \sinh \frac{\Delta \tau}{(a-b) \sigma}
$$

where $\Delta \tau$ is the Coulomb stress perturbation due to the earthquake, $(a-b) \sigma$ and $\dot{\gamma}_{0}$ are constitutive frictional parameters. Relax calculates the temporal evolution of the afterslip following the step changes in Coulomb stress from the two earthquakes.

We use a geometry of thrust interface from McCrory et al. (2012). To represent the subducting plate interface in Relax, rectangular patches with variable dip are used to mesh the McCrory et al. (2012) model. We assume the strike of all the patches is $0^{\circ}$ and the rake is $90^{\circ}$ for pure thrust slip. For the 2010 earthquake, we model the plate interface between $-124.8^{\circ}$ and $-124^{\circ}$ in longtitude and $40.1^{\circ}$ and $41^{\circ}$ in latitude. The surface is meshed into $\sim 11 \mathrm{~km}$ by $\sim 4 \mathrm{~km}$ patches along the strike and dip directions to approximate the nonplanar surface. For the 2015 earthquake, we model the plate interface between $-124.8^{\circ}$ and $-124.3^{\circ}$ in longitude and $40.3^{\circ}$ to $40.4^{\circ}$ in latitude. The surface is meshed into $\sim 3 \mathrm{~km}$ by $2 \mathrm{~km}$ patches along strike and dip directions. The depth where velocity-strengthening behavior starts is set at 10, 13 and $15 \mathrm{~km}$ for the 2010 earthquake and at 10, 15 and 17 $\mathrm{km}$ for the 2015 earthquakes. $\dot{\gamma}_{0}$ is $10 \mathrm{~m} / \mathrm{yr}$ and $(a-b) \sigma$ is $0.7 \mathrm{MPa}$. Here, $\dot{\gamma}_{0}$ represents the initial slip rate right before the Coulomb stress change. It governs how fast afterslip decays on the fault. Its value ranges from tens of millimeters per year to meters per year at different tectonic settings from previous GPS data inversion studies. Larger $\dot{\gamma}_{0}$ leads to rapid afterslip (Wei et al., 2015b), while smaller $\dot{\gamma}_{0}$ leads to long duration afterslip (Thomas et al., 2017). Numerous studies have used GPS data to estimate $(a-b) \sigma$ for afterslip on subduction thrust interfaces and found values on the order of $0.5 \sim 1.0 \mathrm{MPa}$ (Hsu et al., 2006; Miyazaki et al., 2004). The values we choose, $10 \mathrm{~m} / \mathrm{yr}$ for $\dot{\gamma}_{0}$ and $0.7 \mathrm{MPa}$ for $(a-b) \sigma$, are within the range of previous studies and changes in the range of previous studies would not effect the magnitude of the total afterslip and hence the GPS signal.

The accumulated afterslip distribution on the slab interface are shown in Figure 7(A-B). As the velocity-strengthening boundary is placed deeper, the afterslip area shrinks. For the 2010 earthquake, the modelled afterslip is truncated at 26 days after the earthquake. The total afterslip corresponds to $M_{w} 5.8,5.5$ and 4.8 for the three models for velocity-strengtheng starting at 10, 13 and $15 \mathrm{~km}$ on the subduction interface. For the 2015 earthquake, the 

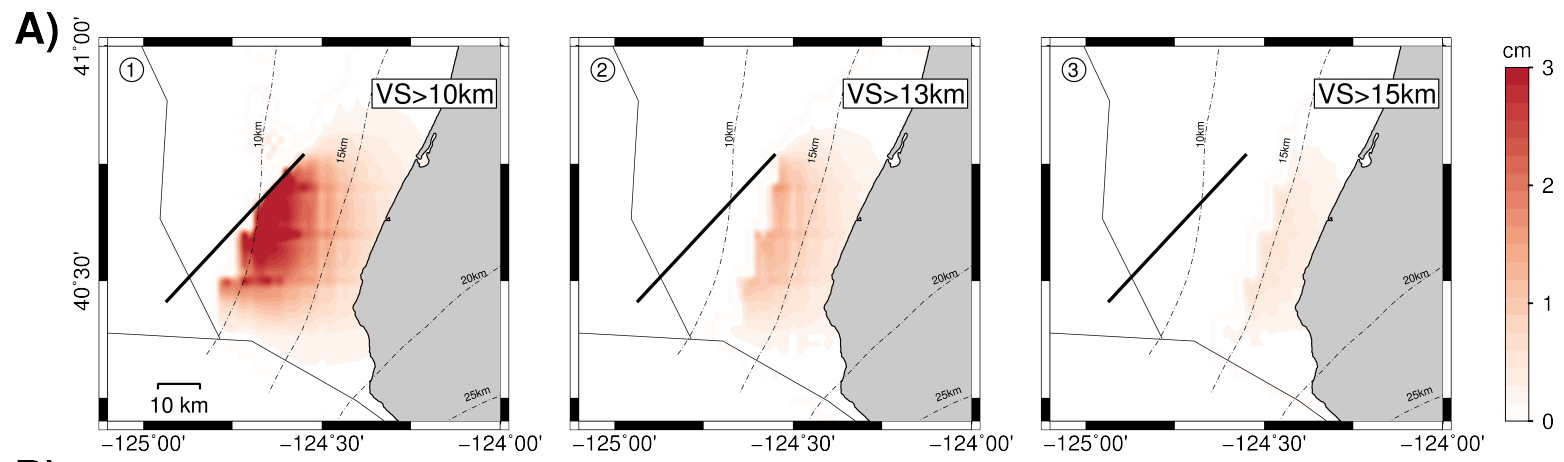

B)
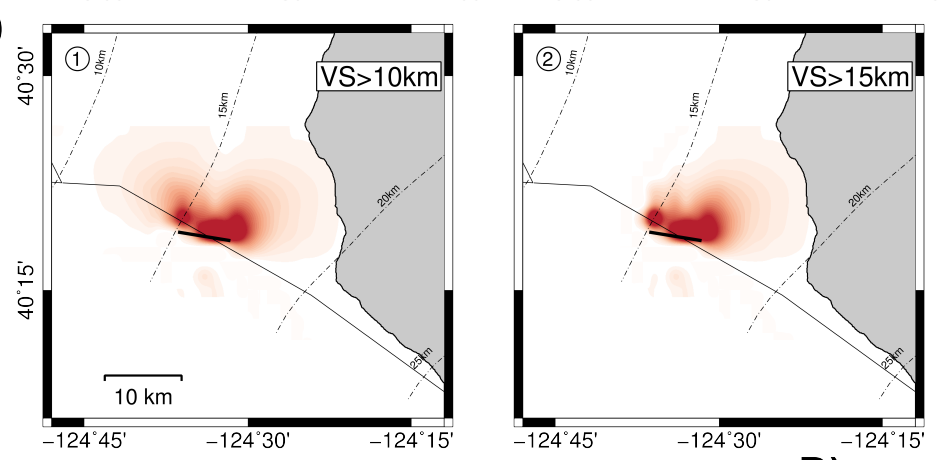

C)

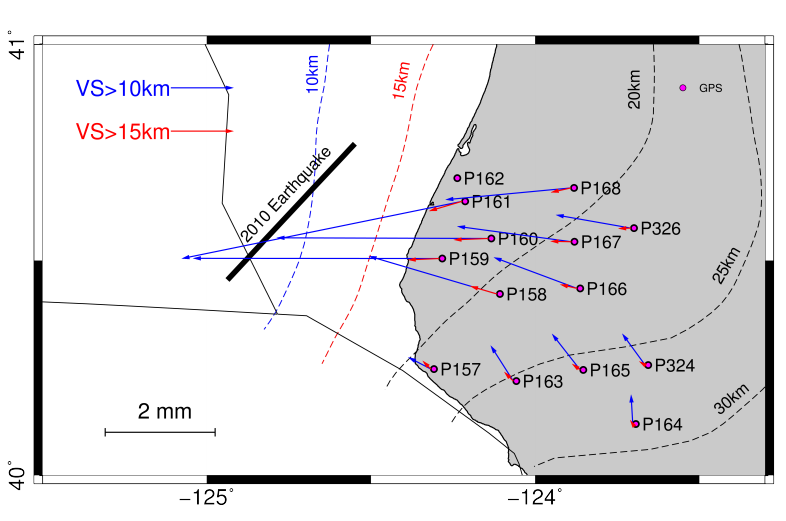

D)
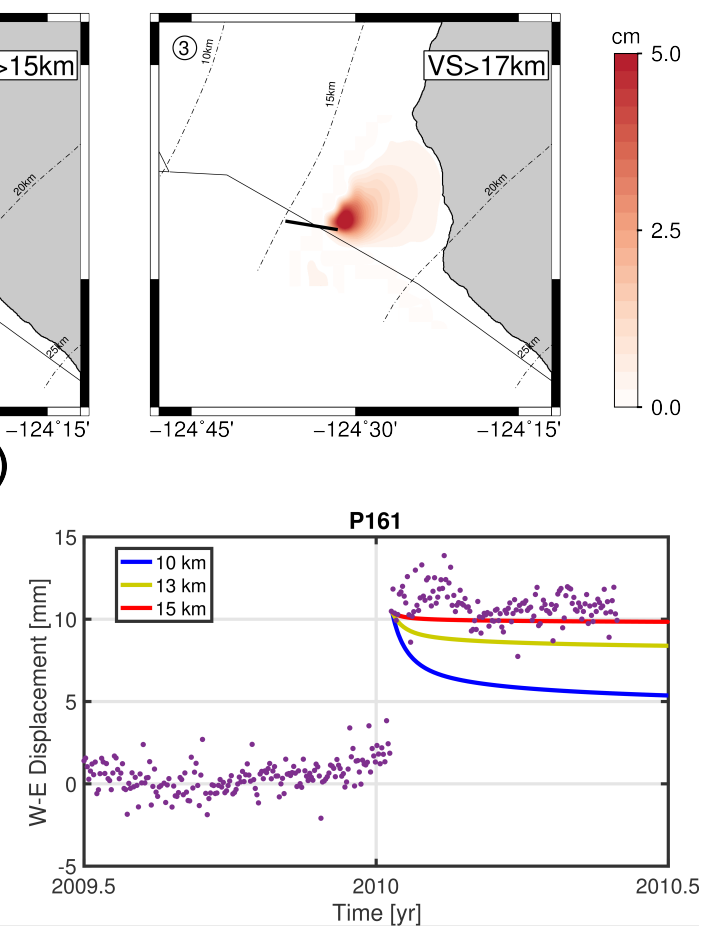
accumulated afterslip is truncated at 7 days after the earthquake, and they correspond to total afterslip moments of $M_{w} 5.4,5.3$ and 5.1 for velocity strengthening starting at 10, 15, and $17 \mathrm{~km}$. Figure 7(C) compares the postseismic horizontal displacements following the 2010 earthquake for velocity-strengthening friction starting at $10 \mathrm{~km}$ and $15 \mathrm{~km}$ on the subduction interface. For all models, the post-seismic signal is in the opposite direction from the coseismic since the 2010 earthquake is a left lateral strike slip earthquake and the afterslip happens on an east dipping thrust fault. For the model with velocity-strengthening friction starting at $10 \mathrm{~km}$, afterslip generates $4 \mathrm{~mm}$ horizontal (westward) displacement on the closest GPS stations. For the model with velocity-strengthening friction starting at 15 $\mathrm{km}$, the surface displacement is $<1 \mathrm{~mm}$, which is under the detection threshold of the GPS data. The simulated displacement history at GPS station P161 for the various models of the 2010 earthquake are shown in Figure 7(D) along with the observed GPS data from Wei and McGuire (2014). The observed GPS record shows no afterslip signal, indicating the velocity strengthening region likely starts at a depth of at least $13 \mathrm{~km}$ on the slab interface and possibly deeper. Perhaps most importantly, the model where the locked zone is limited to depths less than $10 \mathrm{~km}$, and hence located far offshore, clearly does not match the observed time series. The coseismic displacement and potential afterslip signal from the 2015 earthquake at the onshore GPS stations are too small to be detected $(\leq 1 \mathrm{~mm})$ and we do not evaluate them further here.

Figure 2-7 (preceding page): A) (1)-(3): 2010 earthquake. B) (1)-(3): 2015 earthquake. The updip limit of the velocity strengthening region, ranging from $10-17 \mathrm{~km}$, is marked at the top right corner of each panel. Bold straight lines denote locations of each source earthquake. The accumulated afterslip is truncated at 26 days after the 2010 earthquake and truncated at 7 days for the 2015 earthquake. The afterslip corresponds to $\mathrm{Mw}$ 5.8, 5.5, 4.8, 5.4, 5.3 and 5.1 earthquakes from A) (1)-(3) to B) (1)-(3). C) Modelled surface (GPS) displacements generated from afterslip on the slab interface following the 2010 earthquake. Blue arrows denote displacements for the model with velocity strengthening frictional property starting at $10 \mathrm{~km}$ depth. Red arrows denote displacements for the model with velocity strengthening frictional property starting at $15 \mathrm{~km}$ depth. Megenta circles denote the location of GPS stations. D) Displacement of east component at PBO GPS station P161 for 2010 earthquake. Magenta dots are GPS observations with linear and seasonal terms removed (Wei and McGuire, 2014). Solid lines are simulated displacement curves due to afterslip on the slab interface for the models with velocity strengthening starting at depths of $10 \mathrm{~km}$ (blue), $13 \mathrm{~km}$ (yellow) and $15 \mathrm{~km}$ (red). 


\subsection{Discussion}
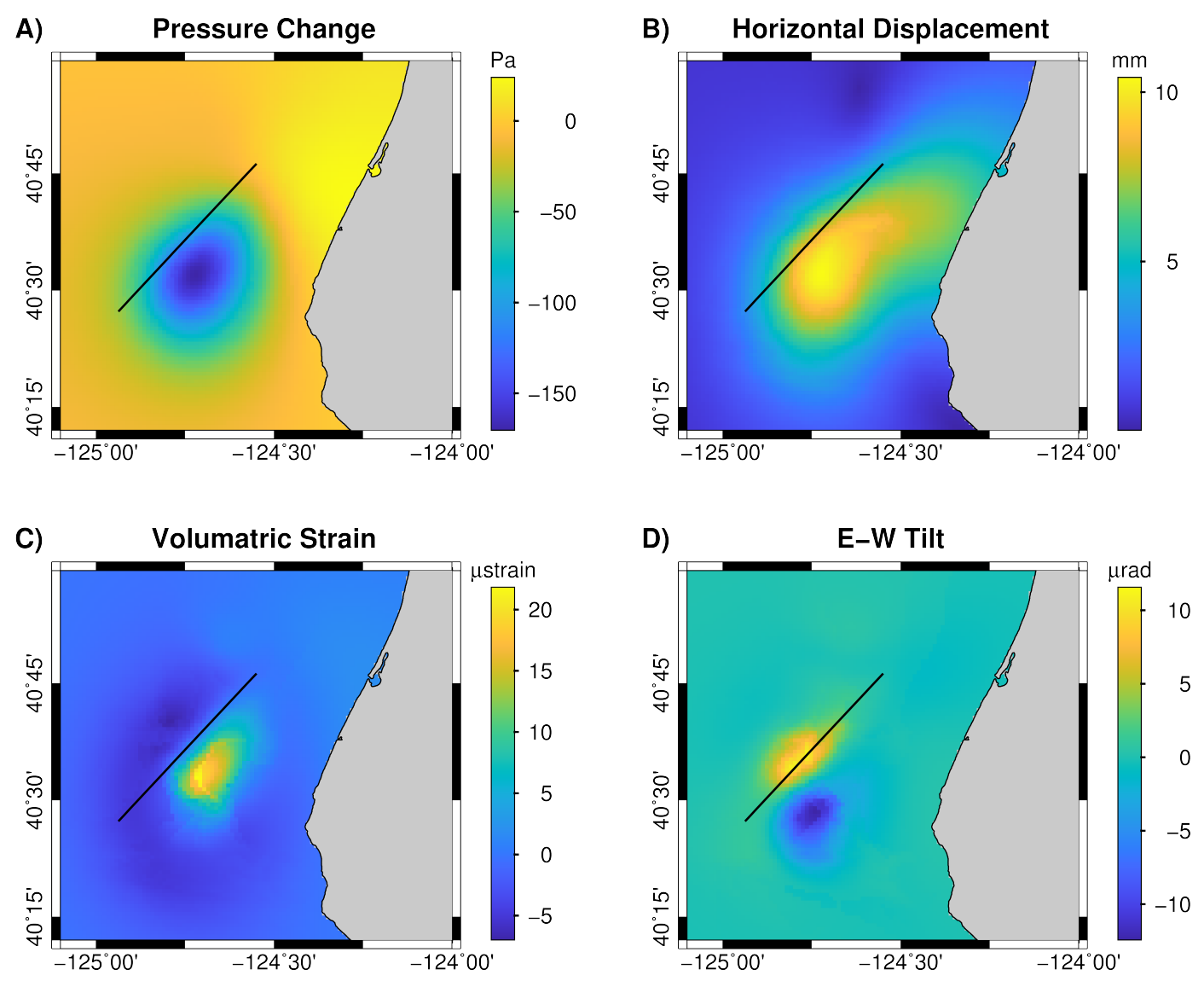

Figure 2-8: Predicted accumulated afterslip signal for multiple measurement types on the seafloor for the 2010 earthquake model with velocity strengthening frictional property beginning at $10 \mathrm{~km}$ depth. The four panels show (A) pressure changes, (B) displacements, (C) volumetric strain and (D) tilt at the seafloor.

An earthquake's stress drop can have a large effect on the magnitude of shaking expected in a region and subducted slabs have the potential to produce significantly larger stress drops than crustal earthquakes owing to the strength of the subducted mantle. We compare our estimated stress drop for the 2015 earthquake, $\sim 4 \mathrm{MPa}$ for crack model, to the strength envelope from Wei and McGuire (2014) for the subducting lithosphere at the location of the 2010 earthquake which should roughly approximate the conditions at the 2015 event as both occurred in the subducted mantle. The strength envelope peaks at about $20 \mathrm{~km}$ depth and $\sim 400 \mathrm{MPa}$ for hydrostatic conditions (and $600 \mathrm{MPa}$ for dry rock). Thus the ratio of the static stress drop $\Delta \sigma$ over ambient stress for the 2015 earthquake is on the order of 0.01 , similar to the 2010 earthquake which had a static stress drop in the range from 
2-20 MPa (Wei and McGuire, 2014). Chen and McGuire (2016) estimated the stress drop of a number of small earthquakes near the MTJ using spectral fitting and their stress drop distribution for events in the mantle portion of the Mendocino transform fault peaks at $\sim 7$ $\mathrm{MPa}$. The three studies combine to give a fairly consistent picture of stress drops on the strike slip earthquakes within the mantle of the subducted Gorda Plate or directly on the Mendocino transform fault that are predominately in the 2-10 MPa range, though the Chen and McGuire (2016) study does find some evidence for a few events with higher values in the 20-40 MPa range.

Locking models of the interface determined from onshore geodetic data have low resolution offshore and the results are strongly model dependent particularly near the southern and northern edges of the subduction zone. In Schmalzle et al. (2014), the locking fraction near the MTJ in the 10-20 km depth range ranges from $~ 0.5$ to 1.0 depending on the regularlization. In Pollitz and Evans (2017), the locking rate near the MTJ in this depth range is $>30 \mathrm{~mm} / \mathrm{yr}$ for the viscoelastic block model and $<10 \mathrm{~mm} / \mathrm{yr}$ for the viscoelastic-cycle model. There is no clear consensus that the thrust interface is locked or unlocked near the MTJ. In contrast, our afterslip simulations indicate that the locking depth is at least $14 \mathrm{~km}$ and there is no evidence for a velocity strengthening region in the 10-20 km depth range as might be expected from some of the locking models. The $>14 \mathrm{~km}$ constraint on the velocity weakening to strengthening transition indicated that the next M8 rupture in this region will likely reach the coastline and strong shaking should be expected there.

While the GPS data from the 2010 earthquake show no obvious post-seismic signal, the expected signal would be much larger on the seafloor closer to the fault. We used our simulations to predict the expected signals for a variety of seafloor geodetic observables including the pressure change, the horizontal displacement, the tilt, and the volumetric strain change due to afterslip following the 2010 earthquake (Figure 8). These signals could be measured by seafloor absolute pressure gauges, GPS-Acoustic systems, borehole tiltmeters and strainmeters, respectively, all of which are in common practice in various locations at subduction zones (see Bürgmann and Chadwell, 2014; Araki et al., 2017). For the 2010 earthquake, assuming the downdip limit of the locking depth at $10 \mathrm{~km}$ on the slab surface, we would expect to observe a maximum pressure change of $\sim 160 \mathrm{~Pa}$, a maximum horizontal displacement of $\sim 1 \mathrm{~cm}$, a maximum EW-tilt of $\sim 10$ microradians and maximum volumetric strain of $\sim 20 \mu$ strain. Compared to the typical resolution levels, borehole tilt measurements 
might be the easiest way to detect or rule out this type of transient deformation on the interface. Given the high level of seismicity near the MTJ and the need to understand more about the locking state of the thrust interface in Cascadia, our results suggest that the offshore region near the MTJ would make an ideal site for seafloor geodetic observations.

\section{Acknowledgements}

This work was supported by NSF EAR award numner 1520690. For NCSN stations, waveform data, metadata, or data products for this study were accessed through the Northern California Earthquake Data Center (NCEDC), doi:10.7932/NCEDC. For CI stations, the data used in this research was provided by Cascadia Initiative Community Experiment, https://doi.org/10.7914/SN/7D_2011. For PBO stations, the data used in this research was provided by UNAVCO. Both CI and PBO waveform data was accessed through IRIS Data Management Center (http://www.iris.edu). The slab model is downloaded at https://earthquake.usgs.gov/data/slab/models.php. Plate boundary model is downloaded at https://earthquake.usgs.gov/learn/kml.php. Topography data is downloaded from NOAA at https://www.ngdc.noaa.gov/mgg/coastal/crm.html. Map figures are generated using GMT Software (Wessel et al., 2013). We thank two anonymous reviewers for insightful comments and suggestions, which greatly improved the paper. 


\section{Chapter 3}

\section{Constraints on the Geometry of the Subducted Gorda Plate from Converted Phases Generated by Local Earthquakes}

\subsection{Abstract}

The largest slip in great megathrust earthquakes often occurs in the 10-30 km depth range, yet seismic imaging of the material properties in this region has proven difficult. We utilize a dense onshore-offshore passive seismic dataset from the southernmost Cascadia subduction zone where seismicity in the mantle of the subducted Gorda Plate produces S-to-P and P-to$\mathrm{S}$ conversions generated within a few $\mathrm{km}$ of the plate interface. These conversions typically occur in the 10-20 km depth range at either the top or bottom of a $\sim 5 \mathrm{~km}$ thick layer with a high $\mathrm{Vp} / \mathrm{Vs}$ that we infer to be primarily the subducted crust. We use their arrival times and amplitudes to infer the location of the top and bottom of the subducted crust as well as the velocity contrasts across these discontinuities. Comparing with both the Slab1.0 and the updated Slab2 interface models, the Slab2 model is generally consistent with the converted phases, while the Slab1.0 model is $1-2 \mathrm{~km}$ deeper in the $2-20 \mathrm{~km}$ depth range and $\sim 6-8 \mathrm{~km}$ too deep in the $10-20 \mathrm{~km}$ depth range between $40.25^{\circ}$ to $40.4^{\circ} \mathrm{N}$. Comparing the amplitudes of the converted phases to synthetics for simplified velocity structures, the amplitude of the 
converted phases requires models containing a $\sim 5 \mathrm{~km}$ thick zone with at least a $\sim 10-20 \%$ reduction in S-wave velocity. Thus the plate boundary is likely contained within or at the top of this low velocity zone, which potentially indicates a significant porosity and fluid content within the seismogenic zone.

\subsection{Introduction}

Paleoseismic studies of the Cascadia subduction zone demonstrate that it routinely generates M8-9 megathrust earthquakes (Atwater et al., 1995; Goldfinger et al., 2003) possibly with signifiant variability in their along-strike extents. However, due to the lack of instrumentally recorded large megathrust earthquakes, the extremely low rates of interplate seismicity, and the inadequate coverage of offshore geodetic observations, we lack a clear delineation of the likely rupture extent of future great earthquakes (Wang and Tréhu, 2016).

From geodetic observations, the Cascadia megathrust (subducted plate interface) is spatially segmented into an interseismically locked zone (Hyndman and Wang, 1995; Hyndman, 2013; McCaffrey et al., 2013; Schmalzle et al., 2014; Pollitz and Evans, 2017) that is likely confined to depths shallower than $\sim 21 \mathrm{~km}$ (Bruhat and Segall, 2016), a region of episodic tremor and slow slip (ETS) at depths between $\sim 30-50 \mathrm{~km}$ (Rogers and Dragert, 2003; Wech and Creager, 2011; Wang and Tréhu, 2016), and an intervening transition zone with uncertain rupture potential (Liu, 2013; Ramos and Huang, 2019). Current hazard models implement three possible scenarios where earthquakes are either contained largely offshore, propagate far onshore to reach the ETS zone, or terminate within the transition zone (Petersen et al., 2014; Wirth et al., 2018). These scenarios predict significantly different impacts on the overlying regions. Thus, whether future great earthquakes that initiate within the locked zone can rupture through the transition zone has considerable consequences for earthquake risk in large cities such as Seattle, Tacoma, Portland and Vancouver. A better understanding of the likely downdip extent of future ruptures requires detailed information on the material properties and physical conditions of the plate boundary zone at depths of $10-30 \mathrm{~km}$.

It is well established that both the shallow and deep parts of subduction megathrusts are weak faults. Direct observations of high pore fluid pressures (Saffer and Tobin, 2011) and low friction coefficients of recovered core samples (Fulton et al., 2013) indicate the shallow 
megathrust often has an effective friction coefficient less than 0.1. Similarly, both receiver function imaging studies and dynamic triggering of tremor suggest that the ETS zone is characterized by near lithostatic pore fluid pressures (Audet et al., 2009; Liu and Rice, 2005; Rubinstein et al., 2007). Moreover, modeling studies of ETS behavior in Cascadia require a contrast of a factor of $\sim 50$ in effective normal stress between the downdip ETS zone and the seismogenic zone (Liu and Rice, 2007; Segall and Bradley, 2012a) suggesting that the zone of high fluid pressure does not extend into the locked zone. Moreover, increases in earthquake stress drop from $\sim 5$ to $30 \mathrm{~km}$ depth (Bilek and Lay, 1999) and the strong high-frequency radiation from the deeper parts of large ruptures (Lay et al., 2012) indicate that shear stress on the megathrust is highest at the downdip end of the seismogenic zone. Understanding these along dip variations in physical conditions, particularly in the depth range where coseismic slip is expected to be greatest $(10-30 \mathrm{~km})$, may help us understand the level of shaking to expect in future great earthquakes.

The geometry and physical properties of the Cascadia megathrust are well imaged at shallow depths by offshore active-source seismic experiments and also at depths of $\sim 30-50$ $\mathrm{km}$, albeit with lower resolution, using onshore teleseismic methods. Han et al. (2017) demonstrated differences in the consolidation state of the sediments in the accretionary wedge are correlated with variations in coupling between the portions of the plate boundary offshore of Oregon and Washington. Their images extended to about $6 \mathrm{~km}$ below the seafloor. Similarly, Peterson and Keranen (2019) imaged porosity variations in the fault-zone down to about $3 \mathrm{~km}$ depth below the seafloor. A few active source reflection studies have been able to characterize the plate boundary zone to great depths. Nedimović et al. (2003) showed that within the seismogenic depth range $(\sim 10-20 \mathrm{~km})$ the plate boundary zone is characterized by a $2 \mathrm{~km}$ wide (or less) zone of sediments while at the depths of ETS events the plate boundary zone expands to a width of over $4 \mathrm{~km}$. Onshore seismic experiments that utilized teleseismic data imaged the ETS zone as a $\sim 5-10 \mathrm{~km}$ thick region of low shear wave velocities $(\mathrm{Vs})$ and a high ratio of compressional to shear wave seismic velocities $(\mathrm{Vp} / \mathrm{Vs})$ that indicates extremely high fluid content and inferred fluid pressure (Audet et al., 2009; Abers et al., 2009; Peacock et al., 2011; Tauzin et al., 2017). The high fluid content of the ETS zone is corroborated by magnetotelluric inversions that show strongly conductive regions immediately above the slab in the 30-40 km depth range (McGary et al., 2014; Evans et al., 2014; Wannamaker et al., 2014). 
The intervening depth range from 5-30 km depth has been less well imaged owing to its combination of being located primarily offshore and at significant depth. Beaudoin et al. (1994) imaged the subducted Gorda crust with an onshore refraction line in our study area and concluded the top of the subducted plate is at approximately $14 \mathrm{~km}$ depth in their alongstrike line located near the coast. They found that the subducted crust was characterized by $\mathrm{P}$-wave velocities from 6.2 to $6.7 \mathrm{~km} / \mathrm{s}$ and is $7-10 \mathrm{~km}$ thick. They found some possible evidence for subducted sediments near the top of the crust but concluded that no low velocity zone was required to fit their data. Their preferred model generated reflections from a 6.0 to $6.7 \mathrm{~km} / \mathrm{s}$ discontinuity in $V_{p}$ at the top of the crust as well as from a 6.7 to $7.7 \mathrm{~km} / \mathrm{s}$ discontinuity in $V_{p}$ at the base of the subducted crust corresponding to $\sim 10^{\smile} 15 \%$ velocity increases.

Recently, several local earthquake tomography studies and large scale community velocity models provided more detailed information on the structure of the Cascadia subduction zone at depths of 10-30 km. Using published geophysical data in addition to borehole and other geological constraints, Stephenson et al. (2017) constructed 3D P and S wave velocity models for large-scale ground motion simulations in Cascadia. Guo et al. (2019) imaged the subduction zone structure near the Mendocino Triple Junction (MTJ) area where the subducting Gorda plate crust is characterized as a high $V_{p} / V_{s}(\sim 1.85)$ layer about $6 \mathrm{~km}$ thick. They interpreted this layer as the subducted oceanic crust. The high $V_{p} / V_{s}$ ratio indicated a significant porosity (few percent) within the depth range of interseismic locking. They estimated the depth of the crust to be slightly $(1-2 \mathrm{~km})$ deeper than in the model of Beaudoin et al. (1994). They also found a reduction in $V_{p} / V_{s}$ and hence decrease in porosity in the geodetic transition zone. They interpreted the spatial variations in $V_{p} / V_{s}$ ratio as indicating that the transition zone is governed by a ductile rheology that would inhibit significant onshore propagation of large ruptures. Similarly, Savard et al. (2018) imaged the forarc area beneath northern Cascadia in the $20-40 \mathrm{~km}$ depth range which revealed a high Poisson's ratio suducted upper oceanic crust and a low Poisson's ratio forearc continental crust above the mantle wedge, suggesting an association between composition, fluids, and seismogenesis. Both tomographic studies covered regions of Cascadia with sufficient local earthquake data to improve the constraints on structure near the downdip edge of interseismic locking.

Most traditional passive source seismic imaging methods, such as receiver functions and first-arrival tomography, produce images with inherently low resolution and have difficulty 
with seafloor seismic data. Teleseismic receiver functions are typically calculated using 0.1-1 Hz waves, which sets a coarse spatial resolution $(\sim 5-10 \mathrm{~km})$ relative to the geologic structures associated with a plate boundary fault. Analyzing the seafloor seismic data collected above the locked zone from the Cascadia Initiative dataset (Toomey et al., 2014) with the receiver function method, Janiszewski and Abers (2015) found evidence for a strong low velocity zone at plate boundary depths from primarily one high quality station, while a stacked image of the whole dataset from Audet and Schaeffer (2018) found that the low velocity zone seen at ETS depths was absent in the seismogenic depth range. Similarly, tomographic velocity models are inherently smooth and often do not resolve a low velocity zone in the vicinity of the plate boundary owing to its short spatial scale despite the high probability that such a zone exists due to the subducted melange layer. A key question for understanding the physical properties and the intensity of shaking that should be expected in Cascadia is whether the deepest part of the locked zone $(\sim 10-20 \mathrm{~km})$ is characterized by high fluid pressure and hence a significant low velocity zone (LVZ). These conditions would imply lower values of the effective stress levels on the plate interface and perhaps weaker seismic radiation than models without a LVZ. Resolving these questions requires imaging methods with high resolution both in depth and laterally that can detect the physical properties of the plate boundary zone at depths of $\sim 20 \mathrm{~km}$.

In this paper, we use S-to-P and P-to-S phases generated by local earthquakes in the mantle of the downgoing plate and converted in the vicinity of the slab interface to constrain the depth and material properties of the plate boundary zone. These type of phases have been used for imaging the structure of subducted slabs in a number of regions including: Japan (Matsuzawa et al., 1986, 1990; Obara and Sato, 1988; Nakamura et al., 1998; Ohmi and Hori, 2000; Horleston and Helffrich, 2012), New Zealand (Eberhart-Phillips and Reyners, 1999; Reading et al., 2001), Mexico (Lomnitz, 1982; Song et al., 2009; Song and Kim, 2011), Alaska (Stephens et al., 1990) and Cascadia (Nowack and Bostock, 2013; Merrill and Bostock, 2019). These types of converted phases typically have high frequency content (1-15 $\mathrm{Hz}$ ) and are able to create sharper images of the interface. Most of the above studies focus on the slab structure below $30 \mathrm{~km}$ depth. We take advantage of the high seismicity rate near the Mendocino Triple Junction and a dense onshore-offshore seismic array to study the slab interface structure from $10 \mathrm{~km}$ to $20 \mathrm{~km}$ depth in the anticipated seismogenic zone. The combination of the high-frequency nature of the local earthquake generated converted 
phases and the dense seismic array allows the potential to study rapid variations in the material properties both in depth and laterally on a scale that matches the variations in geodetic observations of interseismic coupling.

\subsection{Data}

We utilize seismic data from an onshore-offshore network near the MTJ which includes 39 temporary OBS stations, 10 temporary onshore stations and 7 permanent onshore stations (Fig. 3-1). The OBS stations were deployed during the Cascadia Initiative (CI) experiment (Toomey et al., 2014) and included instruments from the Lamont-Doherty Earth Observatory (LDEO), the Scripps Institution of Oceanography (SIO) and the Woods Hole Oceanographic Institution (WHOI). They were deployed during two time periods: 2012-2013 and 2014-2015 (Year 2 and Year 4 in the CI experiment) with slightly different station configurations. All of the OBS stations included 3 component broadband seismometers and most were equipped with either an absolute or differential pressure gauge. Instrument types and their sampling rates are different between the three institutions. The data duration and quality is better in Year 4 than Year 2 due to a number of factors. The pressure sensors at deep water stations were used in our analysis but the oceanographic noise levels at shallow water stations ( $<500 \mathrm{~m}$ depth) prevented us from using those records. The 10 temporary onshore stations were short-period sensors from the IRIS-Portable Array Seismic Studies of the Continental Lithosphere (PASSCAL, 2014-2015). The 7 permanent stations were from broadband stations of the Northern California Seismic Network and the Berkeley Digital Seismic Network, and the short-period borehole stations of the UNAVCO Plate Boundary Observatory.

Waveforms for each earthquake are windowed between 1 minute before and 2 minutes after the origin time. The waveforms are filtered between $1-5 \mathrm{~Hz}, 2-7 \mathrm{~Hz}$ or $4-12 \mathrm{~Hz}$ to identify which frequency band yields the most easily visible converted phases on a particular component. Noisy data for particular earthquakes are then removed from the dataset based on their signal to noise ratio for the direct waves. $\mathrm{P}$ and $\mathrm{S}$ wave arrivals are repicked by cross-correlation and then manually shifted if cross-correlation doesn't yield satisfactory alignment results within a record section.

We utilize earthquake location results and tomography models from Guo et al. (2019) 


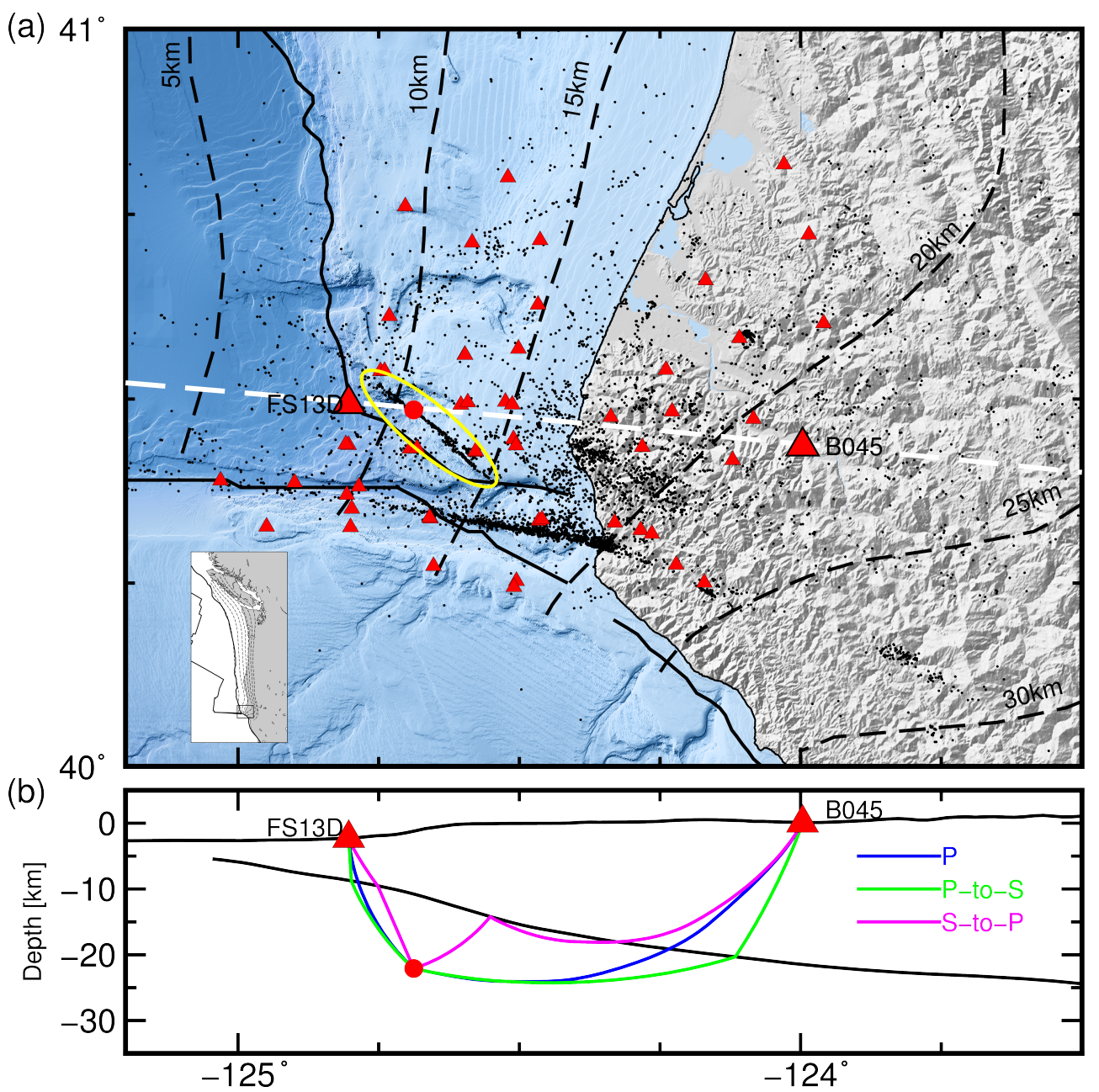

Figure 3-1: Map of the study area and a cross section showing the raypaths of converted phases. (a) Red triangles denote seismic stations. Black dots denote earthquake locations from Guo et al. (2019). Bold black lines denote plate boundaries from the USGS Quaternary Fault and Fold Database. Black dash lines denote the Gorda slab depth contours from the Slab1.0 model. The white dash line denotes the cross section shown in (b). Topography and bathymetry data are from the NOAA Coastal Relief Model and ETOPO1 Global Relief Model. The earthquakes inside the yellow ellipse occur primarily on a fault in the mantle of the downgoing plate (termed the M-Fault) which was analyzed in Chen and McGuire (2016). The inset map shows the Cascadia subduction zone. Our study area is shown as the black rectangle at the southern end of Cascadia. (b) Blue, green and magenta lines are raypaths of the $\mathrm{P}$, Ps and SP phases from one M-fault earthquake to one onshore (B045) and one offshore (FS13D) station. The thin black line denotes topography along the cross section and the bold black line denotes the plate boundary geometry from the Slab1.0 model (McCrory et al., 2012). 
which were determined with the same seismic array. In this study we focus on events in the yellow ellipse in Fig. 3-1 because those events naturally form a source array with similar waveforms. The earthquakes occurred at about $25 \mathrm{~km}$ depth on a strike-slip fault in the subducted oceanic mantle (hereinafter referred as the M-fault). They are shallower to the west and deeper to the east, and the relocated dataset contains about 450 events which are recorded to various degrees by the different stations depending on their duration of recording. We use the Slab1.0 model from McCrory et al. (2012) as a reference slab geometry model as well as for calculating raypaths and arrival times of the different converted phases.

\subsection{Methods}

In this section we demonstrate how to identify S-to-P and P-to-S converted phases generated near the plate boundary interface on seismic record sections. The S-to-P and P-to-S converted phases arrive inbetween the direct $\mathrm{P}$ and $\mathrm{S}$ waves. We use raytracing and the source side beamforming method to identify and classify these converted phases. We also apply the wavefield decomposition method to remove water reflection phases on OBS records. Examples of $\mathrm{P}$, S-to-P and P-to-S raypaths from an M-fault earthquake to both onshore and offshore stations are shown in Fig. 3-1(b).

\subsubsection{Raytracing}

To calculate S-to-P and P-to-S travel times and the locations of the conversion points on the slab interface, we apply a 3D raytracing method to each event-station pair using the $\mathrm{P}$ and S wave velocity models from Guo et al. (2019). The raytracing code is extracted from the TomoDD software (Zhang and Thurber, 2003), which is based on the pseudo ray bending method described in Um and Thurber (1987). Since the smooth tomographic velocity models do not contain discontinuities to generate converted phases, we trace rays that travel as a $\mathrm{P}$ (or S) wave from the event to Slab1.0 model interface and travel as S (or P) wave from slab interface to station. We mesh the slab interface into a $1 \mathrm{~km} \times 1 \mathrm{~km}$ grid and then calculate raypaths and travel times from the event to the slab surface grid points and from the grid points to the station. We then identify the grid point that yields the minimum total travel time as the conversion point. For S-to-P converted phases, two types of raypaths exist: transmission (e.g. FS13D in Fig. 3-1(b)) and reflection refraction (e.g. B045 in Fig. 3-1(b)). 
(a)

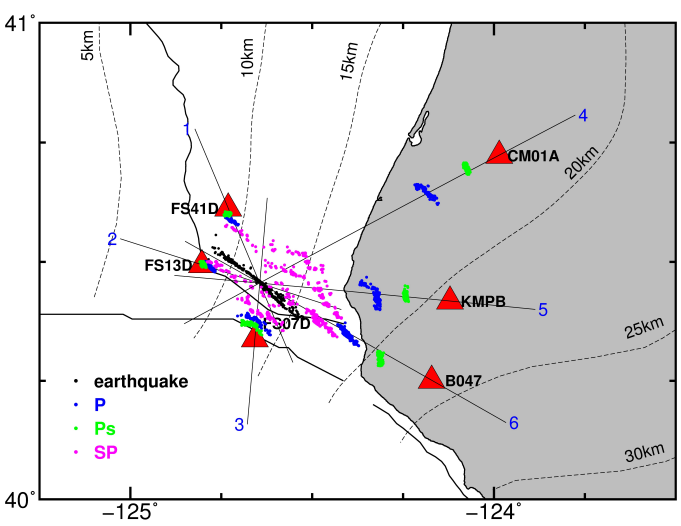

(b)

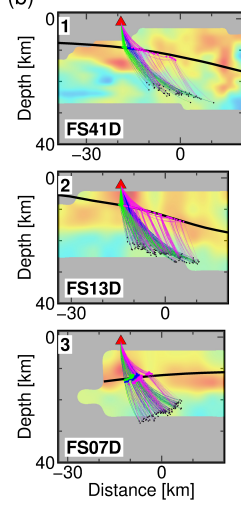

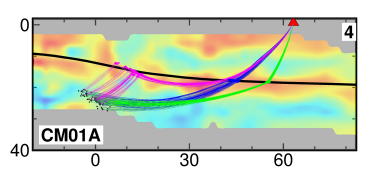
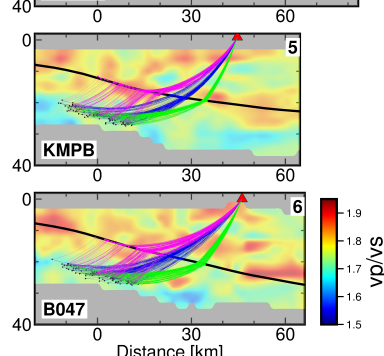

(c)

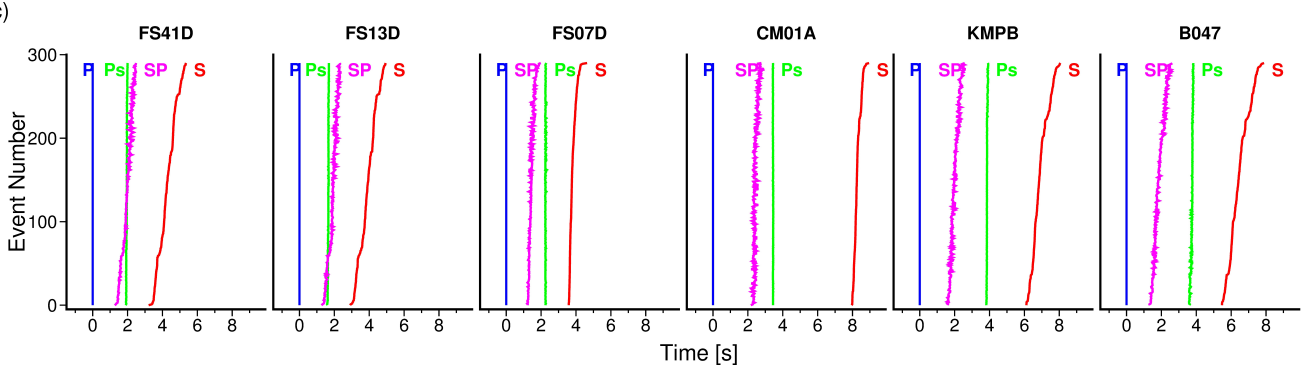

Figure 3-2: Raytracing results. (a) Location of Ps (green) and SP (magenta) conversion points and direct $\mathrm{P}$ (blue) wave piercing points on the slab interface from M-Fault events to stations FS41D, FS13D, FS07D, CM01A, KMPB and B047. Lines 1-6 are locations of the cross sections shown in (b). The 6 cross sections connect the center of the MFault events with each station. (b) Cross sections going through the center of the M-Fault events to each station. The background color denotes the $V_{p} / V_{s}$ ratio model from Guo et al. (2019). Black dots denote the locations of the M-Fault earthquakes. Blue, green and magenta lines denote $\mathrm{P}, \mathrm{Ps}$ and $\mathrm{SP}$ phase raypaths. Blue, green and magenta dots denote P, Ps and SP phase piercing/conversion points on the slab interface. Black lines and red triangles denote the subduction interface geometry and seismic stations. Earthquake locations, piercing/conversion points and ray path are projected onto each cross section. (c) Predicted P (blue), Ps (green), SP (magenta) and S (red) phases traveltime curves for each station from the M-Fault events. Traveltime curves are aligned on the direct $\mathrm{P}$ arrival. The vertical axis is event order sorted by the S-P travel time difference.

The latter occurs when the station is far away enough that the S-to-P conversion phase reaches the total reflection condition (see supplementary information). This is not the case for P-to-S converted phases as the $\mathrm{S}$ wave velocity is always smaller than $\mathrm{P}$ wave at the conversion point and the $\mathrm{S}$ wave part of the ray will always go upward. By traditional naming convention in seismology, we will use Ps to represent P-to-S converted phase from now on for simplicity. And we will use SP to represent S-to-P converted phases of both the transmission type and the reflection refraction type. We use the Slab1.0 model instead of the Slab2 model (Hayes et al., 2018) because Slab2 doesn't cover a large enough area 
offshore to calculate piercing/conversion points of the P, S, Ps and SP phases for some OBS stations. However, we compare our converted phases results with both the Slab1.0 and Slab2 models in the Discussion section. We validated the minimum travel-time path ray tracing approach for the Ps and SP phases using 2D waveform simulations (Tromp et al., 2008) for our velocity model (see supplementary information).

Several raytracing results are shown in Fig. 3-2 that demonstrate the general features of our dataset. Compared to $\mathrm{P}$ wave piercing points, Ps conversion points are closer to the station and are more concentrated, while SP conversion points are farther away from the station and are spread out over a much larger area for a given set of earthquakes. On the traveltime plots (Fig. 3-2c), Ps phases have a similar moveout to the direct $\mathrm{P}$ wave while SP phases show a moveout that is intermediate between the $\mathrm{P}$ and $\mathrm{S}$ wave moveouts but with more scatter. Fig. 3-3 (a) compares the predicted SP arrival times to a vertical component record section at station CM01A. The seismograms are aligned on the $\mathrm{P}$ wave and ordered by their S-P travel time difference. The blue line is the predicted travel time of the SP converted phases. Large amplitude arrivals can be seen close to the predicted arrival time for many earthquakes and the conversion points of the SP phases and the raypaths are shown in Fig. 3-3 (b) and (c). To further establish that these large amplitude signals are SP converted phases, we apply the source side beamforming method described below.

\subsubsection{Source side beamforming}

The clear arrivals between the direct $\mathrm{P}$ and $\mathrm{S}$ phases are suggestive of converted phases and we confirm the sense of the conversion (Ps or SP) using a source side 3D beamforming method (Spudich and Bostwick, 1987; Nakata and Shelly, 2018) and estimate the propagation directions and velocities of theses phases as they leave the earthquake source region. This method uses the reciprocity theory of wave propagation by viewing the seismograms recorded at a single station from a cluster of nearby earthquakes with similar waveforms as being identical to waveforms that would be generated by an earthquake that occurred at the location of the station and was recorded by an array of receivers at the position of the earthquakes. The beamforming method results in estimates of the near source velocities as well as the azimuth and the take-off angles of the raypaths of the waves as they leave the earthquake source region.

The beamforming method may be described mathematically, as noted in Spudich and 

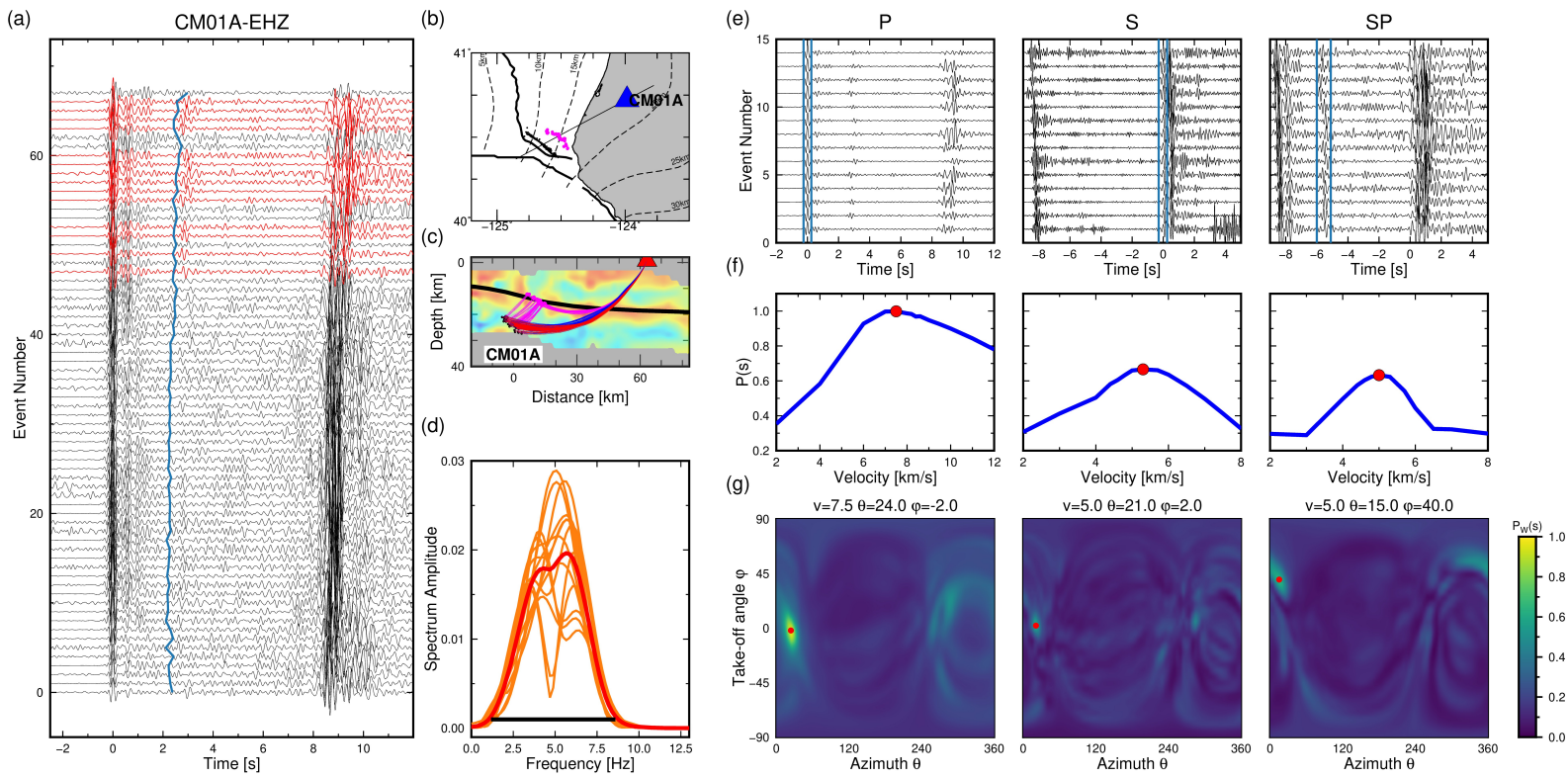

Figure 3-3: Waveform section and source side 3D beamforming results for station CM01A. (a) Z component seismograms from M-Fault events. The seismograms are aligned by the $\mathrm{P}$ wave and sorted by the S-P traveltime difference. Red traces are the ones used for beamforming analysis. The blue line denotes the predicted arrival time of SP phase converted at the Slab1.0 model. (b) Map view of the location of the M-Fault events and station CM01A. (c) Raypaths of P, S and SP phases from the M-fault events to station CM01A. The background colors denote the $\mathrm{Vp} / \mathrm{Vs}$ model as in Fig. 3-2. (d) Orange lines show the power spectrum of each SP converted phase from the red traces in (a) and the red line is the averaged power spectrum. The horizontal black line represents the selected frequency range for the beamforming analysis. (e) Waveform section of the selected traces in (a) with the blue lines denoting the selected windows for P, S and SP phase for beamforming analysis. In the first panel, the seismograms are aligned by the $\mathrm{P}$ wave. In the second and third panels, the seismograms are aligned by the $\mathrm{S}$ wave. All the seismograms are sorted by $\mathrm{S}-\mathrm{P}$ traveltime difference. (f) Maximum slowness power spectrum as a function of velocity. The maximum value is marked by the red dot. (g) Slowness power spectrum as a function of azimuth and take-off angle for the best velocity estimate in (f). The location of the maximum of the slowness power spectrum is marked by the red dots and the best velocity, azimuth $(\theta)$ and take-off angle $(\phi)$ are shown in the title of each panel.

Bostwick (1987), let $\mathbf{r}_{j}$ be the relative location of event $j$ from a reference location and $u\left(\mathbf{r}_{j}, t\right)$ be the wavelet of a certain phase from event $j$ with zero time corresponding to the origin time of each earthquake. Applying a plane-wave decomposition, the complex amplitude in the slowness and frequency domain for $N$ clustered earthquakes is:

$$
\tilde{u}(\mathbf{s}, \omega)=\frac{1}{N} \int_{-\infty}^{\infty} \sum_{j=1}^{N} u\left(\mathbf{r}_{j}, t\right) e^{i\left(\omega \mathbf{s} \cdot \mathbf{r}_{j}-\omega t\right)} d t
$$

where $\mathbf{s}$ is the slowness vector of the outgoing rays and $\omega$ is angular frequency. The corre- 
sponding power spectrum is:

$$
P(\mathbf{s}, \omega)=\tilde{u}(\mathbf{s}, \omega) u^{*}(\mathbf{s}, \omega)
$$

where $u^{*}(\mathbf{s}, \omega)$ is the complex conjugate of $\tilde{u}(\mathbf{s}, \omega)$. Following Eq. (3.1), we have

$$
\begin{aligned}
\tilde{u}(\mathbf{s}, \omega) & =\frac{1}{N} \sum_{j=1}^{N} e^{i \omega \mathbf{s} \cdot \mathbf{r}_{j}} \int_{-\infty}^{\infty} u\left(\mathbf{r}_{j}, t\right) e^{-i \omega t} d t \\
& =\frac{1}{N} \sum_{j=1}^{N} e^{i \omega \mathbf{s} \cdot \mathbf{r}_{j}} \mathscr{F}_{j}(\omega),
\end{aligned}
$$

where $\mathscr{F}_{j}(\omega)$ is the Fourier transform of event $j$. Ideally if we assume that the shape of the wavelets of different events are identical and the phase velocity near the source is nondispersive, the difference between the various $\mathscr{F}_{j}(\omega)$ is just a phase shift $e^{-i \omega \mathbf{s}_{\text {real }} \cdot \mathbf{r}_{j}}$ caused by the traveltime delay of each event from the reference point, and this phase shift will be compensated by the term $e^{i \omega \mathbf{s} \cdot \mathbf{r}_{j}}$ in Eq. (3.3) when the true slowness is used. Hence, the true slowness is identified by finding the slowness that maximizes $\tilde{u}(\mathbf{s}, \omega)$ for the summation over $\mathrm{N}$ events in Eq. (3.3).

For nondispersive waves, the peaks of $P(\mathbf{s}, \omega)$ are independent of frequency, which suggests that stacking the power spectrum in Eq. (3.2) over many frequencies along lines of constant slowness will enhance the resolution of the true slowness. Thus, the slowness power spectrum is defined as:

$$
P(\mathbf{s})=\frac{1}{M} \sum_{j=1}^{M} P\left(\mathbf{s}, \omega_{j}\right)
$$

where $\omega_{j}$ is the set of frequencies at which the power spectrum has been calculated. The slowness resolution can be further enhanced by whitening the spectrum in a frequency band where signal-to-noise ratio is favorable so that power in weak frequencies is equal to the power in the strong frequencies. The whitening factor $w_{j}$ for frequency $\omega_{j}$ is given by:

$$
w_{j}=\max _{\mathbf{s}}\left\{P\left(\mathbf{s}, \omega_{j}\right)\right\},
$$

and the whitened slowness power spectrum is 


$$
P_{W}(\mathbf{s})=\frac{1}{M} \sum_{j=1}^{M} \frac{1}{w_{j}} P\left(\mathbf{s}, \omega_{j}\right)
$$

To apply this method with real data we first align the waveform section by the direct $\mathrm{P}$ wave for potential Ps converted phase and by direct $\mathrm{S}$ wave for potential SP converted phase. Then a narrow window is cut around the wavelet of the converted phase. Each wavelet is normalized by its maximum amplitude and a Hann window is used to taper the wavelet. The wavelets are then shifted back to their arrival time. To choose a favorable frequency band, we first calculate the power spectrum of each wavelet and average them. The frequency band is chosen between the start and end frequencies where the average power spectrum stays above $5 \%$ of its maximum value (Fig. 3-3). The slowness vector is represented in spherical coordinates as $\mathbf{s}=[\cos \phi \cos \theta / v, \cos \phi \sin \theta / v, \sin \phi \sin \theta / v]^{T}$, where $\phi$ is the takeoff angle ranging from $-90^{\circ}$ to $90^{\circ}$ from downward to upward, $\theta$ is azimuth anlge ranging from $0^{\circ}$ to $360^{\circ}$ from eastward counterclockwise and $v$ is the near source velocity. The slowness vector that yields the maximum whitened slowness power spectrum is used to estimate the wave propagation direction and velocity within the earthquake focal region. If the wavelets selected are indeed a Ps or SP converted phases, the estimated velocity, azimuth and takeoff angle should be consistent with the tomographic results for P or S wave velocity at the earthquake source location, the relative locations between the earthquakes and the station, and the raytracing results, respectively.

Fig. 3-3 shows the beamforming results for the P, S and the potential SP phases generated by a cluster of events near the western end of the M-Fault and recorded by station CM01A. Fig. 3-3(e) shows the selected wavelet for P, S and SP phases. Fig. 3-3(f) shows the maximum whitened slowness power spectrum as a function of velocity with the best estimate marked by the red dot. Fig. 3-3(g) shows the beamforming results at the full range of takeoff angles and azimuths associated with the peak velocity estimation in Fig. 3-3(f). For P, S and the potential SP converted phases, the best velocity estimates are $7.5 \mathrm{~km} / \mathrm{s}, 5.0 \mathrm{~km} / \mathrm{s}$ and 5.0 $\mathrm{km} / \mathrm{s}$, respectively. Comparing to the tomographic results, where the $\mathrm{P}$ wave velocity is 8.2 $\mathrm{km} / \mathrm{s}$ and the $\mathrm{S}$ wave velocity is $4.8 \mathrm{~km} / \mathrm{s}$ at the source location, the beamforming yields a reasonable estimate. The azimuth estimations, which are $24^{\circ}$ for $\mathrm{P}, 21^{\circ}$ for $\mathrm{S}$ and $15^{\circ}$ for $\mathrm{SP}$, are within $6^{\circ}$ of the $21^{\circ}$ azimuth calculated from the earthquake and station locations. The takeoff angle is near zero for $\mathrm{P}$ and $\mathrm{S}$ phases, but is $40^{\circ}$ for SP phase, which is consistent 
with the raytracing results shown in Fig. 3-3(c). The comparison between the beamforming estimates and the more direct measurements are listed in Table S1. Thus, the beamforming confirms that the potential SP phases leave the earthquake source region with the S wave velocity and propagate upward (unlike the direct S-wave which leaves nearly horizontally). Given that the travel time of this phase is also close to the predicted arrival time, we identify it as a SP phase converted in the vicinity of the subduction interface.

\subsubsection{Wavefield decomposition}

Seismograms from OBS stations usually contain high-amplitude phases resulting from reflections at the sea surface and in our dataset the SP phases at deep water (1000-2500 m) stations have similar arrival times to the water surface reflected phase. The amplitude of the water phase is usually larger than that of the SP phases making it difficult to analyze the converted phases on raw OBS seismograms. Here we use the dual sensors wavefield decomposition method (Amundsen and Reitan, 1995) to remove the water reverberation phase and improve the visibility of the SP phases.

For wave propagation in an isotropic, plane-layered medium resulting from a point source, within each layer the wavefield (pressure, stress, displacement or velocity) can be decomposed into upgoing and downgoing cylindrical waves propagating with $\mathrm{P}$ or S wave velocities (Aki and Richards, 2002). A schematic decomposition of the wavefield is shown in Fig. 3-4. Here we consider the water layer above the seismometer as layer 1 and the sediment layer below the seismometer as layer 2. Amundsen and Reitan (1995) showed that the pressure field $\mathrm{P}$ in the water layer and the stress tensor component $\sigma_{z z}$ in the sediment layer can

be decomposed into upgoing and downgoing components, $U_{1}^{P}, D_{1}^{P}, U_{2}^{\sigma_{z z}}$ and $D_{2}^{\sigma_{z z}}$ using pressure and velocity records from a pressure gauge and seismometer installed at the same ocean bottom station. Since the water reverberation phases reach the seafloor from above, they are not present on the $U_{2}^{\sigma_{z z}}$ component. A full expression of the decomposition can be found in Amundsen and Reitan (1995), while the expression can be greatly simplified if the wave is propagating vertically as: 
(a)

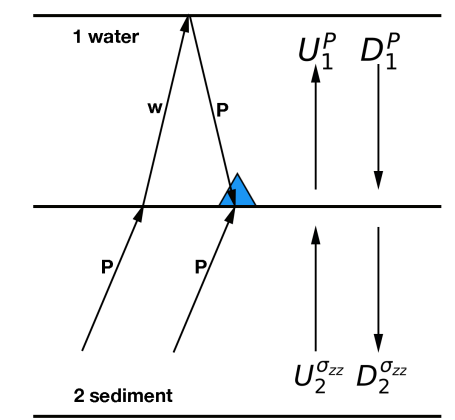

(b)

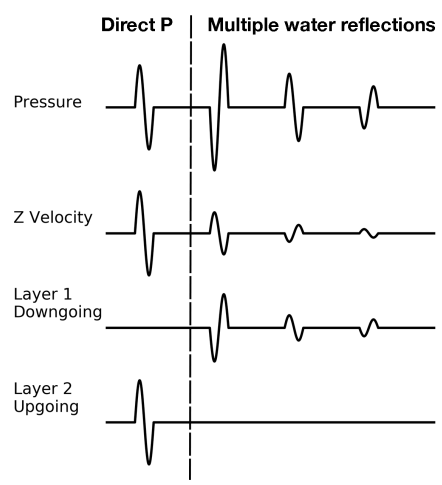

(c)
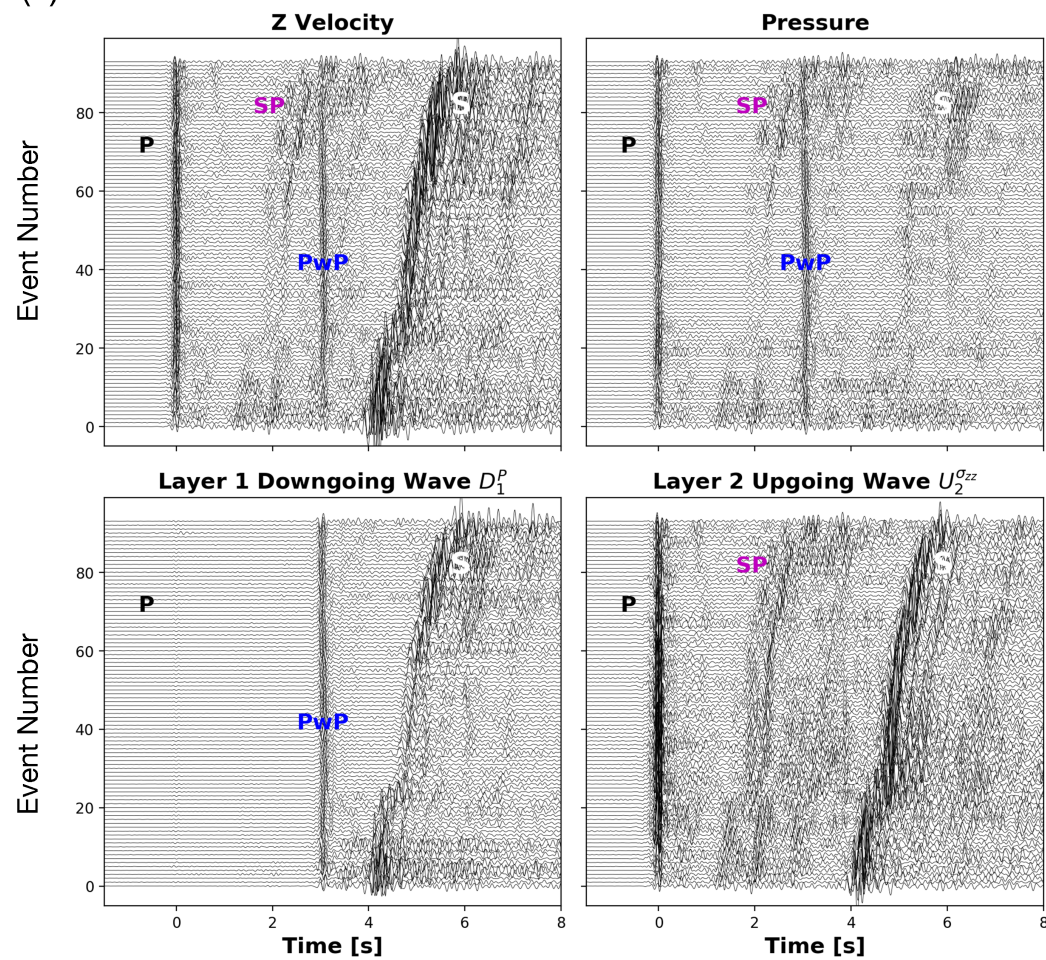

Layer 2 Upgoing Wave $U_{2}^{\sigma_{z z}}$

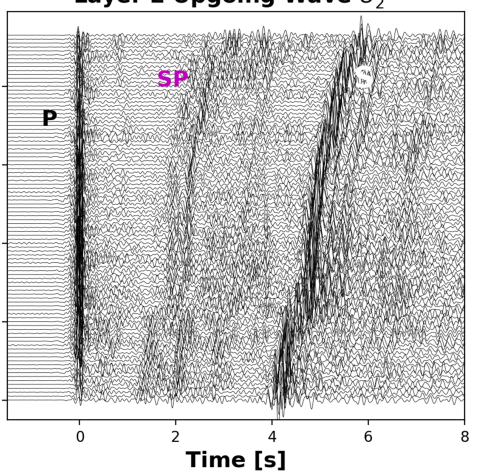

Figure 3-4: Wavefield decomposition results. (a) Schematic ray paths of the direct $\mathrm{P}$ wave and water reflection phase $(\mathrm{PwP})$ recorded by an $\mathrm{OBS}$ (blue triangle) at the boundary between the upper water layer and the lower sediment layer. The pressure in the water layer and the stress component $\sigma_{z z}$ in the sediment layer can be decomposed into upgoing $\left(U_{1}^{P}\right.$, $\left.U_{2}^{\sigma_{z z}}\right)$ and downgoing $\left(D_{1}^{P}, D_{2}^{\sigma_{z z}}\right)$ wavefields. (b) A conceptual plot showing the pressure and vertical velocity records of the direct $\mathrm{P}$ and multiple water reflection phases on an OBS station and the decomposed downgoing pressure field in the water layer and the upgoing stress $\left(\sigma_{z z}\right)$ field in the sediment layer. This plot is modified from Thorwart (2006). (c) Wavefield decomposition results for station FS13D from the M-Fault events. P, S, SP, and $\mathrm{PwP}$ phases are labeled on the record sections. The top two panels are vertical velocity and pressure records. The bottom two panels show the results for the decomposition into the downgoing pressure wavefield in the water layer (left) and upgoing stress $\left(\sigma_{z z}\right)$ wavefield in the sediment layer (right). The seismograms are aligned by $\mathrm{P}$ wave and are sorted by S-P traveltime difference.

$$
\begin{aligned}
D_{1}^{P} & =\frac{1}{2} P-\frac{\rho_{1} \alpha_{1}}{2} v_{z} \\
U_{2}^{\sigma_{z}} & =-\frac{1}{2} P-\frac{\rho_{2} \alpha_{2}}{2} v_{z}
\end{aligned}
$$

where $\rho_{1}, \alpha_{1}, \rho_{2}$ and $\alpha_{2}$ are density and $\mathrm{P}$ wave speed in the water and sediment layer and 
$v_{z}$ is the vertical velocity. Here we use $\rho_{1}=1.0 \times 10^{3} \mathrm{~kg} / \mathrm{m}^{3}, \alpha_{1}=1.5 \mathrm{~km} / \mathrm{s}$. In practice, the pressure sensor is usually biased by a constant calibration factor. Eq. (3.7) is used to estimate the calibration factor by minimizing the energy on the $D_{1}^{P}$ component before the water reverberation phase (Fig. 3-4 (c) bottom left). Then Eq. (3.8) is used to remove the water reverberations by grid searching for the (best) value for $\rho_{2} \alpha_{2}$ that minimizes the energy of the water reverberation phase on the $U_{2}^{\sigma z z}$ component (Fig. 3-4 (c) bottom right). When processing the real data, we first remove the instrument response to transform the waveforms into data with physical units (velocity: $\mathrm{m} / \mathrm{s}$; pressure: $\mathrm{Pa}$ ). Both the velocity and pressure records are upsampled to $200 \mathrm{~Hz}$ if the sampling rates are different on the two instruments at a particular station.

\subsection{Results}

In this section, we describe the results in terms of which phases are identifiable in different portions of the study area and how their timing relates to the plate boundary and velocity models. Usually only one type of converted phase is observable at each onshore station, but both SP and Ps phases can be observed at the same OBS station. To discuss the results we divide the onshore stations into four groups based on which type of converted phase is observed and other common features in the waveforms. In the main text, we show results for three of the onshore groups. Similar discussions of the remaining onshore group and the offshore stations can be found in the Supplementary Material.

\subsubsection{Northern onshore stations with SP phases}

Stations JCC and CM01A in the northernmost part of the array show large amplitude arrivals near the SP arrival time predicted by the Slab1.0 model (Fig. 3-5). Ray tracing estimates the location of the SP conversion points to lie just offshore at depths between 10-15 km. We select events with large amplitude SP phases (red traces) on each station and apply the beamforming method to those wavelets. The beamforming results indicate those phases leave the source region with an $\mathrm{S}$ wave velocity at azimuths consistent with the event-station azimuth. The takeoff angles, which are $38^{\circ}$ and $40^{\circ}$ respectively are consistent with the ray tracing in Fig. 3-5(b), which predicts upward takeoff angles at about this angle. Based on the agreement with the predicted arrival times and the beamforming results, we 
(a)

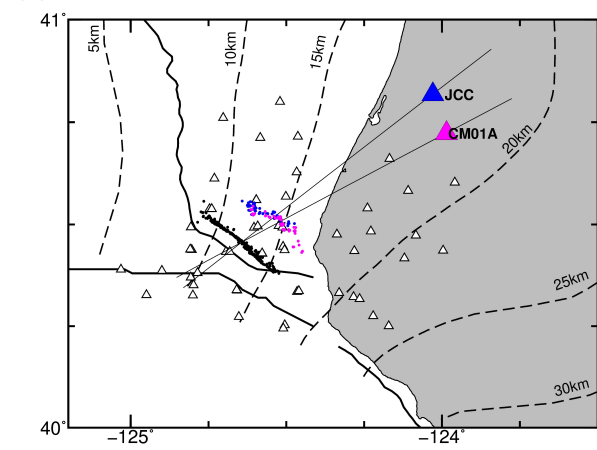

(b)
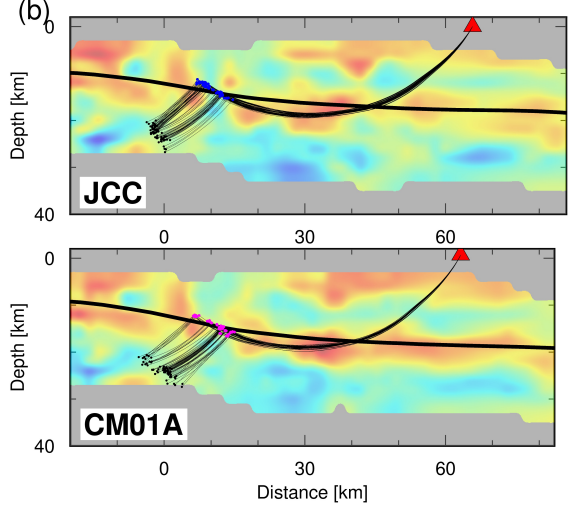

(c)
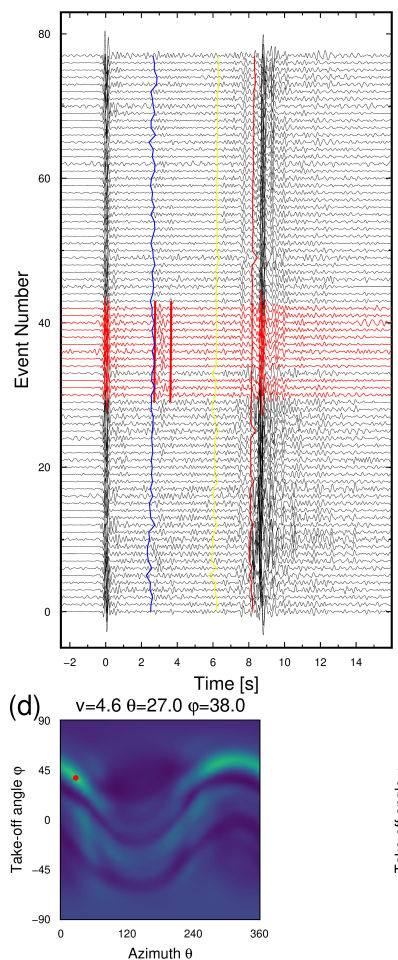

SP-CM01A-EHZ
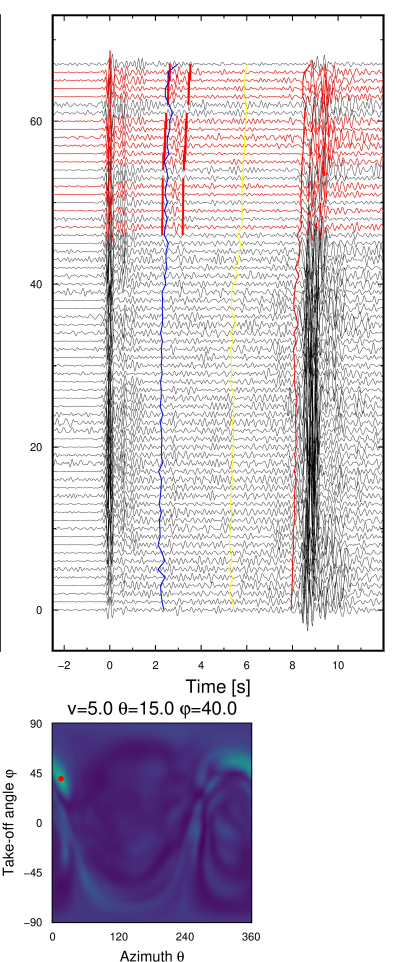

Figure 3-5: SP converted phases at stations in the north. (a) Map view of the locations of the earthquakes (black dots), SP conversion points (magenta dots), the stations (triangles), and the cross sections shown in (b) going through the center of the M-fault events and stations JCC and CM01A. (b) SP phase raypaths from the M-fault events to stations JCC and CM01A. The background colors denote the Vp/Vs model as in Fig. 3-2. (c) Waveform sections of M-fault events on vertical component of stations JCC and CM01A. The waveforms are aligned by $\mathrm{P}$ wave and are sorted by S-P traveltime difference. Waveforms used for beamforming are highlighted in red with the red bars denoting the time window used in the beamforming analysis. The blue curve denotes the predicted SP arrival time from conversion at the Slab1.0 model and the yellow curve denotes the predicted arrival time from a conversion at an interface $10 \mathrm{~km}$ shallower than the Slab1.0 model. (d) Beamforming results for selected converted phases at JCC (left) and CM01A (right). The maximum intensity point is marked by the red dots and the corresponding velocity, azimuth and take off angle are given in the title of the panel.

identify these phases as SP converted phases near the Slab1.0 model interface. The actual arrival times are slightly later than the predicted ones, which might indicate that the actual slab interface is $1-2 \mathrm{~km}$ shallower than the model. Comparing to the $\mathrm{Vp} / \mathrm{Vs}$ cross section in Fig. 3-5(b), the SP conversion points appear to be close to the top of the high $\mathrm{Vp} / \mathrm{Vs}$ zone. 
(a)
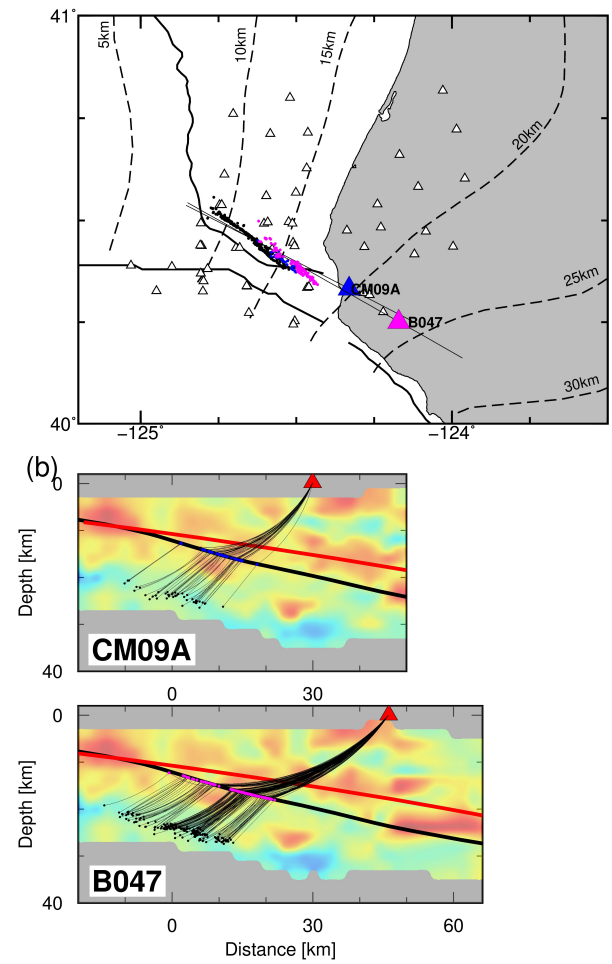

(c)
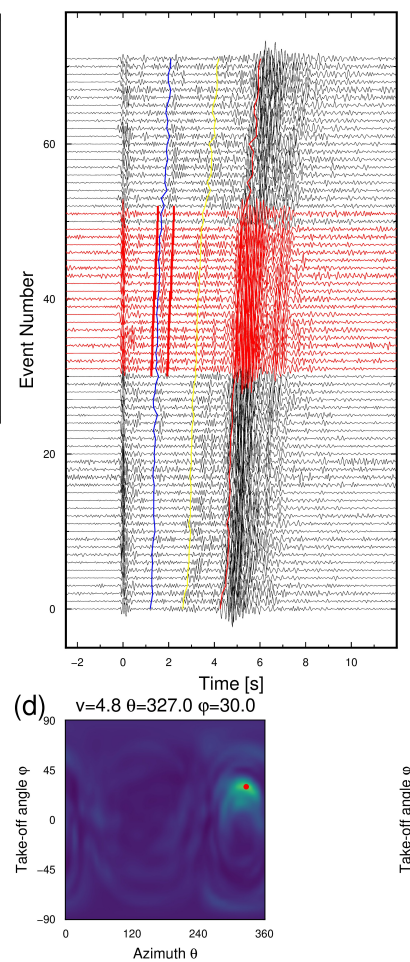

SP-B047-EHZ
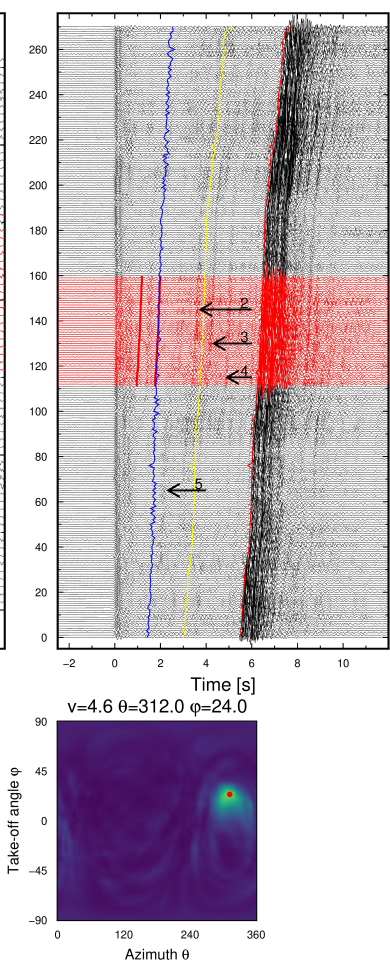

Figure 3-6: SP converted phases at stations in the south. (a) Map view of the locations of the earthquake (black dots), SP conversion points (magenta dots), the stations (triangles), and the cross sections shown in (b) going through the center of the M-fault events and stations CM09A and B047. (b) SP phase raypaths from the M-fault events to stations CM09A and B047. The colors denote the $\mathrm{Vp} / \mathrm{Vs}$ model as in Fig. 3-2. The bold black curves are the Slab1.0 model and the bold red curves are the Slab2 model. (c) Waveform sections of Mfault events on vertical component of stations CM09A and B047. The waveforms are aligned by $\mathrm{P}$ wave and are sorted by S-P traveltime difference. Waveforms used for beamforming are highlighted in red with the red bars denoting the time window used in the beamforming analysis. The blue curve denotes the predicted SP arrival time for conversion at the Slab1.0 model interface and the yellow curve denotes the predicted SP arrival time from an interface $10 \mathrm{~km}$ shallower than the Slab1.0 model. Black arrows and the corresponding numbers denote converted phases from shallow velocity discontinuities that are analyzed in Fig. 37. (d) Beamforming results for the converted phases in between the red lines at CM09A (left) and B047 (right). The maximum intensity point is marked by the red dots and the corresponding velocity, azimuth and take off angle are given in the title of the panel.

\subsubsection{Southern onshore stations with SP arrivals}

We group together five stations in the southern part of the array, CM09A, B046, CM10A, B932 and B047, because they show SP converted phases from the Slab1.0 model depth as well as several SP phases converted at shallower discontinuities. The two stations, CM09A and B047, with the clearest SP converted phases are shown in Fig. 3-6. On the waveform 
(a)
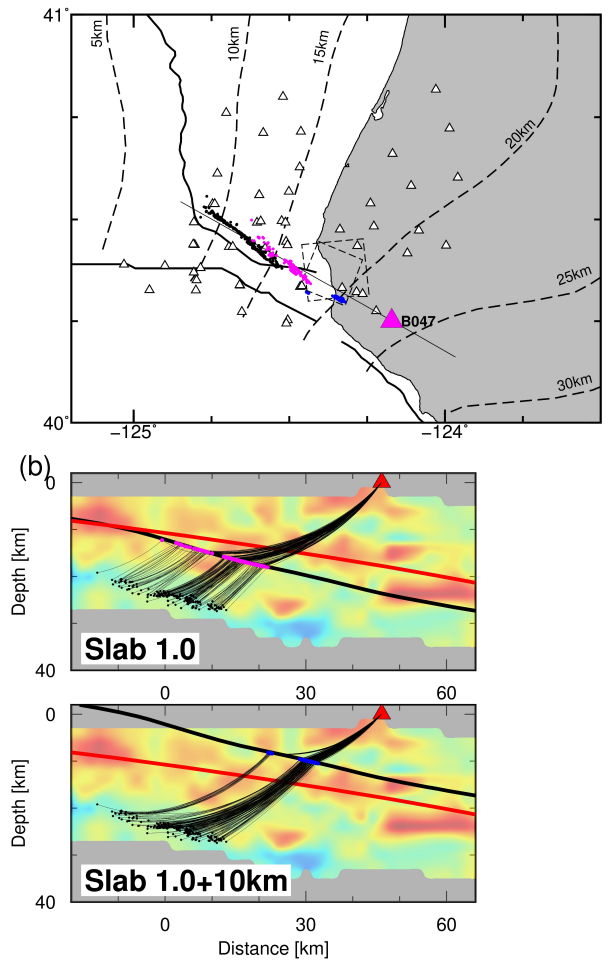

(c)

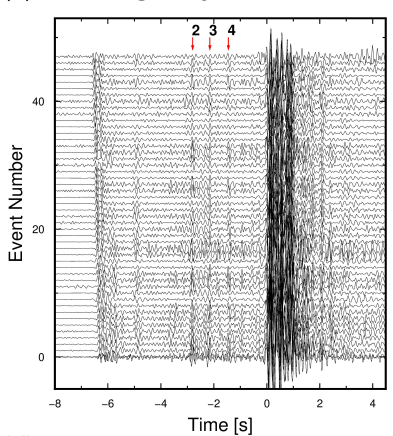

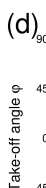
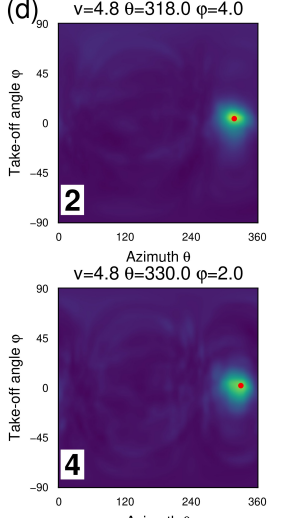

SP-B047-HHZ
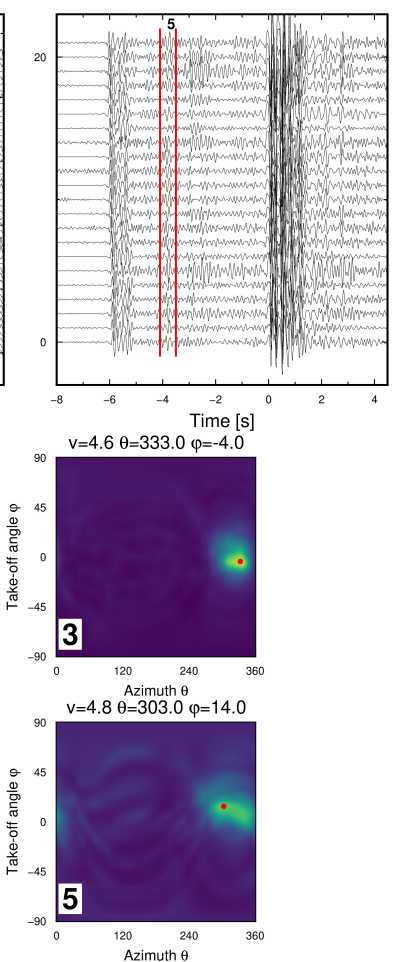

Figure 3-7: Shallow SP converted phases at station B047. (a) Map view of the locations of the earthquake (black dots), SP conversion points from Slab1.0 model interface (magenta dots) and Slab1.0-10 km model interface (blue dots), the station (triangle), the cross sections shown in (b) going through the center of the M-fault and station B047, and the rupture area of the 1992 Cape Mendocino earthquake from Murray et al. (1996). (b) SP phase raypaths from the M-fault events to station B047 for Slab1.0 and Slab1.0-10 km models. The background colors denote the Vp/Vs model as in Fig. 3-2. The bold black curves are the Slab1.0 and Slab1.0-10 km models in the upper and lower panel, respectively. The bold red curves are the Slab2 model. (c) Waveform sections of M-fault events with clear shallow SP converted phases on vertical component of station B047. They are denoted by the same number as in Fig. 3-6(c) The waveforms are aligned by $\mathrm{S}$ wave and are sorted by S-P traveltime difference. (d) Beamforming results for the shallow SP converted phases at B047. The maximum intensity point is marked by the red dots and the corresponding velocity, azimuth and take off angle are given in the title of the panel.

sections, clear large amplitude signals near the predicted arrival time are observed. Their raypaths are shown in Fig. 3-6(b). The SP conversion points on the Slab1.0 model would be between $12.5 \mathrm{~km}-17.5 \mathrm{~km}$ depth and located just offshore. We select events with large amplitudes and apply the beamforming method to those wavelets. The beamforming results indicate these phases leave the source with an $\mathrm{S}$ wave velocity at an azimuth consistent with the events-station azimuth. The takeoff angle estimates are $30^{\circ}$ and $24^{\circ}$ respectively which is consistent with the ray tracing Fig. 3-6(b). Based on the results from arrival time prediction 
and beamforming, we identify these phases as SP converted phases. The cross section in Fig. 3-6(b) indicates that these SP conversion points likely convert near the bottom of the high $\mathrm{Vp} /$ Vs zone.

Several other coherent arrivals can be seen on the waveform section for station B047. They are labeled 2-5 in Fig. 3-6(c). Since their arrival times are later than the SP phase converted from the Slab1.0 interface, if they are also SP converted phases, they would have converted at shallower velocity discontinuities. We apply the beamforming method to these arrivals. The selected waveform for each potential shallow converted phases are shown in Fig. 3-7(c) and their beamforming results are shown in Fig. 3-7(d). The results all indicate that these converted phase leave the source as $\mathrm{S}$ waves. Thus, we interpret these arrivals as SP converted phases. In Fig. 3-7(a) and (b), we plot the location of the conversion points and raypaths for both the Slab1.0 and the Slab1.0-10 km models. The SP 2-4 phases arrive near the predicted arrival time from the Slab1.0-10 km model. The corresponding conversion points are at around $10 \mathrm{~km}$ depth onshore. The azimuth estimates are consistent with the station-events azimuth. The raypaths for the Slab1.0-10 km model have smaller take-off angles for the same events than the Slab1.0 model, which is consistent with the take-off angle estimates from beamforming. Comparing with the $V_{p} / V_{s}$ model, they are likely from the top of the high $V_{p} / V_{s}$ layer (SP2) and other shallow geological boundaries within the overriding continental crust (SP 3 and SP4). The SP3 and SP4 phases convert at interfaces more than $10 \mathrm{~km}$ shallower than the Slab1.0 model and these are likely in the vicinity of the 1992 Petrolia earthquake's fault plane which lies within the overriding plate (Murray et al., 1996; Guo et al., 2019). For SP5 phase, the arrival time is slightly after the predicted arrival time from the Slab1.0 model indicating it comes from a interface that is a few $\mathrm{km}$ shallower. We are not sure what the geologic interpretation of this interface is but it likely lies within the subducted plate. The takeoff azimuth of SP5 phase is somewhat offset from phases 1-4 but we cannot rule out that they are identical due to the higher uncertainty in the phase 5 results.

\subsubsection{Eastern onshore stations with Ps arrivals}

Four stations, CM03A, CM07A, KMPB and B045, in the eastern part of the study area are grouped together owing to clear Ps converted phases from below the depth of the Slab1.0 model. The two stations with the clearest Ps converted phases, CM03A and KMPB, are 
(a)
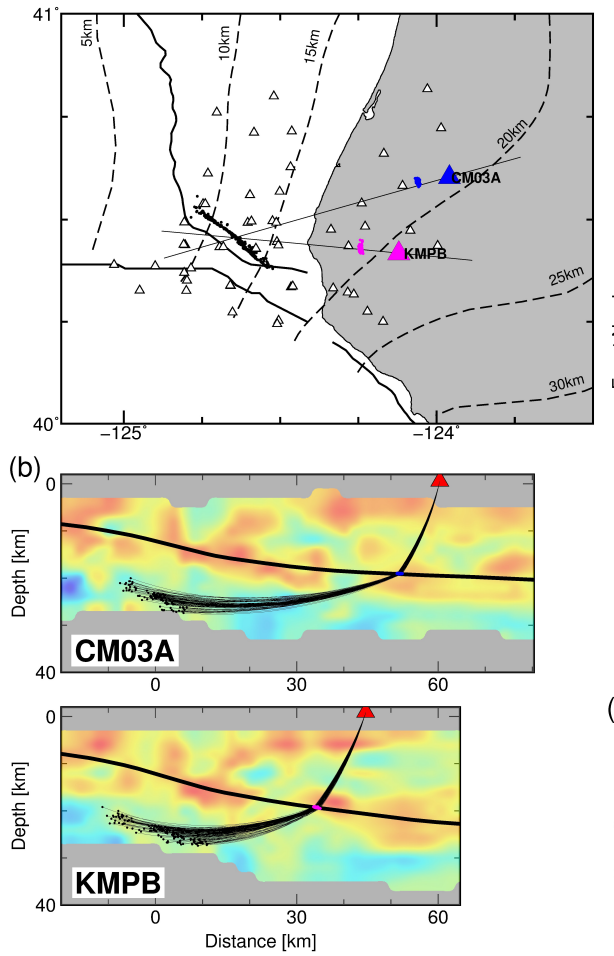

(c)
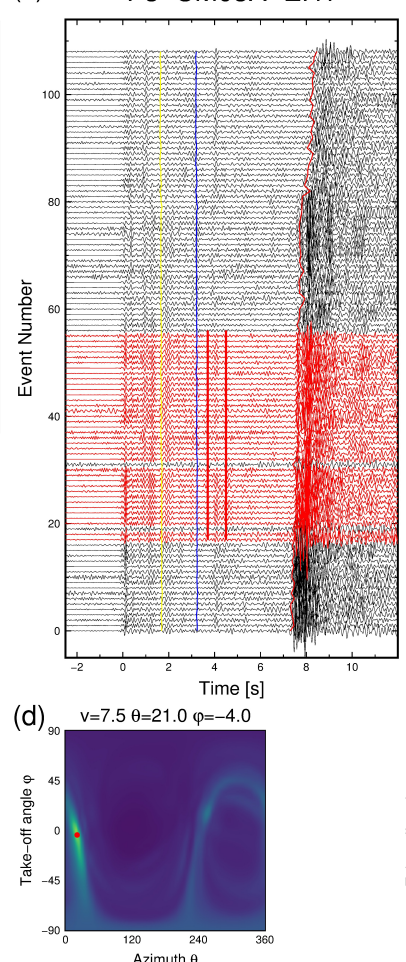

Ps-KMPB-EHE
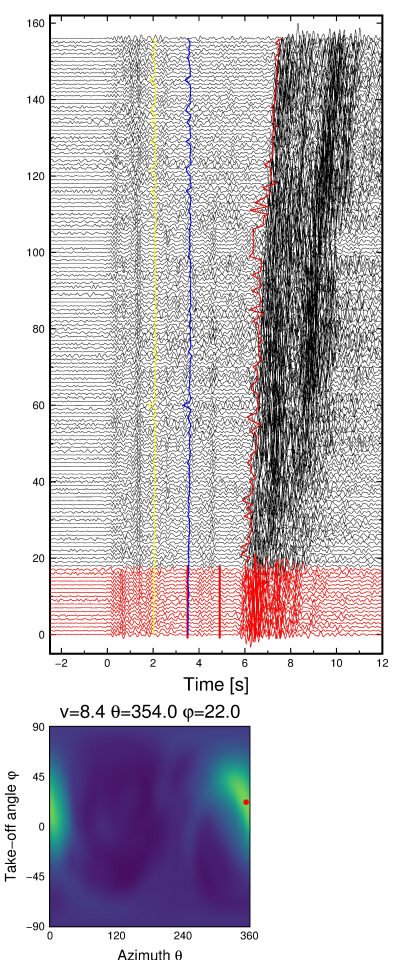

Figure 3-8: Ps converted phases at stations in the east. (a) Map view of the locations of the earthquake (black dots), Ps conversion points (magenta dots), the stations (triangles), and the of cross sections shown in (b) going through the center of the M-fault events to stations CM03A and KMPB. (b) Ps phase raypaths from the M-fault events to stations CM03A and KMPB. The background colors denote the Vp/Vs model as in Fig. 3-2. (c) Waveform sections of M-fault events on horizontal components of station CM03A and KMPB. The waveforms are aligned by $\mathrm{P}$ wave and are sorted by S-P traveltime difference. Waveforms used for beamforming are highlighted in red with the red bars denoting the time window used in the beamforming analysis. The blue curve denotes the predicted Ps arrival time for conversion at the Slab1.0 model interface and the yellow curve denotes the predicted Ps arrival time from an interface $10 \mathrm{~km}$ shallower than the Slab1.0 model. (d) Beamforming results for selected converted phases at CM03A (left) and KMPB (right). The maximum intensity point is marked by the red dots and the corresponding velocity, azimuth and take off angle are given in the title of the panel.

shown in Fig. 3-8. The locations of the Ps conversion points on the interface model would be between $17.5 \mathrm{~km}-20 \mathrm{~km}$ depth and just onshore (Fig. 3-8(b)). On the waveform sections, there are clear signals about $1 \mathrm{~s}$ after the predicted arrival time on both stations. We select events with large amplitude Ps phases and apply the beamforming method to those wavelets. The beamforming results indicate that those phases leaving the source with a $\mathrm{P}$ wave velocity, and the azimuth estimates are consistent with the event-station azimuths. The estimated takeoff angle for CM03A, $-4^{\circ}$, is consistent with the Ps ray tracing Fig. 3-8(b). The takeoff 
angle estimated for $\mathrm{KMPB}, 22^{\circ}$, is slightly larger than raytracing results. The beamforming peak is more diffuse than many examples indicating a relative larger error in the takeoff angle estimates. Based on the results from arrival time prediction and beamforming, we identify these phases as Ps converted phases. Given that they arrive a full second later than the predicted arrival time and comparing to the cross section in Fig. 3-8(b), these Ps conversion points are likely from the bottom of the high $\mathrm{Vp} / \mathrm{Vs}$ zone.

\subsection{Discussion}

\subsubsection{Implications for slab geometry}

Specifying the geometry of the subduction interface is important for the estimation of ground motion in future large earthquakes and for geodetic studies that estimate the distribution of interseismic locking. Here we compare our estimated Ps and SP conversion depths with the Slab1.0 model (McCrory et al., 2012), the Slab2 model (Hayes et al., 2018) and the imaging results from the 93-94 Mendocino active source seismic experiments (Trehu and Mendocino Working Group, 1995). The Slab1.0 model is widely used in studying this part of the Cascadia subduction zone and it contains considerable structure that was derived primarily from earthquake relocations as well as the active source results. In the discussions below, all depth ranges are given in $\mathrm{km}$ below sea level and we assume the plate interface corresponds to a sharp discontinuity near the top of the high $\mathrm{Vp} / \mathrm{Vs}$ zone. It is possible that the actual plate interface lies slightly below the top of the high $\mathrm{Vp} / \mathrm{Vs}$ zone, but that fine scale structure is beyond our resolution.

Offshore, near the deformation front, the Slab1.0 model predicts that the plate interface is at about $7-8 \mathrm{~km}$ depth and the plate interface in the Slab2 model is about $1 \mathrm{~km}$ deeper (Fig. 3-9). Using multichannel seismic data, Gulick et al. (1998) imaged the sediment and crustal structure near the deformation front. Their results for Line 6 (Figure 3 in Gulick et al. (1998)), which intersects the deformation front at about $40.7^{\circ} \mathrm{N}$, indicates that the depth of the top of the oceanic crust is at $5-6 \mathrm{~km}$, which is $1-3 \mathrm{~km}$ shallower than the Slab1.0 model.

Our measurements of the traveltime differences between the Ps and P arrivals or between the SP and S arrivals from the OBS records place constraints on the location of the plate boundary near the deformation front, but they require additional information about $\mathrm{P}$ and $\mathrm{S}$ 

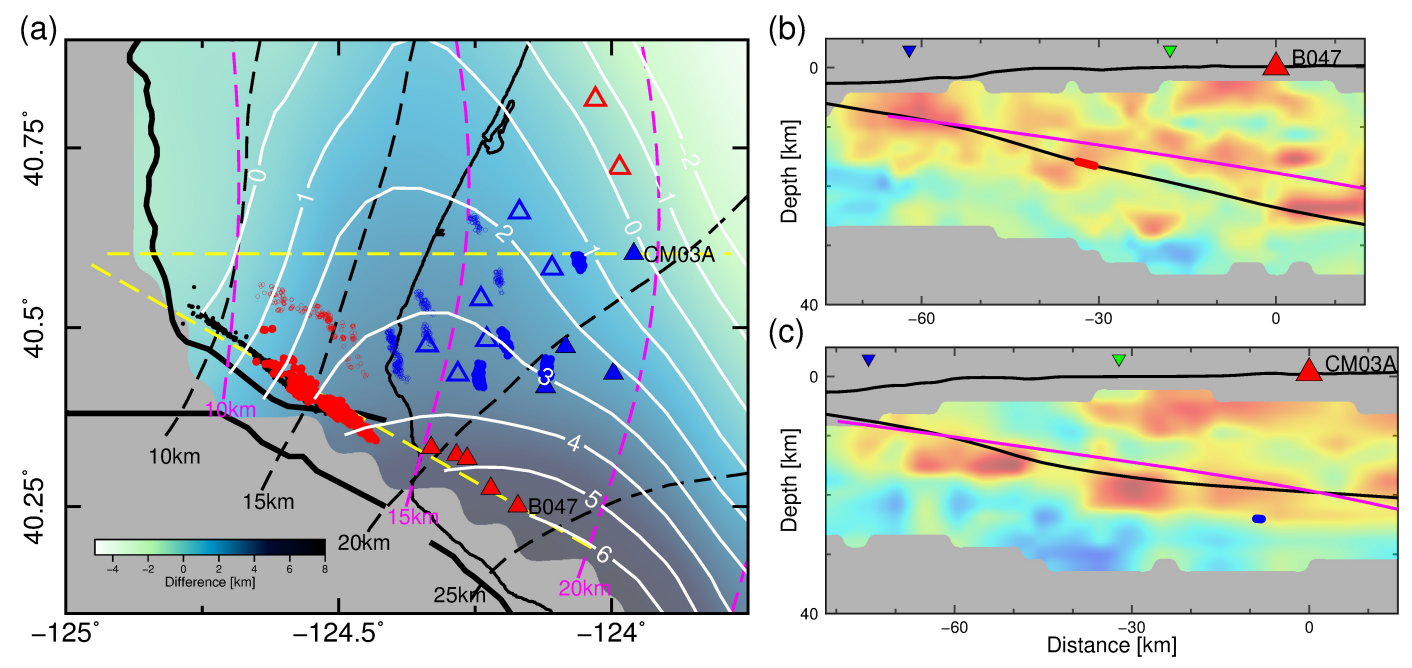

Figure 3-9: Comparison between the Slab1.0 and Slab2 models. (a) Map view of the difference in interface depth between the models. Positive values indicate where Slab1.0 is deeper than Slab2. Black dashed lines denote depth contours from the Slab1.0 model. Magenta dashed lines denote the depth contours from the Slab2 model. Yellow dashed lines are the two cross sections shown in (b) and (c). Red solid circles and red solid triangles are the SP conversion points from the oceanic Moho and the stations where these phases are observed. Red open circles and red open triangles are the $\mathrm{P}$ conversion points from the top of the oceanic crust and the stations where these phases are observed. Blue solid circles and blue solid triangles are the Ps conversion points from the oceanic Moho and the stations where these phases are observed. Blue empty circles and blue empty triangles are the Ps conversion points from the top of the oceanic crust and the stations where these phases are observed. (b) Cross section through station B047. The background colors denote the Vp/Vs model as in Fig. 3-2. The green and blue inverse triangles indicate the point where the cross section intersects with the coastline and deformation front. Black and magenta lines are the slab geometry from Slab1.0 and Slab2 models respectively. Red solid circles are the locations of the SP conversion points from the events used for beamforming analysis in Fig. 3-6 at station B047. (c) Cross section going through station CM03A. The blue solid circles are the locations of the Ps conversion points from the events used form beamforming analysis in Fig. 3-8 at station CM03A. Other symbols are the same as in (b). 
velocities in the shallow sediments which are not resolved by the tomographic model. Let $\mathrm{H}$ be the thickness of the sediment layer with homogeneous velocities $v_{s}$ and $v_{p}$ and assuming vertically traveling waves, the traveltime difference $\Delta t$ between Ps and $\mathrm{P}$ or between $\mathrm{SP}$ and $\mathrm{S}$ wave are both given by

$$
\begin{aligned}
\Delta t & =\frac{H}{v_{s}}-\frac{H}{v_{p}} \\
& =t^{P}(r-1)
\end{aligned}
$$

where $r$ is the $\mathrm{Vp} / \mathrm{Vs}$ ratio and $t^{P}$ is the one-way $\mathrm{P}$-wave traveltime in the sediments. We take stations FS13D and FS41D as example stations (Fig. A-7) and estimate $t^{P}$ using the migration image from Figure 8 of Gulick et al. (1998). In that figure, the two way traveltime (TWT) from the sea surface to the top of the oceanic crust is about $5.5 \mathrm{~s}$ along the entire migrated section. FS13D is located just seaward of the deformation front at a water depth of $2.3 \mathrm{~km}$ and FS41D is located on the continental slope about $10 \mathrm{~km}$ landward of the deformation front at a depth of $1.1 \mathrm{~km}$. Given the water depth of stations and the acoustic velocity in the water $(1.5 \mathrm{~km} / \mathrm{s})$, the $\mathrm{P}$ wave TWT inside the sediment layer would be about $2.4 \mathrm{~s}$ and $4.0 \mathrm{~s}$ for FS13D and FS41D, corresponding to $t^{P}$ values of $1.2 \mathrm{~s}$ and $2.0 \mathrm{~s}$, respectively. Since the traveltime differences between Ps and P or between SP and $\mathrm{S}$ are around $2.5 \mathrm{~s}$ for both stations (Fig. A-6), we estimate the average $\mathrm{Vp} / \mathrm{Vs}$ ratio of the underlaying sediment is about 3.1 for FS13D and 2.3 for FS41D. If we further assume that the average $\mathrm{P}$ wave velocity inside the sediment to be in the range from 2.5 to 3.5 $\mathrm{km} / \mathrm{s}$ (Gulick et al., 1998), the locations of the plate interface are at about 5.3-6.5 km and 6.1-8.1 km at FS13D and FS41D. However the plate interface is at about $9 \mathrm{~km}$ beneath the two stations from the Slab1.0 model. Near the trench, we prefer the active source imaging results. The Slab1.0 model appears to overestimate the depth of the plate interface for by $1-4 \mathrm{~km}$.

Offshore, at the location of the SP conversion points observed by stations JCC and CM01A, the Slab1.0 model is 1-2 km deeper than the Slab2 model (Fig. 3-9). From our converted phase observations, the arrival time of the SP converted phases on stations CM01A and JCC from the top of the crust are slightly later than the predicted arrival time from the Slab1.0 model, which indicates a 1-2 km shallower interface that corresponds to the top of 
the high $\mathrm{Vp} / \mathrm{Vs}$ zone. Thus, just offshore, the SP arrival times are more consistent with the Slab2 model.

At the coastline and just onshore, the Slab1.0 model predicts the plate interface is at about $17 \mathrm{~km}$ depth (Fig. 3-1), while Beaudoin et al. (1994) imaged the top of the Gorda crust at about $13-14 \mathrm{~km}$. The Slab2 model is about 2-4 km shallower than the Slab1.0 model (Fig. 3-9) near the coastline, which is more consistent with the active source result. Ps arrivals at KCT and CM06A (Fig. A-5) convert near the coast and arrive close to the Slab1.0 model predicted arrival time, indicating there is an interface close to the Slab1.0 model. However, the converted phases represented by the open blue triangles in Fig. 3-9 (including KCT and CM06A) are less clear than other stations and multiple Ps phases are observed between the direct $\mathrm{P}$ and S phases (Fig. A-5(c)), which indicates a complex velocity structures near the coast. The main Ps arrival at $\mathrm{KCT}$, the $V_{p} / V_{s}$ model, and the active source results favor an interface 2-3 km shallower than Slab1.0 and consistent with Slab2.

Ps conversions at stations KMPB and CM03A allow us to investigate the slab interface at $20-40 \mathrm{~km}$ inland from the coast from $40.4^{\circ}$ to $40.7^{\circ} \mathrm{N}$. These stations are near the 20 $\mathrm{km}$ contour of the Slab1.0 model and the model lies near the top of the high $\mathrm{Vp} / \mathrm{Vs}$ zone. Both stations show very strong conversions from the subducted Moho that lie $3-5 \mathrm{~km}$ deeper than the Slab1.0 Model. The top of the subducted crust is less clear at these stations but perhaps small coherent arrivals are visible on CM03A (Fig. 3-8 and Fig. A-9). Given that the thickness of oceanic crust is about $6-8 \mathrm{~km}$, the plate interface likely lies about $1-2 \mathrm{~km}$ shallower than the Slab1.0 model in this region based on the $\mathrm{Vp} / \mathrm{Vs}$ model and the Moho conversions at CM03A. At the location of the Ps conversion points for stations KMPB and CM03A, the Slab2 model is 3 and $1 \mathrm{~km}$ shallower than Slab1.0 model (Fig. 3-9). Thus, we prefer the Slab2 model at those locations.

South of $40.5^{\circ} \mathrm{N}$ the Slab1.0 model contours at depths of 20-30 km are highly curved and indicate that the slab dip is significantly steeper from $15-25 \mathrm{~km}$ depth in the $40.3^{\circ}$ to $40.5^{\circ}$ latitude range. Stations B047 and CM09A are located in this area and show very clear SP conversions from the Moho of the subducted slab that arrive at or just before the time predicted for the Slab1.0 model. The Slab2 model is $2-4 \mathrm{~km}$ shallower than the Slab1.0 model at the location of these SP conversion points (Fig. 3-9). Thus, the Slab1.0 model is likely too deep by an amount corresponding to the crustal thickness. This inference is corroborated by the $\mathrm{Vp} / \mathrm{Vs}$ model which shows the interface model lying at the base of the 
high $\mathrm{Vp} / \mathrm{Vs}$ zone. The high Vp/Vs values near station B047 may also reflect the Mendocino Transform Fault's damage zone. Both B047 and CM09As show multiple clear arrivals from shallower depths that are roughly $8-12 \mathrm{~km}$ above the interface model and correspond to the top of the high $\mathrm{Vp} / \mathrm{Vs}$ zone. Thus we prefer a model where the slab interface is roughly 6-8 $\mathrm{km}$ shallower than the Slab1.0 model and about $2 \mathrm{~km}$ shallower than the Slab2 model in the $40.3^{\circ} \mathrm{N}$ to $40.5^{\circ} \mathrm{N}$ latitude range and find no evidence for the considerable steepening of slab dip shown at the southernmost end of the Slab1.0 model.

\subsubsection{Estimation of velocity contrast}

To further investigate the material properties of the high $\mathrm{Vp} / \mathrm{Vs}$ zone, we compare measurements of the amplitude ratios $\mathrm{Ps} / \mathrm{P}$ and $\mathrm{SP} / \mathrm{P}$ made on both the actual data and on synthetic seismograms for simple models of the subducted crust (Fig. 3-10). We measured the amplitude ratio of the $\mathrm{Ps}$ or $\mathrm{SP}$ converted phases to the direct $\mathrm{P}$ wave using the three component velocity seismograms filtered in the same filter bands used in Section 3. The maximum amplitude of the Ps converted phase was measured as the maximum vector length on the two horizontal components. The maximum amplitudes of the SP converted phase were measured on the vertical component. The maximum amplitudes of the $\mathrm{P}$ wave was measured as the maximum vector length on three components. The distribution of the amplitude ratios for each station are shown in Fig. 3-11 (c). The values typically range from 0.1 to 1.0 with many observations in the $0.2-0.5$ range indicating strong velocity contrasts. We note that these measurements were made on the clear arrivals used for beamforming in Section 5. While they are from representative parts of the waveform sections for each station, they likely represent the locations where the velocity contrasts are among the strongest.

We first calculated synthetic seismograms using an averaged 1D velocity model derived from the tomographic model but with a low velocity layer of variable thickness inserted and centered at $15 \mathrm{~km}$ depth, which we term case 1 (Fig. 3-10 (a)). The frequency-wavenumber summation method (Zhu and Rivera, 2002) is used to calculated synthetic seismograms. The thickness of the low velocity layer was varied from $100 \mathrm{~m}$ to $4000 \mathrm{~m}$ and the velocity reduction inside this layer relative to the original velocity at $15 \mathrm{~km}$ depth varies from $1 \%$ to $30 \%$. We fixed the focal mechanism of the sources to be $128^{\circ} / 90^{\circ} / 180^{\circ}$ in strike, dip and rake (convention in Aki and Richards (2002)). The focal mechanism is based on the alignment of earthquake hypocenters and the focal mechanism results from Li et al. (2018a). Synthetic 

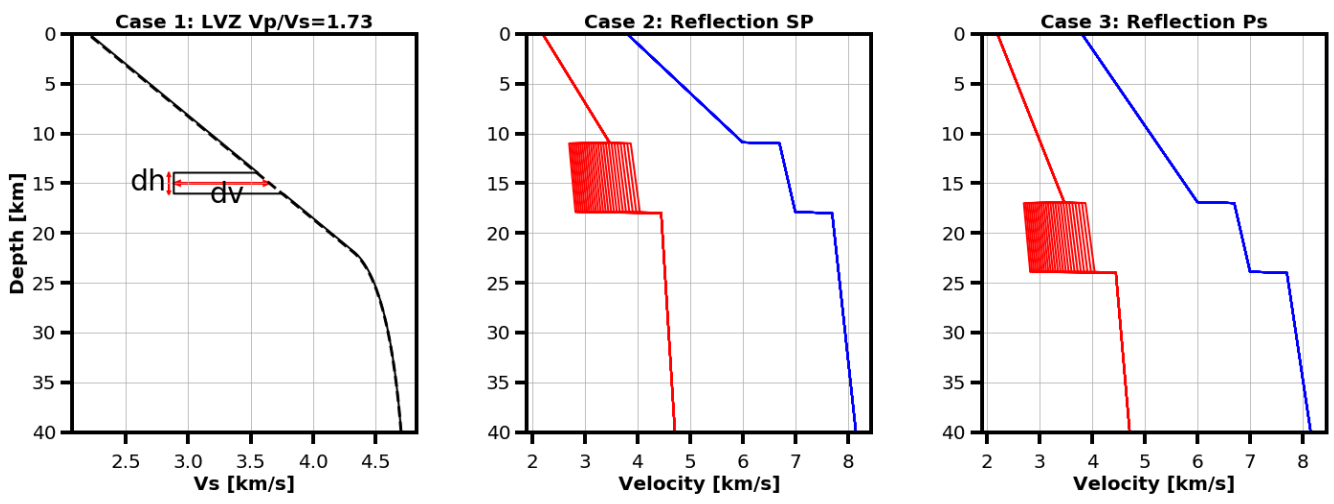

Figure 3-10: Velocity models for calculating synthetic seismograms. (a) Case 1, S-wave LVZ models. A low velocity layer centered at $15 \mathrm{~km}$ depth with various thickness (dh) and velocity reduction $(\mathrm{dv})$. The $\mathrm{Vp} / \mathrm{Vs}$ in the entire model is fixed at 1.73 . (b) and (c) Case 2 and 3, velocity models based on Beaudoin et al. (1994). Blue and red lines denote the P and $\mathrm{S}$ wave velocity models respectively. $\mathrm{P}$ wave velocity increases linearly in depth with two steps representing the top and bottom of the subducted oceanic crust. Outside the subducted crust, the $\mathrm{Vp} / \mathrm{Vs}$ ratio is 1.73 . Inside the subducted crust, the $\mathrm{Vp} / \mathrm{Vs}$ ratio varies from 1.73 to 2.51 for different models. Density $(\rho)$ models follow the default relation in FK software, where $\rho=0.77+0.32 \mathrm{Vp}$.

waveforms were calculated for stations CM09A, B047, CM01A, KMPB and CM03A. The distance and azimuth settings are the averaged distance and azimuth from each station to the earthquakes used for beamforming in section 5 and are listed in Table S2.

We also calculated synthetics for $1 \mathrm{D}$ velocity models that match the P-wave velocity profile from the Beaudoin et al. (1994) refraction model. Importantly this profile does not contain a low velocity zone in the subducted crust for P-wave velocities but is primarily characterized by discontinuities at the top and bottom of the subducted crust. The top of the crust corresponds to a jump from 6.0 to $6.7 \mathrm{~km} / \mathrm{s}$ and the bottom of the crust (Moho) corresponds to a jump from 7.0 to $7.7 \mathrm{~km} / \mathrm{s}$. We developed synthetics for two versions of this model. In case 2 , the crust is between $11-18 \mathrm{~km}$, and in case 3 it is at $17-24$. Case 2 corresponds to our offshore SP conversions and case 3 corresponds to our onshore Ps conversions. For both case 2 and case 3, we varied the Vp/Vs ratio from 1.73 to 2.5 inside the oceanic crust, while keeping the $\mathrm{Vp} / \mathrm{Vs}$ equal to 1.73 outside the crust. Case 2 and Case 3 are meant to provide a simple representation that combines the features of the Beaudoin et al. (1994) and the Guo et al. (2019) tomographic models.

The Case 1 amplitude ratio measurements for stations CM09A, CM01A, CM03A and 

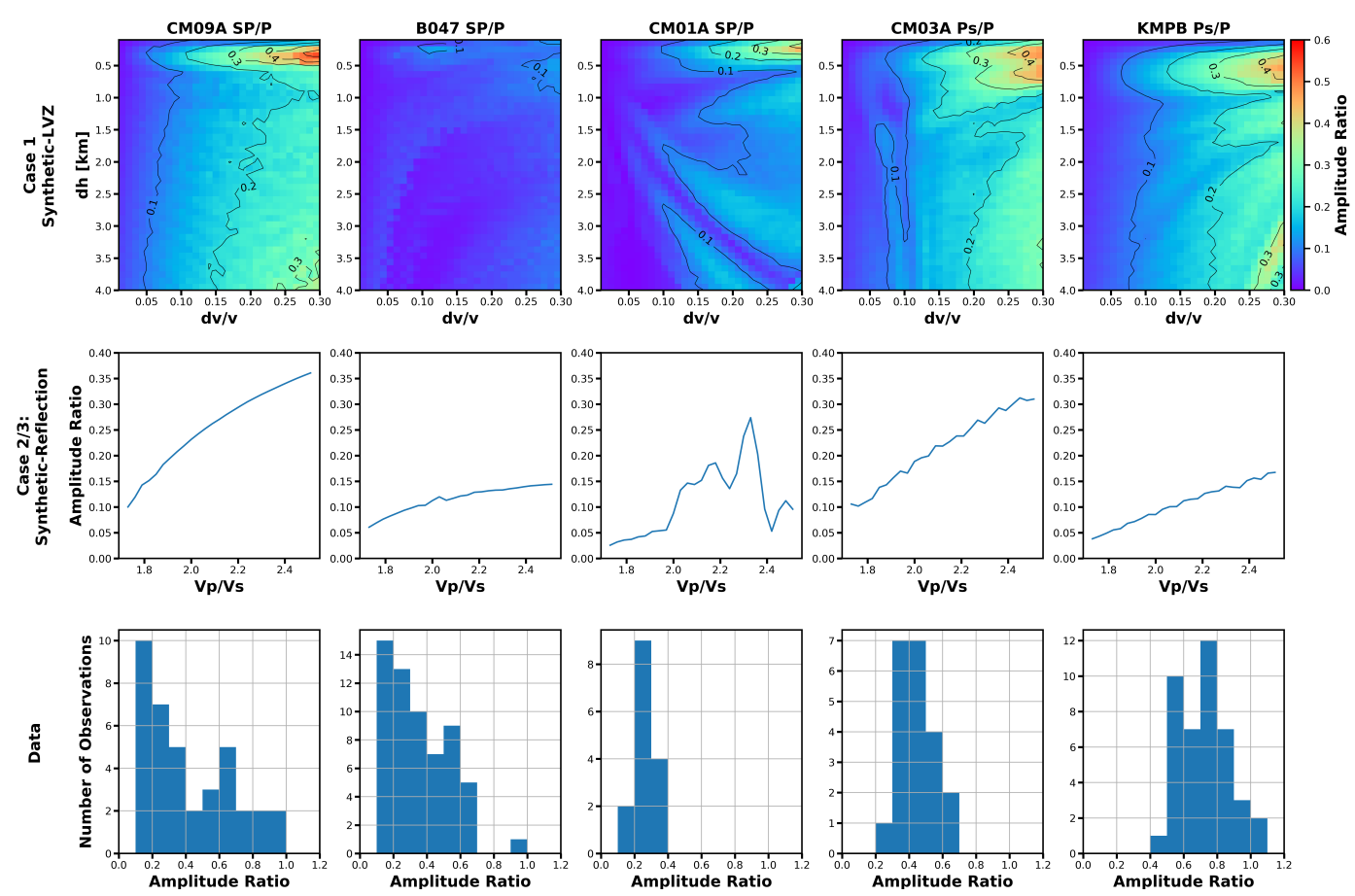

Figure 3-11: Amplitude ratio measurements from synthetic seismograms and real data. Each station is shown as three panels in its own vertical column. (a) SP/P and Ps/P amplitude ratios for the Case $1 \mathrm{LVZ}$ models in Fig. 3-10 as a function of the $\mathrm{dv} / \mathrm{v}$ value and thickness of the LVZ. (b) SP/P and Ps/P amplitude ratio for the Case 2 and Case 3 reflection models in Fig. 3-10. Case 2 is used for the stations with SP observations and Case 3 for the stations with Ps observations. (c) Frequency distribution of the amplitude ratio of the converted phases to the direct $\mathrm{P}$ phases measured on real data using the same subset of seismograms that was utilized for beamforming in section 4. 
KMPB show the expected overall patterns, where the amplitude ratio increases as velocity reduction increases. The largest ratio appears near the top right part of each plot and corresponds to cases with constructive interference between the two converted phases generated at the top and bottom of the low velocity layer. For station B047, the synthetic results are more complicated. The epicentral distance of station B047, about $45 \mathrm{~km}$, corresponds to a range where the SP phases are expected to refract along the bottom interface of the LVZ which causes complex waveforms (1B in Fig. A-8). The amplitude of such phases are not simple measures of the transmission coefficient corresponding to the velocity contrast at the bottom of the LVZ, and we do not interpret the B047 amplitudes.

The Case 2 and 3 amplitude ratio measurements for stations CM09A, B047, CM03A and KMPB show that the amplitude ratio increases as the $\mathrm{Vp} / \mathrm{Vs}$ ratio inside the oceanic crust layer increases as expected. For station CM01A, the sudden increase in amplitude ratio between 1.9 and $2.4 \mathrm{in} \mathrm{Vp} / \mathrm{Vs}$ values is due to the interference of the Ps arrival. But without the contamination of Ps phases, the amplitude ratios are still small, likely below 0.1 .

We seek a representative estimate of the velocity contrast across the top and bottom boundaries of the high $\mathrm{Vp} / \mathrm{Vs}$ zone by comparing the real and synthetic amplitude ratios. However, even though the amplitude ratios are from events in a compact cluster that generates similar waveforms, the observed amplitude ratios are scattered over a certain range. Similarly, the synthetics are calculated for a very simplified velocity model that is not a complete representation of the true Earth. Thus, we focus on the first order implications of the amplitude ratios and recognize that effects like focal mechanism variations as well as local variations in the both the strength and dip of the discontinuities can lead to the significant level of variability in amplitude ratio (factor of $2+$ ) that is observed for any particular station-phase pair.

In general for stations CM09A, CM01A, CM03A, and KMPB, the observed amplitude ratios are larger than can be replicated by the simple synthetics. In particular, there are no models for which a $\mathrm{Vp} / \mathrm{Vs}$ ratio around 1.7-1.8 could satisfy the observed amplitude ratios. For models in case 2 and case 3, once the $\mathrm{Vp} / \mathrm{Vs}$ ratio exceeds 2.0, the subducted crust becomes a low velocity zone. Models in the range $2.0 \leq \mathrm{Vp} / \mathrm{Vs} \leq 2.5$ produce amplitude ratios that overlap the observations but do not capture the full range of the observations. Thus, we do not favor a specific value for the $\mathrm{Vp} / \mathrm{Vs}$ ratio in the subducted crust recognizing 
that our models are highly simplified. However, given the large observed amplitude ratios we favor a $\mathrm{Vp} / \mathrm{Vs}$ value in $\geq 2.0$. Thus, the plate boundary fault is likely contained within a LVZ, at least for shear-wave velocity.

A LVZ would be expected to generate converted phases from both its top and bottom interfaces. In general our observations agree with this in that for certain clusters of stations we clearly see either the top or the bottom of the high $\mathrm{Vp} / \mathrm{Vs}$ layer as a sharp velocity contrast. We have relatively few cases where the seismograms are simple enough to interpret distinct arrivals on the same seismogram as coming from the top and bottom of the high $\mathrm{Vp} / \mathrm{Vs}$ layer. Perhaps the multiple converted phases on B047 is the best case as these are widely separated in time. Station CM03A presents an interesting case that directly constrains the properties of the interseismically locked zone in that while the Moho Ps conversion is the largest phase, coherent phases are observed from shallower depths as well. Fig. A-9 shows an expanded view of a few of these seismograms compared to synthetics. The conversion from the subducted Moho is about twice as large as the phase which arrives immediately before it. The two Ps phases are separated by about 1.1 seconds and may have opposite polarity, though that is difficult to assess. Fig. A-9 shows radial component synthetics for various case 3 models. The synthetics demonstrate that the amplitude of the shallower phase is minimized for a $\mathrm{Vp} / \mathrm{Vs}$ of about 2.0. For $\mathrm{Vp} / \mathrm{Vs}$ larger than 2.0, the LVZ creates two phases with opposite polarities that are separated by 1.3 to $1.5 \mathrm{~s}$ with varying amplitude ratios. Again, we do not attempt to specify a specific $\mathrm{Vp} / \mathrm{Vs}$ ratio from the simplified synthetics, but the CM03A waveforms are consistent with the seismogenic zone being characterized by a $\sim 5 \mathrm{~km}$ thick $\mathrm{LVZ}$ with a $\mathrm{Vp} / \mathrm{Vs} \geq 2$.

The inference of a likely low velocity zone in $V_{s}$ at seismogenic depths likely implies elevated fluid content in the vicinity of the locked zone. The subducted oceanic crustal basalt of Gorda plate is likely to be metamorphosed to greenschist facies at depths of 10-20 $\mathrm{km}$, which has a Vp/Vs value of $\sim 1.76$ (Christensen, 1996). Thus, the elevated Vp/Vs values in Models 2 and 3 that are consistent with the converted phase amplitudes likely indicate the existence of significant fluid-filled porosity in the subducted melange and oceanic crust. To reach $\mathrm{Vp} / \mathrm{Vs}$ values in excess of $\sim 1.85$ would likely correspond to fluid filled porosities in excess of $\sim 3 \%$ (assuming 20-50 MPa effective normal stress) (Peacock et al., 2011; Pimienta et al., 2018). While the exact amount of fluid filled porosity is difficult for us to interpret owing to the variety of factors that effect the converted phase amplitudes, our 
results are consistent with the interpretation of the $10-20 \mathrm{~km}$ depth range as being dominated by brittle deformation that produces significant porosity which is maintained throughout the interseismic period.

\subsubsection{Single station variability in converted phase amplitudes}

The observed $\mathrm{SP} / \mathrm{P}$ or $\mathrm{Ps} / \mathrm{P}$ amplitude ratios at a single station often show a range over a factor of 3 (or more) even for the similar clusters of events that we used for beamforming. Moreover, the clusters that we selected are some of the clearest examples with other portions of an individual record section showing less systematic converted phase arrivals. This variability is surprising, particularly for phases associated with the Moho of the subducted plate whose conversion points are tightly clustered in a few $\mathrm{km}$ area such as for the KMPB Ps arrivals from the bottom of the high Vp/Vs zone (Fig. 3-8). In this section we explore some possible causes of this variability.

While we have only used earthquakes from a linear vertical, strike-slip fault segment for this study to isolate structural effects on the waveforms, focal mechanism variability within the source arrays may still contribute to SP or Ps amplitude variability. Moreover, the $\sim 30$ $\mathrm{km}$ length of the M-fault used to make our record sections leads to a natural variation in the takeoff angles of the direct and converted phases across the record section. To explore how these combined effects on the initial excitation of the $\mathrm{P}$ or $\mathrm{S}$ waves leaving the source are reflected in the converted phase amplitude ratios, we use the $\mathrm{S} / \mathrm{P}$ amplitude ratio as a proxy for focal mechanism and take-off angle changes along the profiles.

Figures S10, S11 and S12 show how the SP/P and Ps/P amplitude ratios vary within clusters of relatively similar earthquakes. Fig. A-10 shows about a factor of two variation in the $\mathrm{SP} / \mathrm{P}$ amplitude ratio at $\mathrm{CM} 01 \mathrm{~A}$ across a cluster of 11 events with very similar waveforms (a subset of the beamforming dataset in Section 3). Despite having extremely similar $\mathrm{P}$-waveforms, there is considerable variation in both the $\mathrm{S} / \mathrm{P}$ and $\mathrm{SP} / \mathrm{P}$ amplitude ratios. Fig. A-11 shows common events recorded by stations CM09A and B047 and by stations $\mathrm{CM} 03 \mathrm{~A}$ and $\mathrm{KMPB}$. The $\mathrm{SP} / \mathrm{P}$ amplitude ratio relation between CM09A and B047 shows a positive correlation while the $\mathrm{Ps} / \mathrm{P}$ amplitude ratio relation between $\mathrm{CM} 03 \mathrm{~A}$ and KMPB shows a negative correlation indicating relatively systematic trends despite the small size of the earthquake cluster. Lastly, Fig. A-12 compares the converted phase and direct wave amplitude ratios, which are expected to be correlated based on standard formulas for 
conversion and transmission coefficients (Aki and Richards, 2002). The strong correlation at stations like CM09A indicates that much of the variability seen in the measurements in Fig. 3-11 results from variations in the initial excitation as the $\mathrm{P}$ and $\mathrm{S}$ waves leave the source region.

Collectively these figures indicate that much of the variation in the converted phase amplitudes on an individual record section results from the natural variability in the initial excitation of the direct and converted waves as they leave the source region of an individual earthquake somewhere along the M-fault. Some of this variability in excitation may be due to focal mechanism variability but it may also result from the variations in takeoff angles between the different locations along the fault. Additionally, any small scale variations in velocity contrasts across the various discontinuities will also contribute the variability seen in a particular record section. Special care should be given in interpreting the $\mathrm{Ps} / \mathrm{P}$ ratios because variation in shear-wave speeds near the station can cause local amplification of the shear-wave amplitude that is not related to the actual conversion at greater depth. For instance, at the OBS stations like FS13D, the Ps phase are extremely clear, which likely reflects the low shear-wave speeds of the near seafloor sediments.

Additionally, there are many examples where the converted phases from either the top or bottom of the subducted crust are strong and easily established but the corresponding arrival from the other interface is not easily identified. For instance, the SP phases in Fig. 3-5 at JCC and CM01A are very consistent with conversions from near the top of the subducted crust, but no similar Moho converted phase is observed. Moreover, some converted phases are only clearly visible at a subset of earthquakes and not in ones located a few km away on the same fault (Also, see Fig. 3-5). Both types of observations imply rapid spatial variations in the strength of the discontinuity.

\subsubsection{Spatial variations in the converted phases observations}

We summarize our observations from the onshore stations in Fig. 3-12. SP converted Phases are primarily observed by stations in the north and south groups and the corresponding conversion points are located just offshore. The SP phases observed at stations in the northern group convert near the top of the LVZ, while the largest SP phases observed at the southern group of stations convert near the bottom of the LVZ but shallower interfaces also generate SP phases. The Ps conversion points are located onshore between 15 and $20 \mathrm{~km}$ 


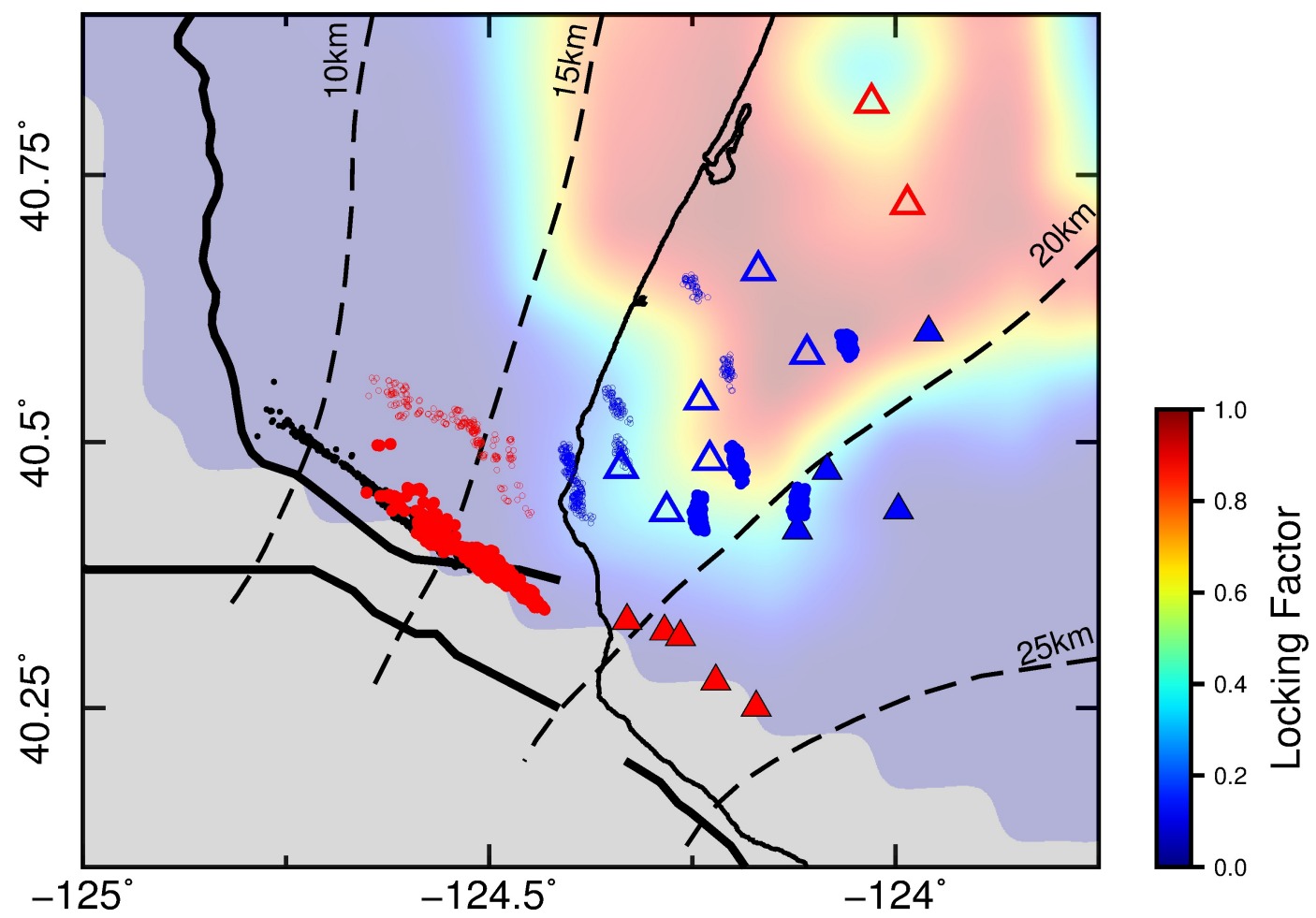

Figure 3-12: Mapview of conversion points on the Slab1.0 interface from onshore stations. Red solid circles and red solid triangles are the SP conversion points from the oceanic Moho and the stations where these phases are observed. Red open circles and red open triangles are the SP conversion points from the top of the oceanic crust and the stations where these phases are observed. Blue solid circles and blue solid triangles are the Ps conversion points from the oceanic Moho and the stations where these phases are observed. Blue empty circles and blue empty triangles are the Ps conversion points from the top of the oceanic crust and the stations where these phases are observed. Background colors represent the interseismic plate locking model from Pollitz and Evans (2017) ranging from freely slipping (locking factor 0 ) to fully locked (locking factor 1 ).

depth. Near the coast the Ps converted phases are from the top of the LVZ, while farther onshore the clearest Ps converted phases are from the bottom of the LVZ. The amplitudes of the Ps converted phases from the top of the LVZ near the coast are typically small, while the amplitude of the Ps converted phases for the slab Moho near 20km depth are typically much larger resulting in clearer phases on the seismogram. The variations in whether Ps or $\mathrm{SP}$ is most clearly observed may reflect the strike-slip radiation pattern.

Fig. 3-12. compares the locations of the conversion points to the interseismic coupling model of Pollitz and Evans (2017). The coupling model shows one of its strongest patches of interseismic locking in southern Cascadia, which overlaps our study area. Many of our conversion points are located offshore where there is no geodetic data and the coupling 
model is unresolved. Additionally, the southern boundary of this coupling patch is very dependent on how the modeling deals with the complicated geometry at the southern end of the subduction zone and the interseismic coupling on the transform boundaries. Thus the decrease in coupling in the southernmost part of our study area is potentially unreliable and we do not seek to interpret it. The primary inferences we can make related to plate coupling are that the Ps conversions from the Moho in the highly coupled zone are some of our brightest phases (e.g. Ps at CM03A and KMPB in Fig. 3-8). We also observe converted phases from the top of the high $\mathrm{Vp} / \mathrm{Vs}$ zone within the region of nearly full interseismic locking (Fig. A-9). Thus, in agreement with the Vp/Vs tomographic model, the converted phases support the inference that the interseismically locked zone is also a region of reduced seismic velocities and likely elevated porosity and fluid content (Guo et al., 2019).

\subsection{Conclusions}

The Cascadia Initative onshore-offshore experiment demonstrates the ability to use converted phases from earthquakes in the mantle of the downgoing plate to study the geometry and physical properties of the plate boundary zone as well as the spatial scales that such observations can be expected to vary over. The combination of the $3 \mathrm{D}$ raytracing and source side beamforming methods was sufficient to identify the type of converted phases and infer the location of the major velocity contrasts in our dataset. In general converted phases are similar among stations spaced less than about $30 \mathrm{~km}$ apart because the conversion points are more closely spaced at depth. For a given station, the SP conversion points occur well updip of where the Ps conversion points occur. At larger separations it can be difficult to identify similar phases between stations. At offshore stations the basalt to sediment in-

terface provides the largest amplitude conversions while at onshore stations, the Moho of the subducted Gorda plate provides the clearest interface at many stations while the top of the subducted crust provides the clearest interface at some stations. In both onshore and offshore stations there are often conversions from multiple interfaces including phases generated within the shallow crust of the overriding plate.

In general, the Slab2 model provides a description of the subducted plate morphology that is more consistent with our converted phase observations and is near the top of the high $\mathrm{Vp} / \mathrm{Vs}$ zone of Guo et al. (2019). Using the Ps converted phases at OBS stations near the 
deformation front and comparing to available active source reflection profiles indicates that the plate interface should be 1-3 km shallower than the Slab1.0 model and 1-4 km shallower than the Slab2 model at the deformation front. Just offshore, SP converted phases observed at CM01A and JCC indicate the top of the oceanic crust is likely about $2 \mathrm{~km}$ shallower than the Slab1.0 model and are consistent with Slab2 model. Near the coast and onshore, multiple Ps converted phases are observed at the stations in the middle of our study area. Slab2 is $2-4 \mathrm{~km}$ shallower than Slab1.0 model in this area and consistent with the $V_{p} / V_{s}$ model. East of $124.25^{\circ} \mathrm{W}$ and north of $40.5^{\circ} \mathrm{N}$, Ps phases indicate that the Slab1.0 model is 1-3 km to deep but are consistent with the Slab2 model. The largest discrepancy between the Slab1.0 and Slab2 models is onshore between $40.3^{\circ}$ and $40.5^{\circ} \mathrm{N}$ where the Slab1.0 model shows a considerable steepening. We find that the high $\mathrm{Vp} / \mathrm{Vs}$ zone lies largely above the Slab1.0 model in this area and that based on SP conversions from the subducted Moho as well as the likely top of the subducted crust, the true interface depth is about $6-8 \mathrm{~km}$ shallower than the Slab1.0 model and about $2 \mathrm{~km}$ shallower than the Slab2 model.

We observe clear converted phases from both the top and bottom of the subducted crust in the seismogenic zone in regions where the interface is inferred to be locked during the interseismic period. To further investigate the material properties of the locked zone we compared the $\mathrm{SP} / \mathrm{P}$ and $\mathrm{Ps} / \mathrm{P}$ amplitude ratios to a series of simplified models via synthetic seismogram calculations. We find that it is difficult to recreate the observed range of amplitude ratios (0.1-0.8) using simple models of a low velocity zone with an ordinary $\mathrm{Vp} / \mathrm{Vs}$ ratio and moderate amounts of velocity reduction $(\leq 10 \%)$. We also tested a model similar to P-wave refraction profile of Beaudoin et al. (1994), which contains $10 \%$ velocity increases at both the top and bottom of the oceanic crust. To recreate the full amplitude of the observed $\mathrm{SP} / \mathrm{P}$ and $\mathrm{Ps} / \mathrm{S}$ ratios from the top and bottom of the subducted crust it was necessary to impose a low velocity zone in the oceanic crust with a $\mathrm{Vp} / \mathrm{Vs}$ ratio $\geq 2.0$. The tested velocity models are highly simplified compared to the real earth and a variety of effects may contribute to the observed range of converted phase amplitudes. However, the observed amplitudes are most easily explained by a subducted crust that is a significant low velocity zone at least for S-waves. Improved imaging of the subducted crust and plate boundary zone could be achieved in this region by designing receiver arrays capable of resolving the energy that propagates within the subducted crust for much of its path. 


\subsection{Acknowledgement}

This work is funded by National Science Foundation Award Numbers EAR-1520690. The offshore data used in this research were provided by instruments from the Ocean Bottom Seismograph Instrument Pool and the on land data are from the PASSCAL facility, Northern California Earthquake Data Center and Plate Boundary Observatory. The seismic data are archived at the Incorporated Research Institutions for Seismology (IRIS) Data Management Center (http://www.iris.edu) and Northern California Earthquake Data Center (https://ncedc.org). We thank OBSIP and PASSCAL technicians and volunteers who contributed to data collection. Work presented here would not have been possible without the tomographic models and earthquake locations from Hao Guo. We thank John Collins for suggesting the wavefield decomposition method for processing the OBS data. We also thank Anne Tréhu for the discussion of the results of the 93-94 Mendocino active source seismic experiments. We appreciate Erin Wirth's, Joan Gomberg's and Stephen Hickman's helpful comments and suggestions on an earlier version of this paper. We thank Editor Michael Bostock and two anonymous reviewers for their constructive comments on the manuscript. 


\section{Chapter 4}

\section{Observations of Guided Waves from Slab Interface Earthquakes}

\subsection{Introduction}

Subduction zone megathrust earthquakes pose a great threat to human society. Our understanding of what to expect in future great earthquakes is limited in part by a lack of knowledge of the fault zone structure in between the subducted oceanic crust and the overriding plate, especially at seismogenic depth. Only the most shallow part of the subduction zone plate boundary has been sampled directly by drilling (Chester et al., 2013) and only a few offshore active source experiments have focused on the plate boundary fault structure all the way down to 40-50 km depth (Nedimović et al., 2003; Li et al., 2015) and some active source experiments could only easily detect energy reflected from the Moho of the subducted oceanic crust and not the actual plate boundary fault (Preston et al., 2003).

The subduction zone megathrust interface generally shows depth-varying slip behaviors (Lay et al., 2012; Scholz, 1998). The shallow, trenchward portion of the subduction plate interface may have the largest displacement during some megathrust earthquakes yet still produce relatively little high frequency seismic radiation (Lay et al., 2012). It is thought to fail primarily by stable sliding due to the existence of velocity-strengthening clay minerals and low effective stresses owing to high pore fluid pressure (Scholz, 1998; Saffer and Tobin, 2011). The middle portion of the megathrust interface is termed the seismogeneic zone where earthquakes nucleate and large coseismic slip occurs over wide areas. This region radiates 
energy in intermediate period bands that can be detected as seismic waves worldwide. Usually, high-frequency strong ground motion comes from the deeper part of the seismogenic zone, near the coast, and is thought to be related to isolated strong rupture patches that can produce bursts of radiation (Lay et al., 2012; Frankel et al., 2018). Below the downdip edge of the seismogenic zone, a variety of failure types occur, including episodic tremor and slip, afterslip and long term slow slip events, all of which are aspects of the gradual transition from frictional sliding to stable sliding and/or ductile flow as the subducted slab reaches the upper mantle (Schwartz and Rokosky, 2007; Obara and Kato, 2016).

This depth-varying slip behavior likely correlates with the seismic reflection character of the subduction thrust faults on seismic images (Nedimović et al., 2003; Li et al., 2015). For example, Li et al. (2015) used seismic reflection data to image the megathrust fault of the Semidi segment offshore Alaska Peninsula and revealed changes in seismic reflectivity with depth. They found that for the top $15 \mathrm{~km}$ of the megathrust, two parallel reflections are imaged and are interpreted as the top and bottom of the subducted sediment section. From $15 \mathrm{~km}$ to $20 \mathrm{~km}$ depth, the plate interface appears as a thin reflection band which represents a single $\sim 100$ to $250 \mathrm{~m}$ thick low-velocity zone. The thin reflection band is located at the center of the $1938 \mathrm{Mw} 8.2$ Semidi earthquake rupture zone. At greater depth, the plate interface becomes a thicker package of reflections about 3 to $5 \mathrm{~km}$ thick which might represent a wide deformation zone with branching faults and fluid-rich layers. This layer projects to the location of tremor at greater depth representing a broad transition from stick-slip sliding to slow slip and tremor.

In Cascadia, the subducted sediment layer is well established in the north where the Juan de Fuca plate subducts (Nedimović et al., 2003), but less clear in the south where the Gorda plate subducts. Near the trench, Gulick et al. (1998) imaged an incoming sediment thickness of 1-2 km on the Gorda plate. However, onshore when the interface reached about $14 \mathrm{~km}$ depth, Beaudoin et al. (1994) examined refraction data for evidence of a low velocity zone coincident with the top of the subducted plate and could find no clear evidence for the expected sediment layer (Fig. 4-1). Gong and McGuire (2020) used S-to-P and P-to-S converted phases from local earthquakes in the mantle of the subducted Gorda plate and found intermittent high reflectivity patches at the top of the Gorda plate between 10 to $20 \mathrm{~km}$ depth. At 20-30 km depth, Beaudoin et al. (1998) also imaged the subducted Gorda plate as intermittent high reflection patches. This is a surprise because at equivalent depths in 
Northern Cascadia, the subducted/underplated sediments show a growing thickness between 15 and $30 \mathrm{~km}$ depth known as the E-layer with significant reflectivity. The extent and continuity of the low velocity sediment layer in the seismogenic zone of the subducted Gorda plate in southern Cascadia remains unclear.

Structural geology studies of the subduction plate boundary fault from oceanic drilling or ancient exhumed subduction plate interface shows that the thickness of active plate boundary faults, which includes multiple simultaneously active, anastomosing fault strands, is typically 100-350 $\mathrm{m}$ from the trench down to $15 \mathrm{~km}$ depth (Rowe et al., 2013). The abundant veins found in these faults indicates the existence of overpressured fluids in and around the plate boundary faults (Vannucchi et al., 2008; Meneghini and Moore, 2007; Bebout and Penniston-Dorland, 2016). These overpressured fluids will reduce the effective pressure the plate boundary faults and weaken the fault strength. Therefore, understanding the velocity structure of the few hundred meter thick active plate boundary faults is important to infer the stress state of the fault and its impact on earthquake rupture. However, it is still challenging to resolve the details of such thin layers by traditional active source seismology (Preston et al., 2003) and traveltime tomography methods.

It is well known that both continental and oceanic strike slip faults are characterized by a hundreds of meters wide damage zone with $30 \%-40 \%$ shear wave velocity reduction compared to country rocks (Li et al., 1994; Peng et al., 2003; Roland et al., 2012) at least at shallow depths where effective stress is low. The fault damage zone also has increased porosity due to intense shearing, which can form fluid pathways and generate earthquake swarms (Ross et al., 2020). The low velocity zones amplify ground motion during earthquakes (Cormier and Spudich, 1984), modulate earthquake rupture behavior (Huang et al., 2014) and affect long term slip and deformation (Thakur et al., 2020). Given how important low velocity zones around strike-slip faults are for understanding earthquake rupture, it is important to improve imaging and understand the extent and lateral continuity of low velocity zones around subduction megathrust at seismogenic depths.

Guided waves, sometimes are called trapped waves, are a popular method to study the structure of low velocity layers embedded in higher velocity materials ( $\mathrm{Li}$ and Vidale, 1996; Peng et al., 2003; Cochran et al., 2009). They are generated by the constructive interference of waves that undergo total internal reflection within the low velocity layer. They typically show an exponential amplitude decay away from the low velocity layer. Using guided waves 
observed from stations deployed near the rupture zone of the 1992 Landers earthquakes, Peng et al. (2003) estimated that the fault zone has a width of approximately $200 \mathrm{~m}$, an S-wave velocity reduction relative to the host rock of approximately $30-40 \%$ and an S-wave attenuation coefficient of approximately 20-30. In subduction zones, a form of guided waves are often observed on forearc stations from intermediate depth earthquakes that occur in the subducted oceanic crust (Fukao et al., 1983; Martin et al., 2003; Furumura and Kennett, 2005; Shiina et al., 2014). In this geometry, the entire subducted oceanic crust becomes a $6 \mathrm{~km}$ thick low velocity channel, relative to the surrounding mantle, that can trap seismic energy as the wave propagate updip. The bending of the slab at the shallow depth or the equalization of velocity between the oceanic crust and overlaying material cause the guided waves to leak out and to be observed by surface stations (Martin et al., 2003; Shiina et al., 2014). These types of studies typically involve propagation paths of $100 \mathrm{~km}$ or more and sources deeper than $50 \mathrm{~km}$ and hence do not differentiate the role of the sediment layer within the seismogenic zone. While the signals from guided waves in the sediment layer may overlap with the waves trapped by the entire subducted crust, to our knowledge, no study has focused on identifying guided waves that are specific to the few hundred meter thick plate boundary zone at seismogenic depths in subduction zones.

In this study, we report observations of apparent guided waves likely from the thin low velocity layer (LVL) near the slab interface of the subducted Gorda plate at seismogenic depths. In the southern end of Cascadia, the Gorda plate subducts beneath the North America at a rate of $27 \mathrm{~mm} / \mathrm{yr}$ (DeMets et al., 2010). The close distance between ridge and trench make it one of the warmest subduction zones. It has the shortest M8 earthquake recurrence rate in Cascadia, about every 200 years (Gomberg, 2018; Goldfinger et al., 2003). The surface topography beneath the sediments may be rough due to intense internal deformation of the Gorda Plate. We observed that earthquakes located close to the plate interface generate longer S-wave coda, including nearly monochromatic low frequency phases, than earthquakes located just a few $\mathrm{km}$ below. We analyze the spatial coherence of these long duration S-waves from several clusters and separate the various arrivals within the S-wave using array processing techniques. 

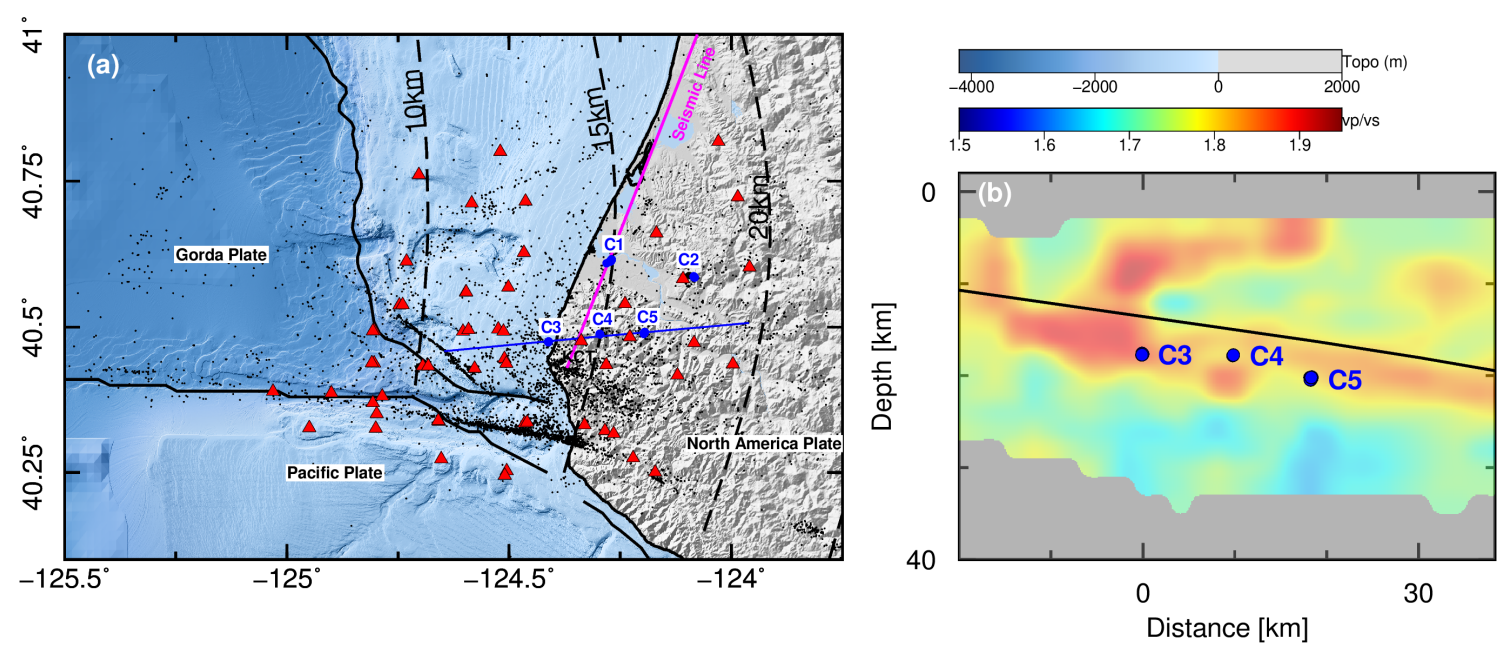

Figure 4-1: CI experiment stations and the locations of five near slab-interface clusters (labeled C1-C5). (a) Red triangles are stations. Small black dots are background seismicity. Blue circles are the five earthquake clusters that are near the slab interface. Dashed black lines are slab contours from the Slab 2.0 model (Hayes et al., 2018). Magenta line is the approximate location of the active source experiment from Beaudoin et al. (1994). Blue line is the location of the cross section shown in (b). (b) Cross section going through cluster C3, $\mathrm{C} 4$ and C5. The background is the Vp/Vs model from Guo et al. (2019). The black line is the slab geometry from Slab 2.0 model.

\subsection{Cascadia Initiative observations}

The Cascadia Initiative (CI) was a community experiment using an amphibious seismic array to study a broad range of phenomena in the Cascadia subduction zone including megathrust earthquakes, episodic tremor, volcanic arc structure and the formation, deformation and hydration of the Juan de Fuca and Gorda Plates (Toomey et al., 2014). The experiment lasted from 2011 to 2015 and during Year 2 (2012.8-2013.7) and Year 4 (2014.7-2015.8), a dense seismic network was deployed near the Mendocino Triple Junction (MTJ) at the southern end the Cascadia subduction zone, to record its abundant seismicity. Both Year 2 and Year 4 had $\sim 20$ ocean bottom seismic stations offshore and Year 4 had 10 temporary short period stations deployed onshore near the MTJ (Fig. 4-1). 7 other permanent seismic stations from Northern California Seismic Network and the Plate Boundary Observatory were also operational in this time period. More than 4000 local earthquakes were recorded during the two years of deployment. The abundant seismicity and the dense station distribution has greatly improved the resolution of the velocity models near MTJ and the precision of the earthquake locations (Guo et al., 2019).

This relocated earthquake catalog from Guo et al. (2019) allows us to study earthquakes 
(a)

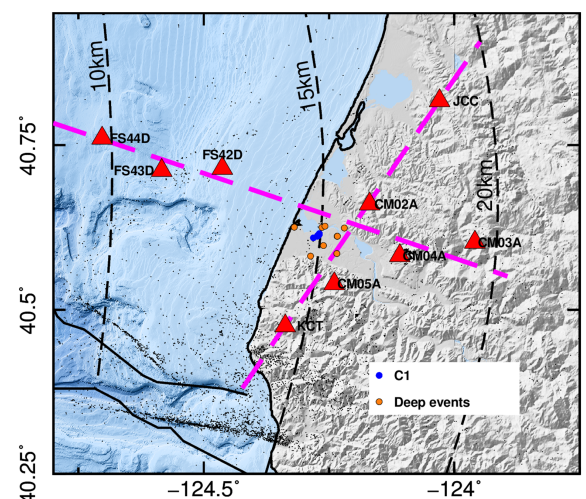

(b)
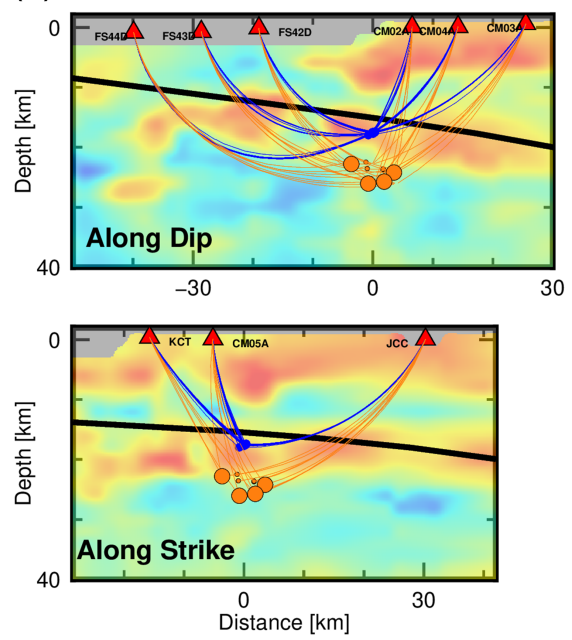

(c)
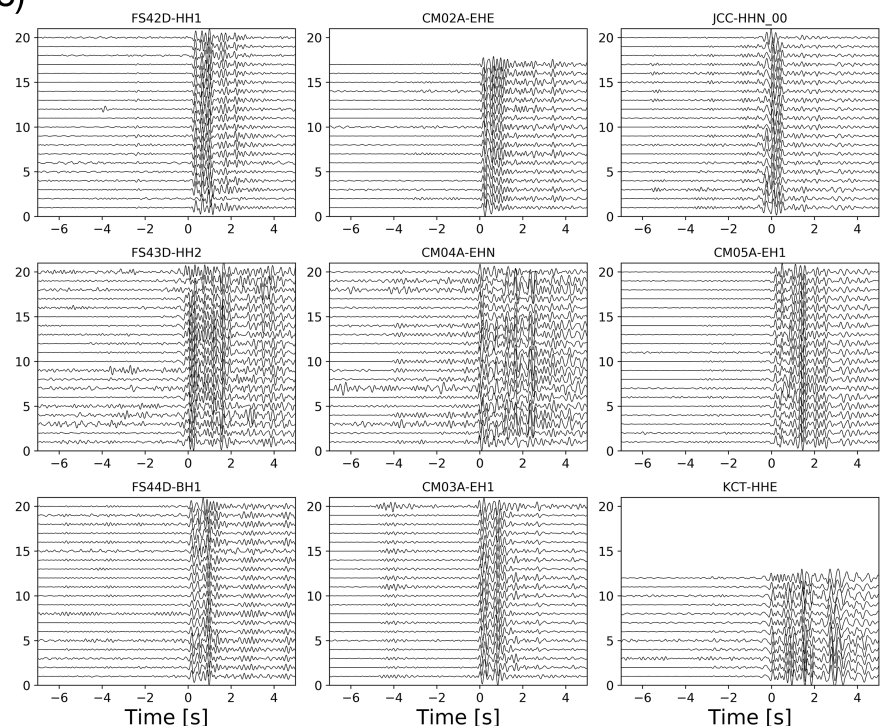

(d)
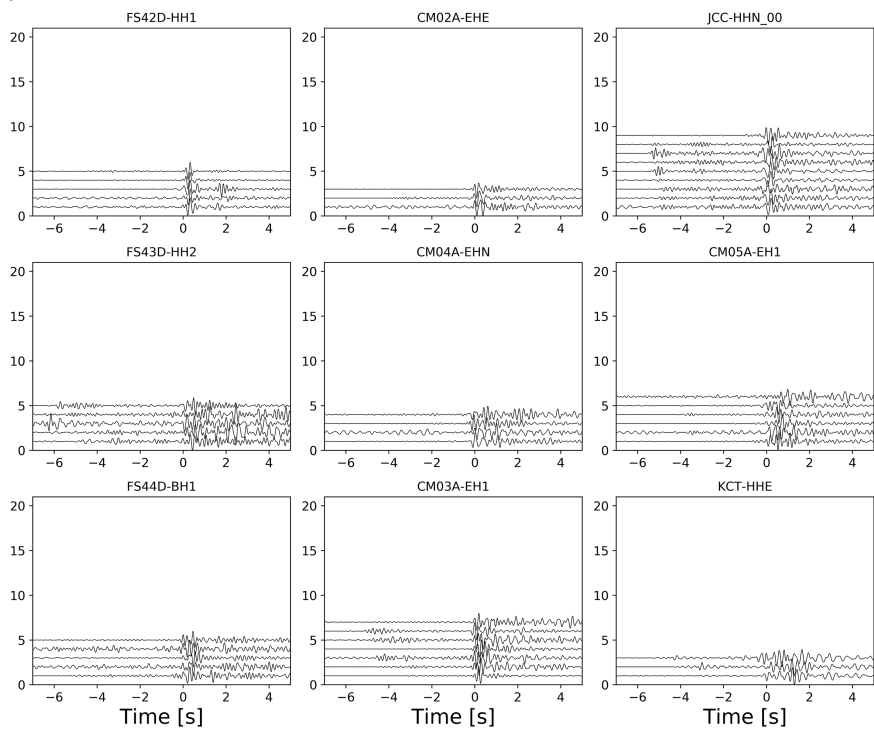
that belong to different tectonic settings near the MTJ. We separated the earthquakes into 3 categories that are above, near and well below the subducted Gorda plate interface. We identified 5 earthquake clusters near the interface based on their locations and waveform similarities and refer to them as C1 to C5. Their locations are shown in Fig. 4-1 and summarized in Table B.2. Cluster C1, C3 and C4 are simple clusters with all the waveforms within each cluster having high correlation coefficients with each other. Clusters C2 and C5, while generally showing similar waveforms, are more complicated and can be divided into several subclusters.

Visual inspection of the waveforms from the clusters indicated that they tend to have significantly longer duration $\mathrm{S}$ waves (main arrivals and big amplitude coda) on several stations compared to nearby events. Here we focus on cluster $\mathrm{C} 1$, which is a simple cluster with the most events. Waveforms of events inside and below the cluster on 9 stations from both the along strike and along dip directions are shown in Fig. 4-2. Waveforms on stations FS42D, FS43D, CM04A, CM05A and KCT show extended S waves for cluster C1 events. However, for some nearby stations, such as CM02A, the S-waves are fairly impulsive with little coda. Fig. 4-3 compares the waveforms on the two horizontal components between events from cluster $\mathrm{C} 1$ (blue traces) and events $5-10 \mathrm{~km}$ below the slab interface (orange traces) on stations FS42D, CM04A and KCT. Waveforms from cluster C1 have delayed S wave peak amplitude and the $\mathrm{S}$ wave train can be as long as 4 seconds. For events a few $\mathrm{km}$ below the slab interface, the $\mathrm{S}$ wave is more impulsive and has much shorter duration despite sharing nearly identical raypaths above the plate interface (Fig. 4-2). This indicates that the long duration $\mathrm{S}$ waves observed from cluster $\mathrm{C} 1$ are likely due to near source velocity anomalies and hence that the long duration $\mathrm{S}$ waves carry information of the seismic velocity structure near the plate boundary.

Figure 4-2 (preceding page): Earthquakes in and below cluster C1. (a) Red triangles are seismic stations. Blue dots are events from cluster C1. Big orange dots are events within $5 \mathrm{~km}$ radius from the center of cluster $\mathrm{C} 1$ but below cluster $\mathrm{C} 1$. Small black dots are background seismicity. Dashed black lines are slab contours from the Slab 2.0 model. Solid black lines are plate boundaries and trench. Dashed magenta lines are the locations of the two cross sections shown in (b). (b) Cross sections along the dipping and strike directions. The blue and orange dots are the same as in (a). Blue and orange lines are $\mathrm{S}$ wave raypaths. The big orange circles are the earthquakes whose waveforms are shown in Fig. 4-3. (c) and (d) Waveforms from earthquakes in and below cluster $\mathrm{C} 1$ on 9 stations. 
Similar phenomena could be found for other clusters, too. For example, for cluster C2, stations CM02A, KCT and three offshore OBS stations have long duration S waves, while nearby stations CM05A and CM03A have more impulsive $\mathrm{S}$ waves. We compare waveforms between events inside cluster $\mathrm{C} 2$ and events several km below at station KCT (Fig. B-4). Waveforms inside $\mathrm{C} 2$ and just $2 \mathrm{~km}$ below have relatively long $\mathrm{S}$ waves and large amplitude, low frequency coda at 3 to $4 \mathrm{~s}$ after the first arrival. In contrast, a nearby event located 8 $\mathrm{km}$ below cluster C2 doesn't produce the large amplitude coda. Therefore, similar to cluster $\mathrm{C} 1$, the long duration $\mathrm{S}$ waves on station $\mathrm{KCT}$ from cluster $\mathrm{C} 2$ likely result from velocity anomalies near the $\mathrm{C} 2$ source and the plate boundary.

One of the stations with the clearest difference between the near interface events and earthquakes located a few $\mathrm{km}$ deeper is $\mathrm{KCT}$, located about $20 \mathrm{~km}$ south of clusters $\mathrm{C} 1$ and C2 (Fig. 4-2). Time frequency analysis of the KCT waveform from cluster C1 shows that S-wave arrival begins with about 3 seconds of high-frequency energy, possibly containing multiple arrivals, followed by a large late phase in the coda that has a clear dominant frequency of about $3 \mathrm{~Hz}$ (Fig. 4-4). We apply polarization analysis to the 3 component waveforms on station KCT for one event in cluster C1 (Fig. B-3). The initial part of the $\mathrm{S}$ wave vibrates in the northwest-southeast direction, consistent with the direct incoming $\mathrm{S}$ wave. The middle part of $\mathrm{S}$ wave is more complicated, but is likely to have a conjugate vibration direction with the initial part of the $\mathrm{S}$ wave, indicating the arrival of another phase. The coda part of $\mathrm{S}$ wave is in circular motion on the horizontal components, possibly indicating a split shear-wave with a delay time equivalent to $\pi / 2$ in phase. The low-frequency, monochromatic nature and polarization features of the late S-phase are reminiscent of guided waves in continental strike-slip faults.

\subsection{Design of nodal array experiment}

Based on the hypothesis that the long duration $\mathrm{S}$ waves are generated by multiple scattering near the source region, we designed a nodal array experiment and deployed it near station KCT. We use array analysis methods to estimate the apparent slowness of the multiple phases in the $\mathrm{S}$ wave train to distinguish their wave types (body wave or surface wave) and ray parameters, which will help us to infer the paths the energy followed. Given the repeatability of earthquakes in cluster $\mathrm{C} 1$, we expected that we would be able to capture a 
FS42D-HH1
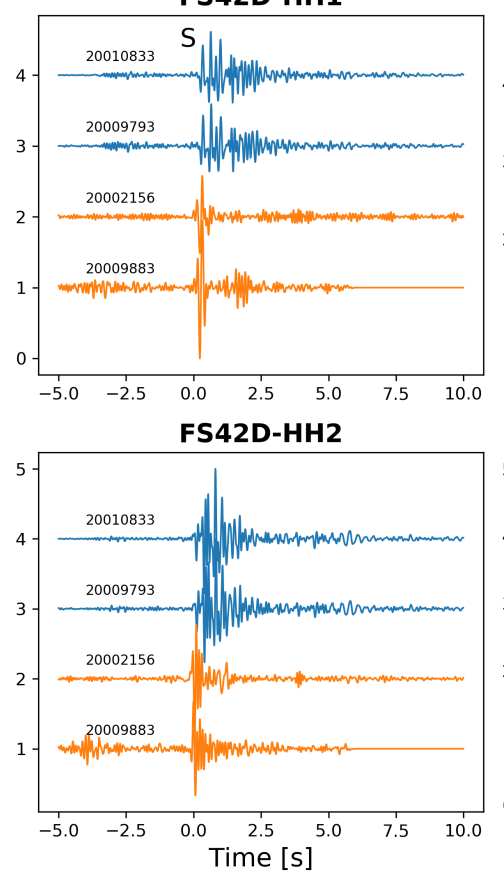

CM04A-EHN

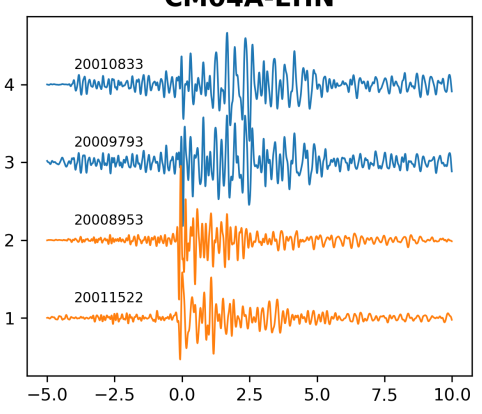

CM04A-EHE

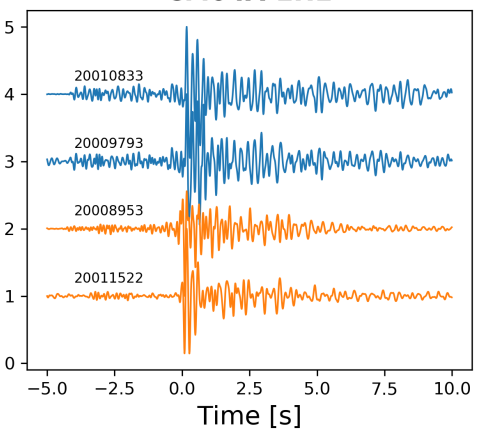

KCT-HHE

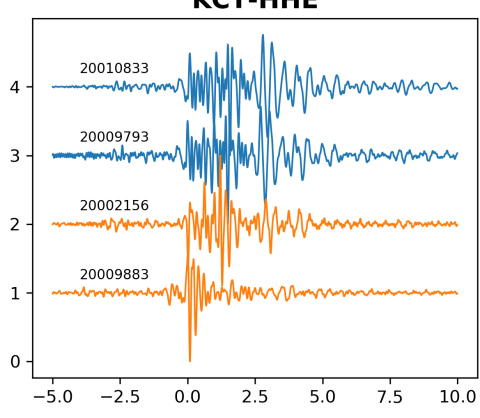

KCT-HHN

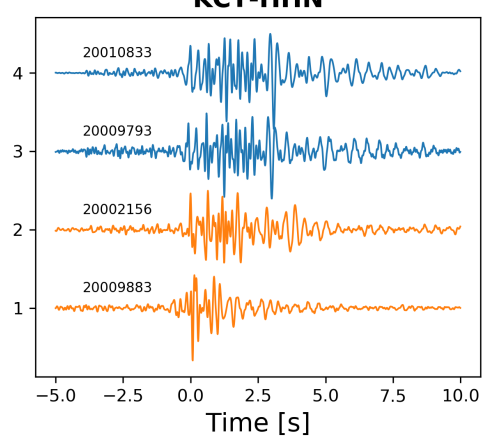

Figure 4-3: Comparison between waveforms of events from cluster $\mathrm{C} 1$ and events below cluster $\mathrm{C} 1$ at stations FS42D, CM04A and KCT. The blue traces are two events from cluster C1. Orange traces are two events blow cluster C1. The event ID is shown to the left of the waveform. Waveforms are aligned by $\mathrm{S}$ wave arrival time.

few events from or near that cluster during the nodal array experiment.

The nodal array is consisted of 20 SmartSoloR IGU-16HR 3 Components portable geophones (the so-called "node") and is distributed around station KCT in an approximate 1 km-radius circle (Fig. 4-5). It is on a hill slope on the north bank of the Bear river in northern California. The irregular pattern of station distribution was chosen to achieve an unbiased array response for all azimuthal directions. The nodes were buried about 4 inches below the surface and were coupled with the ground by a set of spikes. The total deployment lasted for two months from October 12 to December 13 in 2019. We replaced the instruments after a month due to the battery life limit of the nodes. The data is sampled at $250 \mathrm{~Hz}$ for the first month and $500 \mathrm{~Hz}$ for the second month. The instrument response of the node is shown in Fig. B-6 which indicates a high pass filter with a cutoff frequency at around $6 \mathrm{~Hz}$. The nodes worked continuously during the deployment and recorded the local seismic events with good signal to noise ratio (SNR). 

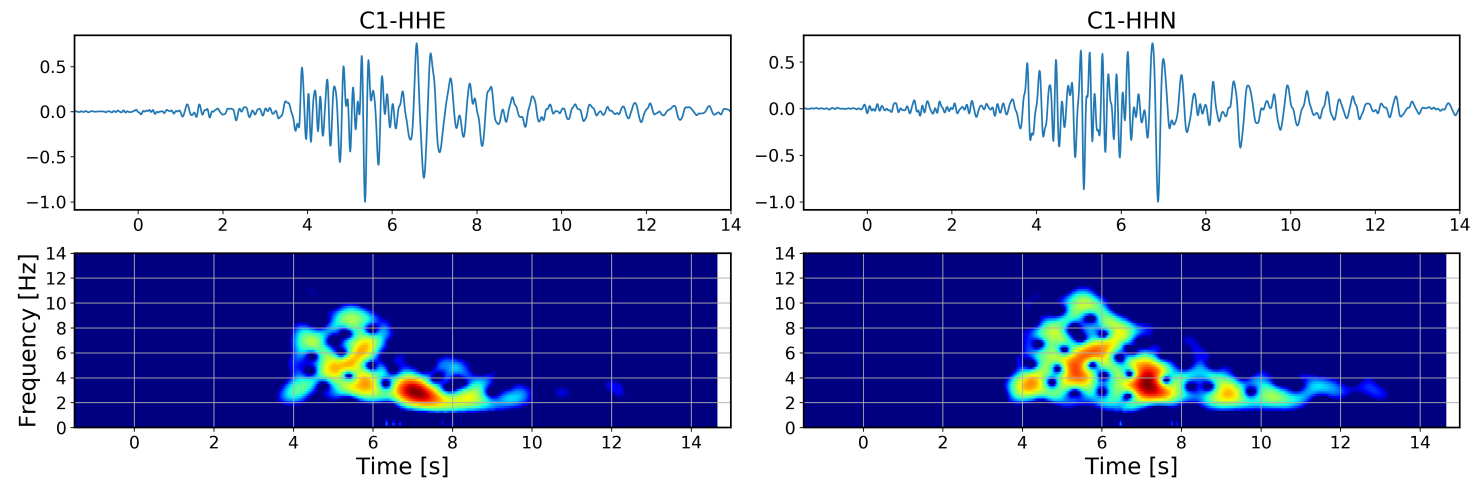

Figure 4-4: Time frequency analysis of waveforms of one event from cluster C1 on the two horizontal components. The high amplitude late arrival has a predominant frequency around $3 \mathrm{~Hz}$.

\subsection{Nodal array experiment data}

During the two-month' deployment, 51 events near the MTJ were reported by the Northern California Earthquake Data Center (Fig. 4-5(c)), but none were near the location of cluster C1. Therefore, we ran a match filter detection algorithm (Beaucé et al., 2017) to detect events from or near cluster $\mathrm{C} 1$. We select one event in cluster $\mathrm{C} 1$ recorded during the CI experiment which had the largest SNR as the master event and use the three component waveforms of the master event at station $\mathrm{KCT}$ to scan the continuous waveforms of station KCT during the two-month deployment. Three candidate events are detected with correlation coefficients greater than 0.5 (Fig. 4-6) that are not in the NCEDC catalog. Candidate 1 has the highest correlation coefficient with the master event and Candidate 2 has the highest SNR. Therefore, we focus on event Candidate 2 in this study.

Waveforms of event Candidate 2 on the nodes are shown in Fig. 4-7. Because of the difference in instrument response between the nodes and station KCT, we first remove the instrument response from the nodes and then convolve them with $\mathrm{KCT}$ instrument response. We also estimate the orientation of the two horizontal components of the nodes and rotate them into north-south and east-west directions (see Section B.2). Stations on the upper part of the hill (ST1 to ST8) have longer duration S wave while stations at the lower part of the hill (ST9 to ST20) show impulsive S wave. Therefore, we divide the S wave into 3 parts and identify them S1, S2 and coda. Fig. 4-7 (d) shows a view of P wave on the vertical component showing similar pattern that $\mathrm{P}$ wave starts with a lower amplitude arrival (ST9 to ST20) and is followed by a larger and impulsive arrival. We name them P1 and P2. 

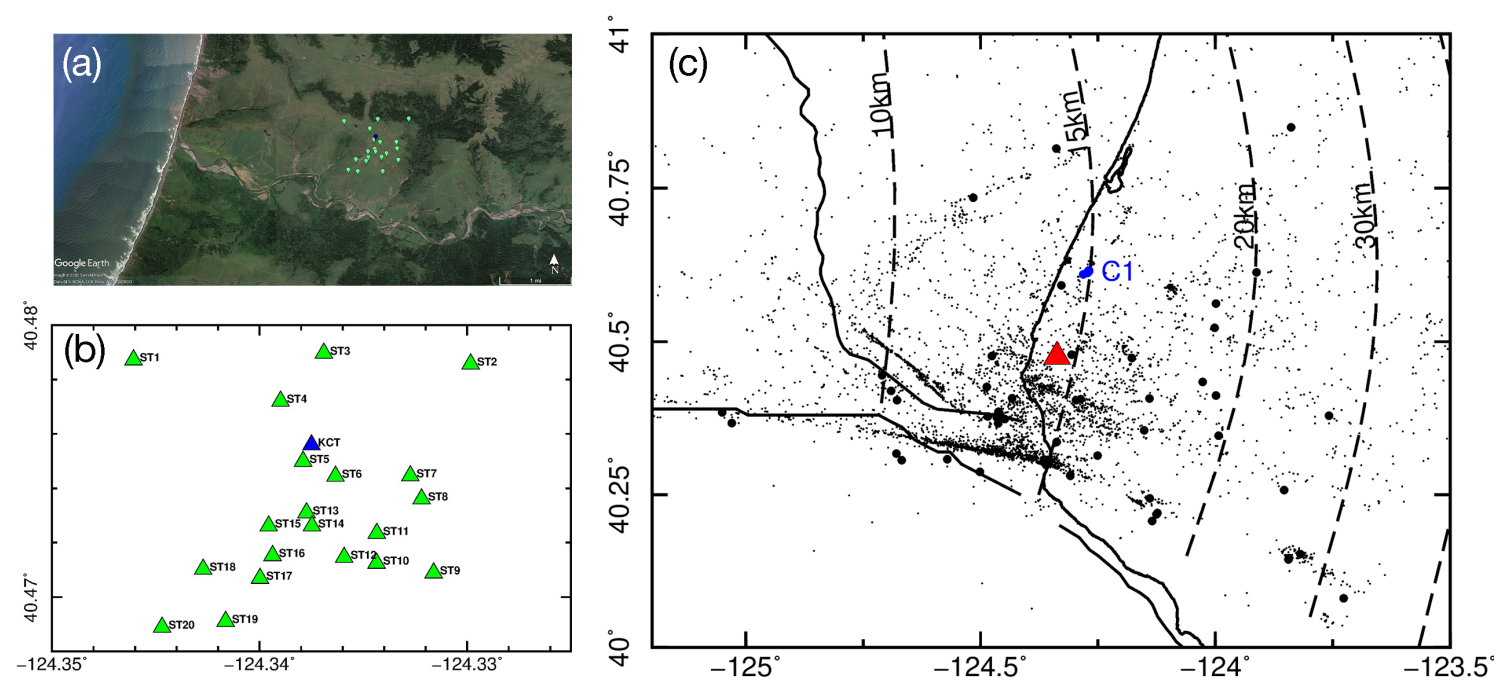

Figure 4-5: Nodal array experiment. (a) Nodal array location on a Google Earth map. The blue marker is station KCT from Northern California Seismic Network. The green markers are the nodes. (b) Zoom in of the nodal array. (c) Seismicity distribution. Small and large black dots are earthquakes that happened during the Cascadia Initiative experiment and the nodal array experiment respectively. The big blue circle is the location of cluster $\mathrm{C} 1$.

The difference in the moveout between $\mathrm{P} 1$ and P2, S1 and S2 indicates they propagate with different apparent slowness across the array. In the next section, we will use array analysis method to study the propagation velocity and direction of the different parts of $\mathrm{P}$ and $\mathrm{S}$ waves.

\subsection{Array analysis}

\subsubsection{Method}

For the conventional $2 \mathrm{D}$ beamformer, the power output for a slowness vector $\mathbf{s}_{\mathbf{k}}$ at single frequency $f_{j}$ is given as

$$
P_{j}\left(\mathbf{s}_{\mathbf{k}}\right)=\mathbf{v}_{\mathbf{k}}^{\dagger} \mathbb{C}\left(f_{j}\right) \mathbf{v}_{\mathbf{k}}
$$

where $\mathbb{C}\left(f_{j}\right)$ is the cross-spectral matrix, $\mathbf{v}_{\mathbf{k}}$ is the steering vector and $\dagger$ is conjugate transpose. The cross-spectral matrix $\mathbb{C}\left(f_{j}\right)$ is given as

$$
\mathbb{C}\left(f_{j}\right)=\mathbf{F}_{\mathbf{j}} \mathbf{F}_{\mathbf{j}}^{\dagger},
$$



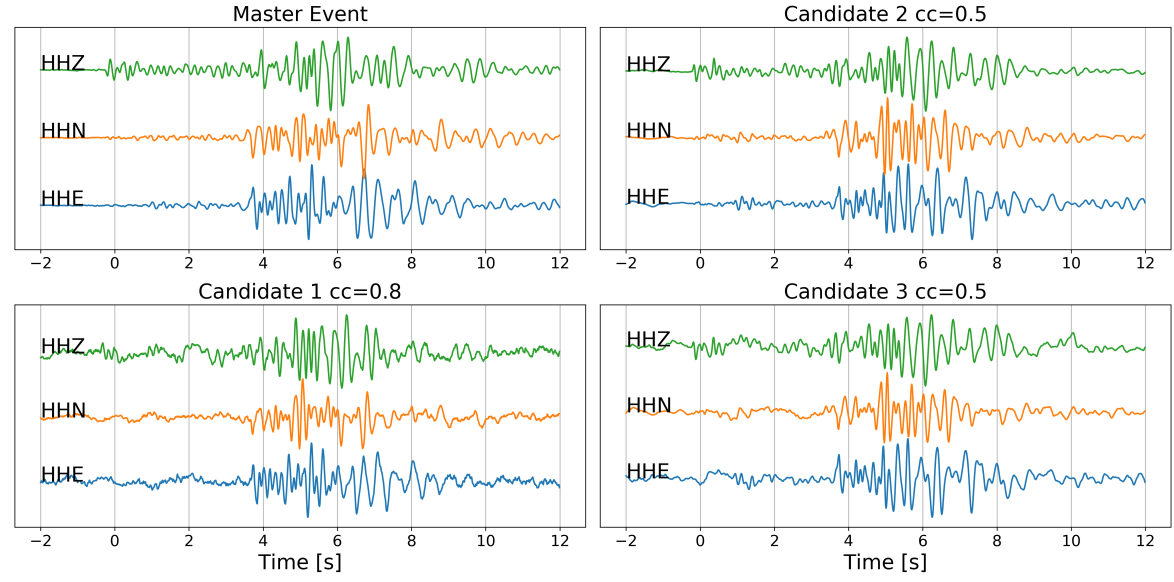

Figure 4-6: Candidate events detected by the match filter method. One event from the CI experiment is used as master event. Three candidate events are detected with the highest correlation coefficients.

where $\mathbf{F}_{\mathbf{j}}$ denotes the vector of the Fourier transform of waveforms at all the stations for frequency $f_{j}$,

$$
\mathbf{F}_{\mathbf{j}}=\left[\begin{array}{c}
\mathcal{F}_{1}\left(f_{j}\right) \\
\ldots \\
\mathcal{F}_{N}\left(f_{j}\right)
\end{array}\right],
$$

where $N$ is the number of stations, $\mathcal{F}_{i}\left(f_{j}\right)$ is the Fourier transform of waveforms at station $i$ for frequency $f_{j}$. The steering vector $\mathbf{v}_{\mathbf{k}}$ is given as

$$
\mathbf{v}_{k}=\left[\begin{array}{c}
e^{-i 2 \pi f_{j} \mathbf{s}_{\mathbf{k}} \cdot \mathbf{r}_{1}} \\
\cdots \\
e^{-i 2 \pi f_{j} \mathbf{s}_{k} \cdot \mathbf{r}_{N}}
\end{array}\right]
$$

and $\mathbf{r}_{i}$ is the location of the $i$ th station.

The absolute power output is the stacking of several single frequency beam powers

$$
P^{\mathrm{abs}}\left(\mathbf{s}_{\mathbf{k}}\right)=\sum_{j} P_{j}\left(\mathbf{s}_{\mathbf{k}}\right)
$$



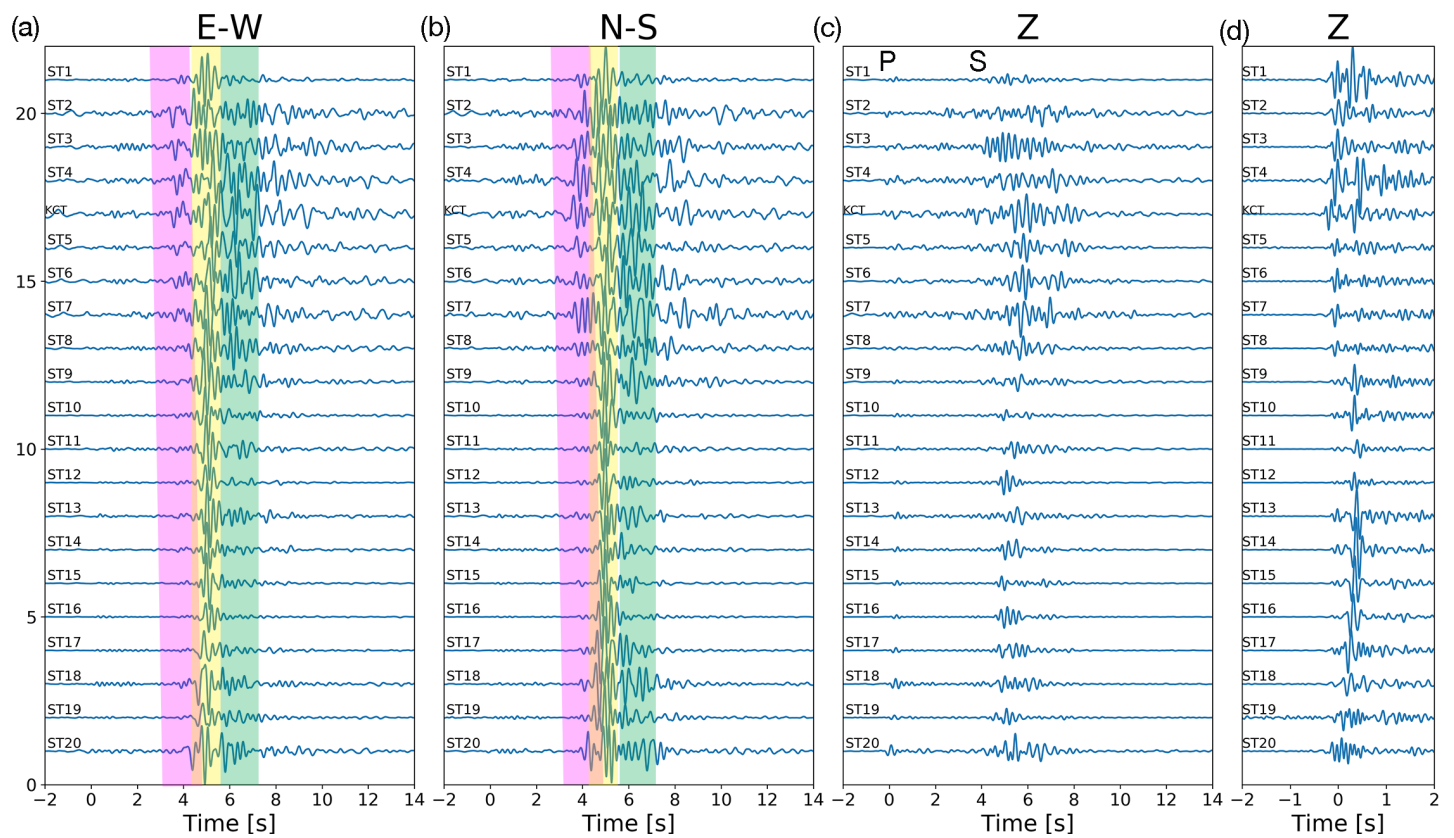

Figure 4-7: 3 component waveforms of Candidate 2 on nodal array and station KCT. The waveforms are filtered between 1 and $5 \mathrm{~Hz}$ for the first 3 panels and are filtered between 4 and $12 \mathrm{~Hz}$ for the last panel. The magenta, yellow and the green shade areas on the N-S and $\mathrm{E}-\mathrm{W}$ components represent the three different parts of the $\mathrm{S}$ wave.

The relative power is given as

$$
P^{\mathrm{rel}}\left(\mathbf{s}_{\mathbf{k}}\right)=\frac{\sum_{j} P_{j}\left(\mathbf{s}_{\mathbf{k}}\right)}{N \cdot N_{f} \cdot W}
$$

where $N_{f}$ is the number of frequency for the summation and $\mathrm{W}$ is a weighting factor which is defined as

$$
W=\sum_{\text {ele }}\left|\sum_{j} \mathbb{C}\left(f_{j}\right)\right|,
$$

where $\sum_{\text {ele }}$ represents the element-wise summation of matrix $\left|\sum_{j} \mathbb{C}\left(f_{j}\right)\right|$.

\subsubsection{Data processing}

We applied a running window $2 \mathrm{D}$ beamforming analysis to estimate the apparent slowness of the different parts of $\mathrm{P}$ and $\mathrm{S}$ waves. Because the stations are at different elevations, the elevations need to be corrected and the near surface $\mathrm{P}$ and $\mathrm{S}$ wave velocities are needed. We applied the 3D beamforming method described in the previous chapter and estimated 
the near surface velocity to be $1.3 \mathrm{~km} / \mathrm{s}$ and $0.7 \mathrm{~km} / \mathrm{s}$ for $\mathrm{P}$ and $\mathrm{S}$ waves (See Section B.3). We first shift the waveform by $\mathrm{dt}=\mathrm{h} / \mathrm{v}$, where $\mathrm{h}$ is the elevation and $\mathrm{v}$ is the near surface $\mathrm{P}$ or S wave velocity. A $1 \mathrm{~s}$ long window slides through the waveform with $0.1 \mathrm{~s}$ step length. Inside each window, a 0.22 percentage cosine taper is applied. For $\mathrm{P}$ waves, the waveforms are filtered between 1.5 and $8 \mathrm{~Hz}$, and for $\mathrm{S}$ waves, the waveforms are filtered between 1 and $5 \mathrm{~Hz}$. We calculate the absolute and relative beampower for each window and estimate the azimuth and apparent slowness by selecting the point with the maximum beampower.

\subsubsection{Results}

(a)

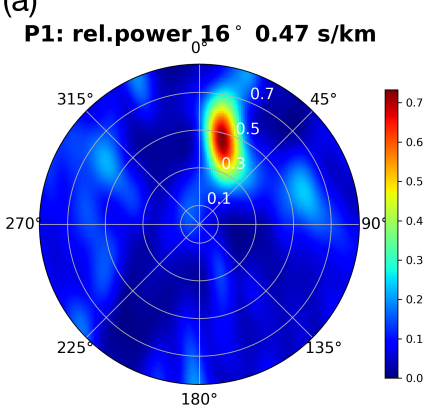

(b)

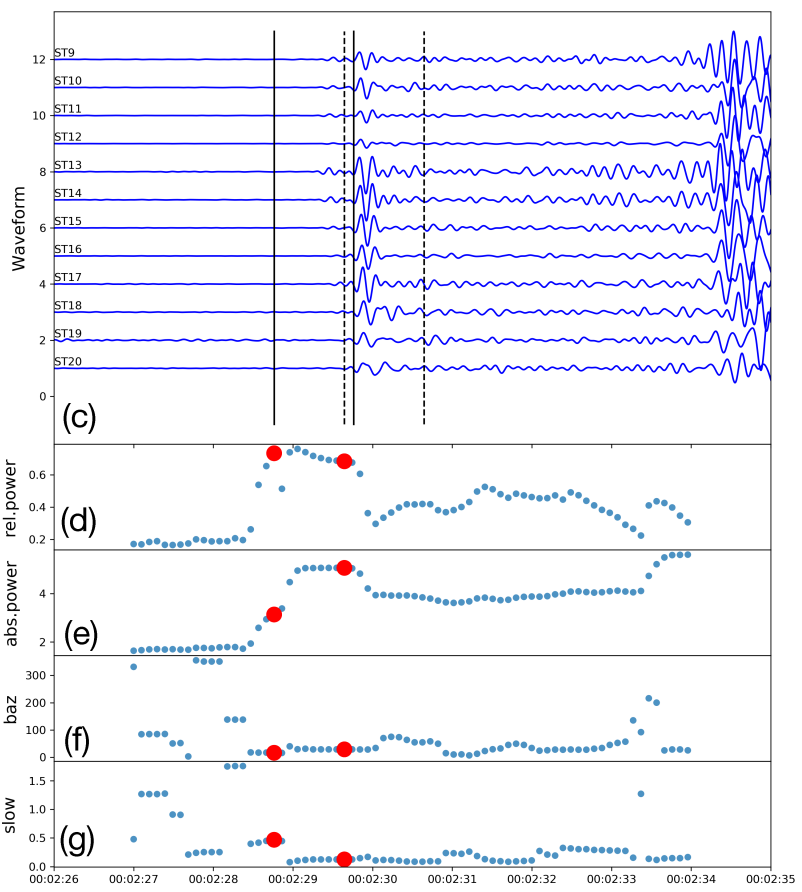

Figure 4-8: Running window beamforming results on $\mathrm{P}$ wave for cluster $\mathrm{C} 1$. (a) and (b) The relative power outputs for the two time windows shown in (c). Titles show the best estimates of the back azimuth and slowness. (c) Vertical component waveforms after elevation correction using near surface $\mathrm{P}$ wave velocity. The solid and dashed black lines represent the two windows for beamforming. (d)-(g) Relative power, absolute power, backazimuth and slowness estimates for the running window beamforming.

$\mathrm{P}$ wave beamforming results are shown in Fig. 4-8 for event candidate 2 . The beamforming results show that $\mathrm{P} 1$ passed through the array from the back azimuth of $16^{\circ}$ and had a horizontal slowness of $0.47 \mathrm{~s} / \mathrm{km}$, while P2 passed through the array from the back azimuth of $28^{\circ}$ and had a horizontal slowness of $0.13 \mathrm{~s} / \mathrm{km}$. Therefore, P1 and P2 are likely coming 


\section{(a)}

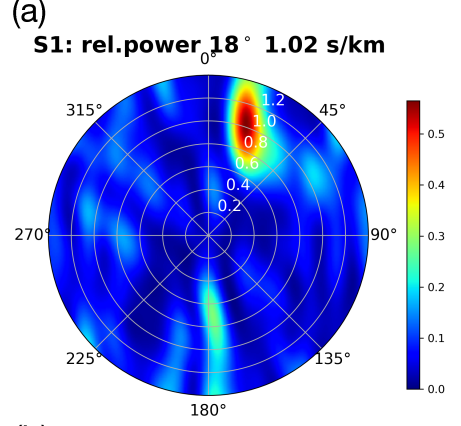

(b)
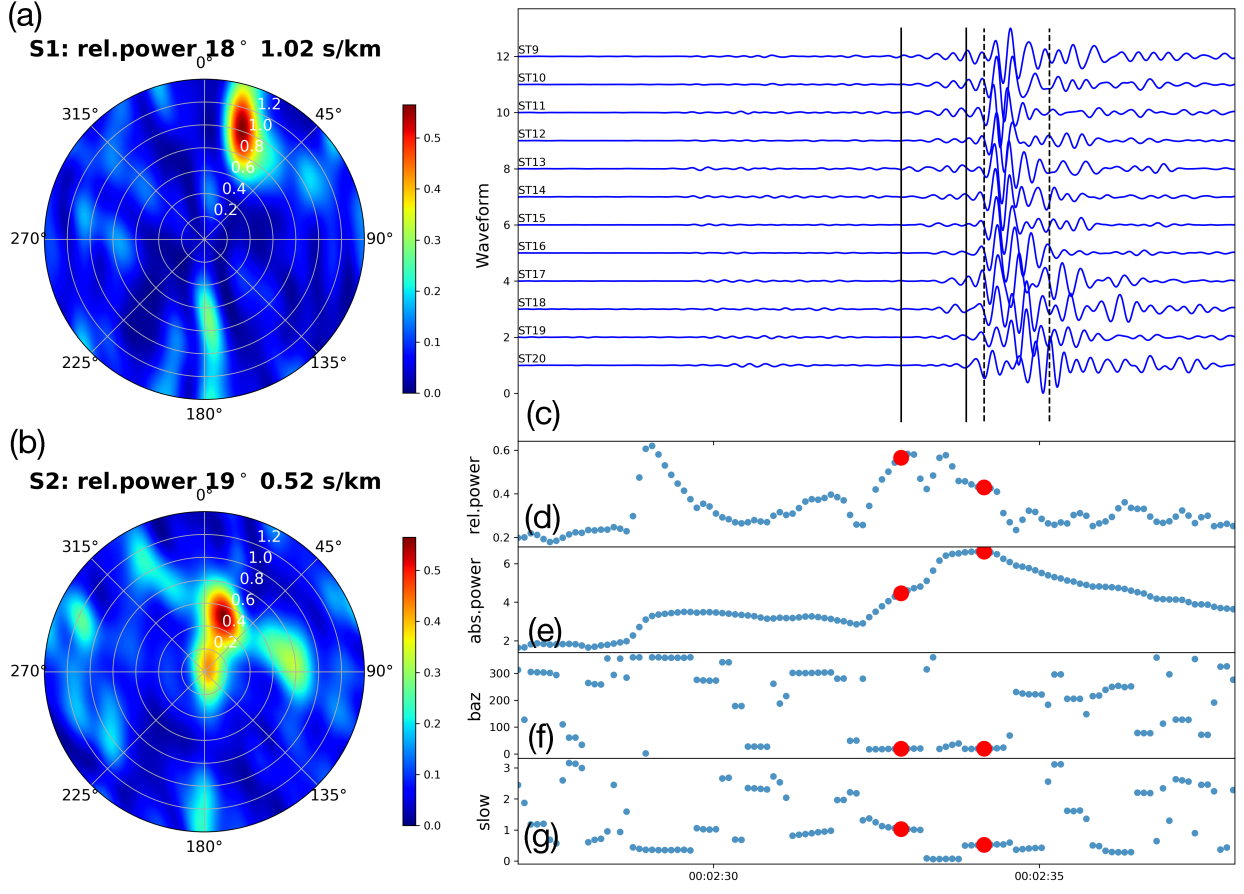

Figure 4-9: Running window beamforming results on $\mathrm{S}$ wave for cluster $\mathrm{C} 1$. (a) and (b) The relative power outputs for the two time windows shown in (c). Titles show the best estimates of the back azimuth and slowness. (c) North-south component waveforms after elevation correction using near surface $\mathrm{S}$ wave velocity. The solid and dashed black lines represent the two windows for beamforming. (d)-(g) Relative power, absolute power, backazimuth and slowness estimates for the running window beamforming.

from similar directions but P2 has steeper incident angle than P1.

A similar phenomenon can be seen for S wave (Fig. 4-9). The beamforming results show that S1 passed through the array from the back azimuth of $18^{\circ}$ and had a horizontal slowness about $1 \mathrm{~s} / \mathrm{km}$, while S2 passed through the array from the back azimuth of $19^{\circ}$ and had a horizontal slowness of $0.52 \mathrm{~s} / \mathrm{km}$. S1 and S2 are likely coming from similar directions but S2 has steeper incident angle than S1.

The double $\mathrm{P}$ and double $\mathrm{S}$ phases could be seen from several events located north of station KCT, but from none of the events located south of KCT (Fig. 4-10). Waveform sections of $\mathrm{P}$ and $\mathrm{S}$ waves for these events shown in Fig. B-8, B-9 and B-10. Event 9, 24 and 32 show clear double $\mathrm{P}$ and double S phases. Event 15 has weak double P and double S phases. Event 19 has double P phases but not clear double S phases. Event 26, 73 and 23 don't have obvious double $\mathrm{P}$ or S phases. Waveforms of one of the events south of station KCT (event 84) are shown in Fig. B-11. No double $\mathrm{P}$ or double $\mathrm{S}$ phases could be seen 


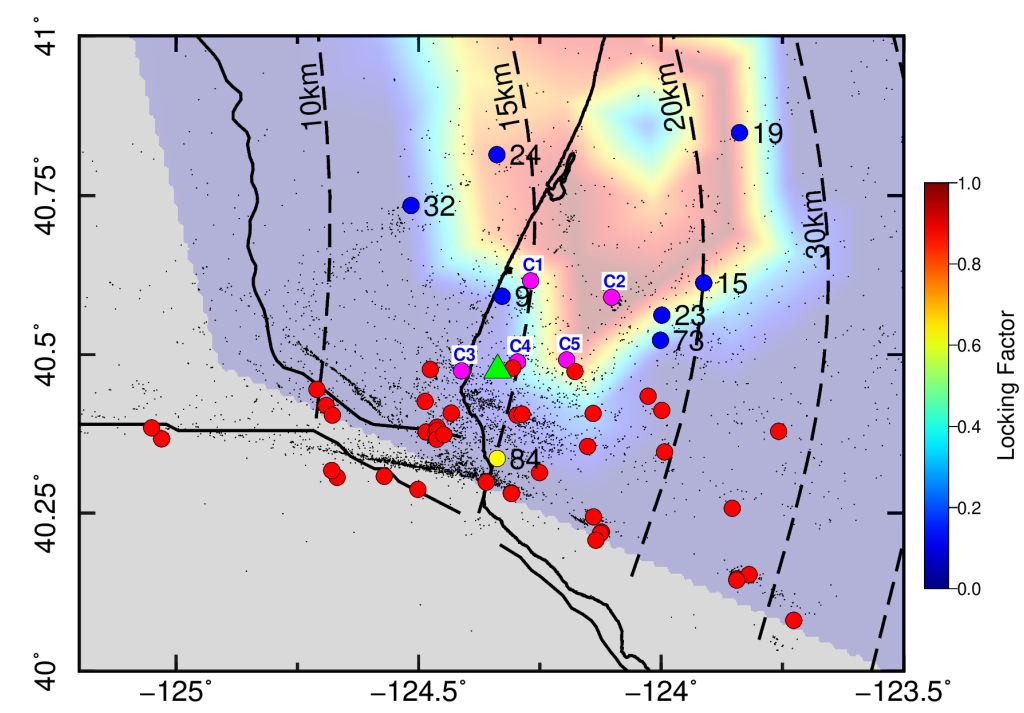

Figure 4-10: Events that show double $\mathrm{P}$ and double S arrivals (large blue circles) and those that do not show clear double $\mathrm{P}$ or $\mathrm{S}$ arrivals (large red circles). Large magenta circles denote the location of the 5 near slab-interface clusters. The green triangle is station KCT. The big yellow dot is event 84 whose waveforms on the nodal array stations are shown in Fig. B-11. Background colors denote the plate locking model from Pollitz and Evans (2017). Small black dots are background seismicity.

from this event. We applied the same 2D beamforming analysis on the events from the north and the results are summarized in Table B.3. Two different subsets of stations are used for the beamforming analysis, one using 12 stations from ST9 to ST20 and one using 16 stations from ST5 to ST20. Although for a given phase, the slowness values vary from event to event and the slowness estimates on the two horizontal components are not the same for the same event, the slowness of $\mathrm{P} 1(\mathrm{~S} 1)$ is generally larger than $\mathrm{P} 2(\mathrm{~S} 2)$ for all these events, which indicates P1(S1) has larger incidence angle than P2(S2). Another feature of the double $\mathrm{P}$ and $\mathrm{S}$ phases is the difference in the relative amplitude between P1(S1) and P2(S2) for stations on the upper hill compared to those located further downhill. On the upper hill stations (ST1-ST8), P1(S1) and P2(S2) have similar amplitude while at downhill stations (ST9-ST20), P2(S2) has a much larger amplitude than P1(S1). This can be seen for events 9, 24, 32, 15 and likely 23. It also makes the coda part of $\mathrm{S}$ wave looks strong on upper hill stations due to the apparently small amplitude S2. The reason for the difference between upper and lower hill stations are unclear.

The coda part of the $\mathrm{S}$ wave are not coherent across the array (Fig. 4-9 and B-7). We tried to beamforming the coda using a variety of station subsets, frequency ranges, instrument responses and observation channels. 2D beamforming analysis did not yield a 
focused beam to identify the direction and slowness of the coda wave. This may be due to the frequency response of the nodes which has a rapid falloff below $6 \mathrm{~Hz}$ and the dominant frequency of the coda wave at $\mathrm{KCT}$ is $3 \mathrm{~Hz}$. It may also result from the coda wave being a split-shear wave with circular particle motion (Fig. B-3). The coda waves may also have a significant contribution from near surface scattering beneath the receivers. However, this would not explain the difference in $\mathrm{KCT}$ waveforms between the near-interface clusters and the earthquakes located a few km deeper which share very similar ray paths (Fig. 4-2 and $4-3)$.

\subsection{Summary}

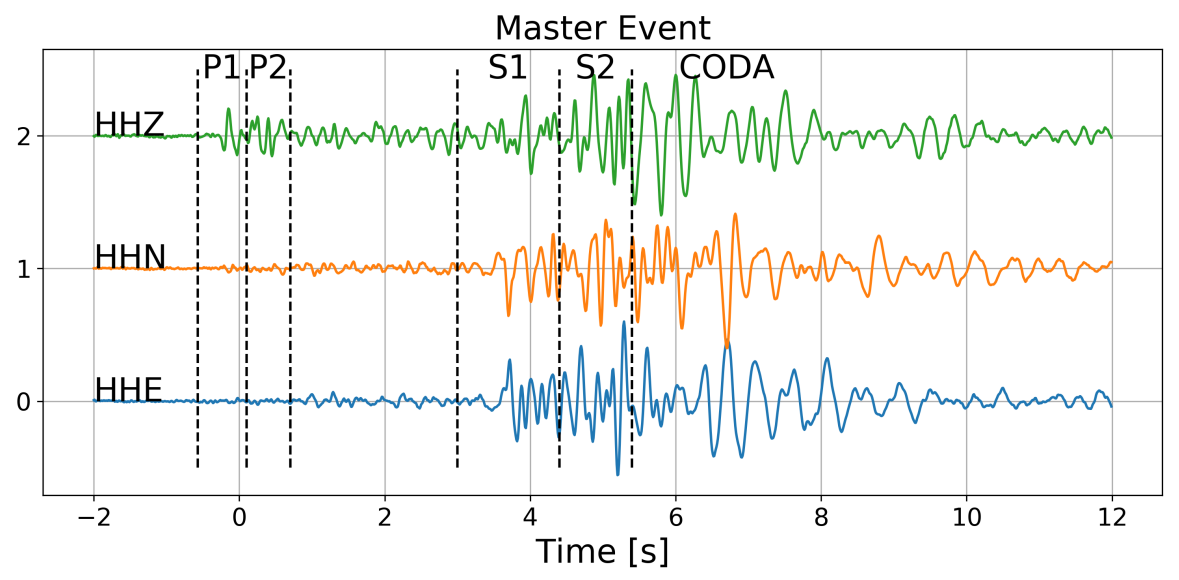

Figure 4-11: Partition of $\mathrm{P}$ and $\mathrm{S}$ waves on the master event.

We observed long duration $\mathrm{S}$ wave from 5 slab interface clusters on several stations from the CI experiment. Such long duration S waves are not produced by earthquakes just a few kilometers below each cluster in the lower crust or mantle of the downgoing plate. This contrasts indicate that the extended S-wave energy reflects complex velocity anomalies near the slab interface. We deployed a dense nodal array near station KCT to capture earthquakes from the location of cluster $\mathrm{C} 1$ in order to study the origin of the long $\mathrm{S}$ waves. 3 candidate events from or near cluster $\mathrm{C} 1$ were recorded during the two-month deployment of the nodal array. We applied the $2 \mathrm{D}$ beamforming method on $\mathrm{P}$ and $\mathrm{S}$ waves of event candidate 2 which has the highest SNR. 2D beamforming shows that $\mathrm{P}$ wave could be separate into 2 parts with different apparent slowness that we refer to as P1 and P2 and S wave could be separate into 3 parts that we refer to as S1, S2 and S coda (Fig. 4-11). P1's apparent slowness is 
larger than P2 and S1's apparent slowness is larger than S2. Therefore, P1(S1) has smaller incident angle than P2(S2). We infer that P1 and S1 share the same mechanism while P2 and S2 share the same mechanism.

The double $\mathrm{P}$ or double $\mathrm{S}$ arrivals can only be seen from events north of the nodal array and not from events south of the array (Fig. 4-10). Raypaths of P2 and S2 are closer to verticle than $\mathrm{P} 1$ and $\mathrm{S} 1$. This indicates the existence of strong along strike velocity variations in the subducted slab and/or the overriding plate. Comparing with the locking model from Pollitz and Evans (2017) (Fig. 4-10), the events with double P or double S arrivals are mostly in or on the edge of the strong locking area. We infer that there might be velocity anomalies associated with the plate interface or the subducted crust near the strong locking area and such velocity anomalies might cause the multipathing effects of $\mathrm{P}$ and $\mathrm{S}$ waves.

For the $\mathrm{S}$ coda wave, events from cluster $\mathrm{C} 1$ and $\mathrm{C} 2$ tend to generate large amplitude codas, especially at station KCT, while events from cluster $\mathrm{C} 4$ and $\mathrm{C} 5$ didn't generate obvious large amplitude coda. We infer that the $\mathrm{S}$ coda wave generated from events in cluster $\mathrm{C} 1$ and $\mathrm{C} 2$ are related to the velocity anomalies of the plate interface in the locking area. It is likely that a thin low velocity layer might exist near the plate interface in the strong locking area that resembles the a few hundred meter thick low velocity fault core on the shallow parts of continental strike slip faults. The large amplitude S coda waves are similar to the guided/trapped waves that are often observed near the continental strike slip faults.

Guided wave amplitude decays exponentially away from the low velocity layer. It is nominally hard to observe guided waves in far distance. However, guideds waves propagating along the subducted oceanic crust are often seen by surface stations in the forearc. Two major mechanisms have been proposed in literatures: bending of the slab at the shallow depth (Martin et al., 2003) and the equalization of velocity between the oceanic crust and overlaying material (Shiina et al., 2014). These two mechanisms will cause the guided waves to leak out and to be observed by surface stations. For our situation, a large topographic anomaly of the subducted slab is unlikely due to the short epicenter distances between the earthquake clusters and the station $(\sim 20 \mathrm{~km})$, and such topographic features don't exist in both Slab 1.0 and Slab 2.0 models (McCrory et al., 2012; Hayes et al., 2018). It is more likely that a low velocity layer exists near the source region of the slab interface clusters (C1 and $\mathrm{C} 2$ ). This low velocity layer either only extends halfway between the earthquake 
clusters and station $\mathrm{KCT}$ or there is low velocity anomalies in the overriding continental crust that equals the velocity in the low velocity layer and results in the scattering the guided wave phases out of the low velocity layer. We favor the former explanation because no low velocity anomalies exists in the overriding continental crust from the tomographic models (Guo et al., 2019). Since the locations of clusters C1 and C2 are inside the locked zone, we infer that a low velocity layer exists at the plate boundary in the locked zone.

In the next chapter, we will construct simple seismic velocity models of the subducting slab and use numerical wave propagation simulations to investigate possible velocity structures of the subducted crust and plate boundary fault that could result in the double $\mathrm{P}$, double $\mathrm{S}$ and large amplitude coda waves. We will also investigate the effects of along strike velocity variations on wave propagation for near slab-interface earthquakes. These simulations will give first order explanations for the generation of the double $\mathrm{P}$, double $\mathrm{S}$ and large amplitude coda waves. 


\section{Chapter 5}

\section{Numerical Simulations of Guided Waves from Earthquakes Located near the Slab Interface}

\subsection{Introduction}

The subduction plate boundary is not a single, planar, discrete interface or a thick homogeneous layer but instead is a volume mixture of materials with diverse physical properties (Fagereng and Sibson, 2010). In active source seismic images, the plate boundary is contained within a hundred meter to kilometer thick layer with a relatively sharp velocity contrast on top and bottom and it is inferred that the layer is comprised of subducted sediments in between the downgoing oceanic crust and the base of the upper plate (Nedimović et al., 2003; Li et al., 2015). Geologists and physical modelers of subduction zones consider the plate boundary along active megathrusts as a specific type of shear zone that contains highly sheared, fluid-saturated trench-fill sediments intermingled with fragments of oceanic crust (Fagereng and Sibson, 2010; Vannucchi et al., 2012). The materials, fluid content and geometry of this shear zone are important characteristics that affect subduction zone geodynamics. In contrast to outcrop studies, seismic images of the layer containing the plate boundary are very low resolution at seismogenic depths often imaging a layer of low seismic velocities or elevated $\mathrm{Vp} / \mathrm{Vs}$ ratios that is many $\mathrm{km}$ wide (Nedimović et al., 2003; Li et al., 2015). Translating the knowledge gained from studies of exhumed subuction zones 
and rock mechanics experiments into improved modelling of megathrust earthquakes and the associated hazards will require more detailed images of active plate boundary zones.

Subduction-related mélange shear zones exposed on the Earth's surface are inferred as the exhumed rock assemblages of the shear zone along the previous active subduction plate boundary (Silver and Beutner, 1980; Kimura et al., 2012b). They provide direct insights into fault mechanics and its relationship to subduction zone earthquakes (Kimura et al., 2012b). Such mélange shear zones have been identified at several places on Earth. Locations thought to represent plate boundary zone at seismogenic depths include: the Shimanto accretionary complex (Kimura and Mukai, 1991), Franciscan Complex (Wakabayashi, 2011), Kodiak Island (Rowe et al., 2005), the Chrystalls Beach Complex (Fagereng, 2011) and the Northern Apennines (Remitti et al., 2007). These mélange shear zones are mixtures of materials with very different viscosity. The materials with higher viscosity are referred to as competent component, such as chert, sandstone and metabasalt, and the materials with lower viscosity are referred to as incompetent materials (Fagereng and Sibson, 2010), such as mudstone. These mélange shear zones are typically a few $\mathrm{km}$ wide, but the active deformation part that host earthquake ruptures is only $\sim 100-350 \mathrm{~m}$ thick within the mélange shear zones (Rowe et al., 2013).

The rheology of the plate boundary shear zone depends critically on the ratio of the competent and incompetent components (Fagereng and Sibson, 2010). Subduction plate boundary fault can accommodate deformation with strain rates that span several orders of magnitude. Earthquake displacements occur at $\mathrm{m} / \mathrm{s}$. Transient slips, such as afterslip and slow slip, occur at $\mathrm{cm} /$ day and the plate convergent rate is $\mathrm{cm} /$ year. Records of mixed continuous-discontinuous deformations can be found in the mélange shear zones. The discontinuous type of deformations which concentrate near lithology boundaries, are interpreted as slips from earthquakes. While continuous type of deformations, which are distributed in the block matrix, are interpreted as afterslip and plate convergent (Fagereng and Sibson, 2010; Rowe et al., 2011; Kimura et al., 2012b). Therefore, it is important to consider the plate boundary as volumetric shear zone and investigate how this will affect the stress distribution, rupture nucleation and rupture propagation in subduction zones (Fagereng and Sibson, 2010).

The distribution of fluid overpressure distribution within the subduction plate boundary shear zone is another critical factor controlling rheology (Sibson, 1996). Fluids enter sub- 
duction zones on the incoming plate as pore water in the sediments and igneous crust or bound water within hydrous minerals (Saffer and Tobin, 2011). Pore fluid is mostly released by dewatering due to burial and lateral tectonic loading at the first $\sim 3-7 \mathrm{~km}$ depths (Bray and Karig, 1985; Bekins and Dreiss, 1992). It causes overpressure at the subduction zone plate boundary (Ranero et al., 2008), promotes shallow slow slip events and tremor (Kodaira et al., 2004), and facilitates megathrust earthquake propagation to the trench (Kimura et al., 2012a). Bound water is released by mineral dehydration and this process is sensitive to temperature and pressure conditions. At the updip of the seismogenic zone, near $100^{\circ} \mathrm{C}$, smectite to illite transformation is inferred to be the largest dehydration-driven fluid source (Bethke, 1986; Meunier, 2005) and likely contributes to overpressure development (Bekins et al., 1994; Spinelli and Saffer, 2004). At the downdip of the seismogenic zone, mineral dehydration induced near lithostatic pore pressure is used to explain the episodic slow slip and tremor (ETS) (Liu and Rice, 2007).

Within the seismogenic zone, various observations indicate high pore pressure exists in the vicinity of the subduction plate boundary. Extensional veining observed in exhumed subduction mélanges from seismogenic depths manifests elevated or extremely high pore pressure inside the fault zone. These crack-seal veins also represent repeated hydraulic fracturing and precipitation events (Meneghini and Moore, 2007; Fisher et al., 1995). Stress inversions from focal mechanism solutions of earthquakes near subduction plate boundary shows that the plate boundary fault is operating at low shear stress which requires a high pore pressure of near $60 \%$ or more of lithostatic stress inside the plate boundary fault (Magee and Zoback, 1993; Hardebeck, 2015; Li et al., 2018a). Geodynamic modeling of the accretionary wedge geometry and forearc mountain building also indicates that the seismogenic portion of the plate boundary is weak because of low friction coefficients and high fluid overpressures (Lamb, 2006; Seno, 2009). Heat flow measurements taken from several subduction zones also indicate that shear stress can only peak as high as $\sim 70 \mathrm{MPa}$ in the $20-30 \mathrm{~km}$ depth range due to a combination of low friction coefficients and high pore pressure of the plate boundary fault (Gao and Wang, 2014). These observations demonstrate that the seismogenic zone is likely to be significantly overpressured even if not to the extreme levels indicated in the SSE zone further downdip (Saffer and Tobin, 2011).

Interseismic locking on the plate interface is an important parameter for forecasts of earthquake hazards along subduction zones (Loveless and Meade, 2010; Feng et al., 2012; 
Petersen et al., 2020). However, the physical mechanisms that control the degree of locking and the reasons causing the along strike variations in locking are not well understood (Bilek and Lay, 1999; Lay et al., 2012; Wang and Bilek, 2014; Wang and Tréhu, 2016). Sediment thickness has been considered as an important factor controlling the locking conditions on the slab interface. However, two likely contradictory theories exist on how sediment thickness can affect plate locking. One theory states that a thick layer will lead to more uniform coupling along the megathrust as it covers the igneous ocean crust roughness resulting in a relatively smooth, homogeneous décollement at the top of the underthrust section that can support high shear stress during interseismic locking (Ruff, 1989; Wang and Bilek, 2014; Wang and Tréhu, 2016; Li et al., 2018b; Bangs et al., 2020). While the other theory states that when little sediment is subducted, the relatively strong oceanic crust will be in direct contact with the relative strong forearc crust, resulting in stronger locking (Han et al., 2017; Liu and Zhao, 2018). Using multichannel seismic data collected along the Cascadia subduction zone, Han et al. (2017) found differences in the consolidation state of the incoming sediment near the deformation front for subduction segments with different locking conditions. Offshore Washington where the megathrust is inferred to be strongly locked, the sediments near the deformation front are over-consolidated and are incorporated into a strong outer wedge, with little sediment subducted. In contrast, offshore Central Oregon where reduced locking is inferred (McCaffrey et al., 2013; Schmalzle et al., 2014), a thick under-consolidated sediment sequence is subducting.

Similar studies offshore of the Alaska peninsula found an opposite correlation. Li et al. (2018b) found that, in the Semidi segment where interseismic locking is strong, the plate boundary is contained within a thicker layer of high-porosity sediments with lower effective stress. In contrast, in the Shumagin Gap, where interseismic locking is weak, they found thinner sediments and higher effective stress. The contrast between the Cascadia and Alaska results indicates that the pore pressure state inside the incoming sediment layer at very shallow depths $(<10 \mathrm{~km})$ does not uniquely determine the locking conditions of the subduction slab at seismogenic depths $(\sim 10-30 \mathrm{~km})$. It is difficult to extrapolate the conditions of the plate boundary fault from activate source images near the trench to the seismogenic zone tens of $\mathrm{km}$ deeper where strong the ground motion that causes seismic hazard is generated.

The seismogenic part of the megathrust usually locates in the temperature range $\sim 150-300^{\circ} \mathrm{C}$ (Oleskevich et al., 1999). But in this temperature range, fluid released by dehydration reac- 
tions is not well characterized because reaction kinetics for low-grade metamorphic minerals are not well known (Underwood et al., 1993). We still have incomplete state of knowledge about the sediment dehydration processes and the relationship between pore pressure and modes of fault slip at seismogenic depths (Saffer and Tobin, 2011). More direct observations of properties of the plate boundary fault at the seismogenic depth are needed to investigate how material composition, pore pressure and stress state within the plate boundary fault interplay with each other and how that affects locking conditions of the slab.

Various geophysical observations have indicated structural control on the megathrust earthquakes (Wells et al., 2003). First, geologic structure of the overriding plate can affect where megathrust earthquakes occur. Bassett et al. (2016) used residual topography and gravity anomalies to constrain the geological structure of the overthrusting (upper) plate offshore northeast Japan and found that the rupture area of the 2011 Tohuko-Oki earthquake had higher density compared to the area to the south, indicating that the structure and frictional properties of the overthrusting plate control megathrust coupling and seismogenic behavior in northeast Japan. Liu and Zhao (2018) used traveltime tomography to image the Tohoku forearc and found the 2011 Tohuko-Oki earthquake nucleated in an area with high seismic velocity, low seismic attenuation, and strong seismic coupling. Strong coseismic high-frequency radiation also occurred in high-velocity patches, whereas large afterslip took place in low-velocity areas. These structural heterogeneities in and around the Tohoku megathrust originate from both the overriding and subducting plates, which influenced the nucleation and rupture processes of the 2011 Tohoku-Oki earthquake.

In Cascadia, the plate boundary fault zone at seismogenic depths has strong along strike variations. In Northern Cascadia, Nedimović et al. (2003) found that the plate boundary zone is characterized as a thin $(<2 \mathrm{~km})$ high reflectivity zone at the depth of peak interseismic locking $(<15 \mathrm{~km})$ offshore Vancouver Island. However, offshore Washington, Preston et al. (2003) found no clear reflection phases from the subduction plate boundary fault but clear reflection signals from the subducted oceanic Moho. Using a continuous onshore-offshore broadband seismic arrays in Washington, Audet and Schaeffer (2018) imaged the slab with the receiver function method and found that a low velocity layer exists on top of the crust in the slow slip region but does not extend into the locked zone offshore. However, Janiszewski and Abers (2015) applied the receiver function method to the same dataset and found such low velocity likely extends into the locked zone at least beneath one station. In southern 
Cascadia, Beaudoin et al. $(1994,1998)$ imaged the subducted Gorda plate as intermittent high reflection patches, but found no evidence of a low velocity zone coincident with the top of the subducted plate. Their studies were in a region where a highly locked patch extends onshore to depths of $20 \mathrm{~km}$ or more along the interface. The variations bwtween these imaging results may reflect heterogeneities of the Cascadia megathrust that relate to the interseismic locking variations. However, Cascadia is uniformly seismically quiet and capable of M9 ruptures that span its entire length suggesting a somewhat uniform seismogenic zone. Thus, the variations between studies may also indicate the difficulty of imaging the plate boundary structure at 15-30 km depth where slip in great earthquakes may do the most damage onshore. This translates directly into uncertain seismic hazard estimates. The high frequency dominated strong ground motion in Cascadia earthquakes will likely be generated by asperities near the down dip edge of the seismogenic zone but we do not yet know where these will be located (Frankel et al., 2018; Wirth et al., 2018).

In the previous chapter we observed long duration $\mathrm{S}$ waves from seismic events that occur near the slab interface in southern Cascadia and especially for the few repeating events inside the region with the strongest interseismic locking of the subducted Gorda plate. Beamforming analysis demonstrated that the long duration $\mathrm{S}$ waves contain at least two body waves with different ray parameters in the earlier part of the $\mathrm{S}$ wave and a large amplitude coda phase in the later part. Since the double body phases arrivals and the coda phase don't typically show on events much deeper or shallower than the slab interface, we infer that their generation derives from velocity anomalies near the source. In this chapter, we construct simple layered velocity models and perform 2D wave propagation simulations using these models to investigate the possible near source velocity anomalies that can cause the $\mathrm{S}$ wave characteristics seen at KCT. We then use these simulation results to infer a possible linkage between plate boundary velocity anomalies and interseismic locking conditions in our study area.

\subsection{Model setup}

We conduct 2D wave propagation simulations to investigate the origin of the long duration $\mathrm{S}$ waves seen at station KCT from earthquakes near the plate interface. Two seismic imaging results are available near station KCT and earthquake cluster C1 (Beaudoin et al., 1994; 
Guo et al., 2019). Beaudoin et al. (1994) imaged the subducted Gorda crust in our area with an onshore refraction line and concluded the top of the subducted plate is at approximately $14 \mathrm{~km}$ depth near the coast. They found that the subducted crust was characterized by P-wave velocities from 6.2 to $6.7 \mathrm{~km} / \mathrm{s}$ and is $7-10 \mathrm{~km}$ thick. They also found some possible evidence for subducted sediments near the top of the crust but concluded that no $\mathrm{P}$ wave low velocity zone was required to fit their data. Their preferred model generated reflections from a 6.0 to $6.7 \mathrm{~km} / \mathrm{s}$ discontinuity in $\mathrm{Vp}$ at the top of the crust as well as from a 6.7 to $7.7 \mathrm{~km} / \mathrm{s}$ discontinuity in $\mathrm{Vp}$ at the base of the subducted crust corresponding to $\sim 10-15 \%$ velocity increases. In Guo et al. (2019) (Fig. 4-2(b)), the subducted slab is imaged as a roughly flat, $\sim 6-8 \mathrm{~km}$ thick high $\mathrm{Vp} / \mathrm{Vs}$ layer in the along strike direction using the traveltime tomography method. Even though both $\mathrm{P}$ and $\mathrm{S}$ velocities are available, the velocity variation in their tomographic model is smooth and doesn't include sharp interfaces as in the Beaudoin et al. (1994) model. The Guo et al. (2019) model confirms the location of the subducted crust in Beaudoin et al. (1994), and identifies it as a high Vp/Vs layer, but it does not resolve the fine scale variations of S-wave velocity near the plate interface.

Based on these seismic imaging results, we consider two main structures that potentially contribute to the long duration $\mathrm{S}$ waves: the oceanic crust identified clearly in Beaudoin et al. (1994); Guo et al. (2019) and a thin low velocity layer near the plate interface that represents the plate boundary shear zone of subducted sediments. This sediment layer may or may not be present in our study area and we seek to determine whether the long duration S-waves are consistent with its presence. We construct three types of models (Fig. 5-1) that consist of only the crust (Model 1), only the low velocity layer (Model 2) and the combination of these two elements (Model 3). All three models are built on top of the 1D Vp and Vs structure from the Guo et al. (2019) tomography model. Model 1 has a $6 \mathrm{~km}$ thick oceanic crust between 15 and $21 \mathrm{~km}$ depth. The top and bottom of the oceanic crust are velocity discontinuities for both $\mathrm{P}$ and $\mathrm{S}$ waves. For the $\mathrm{P}$-wave they are both velocity increases that match the Beaudoin et al. (1994) model. For S waves, we test a series of models with different $\mathrm{Vp} / \mathrm{Vs}$ ratios inside the crust to span the range from no $\mathrm{Vs}$ anomaly up to a $\mathrm{Vp} / \mathrm{Vs}$ ratio of 2.5 which causes a strong S-wave LVZ. Model 2 contains no oceanic crustal layer but includes a $500 \mathrm{~m}$ thick low $\mathrm{S}$ wave velocity layer between $15 \mathrm{~km}$ and $15.5 \mathrm{~km}$ depth. The top and bottom of the LVZ are S-velocity discontinuities. The low $\mathrm{S}$ wave layer represents sediments with significant amounts of fluid filled porosity, and we test a series of models 
with different $\mathrm{Vp} / \mathrm{Vs}$ ratios which would result from varying values of porosity and effective normal stress (Christensen, 1996; Audet et al., 2009; Guo et al., 2019). Model 3 is a combination of Model 1 and Model 2 but with a laterally terminated LVZ. A $6 \mathrm{~km}$ thick oceanic crust is placed between 15 and $21 \mathrm{~km}$ depth. The top and bottom of the oceanic crust are velocity discontinuities for both $\mathrm{P}$ and $\mathrm{S}$ wave. A terminated LVZ is located on top of the crust between $14.5 \mathrm{~km}$ and $15 \mathrm{~km}$. The $\mathrm{Vp} / \mathrm{Vs}$ ratio of the crust is 1.8 . Inside the LVZ, we test a series of models with different $\mathrm{S}$ wave velocity reductions.
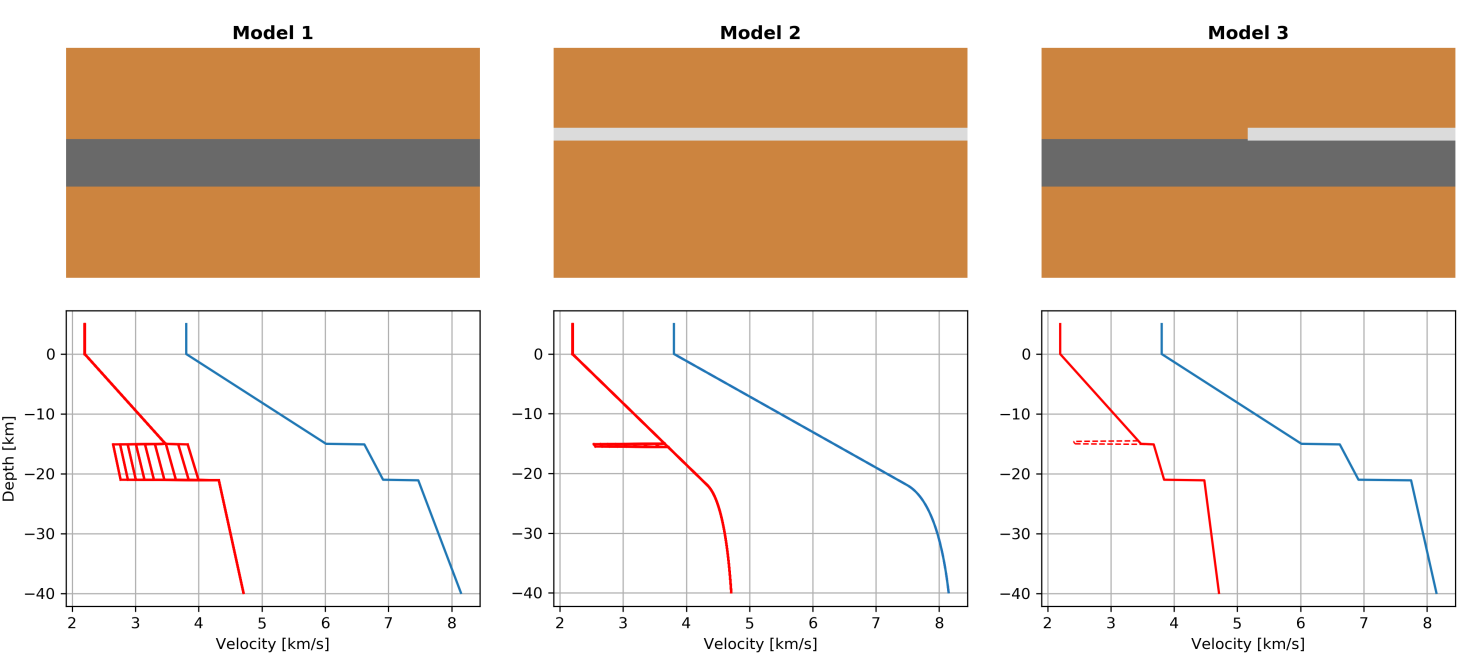

Figure 5-1: The 3 different 2D seismic models utilized in the synthetic waveform simulations. The top row show schematic 2D views of the three models. Colors represent different geologic units, overriding crust and subducted mantle (orange), subducted crust (gray) and subducted sediments (white). All 3 models are intended to represent an along-strike profile with the plate interface at about $15 \mathrm{~km}$ depth. The bottom row shows the range of the $1 \mathrm{D}$ velocity profiles used for each type of model. The blue and red lines denote the $\mathrm{P}$ and $\mathrm{S}$ wave velocities respectively. Model 1 has a $6 \mathrm{~km}$ subducted crust with velocity discontinuities at the top and bottom. There is no P-wave low velocity zone, but models with varying $\mathrm{Vp} / \mathrm{Vs}$ ratio are implemented as decreasing Vs within the crustal layer. Model 2 superimposes a thin, $500 \mathrm{~m}, \mathrm{LVZ}$ layer with varying low $\mathrm{S}$ wave velocities on top of a continuous $\mathrm{Vp} / \mathrm{Vs}$ gradient. Model 3 contains a subducted crustal layer with $\mathrm{Vp} / \mathrm{Vs}$ of 1.9 and a low-velocity, thin sediment layer above the crust in the right hand half of the domain.

We utilize the open source software package SPECFEM $2 D$ (Tromp et al., 2008) for the numerical simulation and the commercial software Trelis for generating the quadrature mesh. The computation domain is $95 \mathrm{~km}$ in length and $40 \mathrm{~km}$ in depth and the mesh size is $100 \mathrm{~m}$ with 4 nodes per element. For Model 1 , the source is placed at $\mathrm{x}=50 \mathrm{~km}, \mathrm{z}$ $=16 \mathrm{~km}$ and is a point force with an angle of $10^{\circ}$ counter-clockwise from the horizontal 
direction. The source time function (STF) is a Ricker wavelet with a central frequency of 5 $\mathrm{Hz}$. The receivers are located on the surface and spaced every $1 \mathrm{~km}$. For model 2, the source is placed at $\mathrm{x}=50 \mathrm{~km}, \mathrm{z}=15.25 \mathrm{~km}$ inside the LVZ and is a point force with an angle of $10^{\circ}$ relative to horizontal direction. The $\mathrm{STF}$ is a Ricker wavelet with a central frequency of $5 \mathrm{~Hz}$. The receivers are located both on the surface and inside the LVZ at $15.1 \mathrm{~km}$ depth spaced every $1 \mathrm{~km}$. For Model 3, the source is placed at $\mathrm{x}=60 \mathrm{~km}, \mathrm{z}=14.75 \mathrm{~km}, 10 \mathrm{~km}$ away from the left end of the thin LVZ. It is a point force with an angle of $10^{\circ}$. The STF is Heaviside function to achieve a broader source spectrum. The receivers are located on top of the surface for every $1 \mathrm{~km}$. A more detailed description of velocity parameters as well as source and receiver locations is listed in Table. 5.1.

\begin{tabular}{|c|c|c|c|c|}
\hline Model & $\begin{array}{l}\text { Source location } \\
{[\mathrm{km}], \text { type, angle }} \\
\text { and STF }\end{array}$ & Crust velocity & LVZ velocity & $\begin{array}{l}\text { Receiver } \\
\text { depth } \\
{[\mathrm{km}]}\end{array}$ \\
\hline 1 & $\begin{array}{l}\mathrm{x}=50, \mathrm{z}=16 \\
\text { point force, } 10^{\circ} \\
\text { ricker wavelet }\end{array}$ & $\begin{array}{l}\mathrm{Vp} / \mathrm{Vs}=1.73, \quad 1.8, \\
1.9,2.0,2.1,2.2, \\
2.3,2.4,2.5\end{array}$ & & 0 \\
\hline 2 & $\begin{array}{c}\mathrm{x}=50, \mathrm{z}=15.25 \\
\text { point force, } 10^{\circ} \\
\text { ricker wavelet }\end{array}$ & & $\begin{array}{l}\mathrm{Vp} / \mathrm{Vs}=1.73, \quad 1.8, \\
1.9,2.0,2.1,2.2, \\
2.3,2.4,2.5\end{array}$ & $0,15.1$ \\
\hline 3 & $\begin{array}{c}\mathrm{x}=60, \mathrm{z}=14.75 \\
\text { point force, } 10^{\circ} \\
\text { Heaviside function }\end{array}$ & $\mathrm{Vp} / \mathrm{Vs}=1.8$ & $\begin{array}{l}\text { Velocity reduction } \\
(\%)=10,20,30, \\
35,40,45,50\end{array}$ & 0 \\
\hline
\end{tabular}

Table 5.1: Parameters for wave propagation simulation.

\subsection{Simulation results}

\subsubsection{Model 1}

Simulation results for Model 1 with a $\mathrm{Vp} / \mathrm{Vs}=2.1$ in the subducted crust are shown in Fig. 52. $\mathrm{P}$ and $\mathrm{S}$ waves are easily identified both from the wave propagation snapshots and from the waveform sections. In Fig. 5-2(a), PmP and PmS are the Moho reflection phases that leave the source as $\mathrm{P}$ waves and in Fig. 5-2(b), $\mathrm{SmP}$ and $\mathrm{SmS}$ are the Moho reflection phases that leave the source as $\mathrm{S}$ waves. The pS phase leaves the source as a $\mathrm{P}$ wave and then converts to $\mathrm{S}$ wave at the top surface of the crust. These phases are also labeled on the 


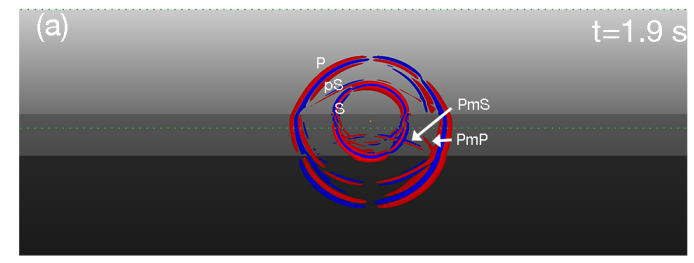

$\mathrm{BXX}$

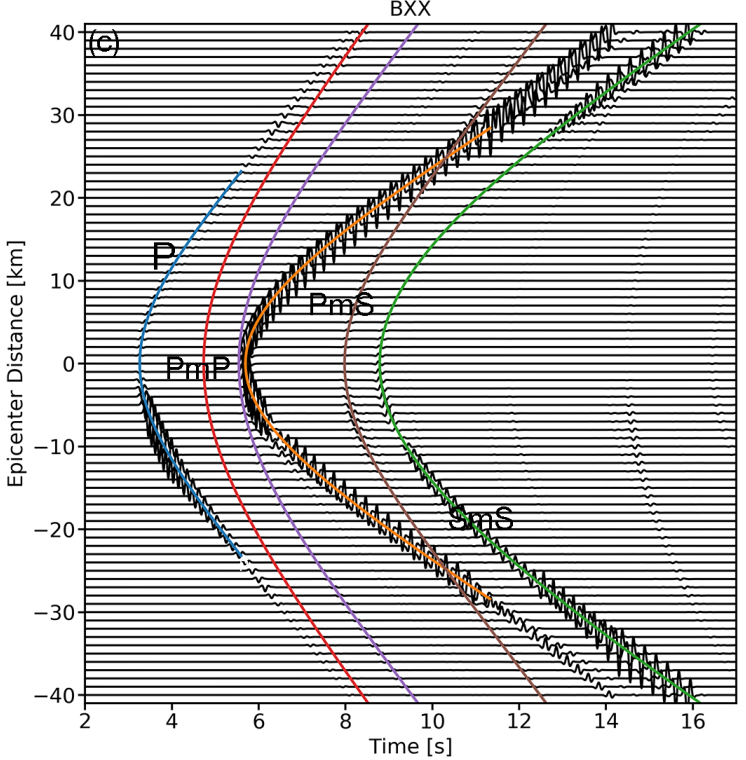

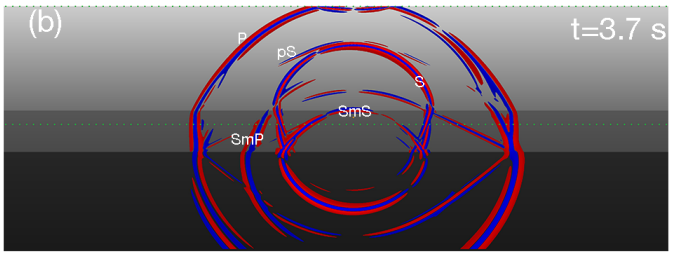

$B X Z$

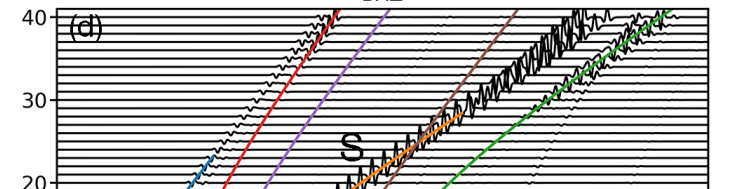

Figure 5-2: Simulation results for Model 1 with $\mathrm{Vp} / \mathrm{Vs}_{\mathrm{s}}=2.1$ inside the subducted crust. (a) and (b) Wave propagation snapshots at $1.9 \mathrm{~s}$ and $3.7 \mathrm{~s}$ after origin time. Yellow start is the location of the source. Small green dots denote the receiver positions. Background colors are proportional to the $\mathrm{P}$ wave velocity and denote the geologic units. The colors of the wavefield represent the amplitude of the horizontal velocity using a log scale. The dimensions of the simulation are $95 \mathrm{~km}$ long and $40 \mathrm{~km}$ deep. The main seismic phases are labeled on the snapshots. (c) and (d) Horizontal and vertical component waveforms recorded at the surface. Names of the different seismic phases are labeled next to their arrivals. Blue, yellow, red and green lines are the predicted arrival time of the P, S, PmP and SmS phases.

waveform sections in Fig. 5-2(c) and (d) next to their arrivals. Waveforms are normalized by the maximum amplitude in each trace. The amplitude of $\mathrm{PmP}$ is very small and $\mathrm{PmS}$ is nearly invisible at this scale. The amplitude of each phase is strongly modulated by the angle of the point source. At our target epicentral distance, around $\pm 20 \mathrm{~km}$, the $\mathrm{SmS}$ phase is about $2 \mathrm{~s}$ after $\mathrm{S}$ wave. Increasing the $\mathrm{Vp} / \mathrm{Vs}$ ratio inside the crust will increase the arrival time difference between $\mathrm{S}$ and $\mathrm{SmS}$ and increase the ray parameter of the SmS phase at a given receiver distance. This model produces two separate phases in the $\mathrm{S}$ wave train. The S1 and S2 phases identified on real data (Fig. 4-11) could correspond to S and SmS. The observed arrival time difference between $\mathrm{S} 1$ and $\mathrm{S} 2$ is about $1.5 \mathrm{~s}$ (Fig. 4-11), indicating that 
the $\mathrm{Vp} / \mathrm{Vs}$ ratio of the subducted crust is smaller than 2.1 or the thickness of the subducted Gorda crust is thinner than $6 \mathrm{~km}$ which would be inconsistent with the tomography results (Beaudoin et al., 1994). Therefore, we find that the average $\mathrm{Vp} / \mathrm{Vs}$ ratio of the subducted crustal section is likely less than 2.1, consistent with the results of (Guo et al., 2019).

\subsubsection{Model 2}

Simulation results for Model 2 are shown in Fig. 5-3 and Fig. 5-4 for the case with $\mathrm{Vp} / \mathrm{Vs}=2.1$ inside the low velocity layer. Fig. 5-3 shows a snapshot of the wave propagation at $5 \mathrm{~s}$. The first arrival among the $\mathrm{S}$ wave train is the Sn phase, which travels at the $\mathrm{S}$ wave speed of the layer below the LVZ. Sn is followed by the guided waves generated inside the LVZ. There are no such guided waves after the $\mathrm{P}$ wave because in this model the LVZ is only a low velocity layer for $\mathrm{S}$ waves. Increasing the $\mathrm{Vp} / \mathrm{Vs}$ ratio increases the amplitude of the guided waves inside the LVZ. Fig. 5-4 shows the waveform sections for station both on top of the surface and inside the LVZ and a zoomed in view of the waveform recorded at $-20 \mathrm{~km}$ epicenter distance. Inside the LVZ, we could see the large amplitude guided waves follow directly after the Sn wave and have a duration of a few seconds. However, these guided waves are not observed on the surface due to their exponential decay away from the LVZ. Therefore, a continuous, homogenous LVZ layer near the slab interface cannot explain the long $\mathrm{S}$ wave train observed at station $\mathrm{KCT}$.

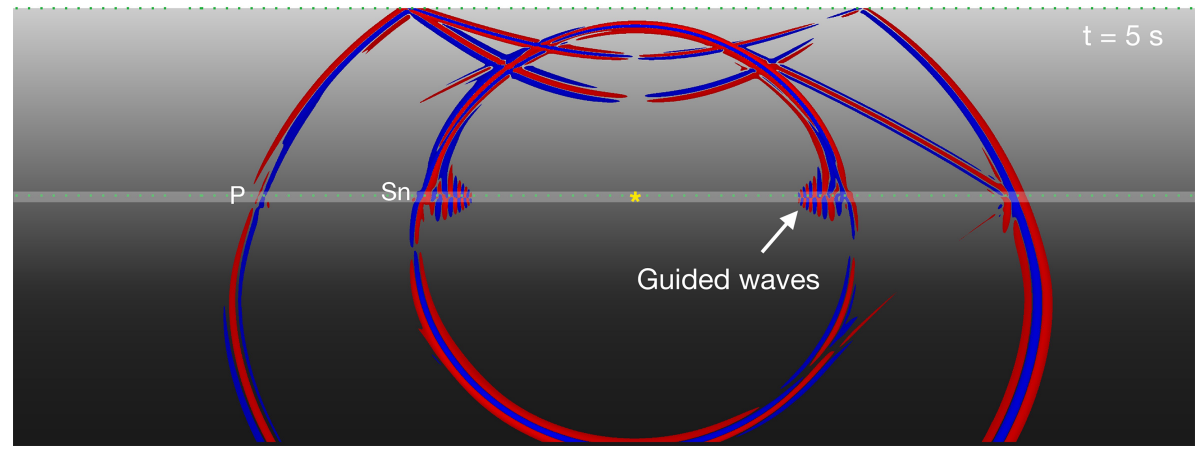

Figure 5-3: Wave propagation snapshot for Model 2 at $5 \mathrm{~s}$ after origin time. The color scheme is the same as in Fig. 5-2. The thin white horizontal layer denotes the S-wave LVZ. Guided waves are visible within the LVZ behind the direct S-wavefront. 

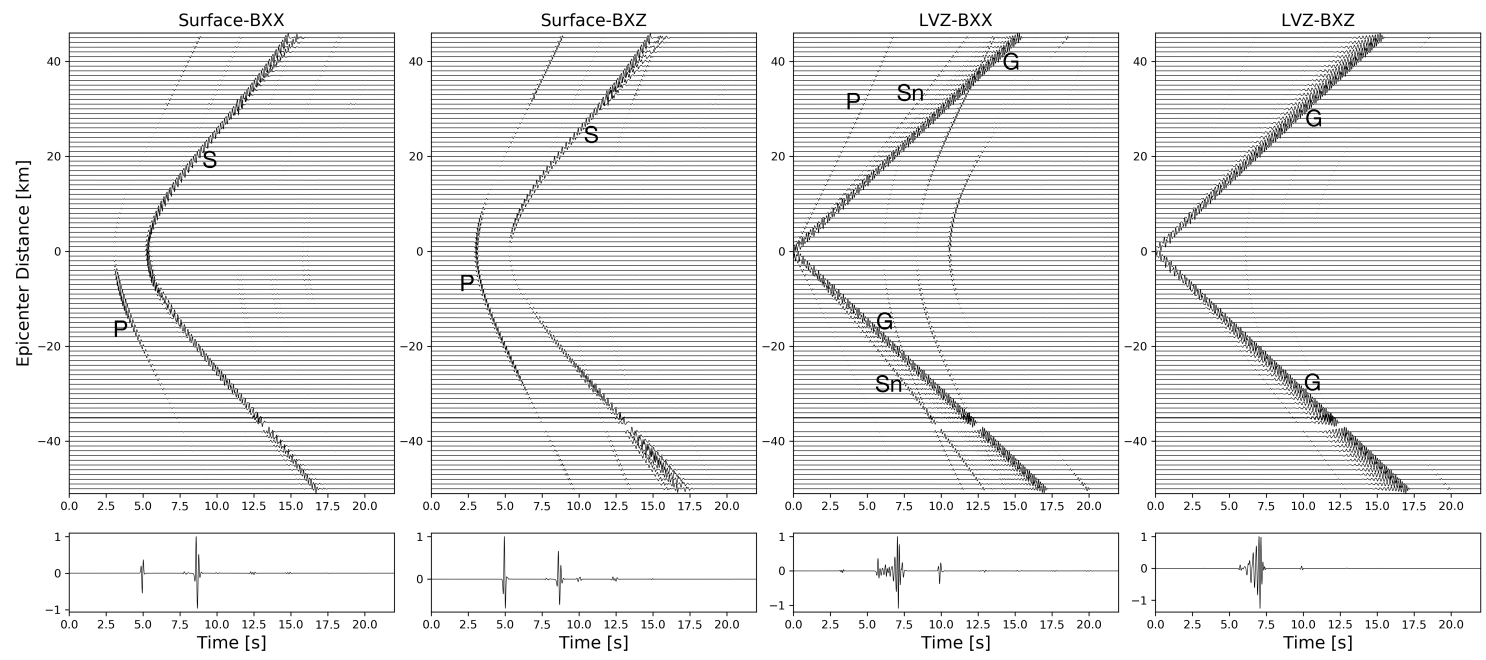

Figure 5-4: Waveform sections from model 2. Top row: horizontal and vertical component waveform sections for stations located on top of the surface and inside the LVZ. Bottom row: zoom in view of the waveforms for station at $-20 \mathrm{~km}$ epicenter distance.

\subsubsection{Model 3}

Results from Models 1 and Model 2 show that neither form of a LVZ is sufficient alone to create the features of the $\mathrm{S}$ waves recorded at station KCT. In Model 3, we investigate whether a combination of Model 1 and 2 is able to achieve a better replication of the KCT observations. To overcome the problem that the guided waves cannot be observed at surface for a continuous LVZ at depth, we truncate the LVZ as a strong form of along-strike heterogeneity. A simulation of Model 3 with an S velocity reduction of $40 \%$ inside LVZ is shown in Fig. 5-5. At $3 \mathrm{~s}$, clear guided waves have been generated which follow the Sn wave. At $4.3 \mathrm{~s}$, guided waves start to scatter from the left end of the LVZ towards the surface. An interesting phenomenon observed from the simulation is that after the passing of the SmS wave over the LVZ, there is a second round of guided waves radiating from the LVZ. We interpret this as the scattering effects between the SmS wave and the termination of the LVZ. The waveforms recorded at surface stations are shown in Fig. 5-5(d) and (e). The $\mathrm{S}$ wave train now consists the direct $\mathrm{S}$ wave, Moho reflection phase and the leaked guided waves. The total duration is 4 to $5 \mathrm{~s}$ long, similar to the duration of the long $\mathrm{S}$ wave train observed at station $\mathrm{KCT}$. 

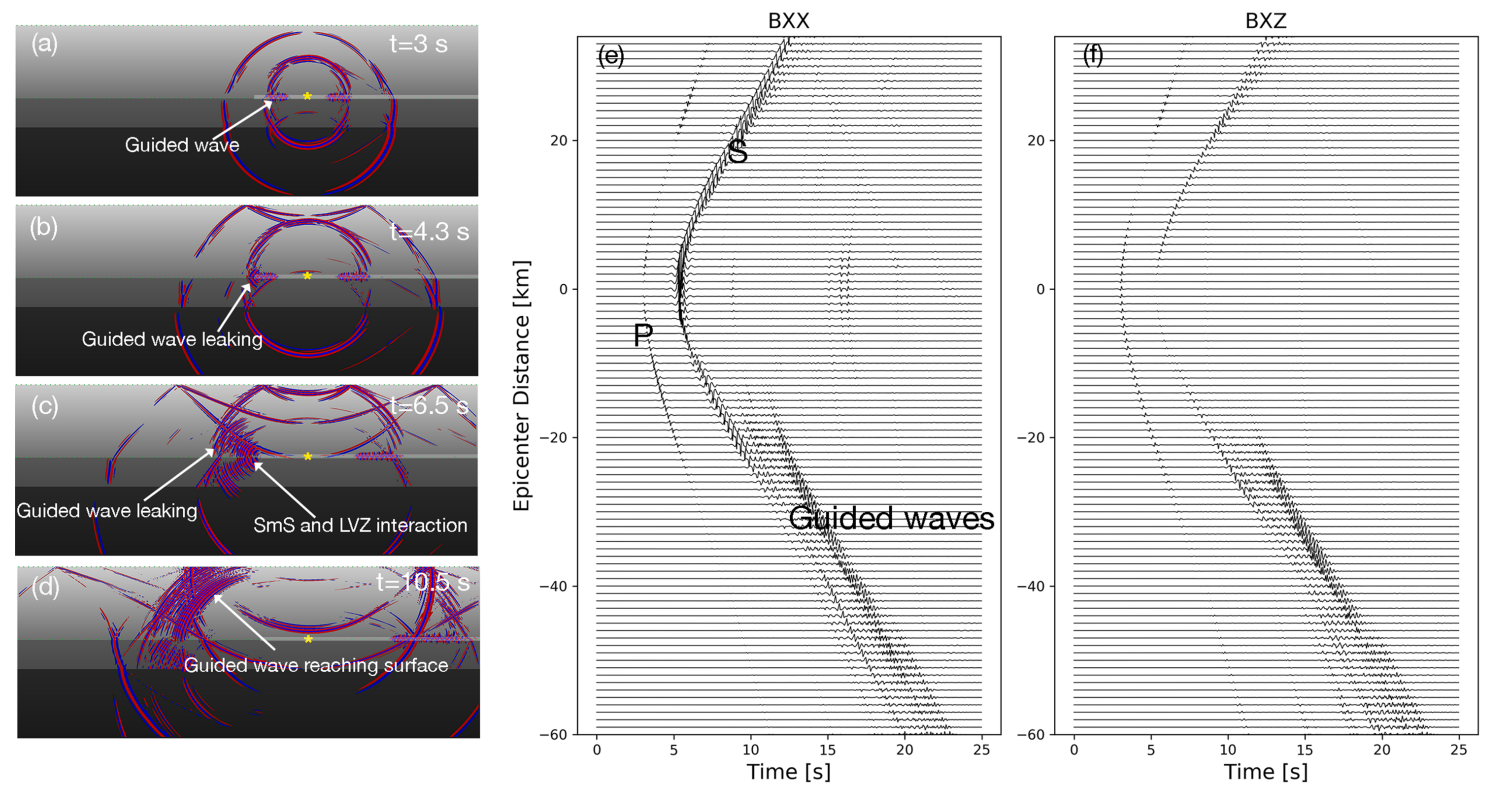

Figure 5-5: Simulation results for Model 3. (a)-(c) Wave propagation snapshots at $3 \mathrm{~s}, 4.3$ s, $6.5 \mathrm{~s}$ and $10.5 \mathrm{~s}$ after origin time. The color scheme is the same as in Fig. 5-2. Different seismic phases are labeled on the snapshots. (d) and (e) Horizontal and vertical component waveforms recorded at the surface. Names of the different seismic phases are labeled next to their arrivals.

\subsection{Discussion}

\subsubsection{S1, S2 phases and Model 1}

The beamforming analysis from the previous chapter shows that the $\mathrm{S}$ wave train for cluster $\mathrm{C} 1$ at $\mathrm{KCT}$ can be roughly separated into 3 phases: $\mathrm{S} 1, \mathrm{~S} 2$ and coda. The ray parameter of $\mathrm{S} 1$ is greater than that of $\mathrm{S} 2$, which means the propagation direction of $\mathrm{S} 2$ arrives at KCT closer to the vertical direction than S1 does. In the Model 1 simulation, the ray parameter of the direct $\mathrm{P}$ and $\mathrm{S}$ arrivals are greater than their Moho reflection phases $\mathrm{PmP}$ and $\mathrm{SmS}$ (Fig. 5-6). Therefore, we interpret that the S1 and S2 phases observed on station KCT likely correspond to the $\mathrm{S}$ and $\mathrm{SmS}$ phases.

\subsubsection{S coda and Model 3}

Model 3 is more successful in generating a long duration S wave than Models 1 and 2 . Waveform comparisons between the 3 models at selected stations and the observed record on station KCT are shown in Fig. 5-7. The simulated waveforms are more complicated on Model 3 and the leaked guided wave has a similar arrival time as the coda part of the $\mathrm{S}$ 


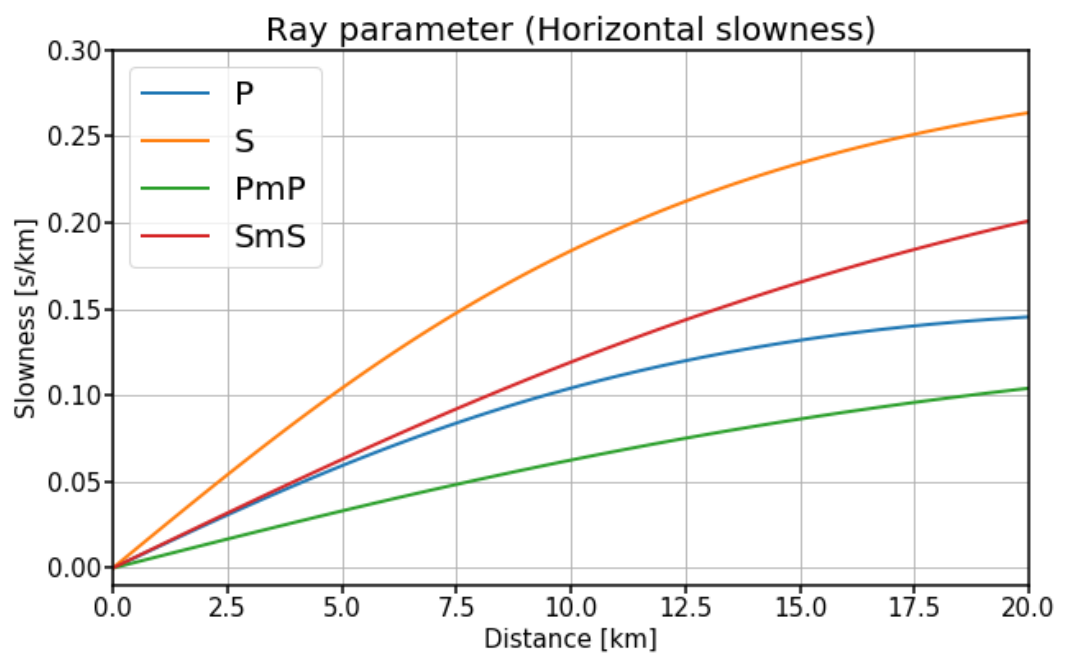

Figure 5-6: Ray parameters of $\mathrm{P}, \mathrm{S}, \mathrm{PmP}$ and $\mathrm{SmS}$ phases as a function of epicentral distance for the Model-1 simulation shown in Fig. 5-2.

wave on station KCT. Therefore, we infer that the terminated LVZ model is one possible explanation for the coda observed on station KCT. Given the separation time of S1 and S2 observed at station $\mathrm{KCT}$, the $\mathrm{Vp} / \mathrm{Vs}$ ratio of the subducted oceanic crust is likely about 1.9, consistent with the Guo et al. (2019) model. A S-wave velocity reduction of at least $30 \%-40 \%$ inside the low velocity sediment is needed to match the amplitude of the coda wave observed at station KCT. The simulated guided waves from model 3 at $20 \mathrm{~km}$ distance in Fig. 2-7 are still smaller than the observed ones at KCT but that difference could likely be reduced with a different combination of source mechanism, and a stronger velocity and attenuation anomaly in the sediment layer. Understanding the full range of parameters that are consistent with the KCT observations will be the subject of future work.

\subsubsection{Geological Implications: LVZ on top of the crust}

A low velocity layer is often imaged near the subduction plate boundary in the ETS zone, just $\sim 10-20 \mathrm{~km}$ deeper than our study area, and those velocities are inferred to indicate that layer contains significant fluid filled porosity (few percent) and has a high, near lithostatic, pore pressure (Audet et al., 2009; Song et al., 2009; Audet and Schaeffer, 2018). Whether the ETS zone low velocity layer extends upwards into the locked zone is an important question as it could significantly alter the stress conditions on the megathrust and affect the rupture of future earthquakes. Conversely, in active source experiments, usually only a $\mathrm{P}$ wave LVZ 
Model 1
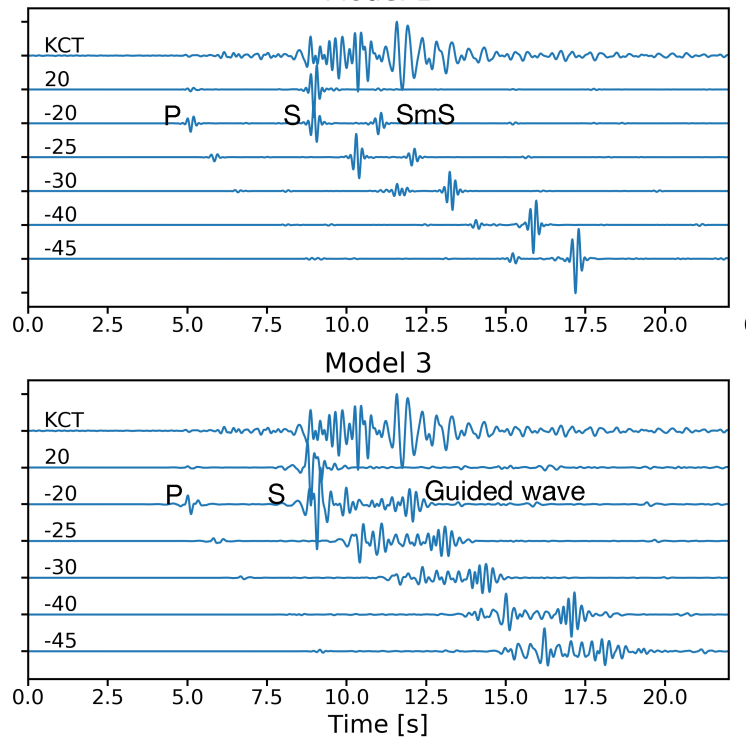

Model 2

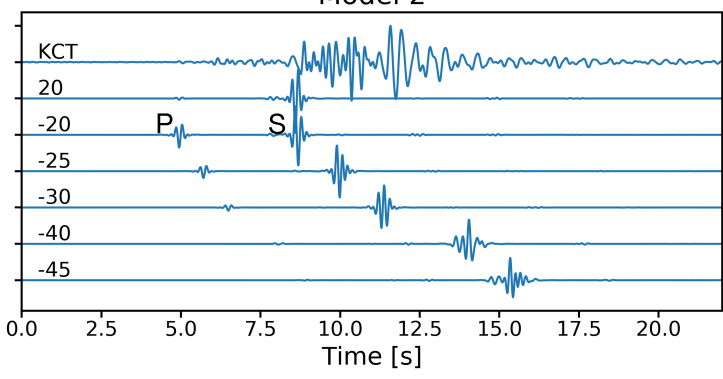

Figure 5-7: Velocity waveform comparisons between the 3 models and the observed record for cluster $\mathrm{C} 1$ on station KCT. Each panel shows the horizontal component waveforms at selected epicenter distances (labelled in km, as in Fig .5-2 and 5-4) and the HHE component waveform at station KCT.

is imaged or no LVZ is imaged at all (Beaudoin et al., 1994; Preston et al., 2003). If the low velocity reflects the existence of fluid filled porosity, the $\mathrm{S}$ wave velocity should be more sensitive to its presence than the $\mathrm{P}$ wave. Therefore, resolving the $\mathrm{S}$ wave velocity of the plate boundary fault zone could provide important constraints on its material properties and possibly its stress level.

Imaging a thin low velocity layer is challenging and the uncertainties in the imaged properties result in further difficulty in explaining their underlying geologic origin. Beaudoin et al. (1994) used an onshore active source experiment to image the subducted Gorda plate roughly along a line parallel to the coast from $\sim 40^{\circ} \mathrm{N}$ to $\sim 42^{\circ} \mathrm{N}$. They found no evidence of a LVZ on top of the oceanic crust in our study area. However, the amplitude of the top side reflection phases from a low velocity layer is a nonlinear function of incident angle, thickness of LVZ, attenuation inside LVZ, density, and both P and S wave velocities inside the LVZ. To overcome this difficulty, Li et al. (2015) used waveform modeling method to infer the structure of the plate boundary fault zone at seismogenic depth offshore the Alaska Peninsula by comparing waveforms of the topside reflection phases from the subduction plate boundary with numerical synthetic waveforms. They found that the plate boundary is 100-250 m thick with strong attenuation. However, they fixed the $\mathrm{P}$ wave velocity values 
inside and outside of the LVZ, assume 0 S-wave velocity and only consider the effects of attenuation. A good waveform fit is hard to achieve and the plate boundary zone is likely to have a more complicated structure than a simple homogeneous $\mathrm{P}$ wave low velocity layer. Active source experiments offshore Japan have shown consistent results of a $\sim 1-2 \mathrm{~km}$ thick LVZ (P wave) at the plate boundary from northern Japan where a cold slab subducts to Nankai Japan where a warm slab subducts (Kodaira et al., 2002; Nakanishi et al., 2002, 2004; Takahashi et al., 2004; Miura et al., 2005). This layer is interpreted as layer 2 of the subducted oceanic crust. Below $\sim 10 \mathrm{~km}$ depth, layer 2 becomes slower than the velocity of the forearc lower crust. However, there is no clear evidence whether a thin low velocity sediment layer exists between the lower crust of the forearc and layer 2 of the subducted oceanic crust in both northern and southern subduction zones offshore Japan. As no shear wave velocity estimates are available in all the above active source models offshore Japan, it is hard to constrain fluid content at the plate boundary. The lack of constraints on the fine scale variations in shear-wave speed at seismogenic depths remains a key obstacle as this property has a large effect on simulations of earthquake rupture (Harris and Day, 1997; Huang and Ampuero, 2011; Kaneko et al., 2011; Kurzon et al., 2020).

Our simulation results indicate the existence of few hundred meter thick LVZ, especially for $\mathrm{S}$ waves, at the plate boundary and that it likely correlates with an area of strong interseismic locking. Tomographic images reveal the location of the subducted crust in our study area as a zone of high Vp/Vs (Fig. 5-8(b)) (Guo et al., 2019). The repeating earthquake clusters that generate the long duration $\mathrm{S}$-waves are located at the top of this high $\mathrm{Vp} / \mathrm{Vs}$ structure, which is likely smeared out by the tomographic imaging method. Our synthetics indicate that in the source region of clusters $\mathrm{C} 1$ and $\mathrm{C} 2$, there is likely a thin (few hundred meter) LVZ with a very high $\mathrm{Vp} / \mathrm{Vs}$ ratio. This thin, high $\mathrm{Vp} / \mathrm{Vs}$ ratio layer would explain the amplitudes of $\mathrm{S}$ to $\mathrm{P}$ converted phases in this region (Chapter 3). The low $\mathrm{S}$ wave velocity indicates the existence of a significant amount of fluid filled porosity (few percent) (Audet et al., 2009). One possible source for the fluid might come from dehydration reactions of the sediments. Another possible source is pore water expelled from the subducted oceanic crust. The Gorda plate is characterized by rough topography seaward of the trench and various normal and strike-slip faults have been imaged within the subducted crust near the trench due to its intense internal deformation and various normal and strike-slip faults have been imaged within the subducted crust near the trench(Gulick et al., 1998). These faults 
potentially might carry water into the subduction zone that would help generate the high Vp/Vs layer in the tomography images (Fig. 5-8(b)) (Guo et al., 2019).

The apparent correlation between the southern end of significant interseismic locking in the model of Pollitz and Evans (2017) with the apparent heterogeneity of the sediment layer that causes the guided waves to be scattered towards the surface is perhaps not surprising. The plate interface in most of Cascadia is after all locked and seismically quiet at seismogenic depths and where it has been imaged, there is a 1-2 km thick sediment layer (Nedimović et al., 2003). However, the fine details of geodetic coupling are variable between studies and not yet explained in terms of specific geologic features. We are not aware of similar observations of guided waves or along-strike discontinuities in the waveguide from other parts of Cascadia. The active source experiments offshore of Vancouver Island in northern Cascadia indicated a continuous sediment layer throughout the locked zone into the ETS zone (Nedimović et al., 2003). The zone of high locking in Fig. 5-8 is a consistent feature of geodetic coupling models (Pollitz and Evans, 2017; Schmalzle et al., 2014) though its exact strength and spatial extent can vary based on choices in the geodetic modeling. Our results indicate that both clusters $\mathrm{C} 1$ and $\mathrm{C} 2$ likely occur within or adjacent to a significant (few hundred m thick) layer of subducted sediments. Additionally, some sort of heterogeneity scatters the S-wave coda from this layer towards the surface about halfway between $\mathrm{C} 1$ and KCT. This latitude $\left(\sim 40.5^{\circ} \mathrm{N}\right)$ coincides with an increase in microearthquake activity really picks up in both the overriding and subducting plates in the vicinity of the triple junction. Southern Cascadia is interpreted to rupture in relatively frequent M8 ruptures that often have rupture lengths of only about $100 \mathrm{~km}$ (Goldfinger et al., 2012; Gomberg, 2018). The shorter ruptures compared to Northern Cascadia may result from the roughness of the incoming plate. On a global scale there is a correlation between incoming plate roughness, the smoothness of interseismic locking, and the size distribution of megathrust ruptures (Bilek et al., 2003; Wang and Bilek, 2014). The scattering of the guided waves we observe may be evidence for an increased level of roughness at seismogenic depths in southernmost Cascadia which in turn might be related to the shorter recurrence interval here. 


\subsubsection{Geological Implications: Heterogeneity of the plate boundary zone}

Some form of heterogeneity, such as the truncated LVZ in Model 3 is necessary for the guided waves from the plate boundary zone to be recorded at the surface stations. A similar phenomenon has been observed in northern Japan. Shiina et al. (2014) identify a clear later phase in seismograms at the western side of the Hidaka Mountain range in Hokkaido for earthquakes occurring at the uppermost part of the subducted Pacific slab beneath the eastern Hokkaido. The later $\mathrm{P}$ wave is interpreted as a guided $\mathrm{P}$ wave propagating in the low-velocity subducting crust of the Pacific plate. The low-velocity subducting crust is in contact with a low-velocity material beneath the Hidaka Mountain range, resulting in the leaking of the guided waves into the overriding plate and enabling their recording by surface stations (Shiina et al., 2014).

The leaking mechanism demonstrated in our simulations indicates that the low velocity layer on top of the oceanic crust is not continuous and implies strong heterogeneities along the plate boundary. Model 3 is one idealized version of this heterogeneity. Undoubtedly there are a wide variety of heterogeneous LVZ models that would be capable of scattering guided waves towards the surface. Model 3 is not intended to be a direct representation of the velocity structure, but we think it likely captures the key features of the LVZ near clusters C1 and C2 (See Chapter 4). The LVZ must be continuous for at least $\sim 10 \mathrm{~km}$ south of clusters $\mathrm{C} 1$ and $\mathrm{C} 2$ to allow the $\sim 3 \mathrm{~Hz}$ guided waves a significant path length to develop. It must be a significant velocity anomaly with a combination of velocity reduction and thickness that produces the $3 \mathrm{~Hz}$ dominant period, similar to strike-slip fault damage zones. Lastly, the LVZ must truncate or become intermittent in some way about $10 \mathrm{~km}$ north of KCT for the guided waves to be observed there.

Heterogeneities along the subduction plate interfaces span a wide variety. Large scale heterogeneities over hundreds of kilometers of the subducted plate boundary include different geological/tectonic units (Bassett et al., 2016), different sediment inputs at the trench ( $\mathrm{Li}$ et al., 2018b; Han et al., 2017) and flatness of the subducted slab (Bletery et al., 2016). However, kilometer or tens of kilometer scale heterogeneous structures on the subduction plate interface are not well documented and are hard to resolve at these depths.

Several factors could contribute to kilometer scale heterogeneities along subduction plate interface: seamounts or other topography anomalies (Kodaira et al., 2000); variations in sed- 
iment thickness (Bangs et al., 2020); faulting within subducted crust and sediments (Gulick et al., 1998; Han et al., 2018); velocity variations of the subducted crust and underthrust sediments (Guo et al., 2019); local underplating or slicing (Calvert et al., 2011); and regional geological structure (McCrory et al., 2012). These factors are not independent from each other. For the subducted Gorda plate, all of these factors are possible explanations for the heterogeneity along subduction plate interface. First, topography of the subducted Gorda plate seaward of the trench is rough due to strong internal deformations. It is likely that the igneous subducted oceanic crust has a surface with similar roughness to the current seafloor topography covered by sediments. Second, active source imaging near the trench of the subducted Gorda plate has revealed multiple normal faults inside the crust. These faults increase the roughness of the slab interface as it descends. They can also form fluid pathways that concentrates fluids and cause regional low velocity structures. Third, the rough topography of downgoing plate may result in variations in sediment thickness that could act as scatterers. Lastly, McCrory et al. (2012) found that hypocenters delineating the seismicity cluster near MTJ illuminate a triangular seismogenic structure approximately $80 \mathrm{~km}$ long in a N-S direction, up to $50 \mathrm{~km}$ long in an E-W direction, and at least $8 \mathrm{~km}$ thick under Cape Mendocino. This tectonic element is inferred to be a detached fragment of oceanic plate that did not subduct and has been stranded within the accretionary prism. It is likely that the terrane above MTJ has a different origin that causes the variations of the subducted slab interface.

\subsubsection{Geological Implications: Pore pressure and stress state of the plate boundary faults}

Our simulation shows that the shear wave velocity reduction inside the LVZ may need to be as large as $30 \%$ to $40 \%$ to create the observed large amplitude guided waves. This would likely require high pore pressure at the plate boundary (Guo et al., 2019; Christensen, 1996). Recent work by Li et al. (2018a) using stress tensor inversions from focal mechanisms solutions of earthquakes near the subducted Gorda plate interface demonstrated that the plate interface supports low shear stress. In fact, the shear stress on the plate boundary in this region is so low that one of the principal components of the stress field in the subducting plate is normal to the interface which implies the plate boundary zone likely has a fluid pore pressure approaching at least $70 \%$ of lithostatic at $\sim 15-20 \mathrm{~km}$ depth (Li et al., 2018a). The 
strong LVZ implied by our guided wave observations could be consistent with the stress field observations if the plate boundary fault operates at low shear-stress levels due to either high fluid pressures or materials of low intrinsic strength.

Clusters $\mathrm{C} 1$ and $\mathrm{C} 4$ show the strongest guided wave signals among all the clusters. They are located near or inside the locking patches in Fig. 5-7(a) (Pollitz and Evans, 2017). We infer that the locking patch near MTJ are likely to be in a uniform low velocity layer that forms a large asperity.

\subsubsection{Additional properties of the S-wave at KCT}

Our beamforming and numerical simulations explain the first order properties of the long duration S-waves from earthquakes from clusters C1 and C2 recorded at KCT. However, there remain several aspects that will require further study. We observe a difference in the relative amplitudes between the S1 and S2 and Coda phases for the stations on the upper part of the hill (ST2 to ST8) compared to stations downhill (ST9 to ST20) (Fig. 4-7). This phenomenon was observed for all the earthquakes located north of the nodal array. The reason could be that uphill stations were on relative flat surface while downhill stations were on a slope, which will modulate the amplitude of each phase depending on its incidence angle and ray parameter. Additionally, the near surface velocity structure may be different with a thicker soil layer on the flat ridge at the top of the hill than on the hillside slop. But we did not observe similar variations for earthquakes located south of the array.

The P1/P2 and S1/S2 phase pairs were widely observed for events north of the nodal array but their explanation as direct path and reflected off the Moho phases is not completely verified by the synthetic simulations. Although we interpret P2 and S2 as top side reflection phases from the subducted oceanic Moho, several of these events appear to be located deeper inside the subducted oceanic mantle (two offshore events north of the nodal array). It is possible those earthquakes are mislocated or the phase pairs result from converted phases

for these two earthquakes. For events south of the nodal array and above the subducted oceanic Moho, no such double $\mathrm{P}$ or $\mathrm{S}$ phases are found. The measured ray parameter ranges for $\mathrm{P} 1 / \mathrm{P} 2$ and $\mathrm{S} 1 / \mathrm{S} 2$ are systematically shifted relative to the synthetic model values. The large amplitude of the ray parameters cannot be explained by simple 1-D velocity models. One hypothesis is that either $\mathrm{P} 1 / \mathrm{S} 1$ or $\mathrm{P} 2 / \mathrm{S} 2$ are strongly effected by a near receiver scattering or diffraction that alters their incidence angle close to KCT. Such an 
effect would require a significant velocity anomaly and be only sensitive to waves coming from the north. Investigating the ray parameter discrepancy will require more sophisticate velocity models and a wider spatial coverage of receiver arrays to test.

We had difficulty comparing the observed guided waves with the simulations for a number of reasons. First, the instrument response of the nodal seismometers is limited at $3 \mathrm{~Hz}$, and while corrections for the response were done, we simply did not observe the large amplitude $3 \mathrm{~Hz}$ guided wave on the events during our study even for the node located closest to KCT. This may be due to not having observed a direct repeat of the $\mathrm{C} 1$ or $\mathrm{C} 2$ cluster during our 2-month time period. It may also reflect the need to couple the seismometers to the ground better than typical nodal installation to observe the S-wave coda phase more reliably similar to the network broadband station. Future deployments should be designed to capture the incoming low frequency wavefield from the north of $\mathrm{KCT}$ to see how wide the region is where the low frequency code is observed.

\subsection{Conclusions}

We constructed 3 simple, layered velocity models and performed 2D wave propagation simulations using these models to investigate how near source velocity anomalies could cause the long duration $\mathrm{S}$ waves observed at station KCT. The long duration $\mathrm{S}$ waves include two ray-theoretic body wave arrivals S1 and S2 with different ray parameters followed by a large amplitude, low-frequency coda phase. Numerical simulations that use velocity models with a $6 \mathrm{~km}$ thick layer representing the subducted oceanic crust indicate that the S1 and S2 are likely to be the direct $\mathrm{S}$ wave and the top side Moho reflection phase (SmS), respectively. Numerical simulations that use velocity models with a thin, truncted low $\mathrm{S}$ wave layer on top of the subducted oceanic crust best replicate the observed S coda in terms of arrival time, duration, frequency content and amplitude. The coda is likely generated by the leaked guided waves from the thin low velocity layer. For this energy to reach the surface, significant heterogeneity of the LVZ layer is required to scatter the energy towards the surface. The low velocity layer likely has to have $30 \%-40 \%$ S-wave velocity reduction to match the observed amplitude of the coda waves.

Models similar to our preferred explanation for the observed guided waves would all involve a truncated low velocity layer. The extent of the velocity reduction needed to 
replicate the duration and frequency content of the S-wave coda require a physical mechanism to produce a strong S-wave LVZ even though no P-wave LVZ was observed by Beaudoin et al. (1994). One potential explanation would be that the subducted sediment layer has significant pore fluid content and perhaps high pore pressure. Moreover, the scattering of the energy to the surface indicates there is significant heterogeneity in this layer in the along-strike direction. Such heterogeneity will cause strong stress and strength variations along the subduction plate interface and will potentially affect where future earthquakes nucleates and how they propagate. Future efforts to use these phases may allow for the mapping of material property variations along the subduction plate interface that will aid in simulations of rupture propagation in large earthquakes as well as the strong ground motion. Guided waves provide a new opportunity to study material properties of the subduction plate interface at seismogenic depths and perhaps even monitor its long-term variation similar to studies of fault-zone healing in crustal strike slip faults (Li et al., 1994). At a minimum, we find that the thin low velocity on top of the subduction Gorda crust can add great complexity to the recorded waveforms which should be taken into account in earthquake source property studies and numerical simulations of megathrust rupture. Moreover, the presence of energy recorded on the surface that has spent a significant part of its path propagating in the vicinity of the plate boundary fault suggests that future studies that utilize the combination of array analysis and wave propagation simulations will help us understand and potentially monitor the structure of the subducted plate interface in great detail. 

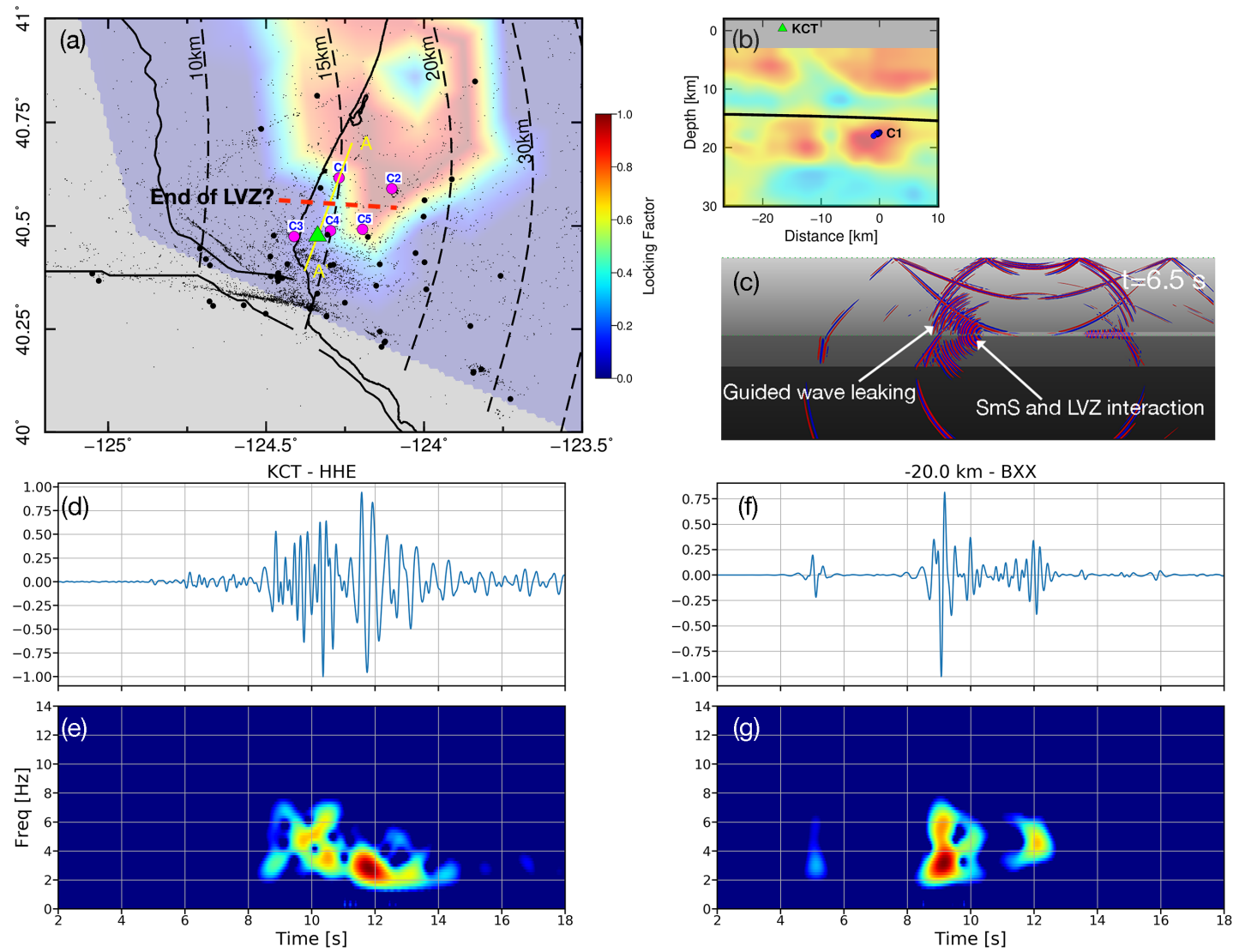

Figure 5-8: Comparison between observations and simulations of guided waves in southern Cascadia. (a), (c)-(e) follow Figures 4-10, 5-5(c) and 4-4. Panels (a) and (b) show the propagation path geometry for the guided waves recorded at station KCT form cluster $\mathrm{C} 1$. The propagation is primarily along strike with the interface at about $15 \mathrm{~km}$ depth and KCT being located about $20 \mathrm{~km}$ from C1. Panel (c) shows the model 3 simulation snapshot. Model 3 contains a source in the subducted sediments and an abrupt end of the LVZ about $10 \mathrm{~km}$ south of the source which scatters guided wave energy towards the surface. Panels (d), (e), (f) and (g) compare the observed and synthetic S-waveforms for cluster C1 and the Model-3 simulation. The simulation recreates the S-P time, as well as the $\sim 5$-second-long duration of the S-wave train. The observered guided wave has a predominant frequency of about $3 \mathrm{~Hz}$ while the simulated guided wave is concentrated around $4-5 \mathrm{~Hz}$. Both simulated and observed guided waves are more narrowly restricted in frequency content than the direct and moho-reflected S-wave phases that arrive before them. 


\section{Chapter 6}

\section{Conclusions and Future Directions}

\subsection{Thesis summary}

Material property of the subduction plate-boundary fault is one of the most important factors controlling slip behavior along the megathrust. An important question of the subduction megathrust is whether a low velocity zone (LVZ) exists at the plate boundary, as a LVZ usually indicates low strength and high fluid content of the fault, which has great implications for rupture dynamics of megathrust earthquakes and seismic and aseismic slip partition on the fault during seismic cycles (Segall and Rice, 1995; Segall and Bradley, 2012b; Thakur et al., 2020). It is well known that continental and oceanic strike-slip faults are characterized as LVZ of a few hundred meter thick, sometimes with 30\%-40\% velocity reduction compared to country rocks(Li et al., 1994; Roland et al., 2012; Guo et al., 2018). However, the existence of such LVZ along megathrust is less well constrained, especially at seismogenic depth.

This thesis integrated seismological observations and numerical modellings to investigate interseismic locking, geometry and material properties of the plate-boundary fault of the subducted Gorda plate near the Mendocino triple junction. We use two types of seismic scattering phases: converted phases (Chapter 3) and guided waves (Chapter 4 and 5) to constrain geometry and material properties and to identify LVZ of the subduction plateboundary fault.

Chapter 2 investigates the locking condition on the subducted Gorda slab. We first study the rupture properties of the January 28, $2015 \mathrm{Mw} 5.7$ earthquake occurred on the Mendocino transform fault. Next we investigate the frictional state of the subduction interface by 
simulating the afterslip that would be expected there as a result of the stress changes from the 2015 earthquake and a $2010 \mathrm{Mw} 6.5$ intraplate earthquake within the subducted Gorda plate. The 2010 earthquake imposed a stronger stress perturbation on the Gorda plate interface, with which we can rule out a very shallow downdip limit of the locking patch on the slab owing to the lack of a detectable signal at onshore GPS stations following the 2010 earthquake. The locking depth on the slab surface is at least $14 \mathrm{~km}$, which suggests that the next M8 earthquake rupture will likely reach the coastline and strong shaking should be expected there. Although the 2015 earthquake couldn't induce strong transient deformation on the subducted Gorda plate that were detectable at onshore GPS stations, the numerical modeling indicates that future seafloor geodesy instruments would be able to measure such transient deformation signal and to better constrain locking conditions on the subducted slab.

In Chapter 3, we developed method to use high frequency (2-12 Hz) P-to-S and S-to$\mathrm{P}$ converted phases generated by local earthquakes to constrain the geometry and material properties of of the subducted Gorda plate at seismogenic depth. Advantages of this method are that such converted phases carry direct information from the subduction plate interface and their higher frequency content is sensitive to velocity discontinuities and small scale (a few $\mathrm{km}$ ) heterogeneities. We first applied raytracing and source array beamforming methods to identify the converted phases on the waveform section and then use their arrival times and amplitudes to infer the locations of the top and bottom of the subducted crust as well as the velocity contrasts across these discontinuities. The locations of the conversion points agree well with the top or bottom of the high Vp/Vs layer from (Guo et al., 2019). The converted phase estimated plate interface geometry is in general consistent with Slab2 model of the Gorda plate and have large discrepancy with the Slab1.0 model between $40.2^{\circ} \mathrm{N}$ and $40.2^{\circ} \mathrm{N}$, where the Slab1.0 model is $6-8 \mathrm{~km}$ too deep. Amplitude of the scattering phases requires models containing a $\sim 5 \mathrm{~km}$ thick zone with at least a $\sim 10-20 \%$ reduction in S-wave velocity. Thus the plate boundary is likely contained within or at the top of this low velocity zone, which potentially indicates a significant porosity and fluid content within the seismogenic zone. We also observe strong spatial variations of velocity contrast at the top and bottom of the subducted Gorda crust, indicating material properties of both the plate boundary fault and the subducted oceanic crust are perhaps more heterogeneous.

Chapter 4 and 5 study the seismic guided waves that propagate along a thin low velocity 
layer at the subduction plate boundary. From the Cascadia Initiative dataset, we observed long duration $\mathrm{S}$ waves with large amplitude coda at station $\mathrm{KCT}$ (network code $\mathrm{NC}$ ) from earthquakes inside a few event clusters that were located near the subduction plate interface. The frequency content and the arrival time of the large coda waves imitated the guided waves frequently observed at continental strike slip faults. To investigate the origin of the long duration $\mathrm{S}$ wave and the large amplitude coda and their relations with slab interface velocity structures, a dense nodal array was deployed near station KCT for 2 months in late 2019. One event that occurred during the deployment was in or close to the slab interface cluster. Beamforming analysis of the $\mathrm{S}$ waves recorded by the nodal array for this event demonstrated that the long duration $\mathrm{S}$ waves contain at least two body waves with different ray parameters in the earlier part of the $\mathrm{S}$ wave, which we named phase S1 and S2.

We constructed 3 simple, layered velocity models and performed 2D wave propagation simulations using these models to investigate how near source velocity anomalies could cause the long duration S waves observed at station KCT. Numerical simulations that use velocity models with a $6 \mathrm{~km}$ thick layer representing the subducted oceanic crust indicate that the S1 and S2 are likely to be direct S wave and the top side Moho reflection phase, respectively. Numerical simulations that use velocity models with a truncated thin low $\mathrm{S}$ wave layer on top of the subducted oceanic crust best replicate the observed S coda. The coda is likely generated by the leaked guided waves from the thin low velocity layer and scattering effects between the Moho reflection phase and a lateral edge of the low velocity layer. These simulations indicate that distribution of such low velocity layer at the plate boundary is heterogenous near MTJ, which is consistent with the observations of converted phases in Chapter 3. Location of the low velocity layer coincides with the strong locking patch on the plate interface inferred from GPS study (Pollitz and Evans, 2017). Results from these two chapters show the possibility of using the guided waves to constrain thin layer structure at the subduction plate boundary and to infer the relationship between velocity structures of the plate boundary-fault and its seismogenic behavior. 


\subsection{Future directions}

\subsubsection{Numerical simulation of wave propagation in subduction zones}

Numerical simulations of seismic wave propagation through subduction zones will help us to seek further insights of the generation and propagation mechanisms of the seismic scattering phases and solve several challenges of using the scattering phase method to image the subduction plate interface.

Based on the converted phase observations near MTJ, the following two challenges still exist for the identification and interpretation of the scattering phases, which requires numerical simulations to validate the observations. First, due to heterogeneous nature of the subduction zone, avoiding misidentification of other seismic phases as slab related later phase is challenging. Water layer, low velocity sediments, multipathing effects, scattering from irregular geometry structure, etc., are all possible ways to create seismic phases that have similar arrival as the slab phases. It is important to understand the propagation of these phases and to ensure that they are well separated from the target phase. Numerical simulation is an essential tool to handle the complex structure of the subduction zone and to justify the identification of slab phases on the seismograms. Second, explaining the amplitude and shape of the scattering phases is still challenging. Near MTJ, the observed converted phases amplitudes at a single station can vary by a factor of 3 or more even for a small cluster of events. The waveform of the later phases is a combination of effects from the earthquake source properties, the wave propagation process and the site response. It is important to conduct simulations to systematically test the effects of earthquake focal mechanism, 3D geometry of slab interface and the low velocity layers at the subduction plate boundary on the waveform of the scattering phases. Such wave propagation simulations will lay theoretical foundations for the interpretation of both the slab related scattering phases and the corresponding seismic structures that generate those phases.

\subsubsection{Dense arrays}

Seismic scattering phases are ubiquitously present on seismic waveforms, especially at higher frequency. However, they usually have small amplitude, and it is difficult to confidently identify them at a single station. Recent dense array deployments offer a great opportunity to understand the physical origins of these scattered waves. Waveform sections from dense 
arrays can help to reveal weak but coherent scattering phases. The number of stations in a dense array can range from tens of stations in small arrays to hundreds or thousands of stations in large-N arrays. The emerging Distributed Acoustic Sensing technique will further boost the acquisition capabilities. The key to imaging heterogeneities along subduction zone plate interface from scattering phases and associating the heterogeneities with earthquake rupture behavior is to develop robust and efficient array analysis methods that harness the coherent information embedded in the array data.

There are already several dense arrays deployed in subduction zones in the US. For example, in 2012, a network consisted of 8 small aperture arrays, named Array of Array, was installed in the Olympic Peninsula, northern Washington above the ETS zone. Each small array was armed with 10-20 stations. Such network provides a valuable dataset to study the subducted slab structure from the transition zone to the ETS zone. Recently, the Alaska Amphibious Community Seismic Experiment deployed a linear dense nodal array cross the Kodiak Island. This nodal array consists of 4003 -component compact and portable geophones and the data is open to public. Kodiak Island sits above the northwest part of the 1964 M9.2 Prince William Sound earthquake rupture zone offshore Alaska Peninsula. The abundant seismicity in both the down-going Pacific plate and the overriding Alaska Peninsula provides an ideal natural laboratory to study the plate interface properties with scattering phases. Understanding materials properties across a large depth range is important as the potential penetration of large earthquake slips will cause very different regional ground motions. The small spacing between the nodes will create image of the plate-boundary fault with unprecedented spatial resolutions.

Generating a continuous picture of the subduction plate-boundary fault structures from the seismogenic zone to the ETS zone will shed light on the feedback mechanisms between velocity structure and slip mode on the faults and better facilitate earthquake hazard assessment in the future. Comparing the plate-boundary fault structures at different subduction zones that have host M8+ earthquakes will help to identify common features that govern megathrust earthquakes as well as revealing important variations at each subduction zone.

\subsubsection{Advanced imaging methods}

The advent of the dense array makes the spacing of seismic receivers just tens or hundreds of meter apart. More advanced imaging methods traditionally only applicable in exploration 
seismology (Shabelansky et al., 2014) or even medical imaging (Robert and Fink, 2008; Touma et al., 2020) can be used for passive seismology. Recently several migration methods have been developed to image subsuface discontinues with converted phases (Shabelansky et al., 2014, 2015; Pollitz, 2019). These methods show the advantage of using just a few earthquakes and a receiver array on the surface to image subsurface structures, such as vertical faults, which are generally hard for traditional imaging methods.

Another promising technique for imaging subsurface structures is seismic interferometry. In places like central Cascadia, where few earthquakes occur, it is hard to rely on local earthquakes for seismic imaging. Several different techniques belong to the seismic interferometry category, such as noise cross-correlation, noise autocorrelation, coda wave autocorrelation. These methods can be used to retrieve body waves and generate reflection images of the subsurface. They has already been used to retrieve body waves using dense array in both local scale (Nakata et al., 2015) and global scale (Poli et al., 2012), with a few attempts in subduction zone environments (Ito and Shiomi, 2012; Tonegawa et al., 2015; Shiraishi et al., 2017).

Ocean bottom seismometer (OBS) is essential for studying subduction zone structures. The dense onshore-offshore array near MTJ used in this thesis has shown that OBS data can greatly increase the tomography resolution and the accuracy of earthquake locations. Although many challenges exist for processing OBS data, things could be improved by securing instrument to the ground, deploying long term cabled array like the S-net in Japan and using multiple collocated sensors. There are many subduction zones where no OBS has been deployed but being prone to damaging earthquakes, such as Middle and South America and the Caribbean area. Conducting OBS experiments similar to the Cascadia Initiative project in those places will result in both big scientific and societal benefits. 


\section{Appendix A}

\section{Appendix for "Constraints on the Geometry of the Subducted Gorda Plate from Converted Phases Generated by Local Earthquakes"}

\section{A.1 Tables}

\section{A.2 Ray tracing validation}

In this section we discuss some detailed features of the ray tracing calculations to show that the minimum travel time approach we used matches the arrival times of converted phases in full waveform synthetics. Due to the range of epicentral distances considered in our different waveform sections as well as the presence of the high velocity subducted slab, there are two possible types of SP converted phases generated at a particular discontinuity: a direct transmitted SP phase that for short epicentral distances is an upgoing ray along its entire path, and secondly a SP phase where the $\mathrm{P}$-wave portion is actually reflected downward from the discontinuity and refracts through the subducted slab before bending upward, crossing the slab interface a second time (as a transmitted P) and arriving at the station.

To demonstrate the transition between the two we consider a 1D layered model (Fig.A-1) 
Table A.1: Summary of beamforming results. For the velocity, azimuth and takeoff angle columns, the numbers before / are results from beamforming analysis, the numbers after / are velocities from the tomographic model, azimuths calculated from station-events locations and takeoff angles calculated from raypaths.

\begin{tabular}{c|c|c|c|c}
\hline Station & Phase & Velocity $[\mathrm{km} / \mathrm{s}]$ & Azimuth & Takeoff Angle \\
\hline JCC & SP & $4.6 / 4.7$ & $27^{\circ} / 32^{\circ}$ & $38^{\circ} / 29^{\circ}$ \\
CM01A & SP & $5.0 / 4.8$ & $15^{\circ} / 21^{\circ}$ & $40^{\circ} / 32^{\circ}$ \\
CM01A & P & $7.5 / 8.2$ & $24^{\circ} / 21^{\circ}$ & $-2^{\circ} /-11^{\circ}$ \\
CM01A & S & $5.0 / 4.8$ & $21^{\circ} / 21^{\circ}$ & $-2^{\circ} /-13^{\circ}$ \\
CM09A & SP & $4.8 / 4.7$ & $327^{\circ} / 332^{\circ}$ & $30^{\circ} / 37^{\circ}$ \\
B047 & SP & $4.6 / 4.7$ & $312^{\circ} / 330^{\circ}$ & $24^{\circ} / 18^{\circ}$ \\
B047-2 & SP & $4.8 / 4.7$ & $318^{\circ} / 330^{\circ}$ & $4^{\circ} / 5^{\circ}$ \\
B047-3 & SP & $4.6 / 4.7$ & $333^{\circ} / 330^{\circ}$ & $-4^{\circ} / 4^{\circ}$ \\
B047-4 & SP & $4.8 / 4.7$ & $330^{\circ} / 330^{\circ}$ & $2^{\circ} / 4^{\circ}$ \\
B047-5 & SP & $4.8 / 4.7$ & $303^{\circ} / 332^{\circ}$ & $14^{\circ} / 37^{\circ}$ \\
CM03A & Ps & $7.5 / 8.2$ & $21^{\circ} / 18^{\circ}$ & $-4^{\circ} /-10^{\circ}$ \\
KMPB & Ps & $8.4 / 8.3$ & $354^{\circ} / 5^{\circ}$ & $22^{\circ} / 6^{\circ}$ \\
CM06A & Ps & $9.0 / 8.4$ & $3^{\circ} / 359^{\circ}$ & $-6^{\circ} / 1^{\circ}$ \\
KCT & Ps & $7.0 / 8.1$ & $297^{\circ} / 4^{\circ}$ & $60^{\circ} / 15^{\circ}$ \\
FS13D & Ps & $8.6 / 8.1$ & $153^{\circ} / 163^{\circ}$ & $30^{\circ} / 37^{\circ}$ \\
FS13D & SP & $5.0 / 4.7$ & $162^{\circ} / 163^{\circ}$ & $46^{\circ} / 61^{\circ}$ \\
\hline
\end{tabular}

Table A.2: Station parameters for FK simulation.

\begin{tabular}{c|c|c}
\hline Station & Azimuth & Distance $[\mathrm{km}]$ \\
\hline B047 & $118^{\circ}$ & 45 \\
CM09A & $118^{\circ}$ & 30 \\
CM01A & $68^{\circ}$ & 65 \\
KMPB & $88^{\circ}$ & 40 \\
CM03A & $68^{\circ}$ & 60 \\
\hline
\end{tabular}

with the earthquake source located at $25 \mathrm{~km}$ depth and the SP phase converting at $15 \mathrm{~km}$ depth. The velocity model is equally discretized into 400 intervals and within each interval, the velocity is a linear function of depth allowing an analytical solution for the ray path. There are two types of $\mathrm{S}$ wave depending on whether the raypath goes upward (S1) or downward (S2) leaving the source. For the S2 type, we only consider the rays that could bend upwards above $40 \mathrm{~km}$ depth. Next, we calculate raypaths of $\mathrm{P}$ waves which starts at $15 \mathrm{~km}$ depth and ends at the surface $(0 \mathrm{~km})$. Similarly, there are two types of $\mathrm{P}$ waves depending on whether the raypath goes upward (P1) or downward (P2) leaving the starting point. The ray parameter ranges for the 4 types of waves are listed in Table A.3. SP phases can potentially result from the following combinations: $\mathrm{S} 1+\mathrm{P} 1, \mathrm{~S} 1+\mathrm{P} 2, \mathrm{~S} 2+\mathrm{P} 1$ and $\mathrm{S} 2+\mathrm{P} 2$. 

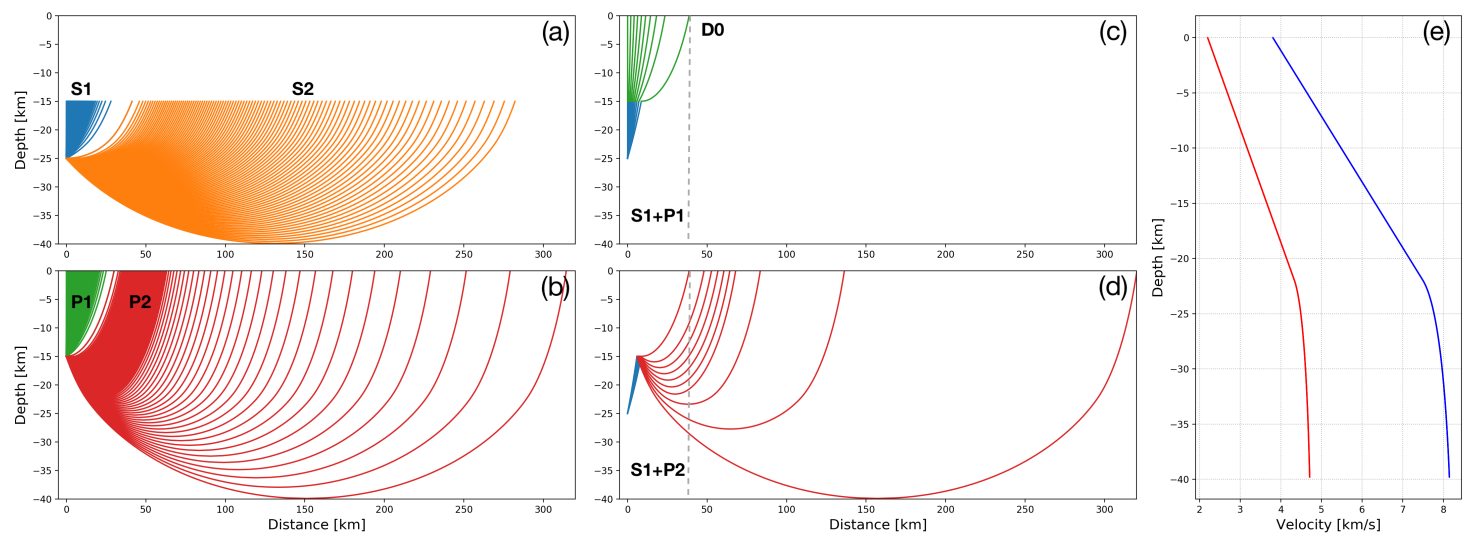

Figure A-1: Raypaths for simple layer models. (a) $\mathrm{P} / \mathrm{S}$ raypath from $25 \mathrm{~km}$ to $15 \mathrm{~km}$. Blue lines are rays leaving the source upwards. Orange lines are rays leaving the source downward. (b) $\mathrm{P} / \mathrm{S}$ raypath from $15 \mathrm{~km}$ to $0 \mathrm{~km}$. Green lines are rays leaving the source upwards. Red lines are rays leaving the source downward. (c) Raypaths of SP phase of the transmission type. (d) Raypaths of SP phase of the reflection type. (e) Velocity model used to calculate the raypaths. $\mathrm{Vp} / \mathrm{Vs}=1.73$.

\begin{tabular}{ccc} 
Wave Type & Min Ray Parameter & Max Ray Parameter \\
\hline P1 & 0.000000 & 0.128707 \\
P2 & 0.122716 & 0.128707 \\
P3 & 0.000000 & 0.158134 \\
P4 & 0.122716 & 0.158134 \\
S1 & 0.000000 & 0.222663 \\
S2 & 0.212298 & 0.222663 \\
S3 & 0.000000 & 0.273572 \\
S4 & 0.212298 & 0.273572 \\
\hline
\end{tabular}

Table A.3: Ray parameter range for the different type of waves shown in Fig. A-1.

By comparing the ray parameter ranges in Table A.3, we find that the $\mathrm{S} 2+\mathrm{P} 1$ and $\mathrm{S} 2+\mathrm{P} 2$ are impossible in our distance ranges since we only consider rays that bend above $40 \mathrm{~km}$ depth. Raypaths for the $\mathrm{S} 1+\mathrm{P} 1$ and $\mathrm{S} 1+\mathrm{P} 2$ combinations are shown in Fig. A-1(c). There is a transition distance D0 which corresponds to the beginning of the total reflection for the $\mathrm{P}$ wave. In this case, which roughly represents our dataset, $\mathrm{D} 0$ is $\approx 38 \mathrm{~km}$. Beyond this distance, only the reflection type of SP phase is seen at the surface. Most of our converted phase observations are at closer epicentral distances than this (Fig. A-1) and correspond to the $\mathrm{S} 1+\mathrm{P} 1$ paths. However, stations JCC and CM01A are typically at a distance of $>60 \mathrm{~km}$ and the SP phases observed on those two stations are likely of the reflection type $(\mathrm{S} 1+\mathrm{P} 2)$.

We use the pseudo-bending raytracing code from the tomoDD code (Um and Thurber, 1987), for efficiency and to be consistent with the tomography model generation (Guo et al., 


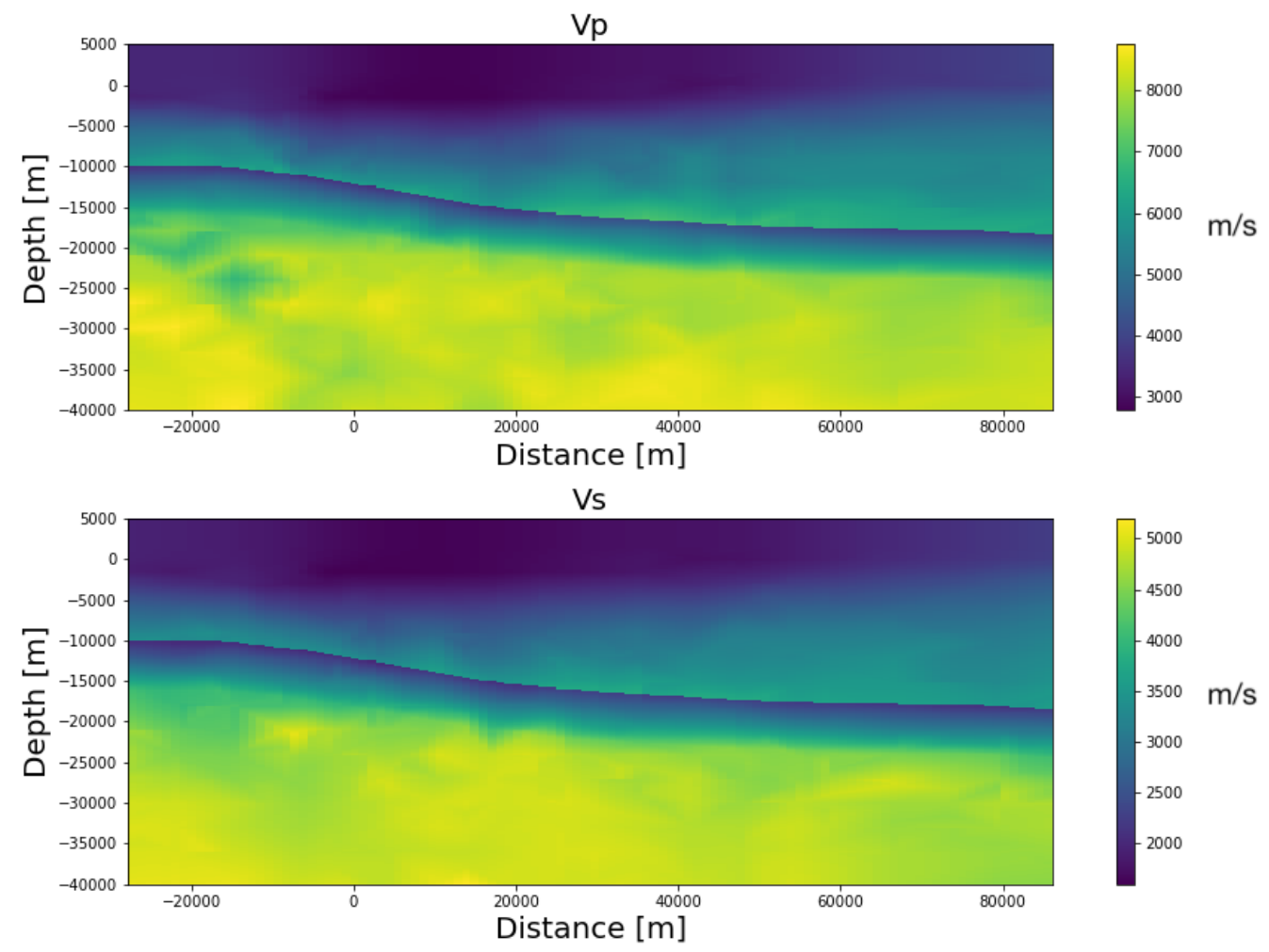

Figure A-2: Velocity models used for 2D wave propagation simulation and raytracing.

2019). Given the variety of the converted phases that may be present and the possibility of multipathing in the complex 3D subducted slab structure, we validated the minimumtime ray-tracing approach by comparing the results to $2 \mathrm{D}$ wave propagation simulations that replicate the complex wave propagation in our study area. We simulate the $2 \mathrm{D}$ wave propagation using SPECFEM (Tromp et al., 2008) and a velocity model cross section going through the center of the M-fault and station JCC. A $6 \mathrm{~km}$ thick slab is manually inserted into the model using the geometry from Slab 1.0. A $20 \%$ velocity reduction is imposed within the subducted crust relative to the background model Fig.A-3(a). The earthquake is set at $27 \mathrm{~km}$ depth. The receivers are along a free surface with no topography. We also perform the minimum-time ray tracing calculation with this model for SP conversions from the top of the subducted crust.

The simulated waveforms and the predicted arrival times from the raytracing code are shown in Fig. A-3(b). Owing to the slab and other heterogeneities in the velocity model, the waveform sections show a lot of complexities. However, a number of expected phases are easily recognized including $\mathrm{P}, \mathrm{S}, \mathrm{SP}$ and Ps phases from the top and bottom of the slabs. 

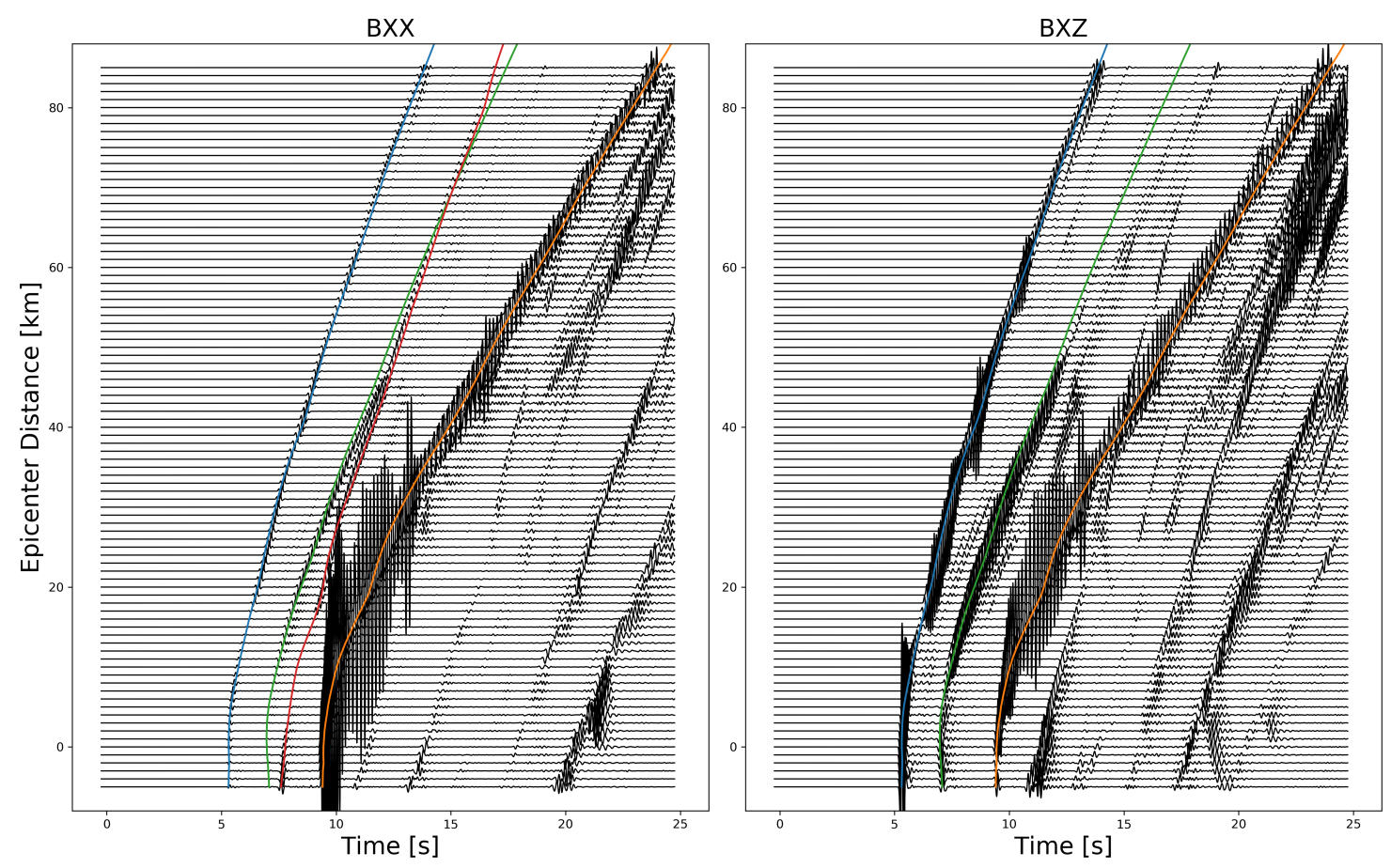

Figure A-3: 2D wave propagation simulation. Waveforms recorded at surface stations. Blue, orange, green and red lines are the predicted arrival times for P, S, SP and Ps.

For $\mathrm{P}$ and $\mathrm{S}$ wave, the predicted arrival times match the actual arrival time within $0.2 \mathrm{~s}$. For SP and PS phase from the top of the slab, the raytracing code also makes a reasonable prediction. The arrival times of the SP and Ps phases become very close to each other beyond $50 \mathrm{~km}$. There would be interference between the two phases. This might explain the notch observed in the frequency spectrum in Fig. 3-3, but the SP phases will be stronger on vertical component and PS stronger on horizontal component.

In general, we define what we mean by converted phase in the earlier part of the paper to avoid confusion with conventional seismology definations. The reflection type of SP phase is indeed what we see on some of the stations. This type of phase will appear beyond a certain distance when there will be total reflection occurs for the transmission type of $\mathrm{P}$ wave. For the distance that we considered in the paper, it is unlikely to observe a PP phase. The raytracing code from tomoDD could give a relative accurate prediction of the $\mathrm{P}, \mathrm{S}, \mathrm{Ps}$ and SP phases. For station JCC, the arrival times of Ps and SP phases are close. There might be some interference between these two phases. Since the converted phase observed on station JCC is stronger on the vertical component, and the beamforming result indicate that the ray leaves the source with an shear wave speed. We believe that it is the SP converted phase. 


\section{A.3 Effects of dipping slab}
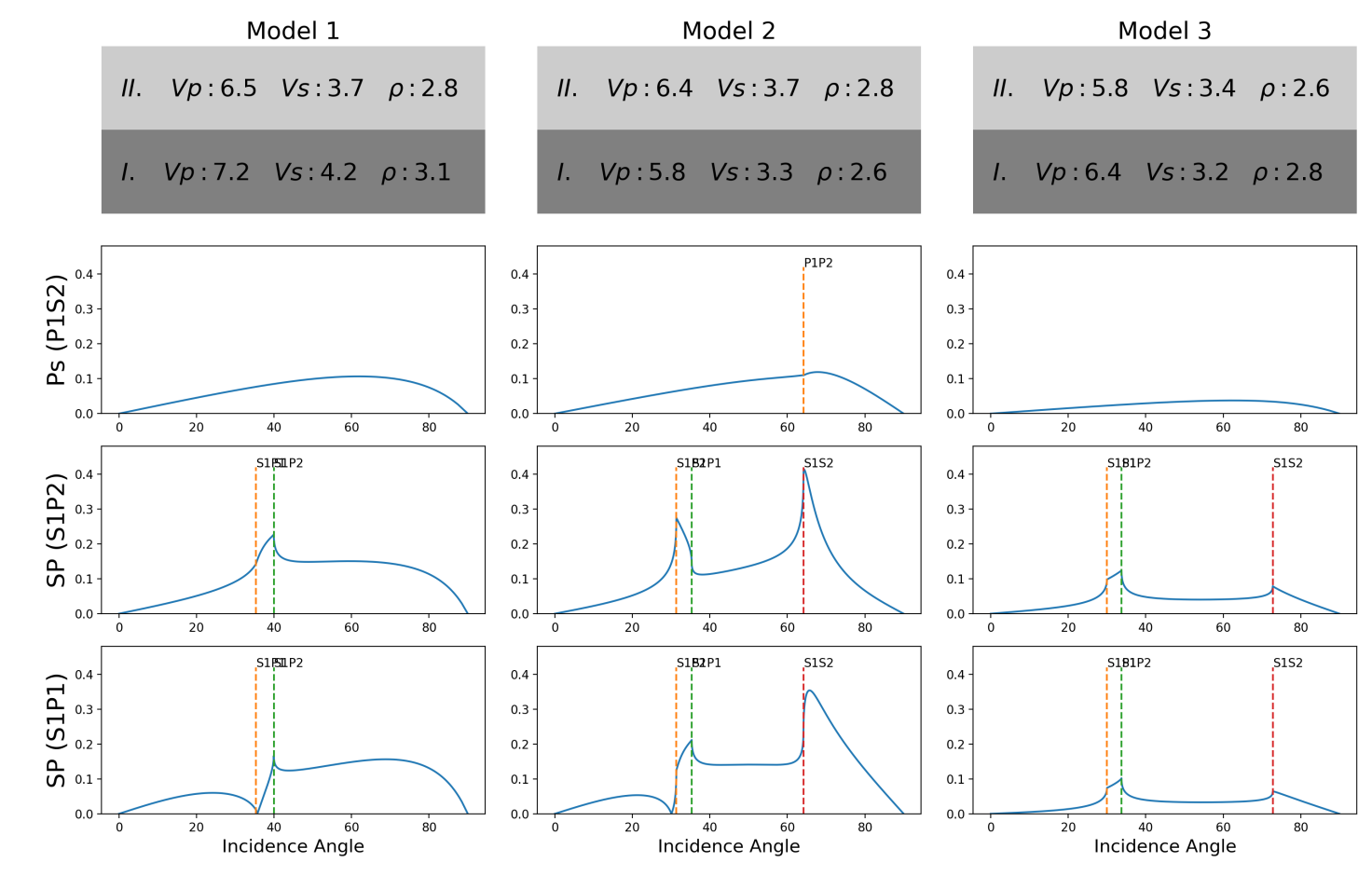

Figure A-4: Transmission/reflection coefficients as a function of incident angle for Ps and $\mathrm{SP}$ phases. The dashed lines represent the incidence angle at which certain phases reach the total reflection angle ( $0^{\circ}$ is normal incidence).

Our results should not be significantly affected by the slab dip because the dip angle is only about $5-6^{\circ}$ at the location of the conversion points. To quantify this, we constructed three simple models, shown in Fig. A-4 and calculated the reflection/transmission coefficients for Ps and SP converted phases as a function of incident angle. Model 1 has a velocity change from high to low for both $\mathrm{P}$ and $\mathrm{S}$ waves, which potentially represents the top of the subducted oceanic Moho. Model 2 has a velocity change from low to high for both $\mathrm{P}$ and $\mathrm{S}$ waves, which represents the top of a low velocity layer. Model 3 has a high to low velocity change for $\mathrm{P}$ but a low to high velocity change for $\mathrm{S}$, which represents the top of a low shear-wave velocity layer. The incident $\mathrm{P}$ or $\mathrm{S}$ propagates upward through layer 1 to the boundary. Figure 1 uses a simple naming convention for the various phases, e.g. a wave that starts as a $\mathrm{P}$-wave in layer 1 and converts to a $\mathrm{S}$ wave in layer 2 is called: P1S2. We use equations (5.35) to (5.40) in Aki and Richards (2002) to calculate the reflection/transmission coefficients for the three types of converted phases considered in the paper (Fig. A-4).

For Ps phases, the analysis is relatively simple. Even though the true incidence angle is 
unknown, we assume that it is in the $\sim 40^{\circ}-60^{\circ}$ range based on raytracing. A $6^{\circ}$ incident angle change will cause less than $\sim 10 \%$ transmission coefficient reduction. Similarly, for most incidence angles, a $6^{\circ}$ change in the SP phase would produce a small change in the transmission/reflection coefficient. However, near the total internal reflection angles the coefficients might change by $\sim 30-50 \%$ over a small change in incidence angle (Fig. A-4), but we don't expect this to be a common occurrence in our dataset.

In general, compared to our synthetic calculations with a 1D layered model, introducing a dipping slab would reduce the amplitude of the converted phase in most cases. This reduction would increase the difference between the simulation results and the real data in Fig. 3-11 of the paper. Thus, adding the effect of dip would strengthen our conclusion that the subducted slab is likely to be a low velocity zone for at least the $\mathrm{S}$ wave.

\section{A.4 Additional results}

\section{A.4.1 Central onshore stations with Ps arrivals}

Six onshore stations, CM02A, CM04A, CM05A, CM06A, CM08A and KCT, are grouped together owing to converted phases close to the predicted Ps arrival time from Slab 1.0 model. Two stations, CM06A and KCT, are shown in Fig. A-5. The location of the Ps conversion points from Slab 1.0 model would be between $16 \mathrm{~km}-19 \mathrm{~km}$ depth and just onshore. On the waveform sections, seismic phases at the predicted arrival time from the Slab 1.0 model are observed on both stations. Their raypaths are shown in Fig. A-5(b). We select events with larger amplitudes and apply the beamforming method to those phases. The beamforming results indicate those phases leave the source with $\mathrm{P}$ wave velocity. The azimuth and takeoff angle estimates of CM06A are consistent with the event-station azimuths and raytracing. The azimuth and takeoff angle estimates for $\mathrm{KCT}$ have greater uncertainty, but still indicate the raypath leaving the source likely has a larger takeoff angle than CM06A as expected. Based on the predicted arrival times and beamforming, we identify these phases as Ps converted phases from discontinuities near the slab interface model. Comparing to the cross section Fig. A-5(b), the Ps conversion points are likely from the top of the high $\mathrm{Vp} / \mathrm{Vs}$ zone. 

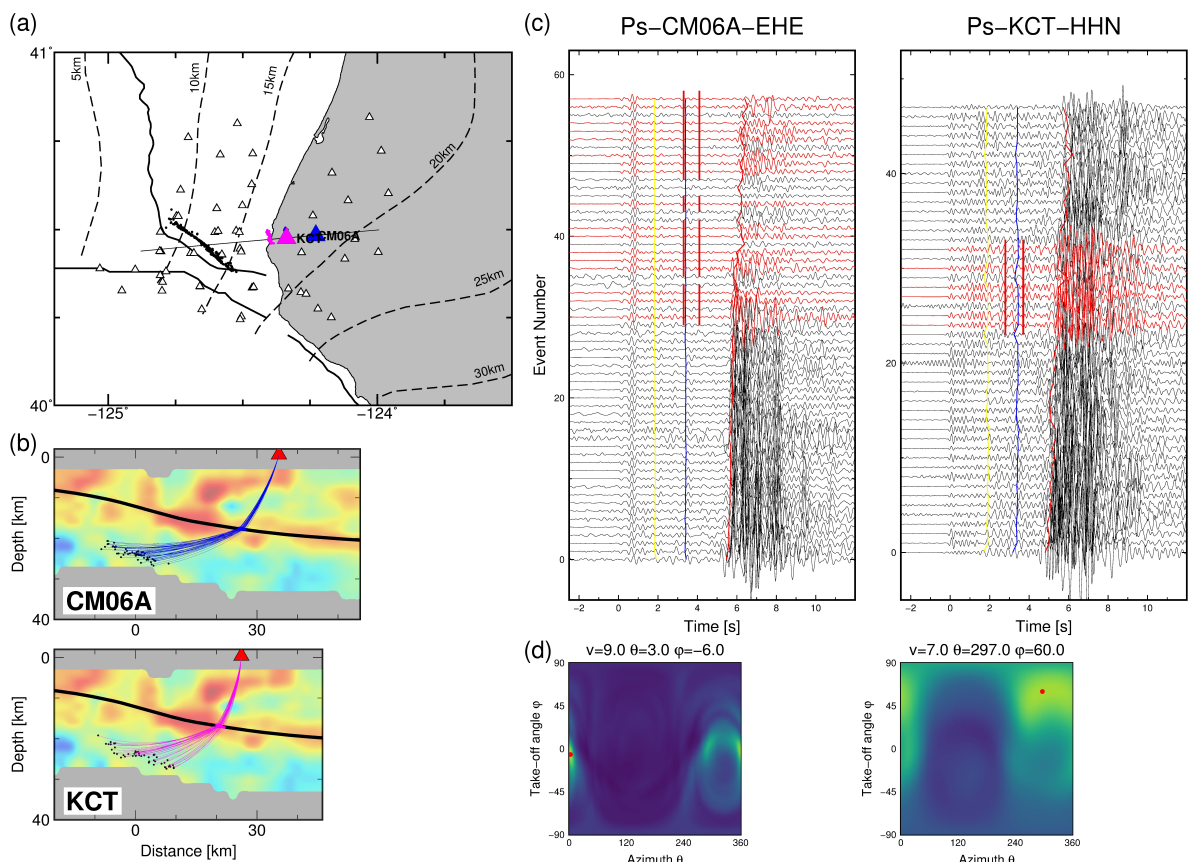

Figure A-5: Ps converted phases at stations in the middle of the array. (a) Map view of the locations of earthquake (black dots), Ps conversion points (magenta dots), the stations (triangles), and the of cross sections shown in (b) going through the center of M-fault events to stations CM06A and KCT. (b) Ps phase raypaths from the M-fault events to stations CM06A and KCT. The background colors denote the Vp/Vs model as in Fig. 3-2 . (c) Waveform sections of M-fault events on vertical component of station CM06A and KCT. The waveforms are aligned by $\mathrm{P}$ wave and are sorted by S-P traveltime difference. Waveforms used for beamforming are highlighted in red with the red bars denoting the time window used in the beamforming analysis. The blue curve denotes the predicted Ps arrival time for conversion at the Slab 1.0 model interface and the yellow curve denotes the predicted Ps arrival time from an interface $10 \mathrm{~km}$ shallower than the Slab 1.0 model. (d) Beamforming results for selected converted phases at CM06A (left) and KCT (right). The maximum intensity point is marked by the red dots and the corresponding velocity, azimuth and take off angle are given in the title of the panel.

\section{A.4.2 OBS stations with SP and Ps arrivals}

For the OBS stations, we focus on the deep water stations because they have sufficiently high signal to noise ratios on the pressure components to permit the use of the wavefield decomposition technique. Both the Ps and SP phases are observable on those stations. As an example, Ps and SP results for station FS13D are shown in Fig. A-6. The location of the Ps conversion points are very close to the station, while the location of the SP conversion points spread out between 10 and $15 \mathrm{~km}$ depth on the slab interface. On the waveform sections, clear signals arrived about $2.4 \mathrm{~s}$ after the direct $\mathrm{P}$ wave (BH2 component) and at 
(a)
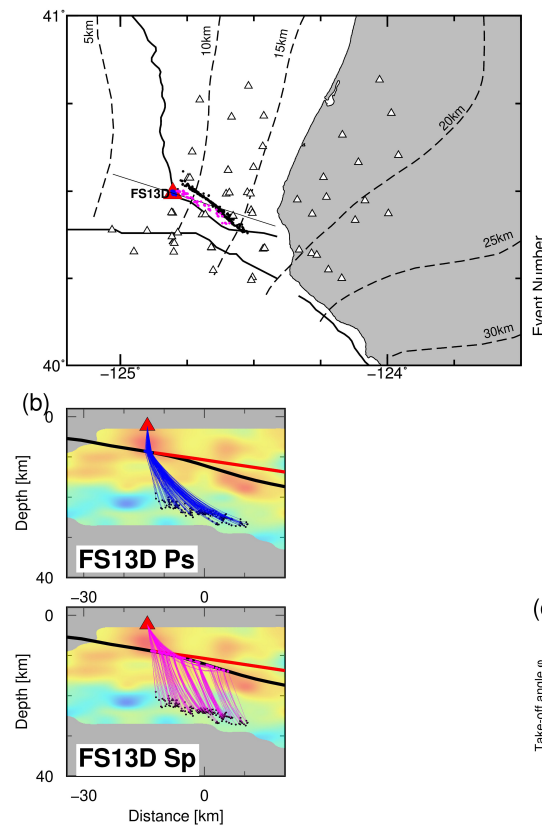

(c)
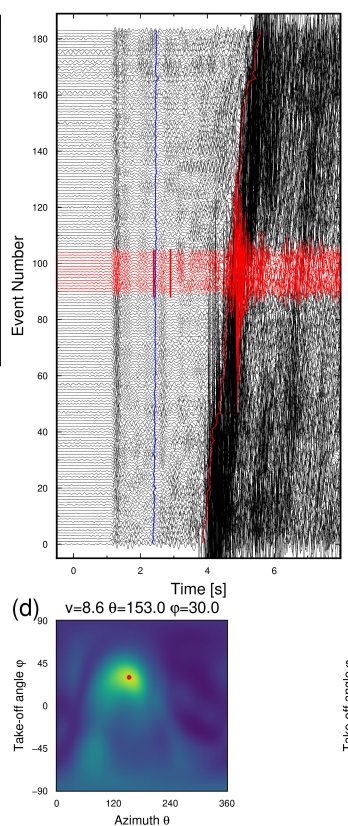

SP-FS13D- $U_{2}^{\sigma_{z z}}$
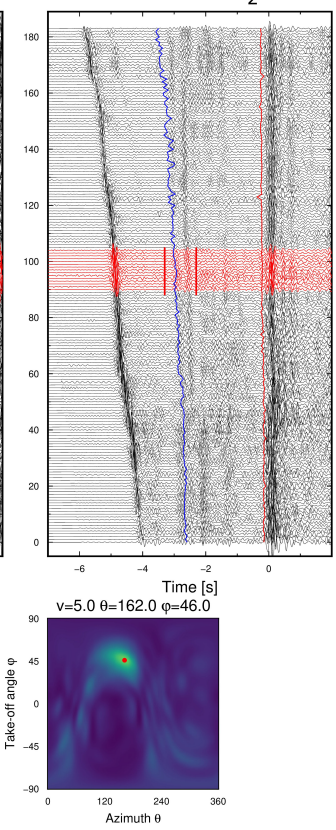

Figure A-6: Ps and SP converted phases on OBS station FS13D near the deformation front. (a) Map view of the locations of earthquakes (black dots), SP (magenta dots) and Ps (blue dots) conversion points, station FS13D (triangle), and the cross sections shown in (b) going through station FS13D and the center of the M-fault events. (b) Ps and SP raypaths from the M-fault events to station FS13D. The background colors denote the Vp/Vs model as in Fig. 3-2. (c) Waveform sections of M-fault events on the horizontal and $U_{2}^{\sigma_{z z}}$ components of station FS13D. For the Ps converted phase, the waveforms are aligned by $\mathrm{P}$ wave and for the SP converted phase, the waveforms are aligned by S wave. All the waveforms are sorted by S-P traveltime difference. Waveforms used for beamforming are highlighted in red with the red bars denoting the time window used in the beamforming analysis. The blue curves denote the predicted Ps and SP arrival times for conversion at the Slab 1.0 model interface. (d) Beamforming results for the selected converted phases on the horizontal (left) and the $U_{2}^{\sigma_{z z}}$ component (right). The maximum intensity point is marked by the red dots and the corresponding velocity, azimuth and take off angle are given in the title of the panel.

about $2.7 \mathrm{~s}$ before $\mathrm{S}$ wave on the $U_{2}^{\sigma_{z z}}$ component. Their raypaths are shown in Fig. A-6(b). We selected events with large amplitude arrivals and applied the beamforming method to those phases. The beamforming results indicate the phases on the $\mathrm{BH} 2$ component leave the source with a $\mathrm{P}$ wave velocity while the phase on the $U_{2}^{\sigma_{z z}}$ component leave the source with a $\mathrm{S}$ wave velocity. The azimuth and takeoff angle estimates are consistent with eventstation geometry and raytracing results. Based on the results from arrival time prediction and beamforming, we identify these phases as Ps on BH2 and SP on $U_{2}^{\sigma_{z z}}$. And due to the relatively strong amplitude of these converted phases, we identify them as converted phases generated from sediment to oceanic crust boundary. Similar results were found for stations 
FS09D, FS07D, FS16D and FS41D.

\section{A.5 Figures}
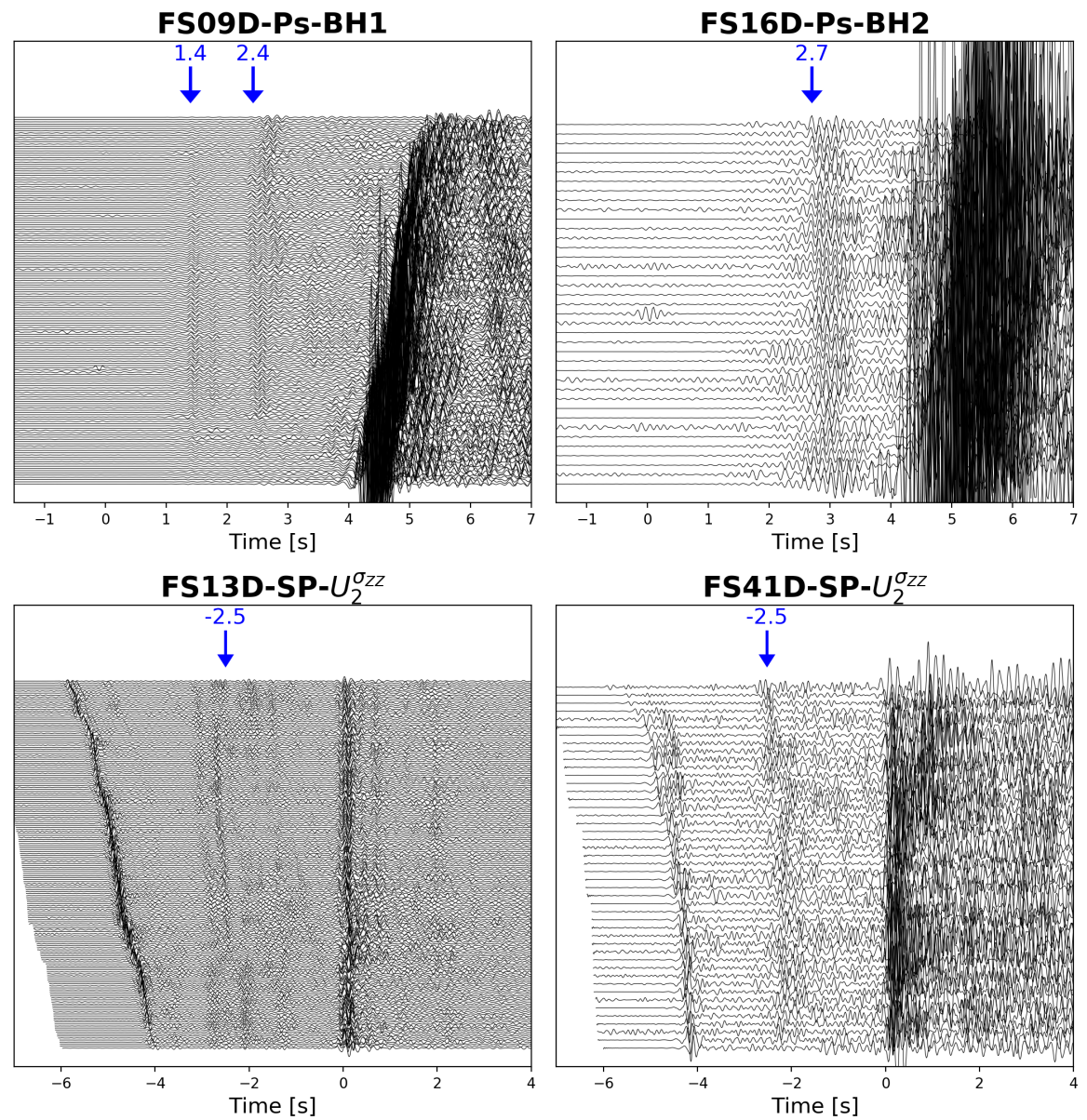

Figure A-7: Ps and SP converted phases on OBS stations. Top row: Ps converted phases on one of the horizontal components of stations FS09D and FS16D. The waveforms are aligned by $\mathrm{P}$ wave and sorted by S-P traveltime difference. The blue arrows show the arrival time of the converted phase after $\mathrm{P}$ wave. The Ps phases around $2.5 \mathrm{~s}$ are interpreted as conversions from the top of the oceanic crusts. Bottom row: SP converted phases on the $U_{2}^{\sigma_{z z}}$ component after wavefield decomposition on stations FS13D and FS41D. The waveforms are aligned by $\mathrm{S}$ wave and sorted by S-P traveltime difference. The blue arrows show the arrival time of the SP converted phase before S wave. They are interpreted as conversions from the top of the oceanic crusts. 
$1 \mathrm{~A}$

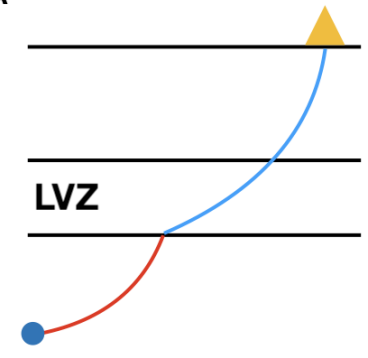

1B

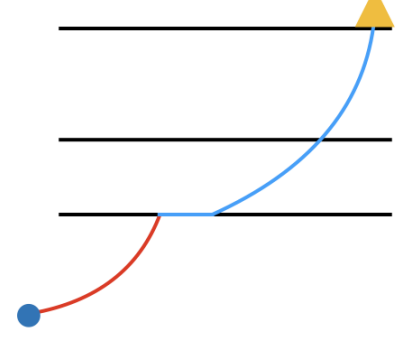

2

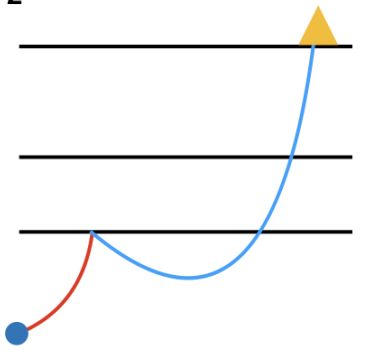

Figure A-8: Schematic plots of SP converted phase raypaths for B047 synthetic waveforms. Red curves represent $\mathrm{S}$ wave and blue curves represent $\mathrm{P}$ wave. Visually inspecting the synthetic waveforms, there are two SP converted phases generated from the bottom of the low velocity layer. It is either the combination of $1 \mathrm{~A}$ and 2 or the combination of $1 \mathrm{~B}$ and 2 .

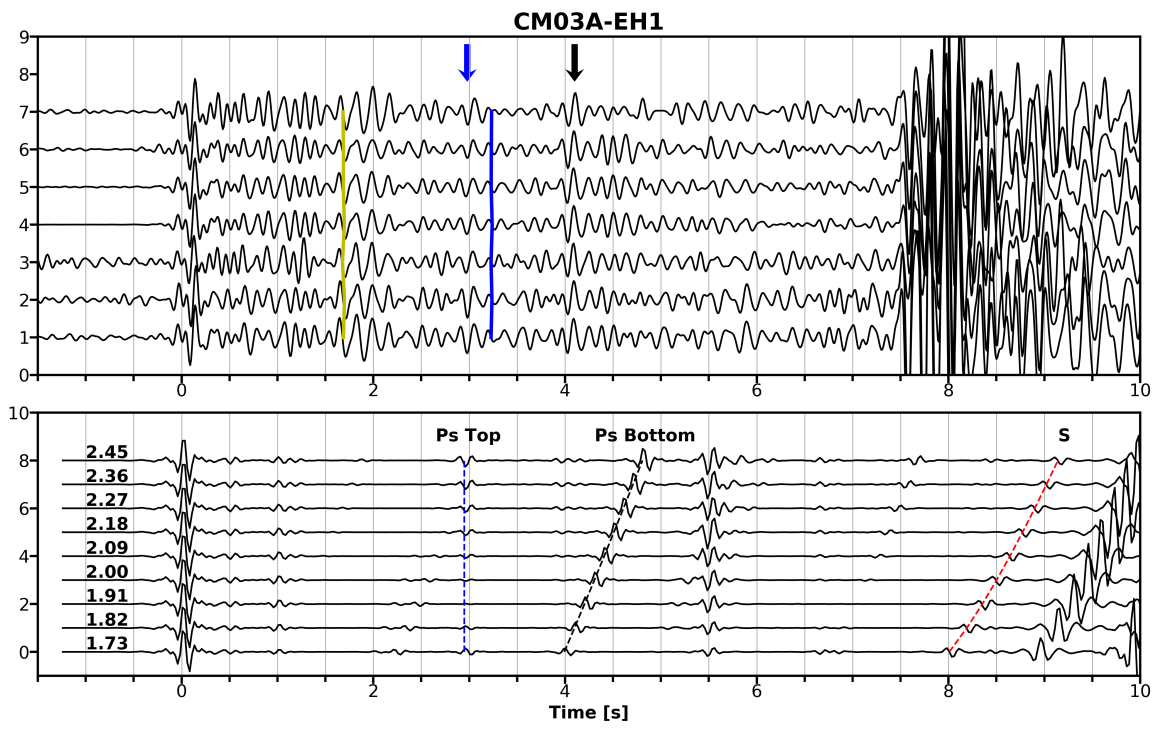

Figure A-9: Comparison between real data and synthetic data for station CM03A. Top: First 7 waveforms used in the beamforming analysis on the EH1 component of station CM03A. They are aligned by $\mathrm{P}$ wave and sorted by S-P traveltime difference. Blue and yellow lines are the predicted Ps arrival times for Slab 1.0 and Slab $1.0+10 \mathrm{~km}$ models. A weak coherent phase is visible before the predicted Ps arrival time of Slab 1.0 model and is indicated by the blue arrow. The black arrow indicates the Ps phase used for beamforming analysis that likely is the Ps conversion from the subducted slab Moho. Bottom row: Case 3 synthetic waveforms for station CM03A with different $\mathrm{Vp} / \mathrm{Vs}$ ratios inside the subducted oceanic crust. The $\mathrm{Vp} / \mathrm{Vs}$ value for each simulation is labeled at the beginning of each trace. The dashed blue, black and red lines are the arrival times of Ps from the top of the crust, Ps from the bottom of the crust and $\mathrm{S}$ waves. 

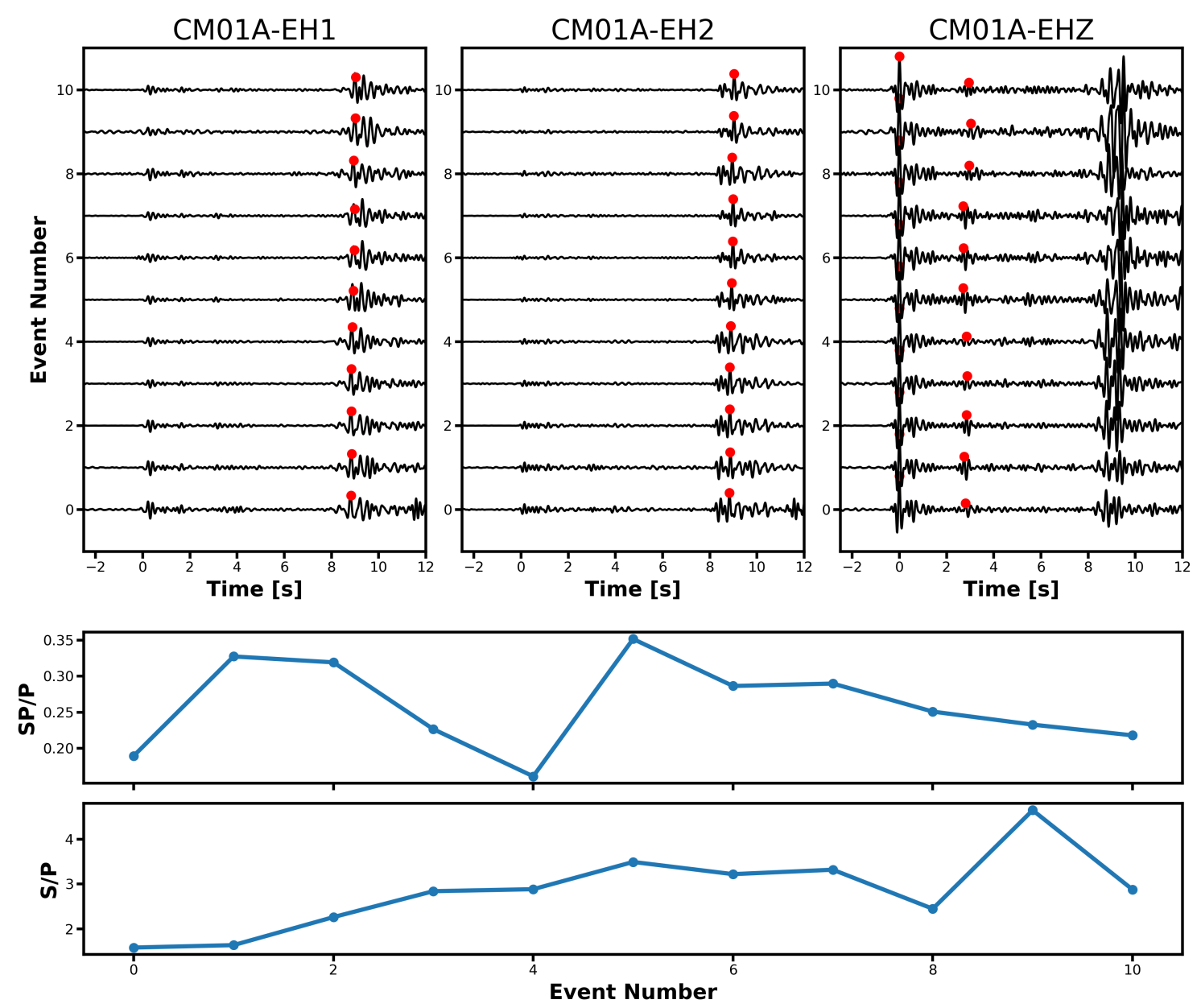

Figure A-10: Examples of amplitude ratio variations for clustered events at station CM01A. (a) Three component seismograms on CM03A. The red dots show the points where P, S and $\mathrm{SP}$ phase amplitudes are measured. Waveforms are aligned by $\mathrm{P}$ wave and sorted by S-P traveltime difference. (b) $\mathrm{SP} / \mathrm{P}$ and $\mathrm{S} / \mathrm{P}$ amplitude ratio measurements. 

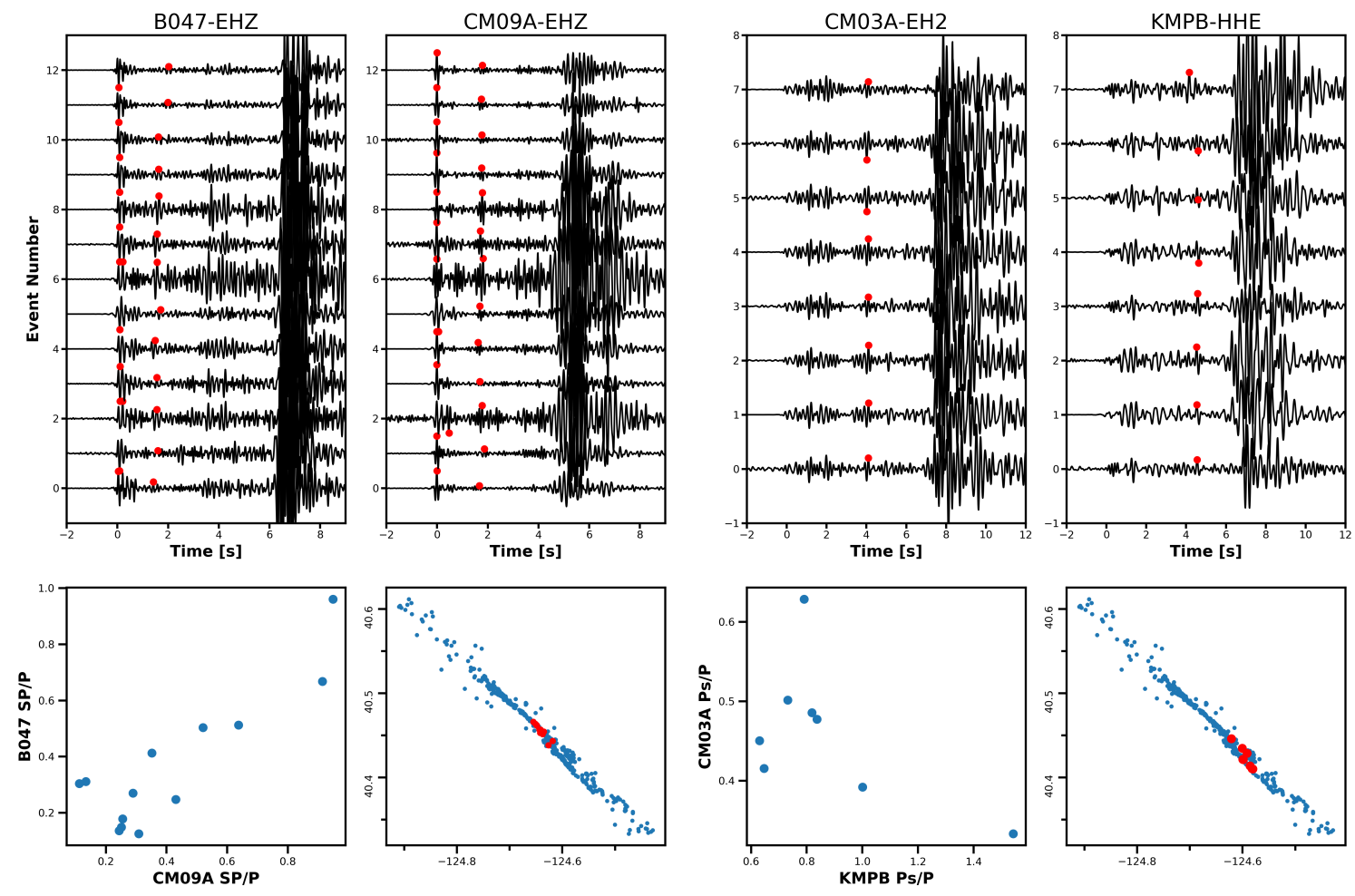

Figure A-11: Examples of amplitude ratio variations for common events recorded by two station pairs B047-CM09A and CM03A-KMPB. (a) Vertical component seismograms of common events recorded by B047 and CM09A and one of the horizontal component seismograms of common events recorded by CM03A and KMPB. The red dots show the points where P and SP phase amplitudes are measured for B047 and CM09 and the points where Ps phase amplitudes are measured for CM03A and KMPB. (b) Relation between amplitude ratio measurements on the two station pairs and the locations of the common events on the M-fault.
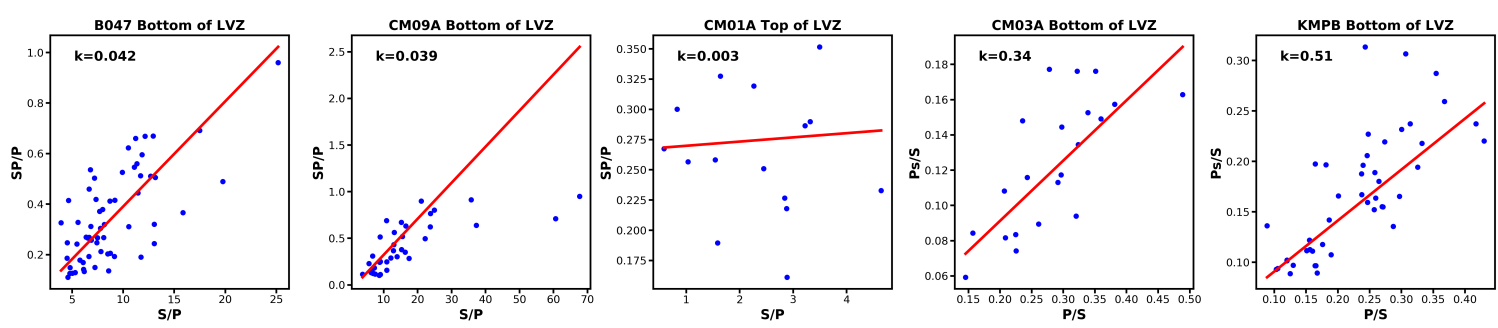

Figure A-12: Amplitude ratio variations on single station. The red lines are linear fittings of the scattering points. Their slopes are shown in the top left corner. 


\section{Appendix B}

\section{Appendix for "Observations of}

\section{Guided Waves from Slab Interface}

\section{Earthquakes"}

\section{B.1 Recurrence rate of the five clusters}

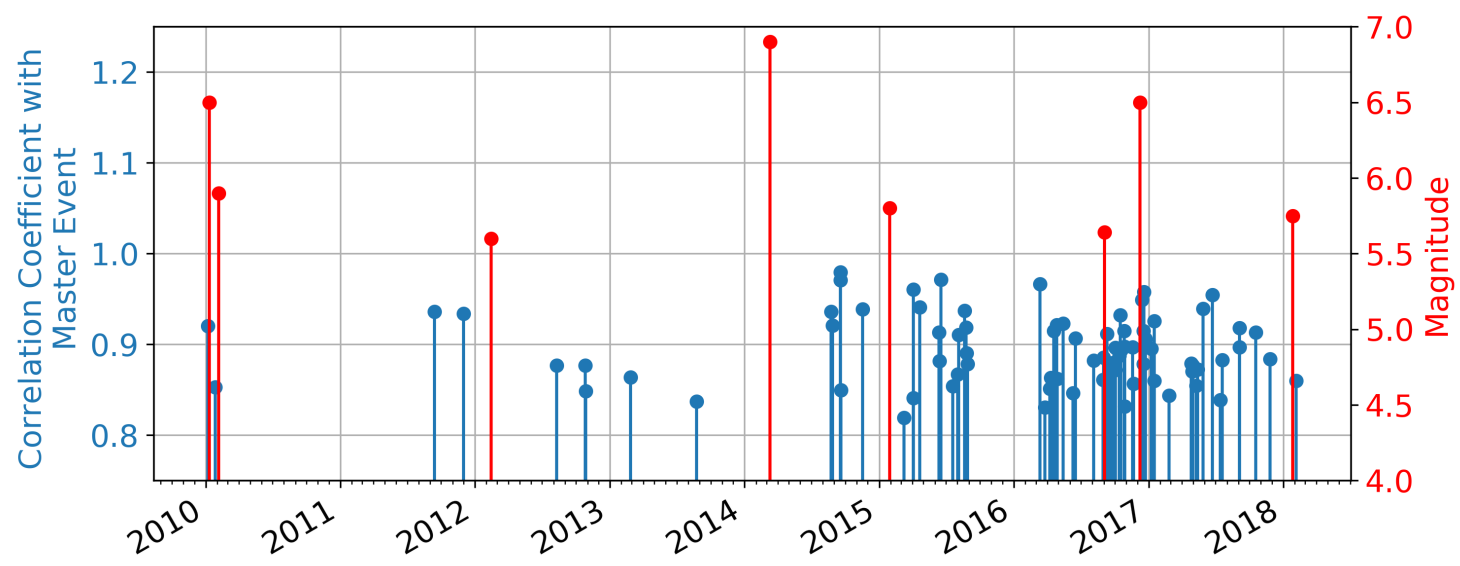

Figure B-1: Recurrence rate of events in cluster C1 from 2008 to 2018. Each blue stem represents an event in cluster $\mathrm{C} 1$. The amplitude represents the correlation coefficient with the master event. Each red stem represents the occurrence an earthquake with magnitude greater than 5.5 near MTJ.

We performed a match filter detection to study the temporal variation of the occurrence rate of the cluster events using the permanent stations near MTJ from year 2008 to year 2018. The recurrence behavior of the cluster C1 is shown in Fig. B-1. For cluster C1, the 


\begin{tabular}{cc|cc}
\hline Station Name & Rotation Angle $\left(^{\circ}\right)$ & Station Name & Rotation Angle $\left(^{\circ}\right)$ \\
\hline ST1 & -181 & ST11 & -179 \\
ST2 & 192 & ST12 & -178 \\
ST3 & -163 & ST13 & -175 \\
ST4 & -173 & ST14 & -155 \\
ST5 & -169 & ST15 & -170 \\
ST6 & 5 & ST16 & -154 \\
ST7 & 13 & ST17 & -171 \\
ST8 & -181 & ST18 & -171 \\
ST9 & -182 & ST19 & -181 \\
ST10 & 181 & ST20 & -170 \\
\hline
\end{tabular}

Table B.1: Rotation angle estimates for the nodes in the second deployment.

occurrence rate is higher from 2014 to 2017. However, there is no clear correlation between the occurrence of the clustered earthquakes with big offshore earthquakes, indicating these earthquakes are not triggered by the stress perturbation induced from these earthquakes or there is a delayed response.

\section{B.2 Sensor rotate}

The orientation of the two horizontal components were not well constrained during nodal array deployment. We calibrate the orientation of the two horizontal components on the nodes by correlating teleseismic waveforms of the nodes with station KCT. A hour long waveforms of a M6.3 earthquake occurred on 2019-11-24 00:54:01 from Aleutian Islands were used for the correlation. The waveforms are filtered between 0.04 to $0,1 \mathrm{~Hz}$. We grid search the rotation angle for the nodes to achieve the best correlation coefficients with the two horizontal components of station KCT. The estimated rotation angle for each node is listed in Table B.1.

\section{B.3 Near surface velocity}

We used the 3D beamforming method described in the previous chapter to estimate the near surface $\mathrm{P}$ and $\mathrm{S}$ wave velocity. This method assumes that $\mathrm{P}$ and $\mathrm{S}$ waves can be approximated as plane waves passing through the network. With the beamforming technique, we are able to estimate the propagation velocity, azimuth and incident angle of $\mathrm{P}$ and $\mathrm{S}$ waves. An example of the beamforming process on $\mathrm{P}$ wave of event 84 is shown in Fig. B-2. 
(a)

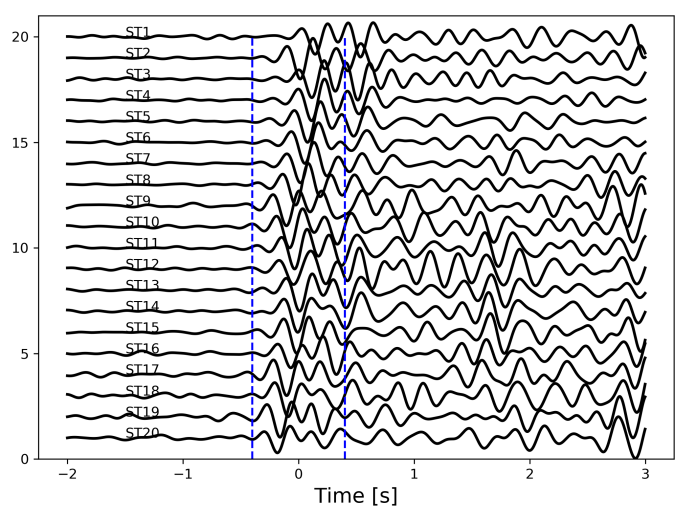

(c)

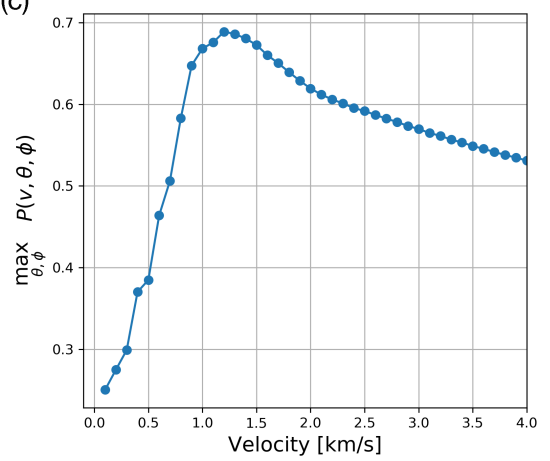

(b)
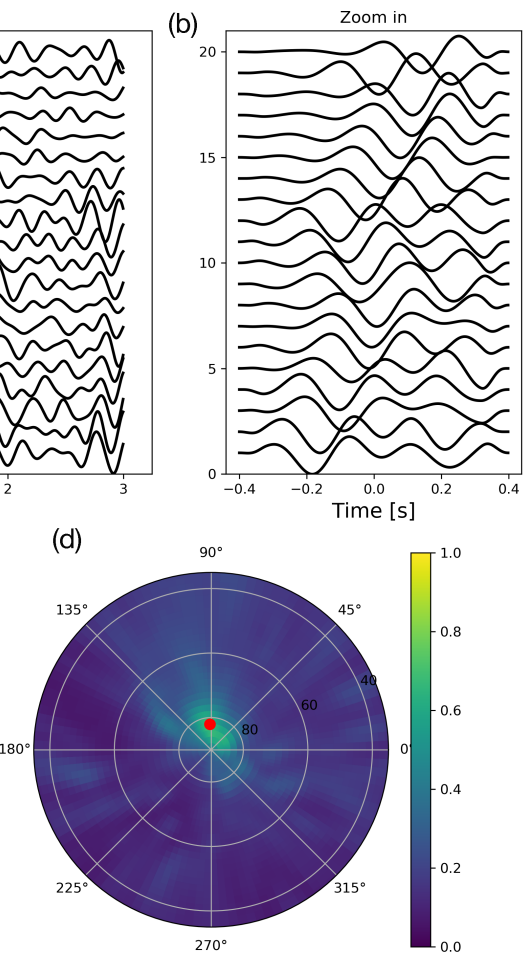

(e)

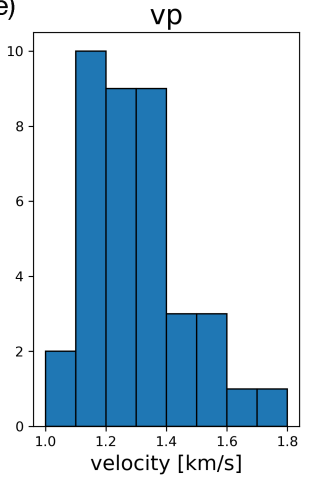

(f)

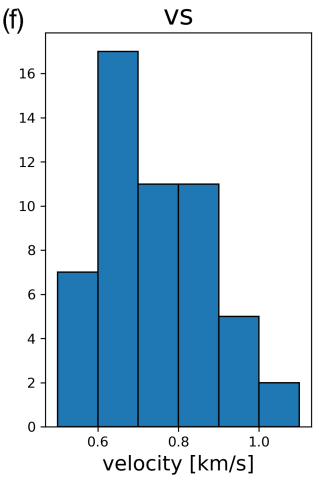

Figure B-2: 3D beamforming result on $\mathrm{P}$ wave of event 84. (a) Vertical component waveform section of event 84 on all the nodes. The waveforms are filtered between $1-5 \mathrm{~Hz}$. The blue dashed lines mark the time window for doing 3D beamforming. (b) Zoom in of the waveform between the two blue dashed lines. (c) Maximum beam power as a function of velocity. (d) Beam power as a function of incident angle and azimuth that is associated with the best velocity estimate in (c). (e) and (f) Near surface $\mathrm{P}$ and $\mathrm{S}$ wave velocity estimates from $3 \mathrm{D}$ beamforming method from all available events.

The waveforms are filtered between $1.5 \mathrm{~Hz}$ to $8 \mathrm{~Hz}$ for $\mathrm{P}$ waves and $1 \mathrm{~Hz}$ and $5 \mathrm{~Hz}$ for S waves. A short window including the $\mathrm{P}$ or $\mathrm{S}$ waves is cut from the waveform section and is used as input for the 3D beamforming to calculate the beam power $P$ as a function of near surface velocity $v$, azimuth $\theta$ and incident angle $\phi$. For event 84 , the best estimates for $\mathrm{P}$ wave velocity, azimuth and incident angles are $1.2 \mathrm{~km} / \mathrm{s}, 90^{\circ}$ and $81^{\circ}$. We applied the same procedure to 38 events reported in NCEDC catalog and the distributions of estimated near surface $\mathrm{P}$ and $\mathrm{S}$ wave velocity are shown in Fig. B-2 (e) and (f). The medium value for $\mathrm{P}$ and $\mathrm{S}$ wave velocity estimations are $1.3 \mathrm{~km} / \mathrm{s}$ and $0.7 \mathrm{~km} / \mathrm{s}$. These numbers are used for elevation correction in the Section 4.5.2. 


\section{B.4 Polarization analysis}

Particle motion polarization can help in identifying phases on three-component seismograms (Vidale, 1986). Here we apply the principle component analysis method (Shlens, 2014) on the three-component seismograms of the master event at station KCT to calculate instantaneous strike, dip, rectilinearity, planarity and ellipticity of the particle motion. The definitions of strike, dip, rectilinearity, planarity and ellipticity could be found in Jurkevics (1988) and Vidale (1986). The results are shown in Fig. B-3.
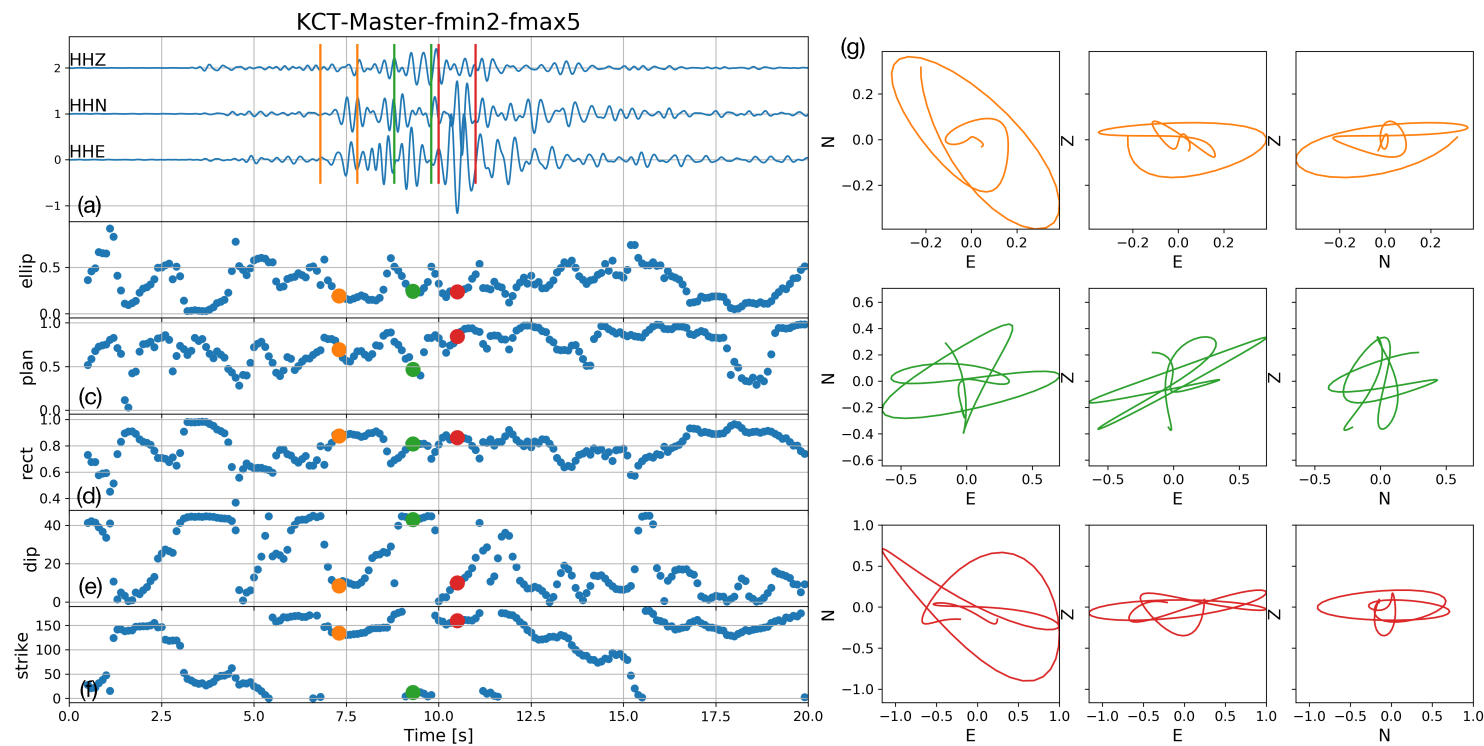

Figure B-3: Polarization analysis of the master event. (a) Three component waveforms of the master event and 3 one second long windows. (b)-(f) Running window polarization analysis and the results for ellipticity, planarity, rectilinearity, dip and strike. The big orange, green and red dots are the polarization estimates for the 3 windows in (a). (g) Particle motions of the 3 windows in (a). 


\section{B.5 Tables}

\begin{tabular}{ccc}
\hline Cluster Name & Lat/Lon/Depth $(\mathrm{km})$ & Number of Events \\
\hline C1 & $40.61^{\circ} /-124.27^{\circ} / 17.5$ & 33 \\
C2 & $40.58^{\circ} /-124.09^{\circ} / 18.4$ & 144 \\
C3 & $40.47^{\circ} /-124.41^{\circ} / 17.7$ & 10 \\
C4 & $40.49^{\circ} /-124.30^{\circ} / 17.8$ & 8 \\
C5 & $40.49^{\circ} /-124.20^{\circ} / 20.3$ & 25 \\
\hline
\end{tabular}

Table B.2: Summay of five slab interface earthquake clusters.

\begin{tabular}{|c|c|c|c|c|}
\hline Event ID & Lat/Lon/Dep & $\begin{array}{c}\text { SSZ } \\
\mathrm{P} 1 / \mathrm{P} 2\end{array}$ & $\begin{array}{c}\text { SSE } \\
\text { S1/S2 }\end{array}$ & $\begin{array}{c}\text { SSN } \\
\text { S1/S2 }\end{array}$ \\
\hline 24 & $-124.34^{\circ} / 40.81^{\circ} / 22.0$ & $0.38 / 0.2$ & $\begin{array}{l}\mathrm{NA} / 0.58 \\
\mathrm{NA} / 0.56\end{array}$ & $\begin{array}{c}\mathrm{NA} / 0.7 \\
\mathrm{NA} / 0.22\end{array}$ \\
\hline 32 & $-124.52^{\circ} / 40.73^{\circ} / 19.2$ & $0.38 / 0.28$ & $\begin{array}{l}1.04 / 0.73(1) \\
0.68 / 0.57(2)\end{array}$ & $\begin{array}{l}1.1 / 0.51(1) \\
0.8 / 0.47(2)\end{array}$ \\
\hline 9 & $-124.33^{\circ} / 40.59^{\circ} / 20.1$ & $0.34 / 0.23$ & $\begin{array}{l}1.04 / 0.31(1) \\
0.82 / 0.27(2)\end{array}$ & $\begin{array}{l}1.04 / 0.09(1) \\
0.76 / 0.11(2)\end{array}$ \\
\hline 15 & $-123.91^{\circ} / 40.61^{\circ} / 22.2$ & $0.33 / 0.24$ & $\begin{array}{c}0.9 / 0.24(1) \\
0.72 / 0.24(2)\end{array}$ & $\begin{array}{c}0.76 / 0.53(1) \\
0.49 / 0.9(2)\end{array}$ \\
\hline 19 & $-123.84^{\circ} / 40.85^{\circ} / 27.3$ & $0.33 / 0.21$ & $\begin{array}{c}\mathrm{NA} / 0.7(1) \\
\mathrm{NA} / 0.59(2)\end{array}$ & $\begin{array}{l}\mathrm{NA} / 0.43(1) \\
\mathrm{NA} / 0.36(2)\end{array}$ \\
\hline 23 & $-124.00^{\circ} / 40.56^{\circ} / 28.5$ & 0.28 & $\begin{array}{l}\mathrm{NA} / 0.26(1) \\
\mathrm{NA} / 0.69(2)\end{array}$ & $\begin{array}{l}\mathrm{NA} / 0.68(1) \\
\mathrm{NA} / 0.69(2)\end{array}$ \\
\hline 26 & $-123.49^{\circ} / 40.63^{\circ} / 29.4$ & 0.23 & $\begin{array}{c}\mathrm{NA} / 0.64(1) \\
\mathrm{NA} / 0.7(2)\end{array}$ & $\begin{array}{l}0.35 / 0.71(1) \\
0.34 / 0.69(2)\end{array}$ \\
\hline 73 & $-124.00^{\circ} / 40.52^{\circ} / 20.6$ & 0.21 & $\begin{array}{l}\mathrm{NA} / 0.38(1) \\
0.44 / 0.38(2)\end{array}$ & $\begin{array}{l}\mathrm{NA} / 0.43(1) \\
0.69 / 0.46(2)\end{array}$ \\
\hline
\end{tabular}

Table B.3: Summay of slowness analysis of events north of station KCT. Depth is in $\mathrm{km}$. Column 3 to 5 are the slowness estimates for the double $\mathrm{P}$ and doubel $\mathrm{S}$ phases. (1) represents using stations ST9 to ST20 and (2) represents using stations ST5 to ST20. NA represents no good estimates are available. 


\section{B.6 Figures}
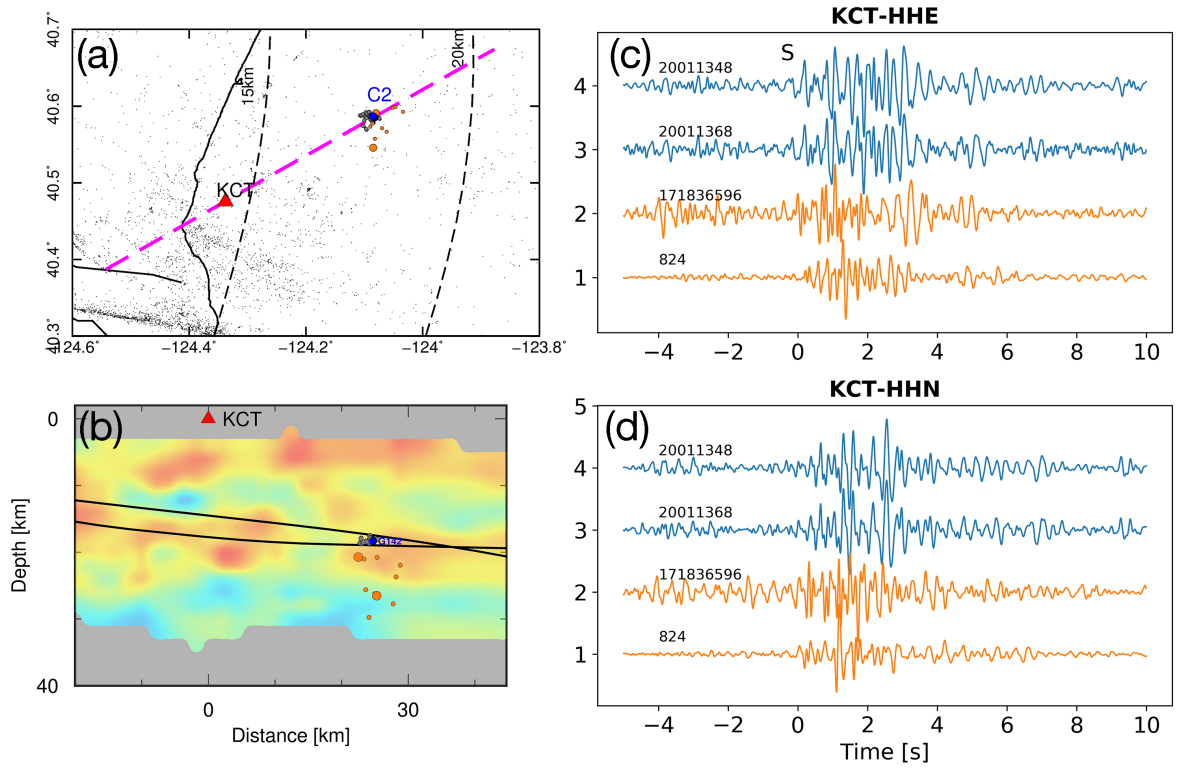

Figure B-4: Waveforms of events in and below cluster C2. (a) Map showing the locations of station $\mathrm{KCT}$, cluster $\mathrm{C} 2$ (blue circles) and events below cluster $\mathrm{C} 2$ (orange circles). The dashed line is the location of the cross section shown in (b). (b) Cross section going through cluster $\mathrm{C} 2$ and station KCT. The two big orange circles are the two events shown in (c) and (d). (c) and (d) Comparison between waveforms of events from cluster C2 (blue traces) and events below cluster $\mathrm{C} 2$ at station KCT (orange traces). The event ID is shown to the left of the waveform. Event 171836596 is the upper big orange circle and event 824 is the lower big orange circle. 

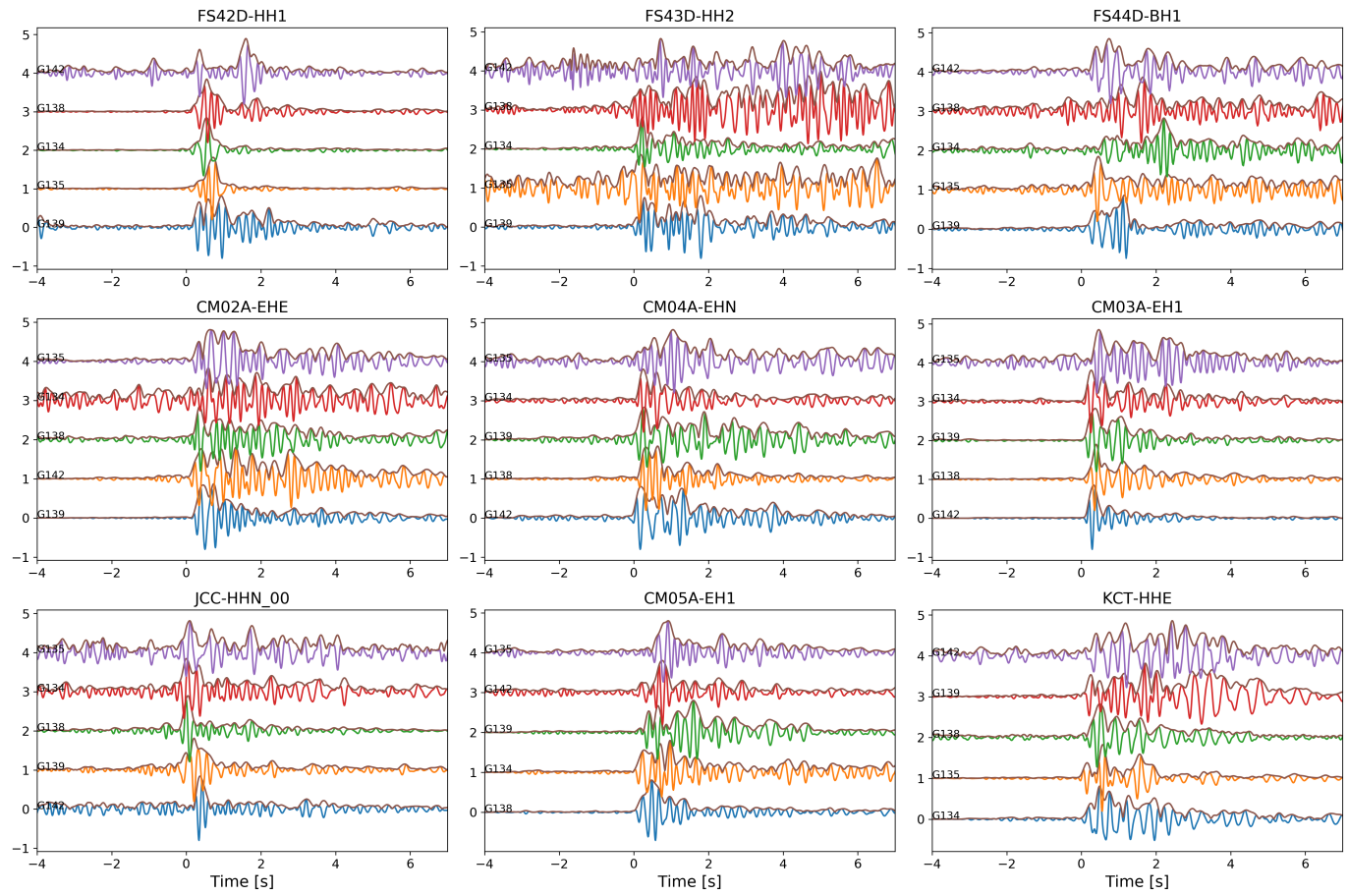

Figure B-5: Comparison of waveforms from the five clusters at individual station. The waveforms are aligned by $\mathrm{S}$ wave and sorted by epicenter distance for each station.

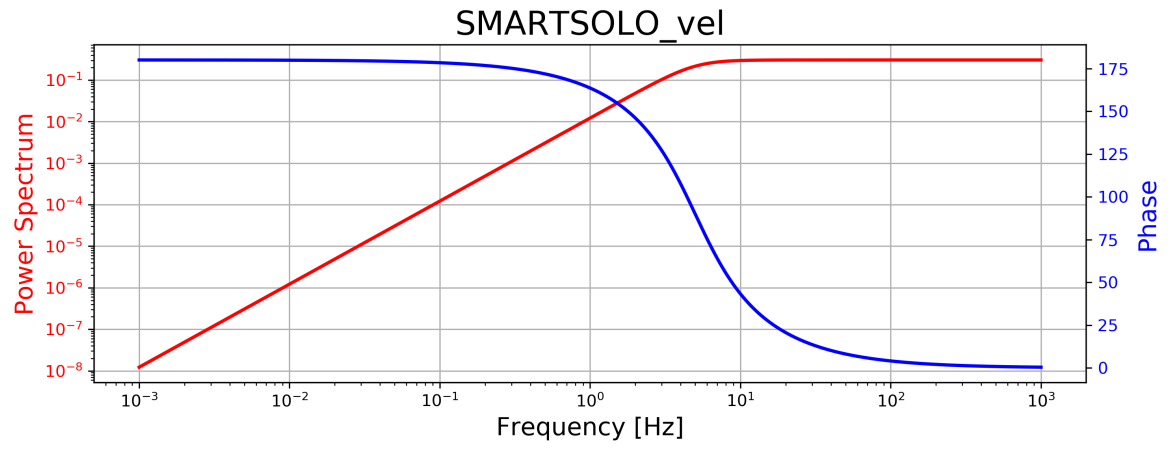

Figure B-6: Instrument response of the node. 


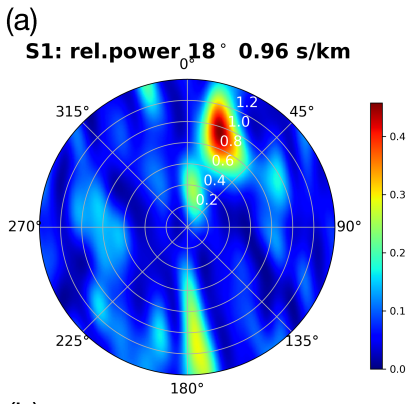

(b)

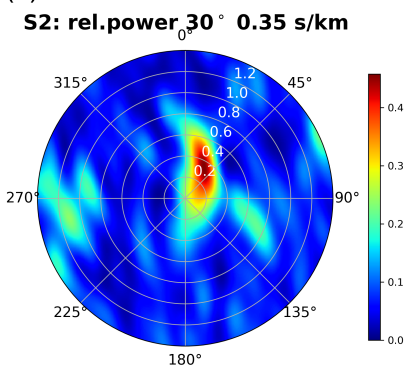

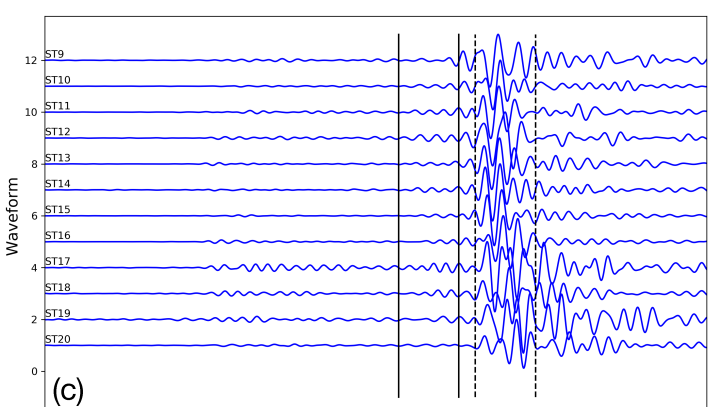
离 0.5 .
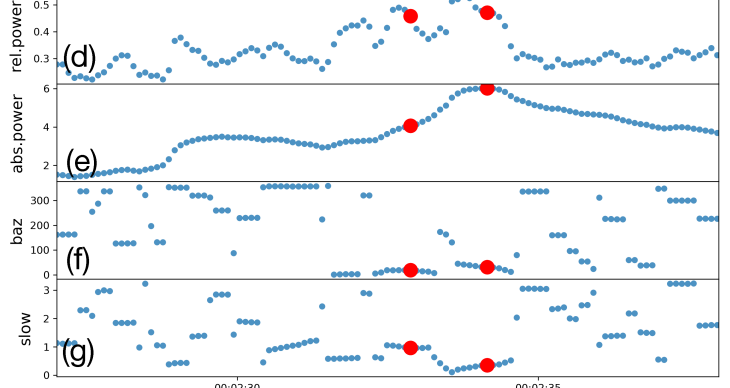

Figure B-7: Running window beamforming results on S wave for cluster C1. (a) and (b) The relative power outputs for the two time windows shown in (c). Titles show the best estimates of the back azimuth and slowness. (c) North-south component waveforms after elevation correction using near surface $\mathrm{S}$ wave velocity. The solid and dashed black lines represent the two windows for beamforming. (d)-(g) Relative power, absolute power, backazimuth and slowness estimates for the running window beamforming. Small black dots are background seismicity. 

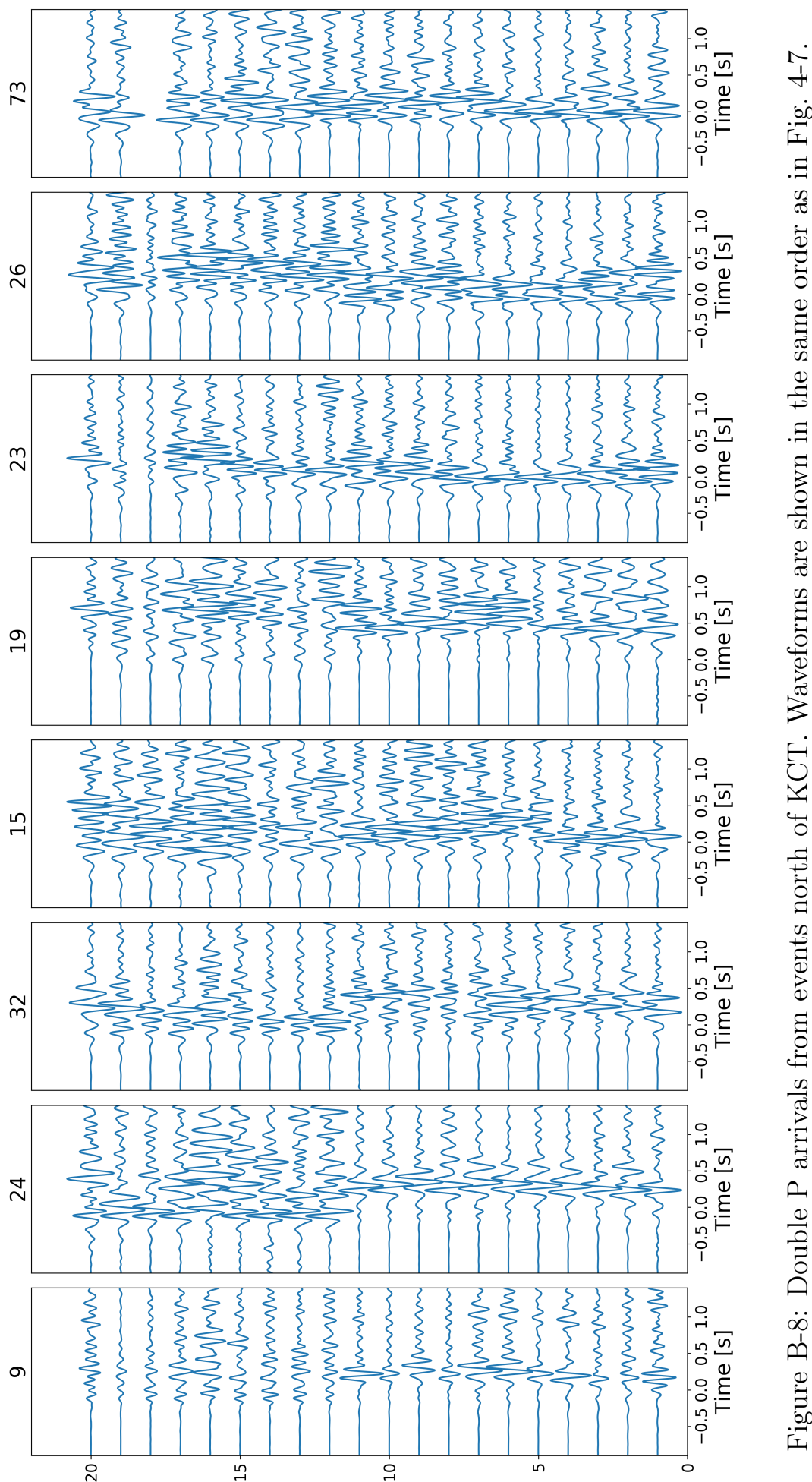


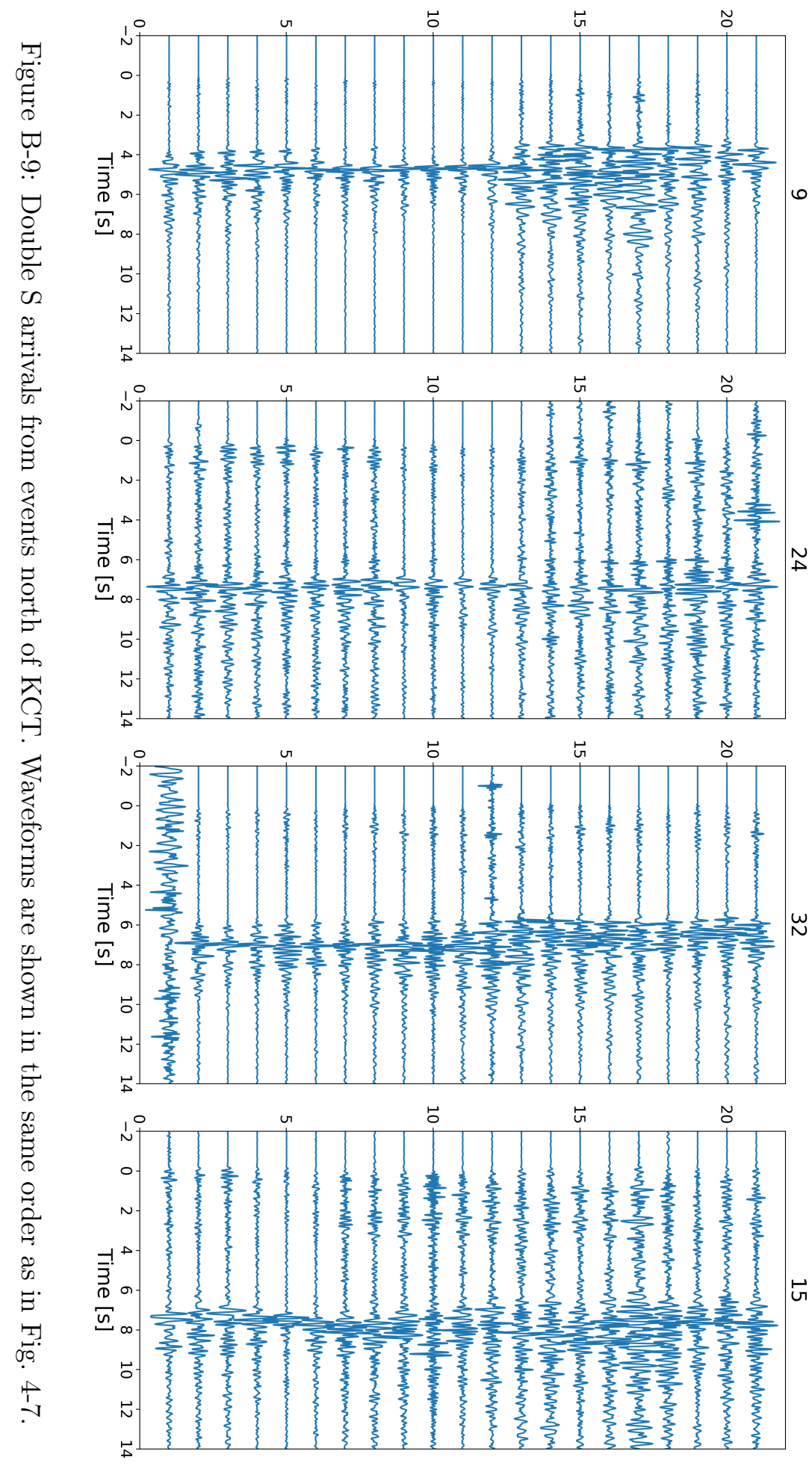




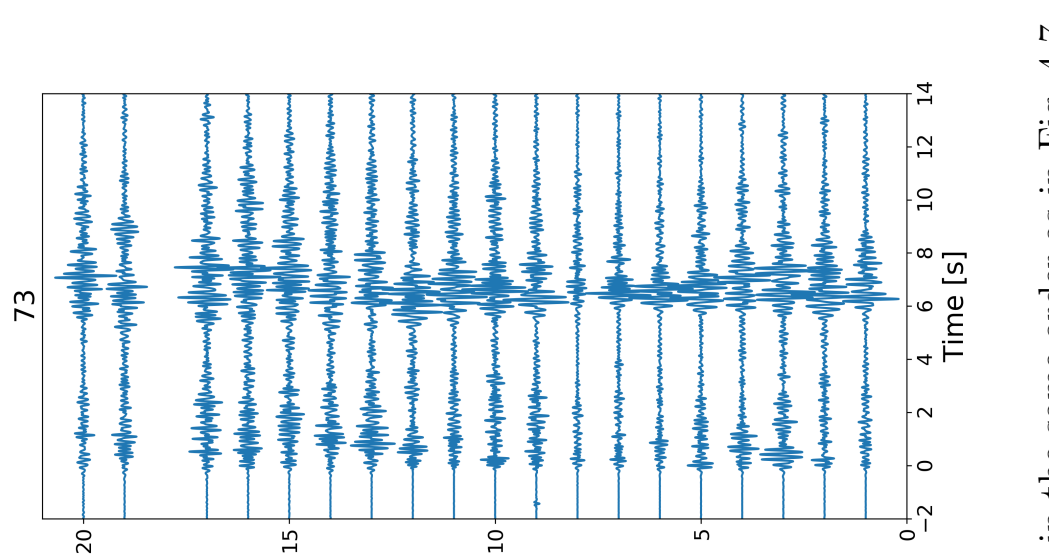

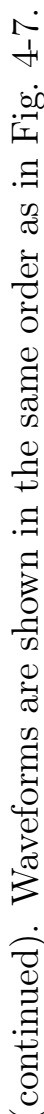
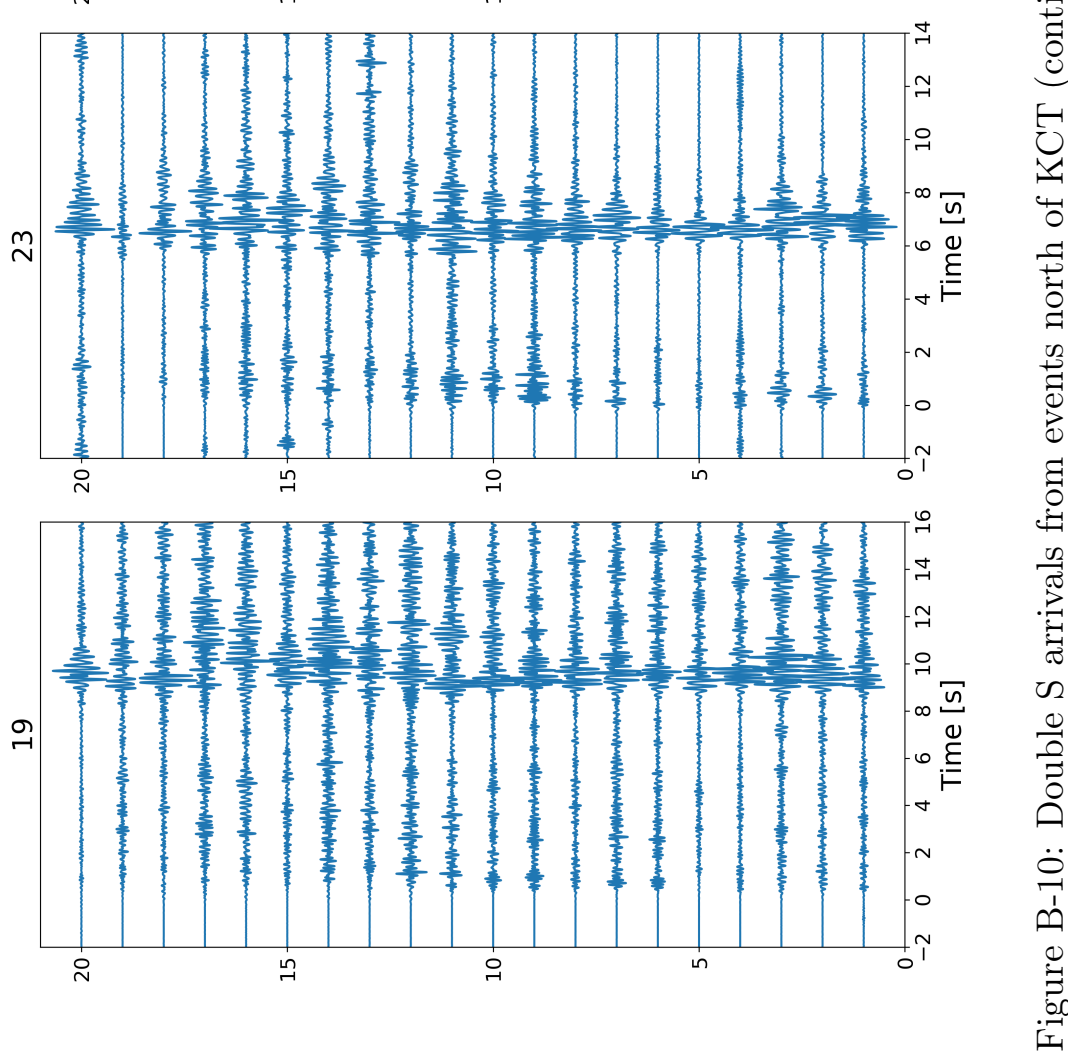


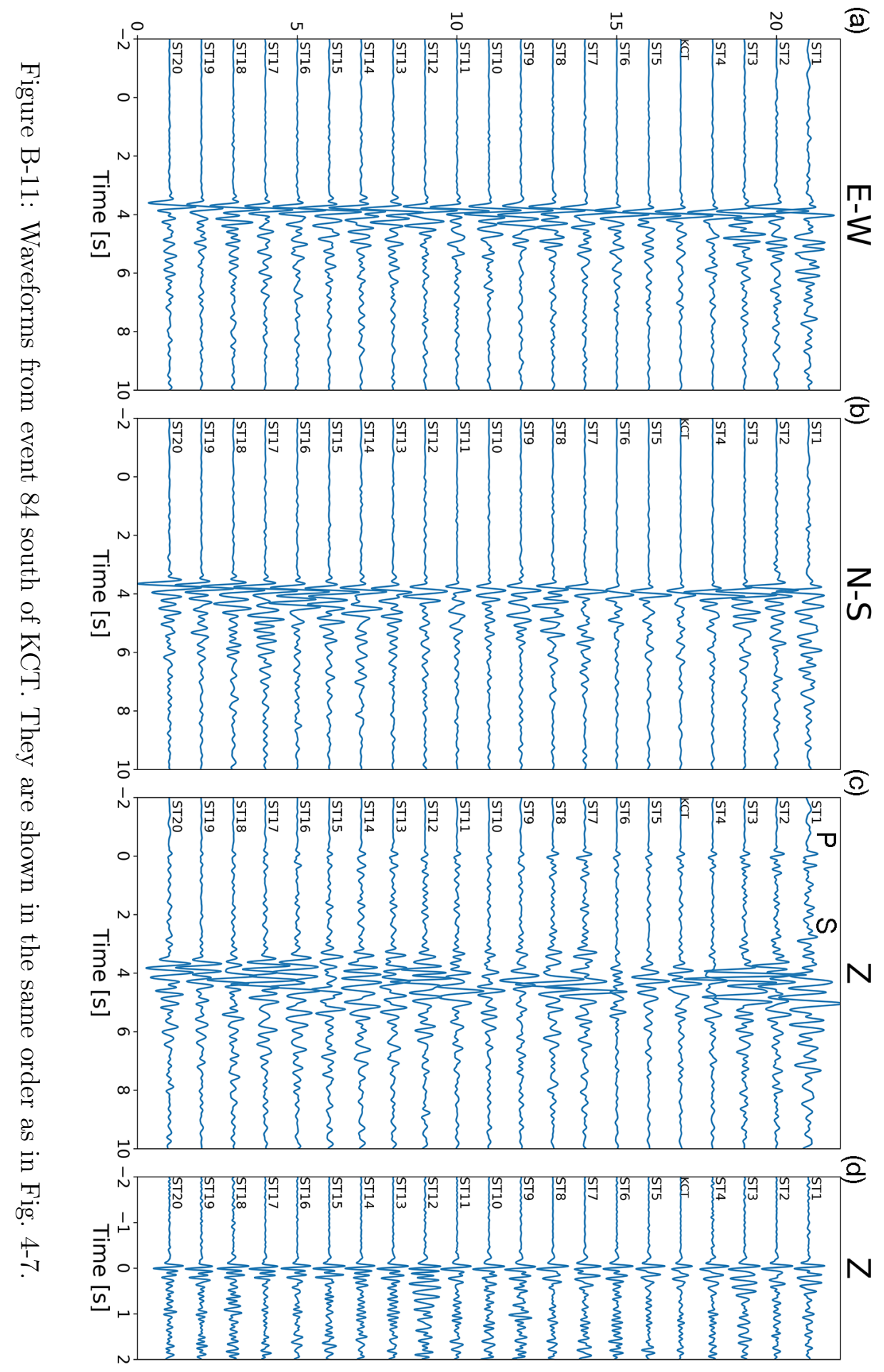




\section{Bibliography}

Abers, G. A., MacKenzie, L. S., Rondenay, S., Zhang, Z., Wech, A. G., and Creager, K. C. (2009). Imaging the source region of Cascadia tremor and intermediate-depth earthquakes. Geology, 37(12):1119-1122.

Aki, K. and Richards, P. G. (2002). Quantitative seismology,. University Science Books, 2 edition.

Akuhara, T., Bostock, M. G., Plourde, A. P., and Shinohara, M. (2019). Beyond receiver functions: Green's function estimation by transdimensional inversion and its application to OBS data. Journal of Geophysical Research: Solid Earth, 124(2):1944-1961.

Akuhara, T. and Mochizuki, K. (2015). Hydrous state of the subducting Philippine Sea plate inferred from receiver function image using onshore and offshore data. Journal of Geophysical Research: Solid Earth, 120(12):8461-8477.

Akuhara, T., Mochizuki, K., Kawakatsu, H., and Takeuchi, N. (2016). Non-linear waveform analysis for water-layer response and its application to high-frequency receiver function analysis using OBS array. Geophysical Journal International, 206(3):1914-1920.

Akuhara, T., Mochizuki, K., Kawakatsu, H., and Takeuchi, N. (2017). A fluid-rich layer along the Nankai trough megathrust fault off the Kii Peninsula inferred from receiver function inversion. Journal of Geophysical Research: Solid Earth, 122(8):6524-6537.

Akuhara, T., Tsuji, T., and Tonegawa, T. (2020). Overpressured underthrust sediment in the Nankai trough rorearc inferred from transdimensional inversion of high-frequency teleseismic waveforms. Geophysical Research Letters, 47(15):e2020GL088280.

Ammon, C. J., Velasco, A. A., and Lay, T. (1993). Rapid estimation of rupture directivity: Application to the 1992 Landers (MS $=7.4$ ) and Cape Mendocino (MS =7.2), California earthquakes. Geophysical Research Letters, 20(2):97-100.

Amundsen, L. and Reitan, A. (1995). Decomposition of multicomponent seafloor data into upgoing and downgoing P and S waves. Geophysics, 60(2):563-572.

Araki, E., Saffer, D. M., Kopf, A. J., Wallace, L. M., Kimura, T., Machida, Y., Ide, S., Davis, E., and shipboard scientists, I. E. . (2017). Recurring and triggered slow-slip events near the trench at the Nankai Trough subduction megathrust. Science, 356(6343):1157-1160.

Atwater, B. F., Nelson, A. R., Clague, J. J., Carver, G. A., Yamaguchi, D. K., Bobrowsky, P. T., Bourgeois, J., Darienzo, M. E., Grant, W. C., Hemphill-Haley, E., Kelsey, H. M., Jacoby, G. C., Nishenko, S. P., Palmer, S. P., Peterson, C. D., and Reinhart, M. A. 
(1995). Summary of coastal geologic evidence for past great earthquakes at the Cascadia subduction zone. Earthquake Spectra, 11(1):1-18.

Atwater, T. (1970). Implications of plate tectonics for the Cenozoic tectonic evolution of western North America. GSA Bulletin, 81(12):3513-3536.

Audet, P. (2016). Receiver functions using OBS data: promises and limitations from numerical modelling and examples from the Cascadia Initiative. Geophysical Journal International, 205(3):1740-1755.

Audet, P., Bostock, M. G., Christensen, N. I., and Peacock, S. M. (2009). Seismic evidence for overpressured subducted oceanic crust and megathrust fault sealing. Nature, 457:76.

Audet, P. and Schaeffer, A. J. (2018). Fluid pressure and shear zone development over the locked to slow slip region in Cascadia. Science Advances, 4(3).

Audet, P. and Schwartz, S. Y. (2013). Hydrologic control of forearc strength and seismicity in the Costa Rican subduction zone. Nature Geoscience, 6(10):852-855.

Austrheim, H. and Andersen, T. B. (2004). Pseudotachylytes from Corsica: fossil earthquakes from a subduction complex. Terra Nova, 16(4):193-197.

Bangs, N. L., McIntosh, K. D., Silver, E. A., Kluesner, J. W., and Ranero, C. R. (2015). Fluid accumulation along the Costa Rica subduction thrust and development of the seismogenic zone. Journal of Geophysical Research: Solid Earth, 120(1):67-86.

Bangs, N. L., Morgan, J. K., Tréhu, A. M., Contreras-Reyes, E., Arnulf, A., Han, S., Olsen, K. M., and Zhang, E. (2020). Basal accretion along the south-central Chilean margin and its relationship to great earthquakes. Journal of Geophysical Research: Solid Earth, 125(11):e2020JB019861.

Bangs, N. L. B., Shipley, T. H., Moore, J. C., and Moore, G. F. (1999). Fluid accumulation and channeling along the northern Barbados Ridge decollement thrust. Journal of Geophysical Research: Solid Earth, 104(B9):20399-20414.

Barbot, S. (2020). Mantle flow distribution beneath the California margin. Nature Communications, 11(1):4456.

Barbot, S. and Fialko, Y. (2010a). Fourier-domain green's function for an elastic semi-infinite solid under gravity, with applications to earthquake and volcano deformation. Geophysical Journal International, 182(2):568-582.

Barbot, S. and Fialko, Y. (2010b). A unified continuum representation of post-seismic relaxation mechanisms: semi-analytic models of afterslip, poroelastic rebound and viscoelastic flow. Geophysical Journal International, 182(3):1124-1140.

Bartlow, N. M. (2020). A long-term view of episodic tremor and slip in Cascadia. Geophysical Research Letters, 47(3):e2019GL085303.

Bassett, D., Sandwell, D. T., Fialko, Y., and Watts, A. B. (2016). Upper-plate controls on co-seismic slip in the 2011 magnitude 9.0 Tohoku-oki earthquake. Nature, 531(7592):9296. 
Beaucé, E., Frank, W. B., and Romanenko, A. (2017). Fast Matched Filter (FMF): An efficient seismic matched filter search for both CPU and GPU architectures. Seismological Research Letters, 89(1):165-172.

Beaudoin, B. C., Godfrey, N. J., Klemperer, S. L., Lendl, C., Tréhu, A. M., Henstock, T. J., Levander, A., Holl, J. E., Meltzer, A. S., Luetger, J. H., and Mooney, W. D. (1996). Transition from slab to slabless: Results from the 1993 Mendocino triple junction seismic experiment. Geology, 24(3):195-199.

Beaudoin, B. C., Hole, J. A., Klemperer, S. L., and Tréhu, A. M. (1998). Location of the southern edge of the Gorda slab and evidence for an adjacent asthenospheric window: Results from seismic profiling and gravity. Journal of Geophysical Research: Solid Earth, 103(B12):30101-30115.

Beaudoin, B. C., Magee, M., and Benz, H. (1994). Crustal velocity structure north of the Mendocino triple junction. Geophysical Research Letters, 21(21):2319-2322.

Bebout, G. E. and Penniston-Dorland, S. C. (2016). Fluid and mass transfer at subduction interfaces - The field metamorphic record. Lithos, 240-243:228-258.

Bedford, J., Moreno, M., Baez, J. C., Lange, D., Tilmann, F., Rosenau, M., Heidbach, O., Oncken, O., Bartsch, M., Rietbrock, A., Tassara, A., Bevis, M., and Vigny, C. (2013). A high-resolution, time-variable afterslip model for the 2010 Maule $\mathrm{Mw}=8.8$, Chile megathrust earthquake. Earth and Planetary Science Letters, 383:26-36.

Béjar-Pizarro, M., Socquet, A., Armijo, R., Carrizo, D., Genrich, J., and Simons, M. (2013). Andean structural control on interseismic coupling in the North Chile subduction zone. Nature Geoscience, 6(6):462-467.

Bekins, B., McCaffrey, A. M., and Dreiss, S. J. (1994). Influence of kinetics on the smectite to illite transition in the Barbados accretionary prism. Journal of Geophysical Research: Solid Earth, 99(B9):18147-18158.

Bekins, B. A. and Dreiss, S. J. (1992). A simplified analysis of parameters controlling dewatering in accretionary prisms. Earth and Planetary Science Letters, 109(3):275-287.

Bertero, M., Bindi, D., Boccacci, P., Cattaneo, M., Eva, C., and Lanza, V. (1997). Application of the projected landweber method to the estimation of the source time function in seismology. Inverse Problems, 13(2):465.

Bethke, C. M. (1986). Inverse hydrologic analysis of the distribution and origin of gulf coasttype geopressured zones. Journal of Geophysical Research: Solid Earth, 91(B6):6535-6545.

Bilek, S. L. and Lay, T. (1998). Variation of interplate fault zone properties with depth in the Japan subduction zone. Science, 281(5380):1175-1178.

Bilek, S. L. and Lay, T. (1999). Rigidity variations with depth along interplate megathrust faults in subduction zones. Nature, 400(6743):443-446.

Bilek, S. L., Schwartz, S. Y., and DeShon, H. R. (2003). Control of seafloor roughness on earthquake rupture behavior. Geology, 31(5):455-458. 
Blake, M. J., Howell, D., and Jones, D. (1982). Preliminary tectonostratigraphic terrane map of California. U.S. Geological Survey Open-File Report 82-593.

Blake Jr, M. C., Jayko, A., and McLaughlin, R. (1985). Tectonostratigraphic terranes of the northern Coast Ranges, California. In Howell, D., editor, Tectonostratigraphic Terranes of the Circum-Pacific Region, pages 159-171. Circum Pacific Council Publications.

Blanpied, M. L., Lockner, D. A., and Byerlee, J. D. (1991). Fault stability inferred from granite sliding experiments at hydrothermal conditions. Geophysical Research Letters, 18(4):609-612.

Bletery, Q., Thomas, A. M., Rempel, A. W., Karlstrom, L., Sladen, A., and De Barros, L. (2016). Mega-earthquakes rupture flat megathrusts. Science, 354(6315):1027-1031.

Boettcher, M. S. and Jordan, T. H. (2004). Earthquake scaling relations for mid-ocean ridge transform faults. Journal of Geophysical Research: Solid Earth, 109(B12).

Bray, C. J. and Karig, D. E. (1985). Porosity of sediments in accretionary prisms and some implications for dewatering processes. Journal of Geophysical Research: Solid Earth, 90(B1):768-778.

Brodsky, E. E., Mori, J. J., Anderson, L., Chester, F. M., Conin, M., Dunham, E. M., Eguchi, N., Fulton, P. M., Hino, R., Hirose, T., Ikari, M. J., Ishikawa, T., Jeppson, T., Kano, Y., Kirkpatrick, J., Kodaira, S., Lin, W., Nakamura, Y., Rabinowitz, H. S., Regalla, C., Remitti, F., Rowe, C., Saffer, D. M., Saito, S., Sample, J., Sanada, Y., Savage, H. M., Sun, T., Toczko, S., Ujiie, K., Wolfson-Schwehr, M., and Yang, T. (2020). The state of stress on the fault before, during, and after a major earthquake. Annual Review of Earth and Planetary Sciences, 48(1):49-74.

Bruhat, L. and Segall, P. (2016). Coupling on the northern cascadia subduction zone from geodetic measurements and physics-based models. Journal of Geophysical Research: Solid Earth, 121(11):8297-8314.

Burgette, R. J., Weldon, R. J., and Schmidt, D. A. (2009). Interseismic uplift rates for western Oregon and along-strike variation in locking on the Cascadia subduction zone. Journal of Geophysical Research: Solid Earth, 114(B1). B01408.

Bürgmann, R. and Chadwell, D. (2014). Seafloor geodesy. Annual Review of Earth and Planetary Sciences, 42(1):509-534.

Calvert, A. J., Preston, L. A., and Farahbod, A. M. (2011). Sedimentary underplating at the Cascadia mantle-wedge corner revealed by seismic imaging. Nature Geoscience, $4(8): 545-548$.

Canales, J. P., Carbotte, S. M., Nedimović, M. R., and Carton, H. (2017). Dry Juan de Fuca slab revealed by quantification of water entering Cascadia subduction zone. Nature Geoscience, 10(11):864-870.

Cande, S. C. and Kent, D. V. (1995). Revised calibration of the geomagnetic polarity timescale for the Late Cretaceous and Cenozoic. Journal of Geophysical Research: Solid Earth, 100(B4):6093-6095. 
Carver, G. and Burke, R. (1988). Final report, trenching investigation of northwestern California faults, Humboldt bay region. USGS Grant, pages 14-08.

Chaves, E. J. and Schwartz, S. Y. (2016). Monitoring transient changes within overpressured regions of subduction zones using ambient seismic noise. Science Advances, 2(1).

Chaytor, J. D., Goldfinger, C., Dziak, R. P., and Fox, C. G. (2004). Active deformation of the Gorda plate: Constraining deformation models with new geophysical data. Geology, 32(4):353-356.

Chen, X. and McGuire, J. J. (2016). Measuring earthquake source parameters in the Mendocino triple junction region using a dense OBS array: Implications for fault strength variations. Earth and Planetary Science Letters, 453:276-287.

Cheng, C., Bodin, T., Tauzin, B., and Allen, R. M. (2017). Cascadia subduction slab heterogeneity revealed by three-dimensional receiver function Kirchhoff migration. Geophysical Research Letters, 44(2):694-701.

Chester, F. M., Rowe, C., Ujiie, K., Kirkpatrick, J., Regalla, C., Remitti, F., Moore, J. C., Toy, V., Wolfson-Schwehr, M., Bose, S., Kameda, J., Mori, J. J., Brodsky, E. E., Eguchi, N., Toczko, S., and Expedition 343 and 343T Scientists (2013). Structure and composition of the plate-boundary slip zone for the 2011 Tohoku-Oki earthquake. Science, 342(6163):1208-1211.

Chlieh, M., Avouac, J. P., Sieh, K., Natawidjaja, D. H., and Galetzka, J. (2008). Heterogeneous coupling of the Sumatran megathrust constrained by geodetic and paleogeodetic measurements. Journal of Geophysical Research: Solid Earth, 113(B5).

Chlieh, M., Perfettini, H., Tavera, H., Avouac, J.-P., Remy, D., Nocquet, J.-M., Rolandone, F., Bondoux, F., Gabalda, G., and Bonvalot, S. (2011). Interseismic coupling and seismic potential along the Central Andes subduction zone. Journal of Geophysical Research: Solid Earth, 116(B12).

Christensen, N. I. (1996). Poisson's ratio and crustal seismology. Journal of Geophysical Research: Solid Earth, 101(B2):3139-3156.

Christeson, G. L., McIntosh, K. D., Shipley, T. H., Flueh, E. R., and Goedde, H. (1999). Structure of the Costa Rica convergent margin, offshore Nicoya Peninsula. Journal of Geophysical Research: Solid Earth, 104(B11):25443-25468.

Clarke, S. H. and Carver, G. A. (1992). Late Holocene tectonics and paleoseismicity, southern Cascadia subduction zone. Science, 255(5041):188-192.

Cochran, E. S., Li, Y.-G., Shearer, P. M., Barbot, S., Fialko, Y., and Vidale, J. E. (2009). Seismic and geodetic evidence for extensive, long-lived fault damage zones. Geology, $37(4): 315-318$.

Contreras-Reyes, E. and Carrizo, D. (2011). Control of high oceanic features and subduction channel on earthquake ruptures along the Chile-Peru subduction zone. Physics of the Earth and Planetary Interiors, 186(1):49 - 58. 
Contreras-Reyes, E., Flueh, E. R., and Grevemeyer, I. (2010). Tectonic control on sediment accretion and subduction off south central Chile: Implications for coseismic rupture processes of the 1960 and 2010 megathrust earthquakes. Tectonics, 29(6).

Cormier, V. F. and Spudich, P. (1984). Amplification of ground motion and waveform complexity in fault zones: examples from the San Andreas and Calaveras Faults. Geophysical Journal International, 79(1):135-152.

Das, S. and Kostrov, B. V. (1997). Determination of the polynomial moments of the seismic moment rate density distribution with positivity constraints. Geophysical Journal International, 131(1):115-126.

DeMets, C., Gordon, R. G., and Argus, D. F. (2010). Geologically current plate motions. Geophysical Journal International, 181(1):1-80.

den Hartog, S., Niemeijer, A., and Spiers, C. (2012). New constraints on megathrust slip stability under subduction zone P-T conditions. Earth and Planetary Science Letters, 353-354:240 - 252.

den Hartog, S. and Spiers, C. (2013). Influence of subduction zone conditions and gouge composition on frictional slip stability of megathrust faults. Tectonophysics, 600:75-90.

Dickinson, W. (1981). Plate tectonics and the continental margin of California. In Ernst, W., editor, The Geotectonic Development of California, pages 1-28. Prentice-Hall Inc.

Dickinson, W. R. and Snyder, W. S. (1979). Geometry of triple junctions related to San Andreas Transform. Journal of Geophysical Research: Solid Earth, 84(B2):561-572.

Dieterich, J. H. (1979). Modeling of rock friction: 1. experimental results and constitutive equations. Journal of Geophysical Research: Solid Earth, 84(B5):2161-2168.

Dieterich, J. H. (1981). Constitutive properties of faults with simulated gouge. In Carter, N. L., Friedman, M., Logan, J. M., and W., S. D., editors, Mechanical Behavior of Crystal Rocks, Geophys. Monogr. 24, pages 103-120. American Geophysical Union (AGU).

Doornbos, D. J. (1982). Seismic source spectra and moment tensors. Physics of the Earth and Planetary Interiors, 30(2):214-227. Special Issue Earthquake Algorithms.

Eakin, C. M., Obrebski, M., Allen, R. M., Boyarko, D. C., Brudzinski, M. R., and Porritt, R. (2010). Seismic anisotropy beneath Cascadia and the Mendocino triple junction: Interaction of the subducting slab with mantle flow. Earth and Planetary Science Letters, 297(3):627-632.

Eberhart-Phillips, D. and Reyners, M. (1999). Plate interface properties in the northeast Hikurangi subduction zone, New Zealand, from converted seismic waves. Geophysical Research Letters, 26(16):2565-2568.

Edwards, J. H., Kluesner, J. W., Silver, E. A., Brodsky, E. E., Brothers, D. S., Bangs, N. L., Kirkpatrick, J. D., Wood, R., and Okamoto, K. (2018). Corrugated megathrust revealed offshore from Costa Rica. Nature Geoscience, 11(3):197-202.

Ernst, W. G. (1970). Tectonic contact between the Franciscan Mélange and the Great Valley sequence-crustal expression of a Late Mesozoic Benioff zone. Journal of Geophysical Research, 75(5):886-901. 
Evans, R. L., Wannamaker, P. E., McGary, R. S., and Elsenbeck, J. (2014). Electrical structure of the central Cascadia subduction zone: The EMSLAB Lincoln Line revisited. Earth and Planetary Science Letters, 402:265-274.

Fagereng, A. (2011). Geology of the seismogenic subduction thrust interface. Geological Society, London, Special Publications, 359(1):55-76.

Fagereng, Å. and Sibson, R. H. (2010). Mélange rheology and seismic style. Geology, $38(8): 751-754$.

Feng, L., Newman, A. V., Protti, M., Gonzélez, V., Jiang, Y., and Dixon, T. H. (2012). Active deformation near the Nicoya Peninsula, northwestern Costa Rica, between 1996 and 2010: Interseismic megathrust coupling. Journal of Geophysical Research: Solid Earth, 117(B6).

Fisher, D. M., Brantley, S. L., Everett, M., and Dzvonik, J. (1995). Cyclic fluid flow through a regionally extensive fracture network within the Kodiak accretionary prism. Journal of Geophysical Research: Solid Earth, 100(B7):12881-12894.

Frankel, A., Wirth, E., Marafi, N., Vidale, J., and Stephenson, W. (2018). Broadband synthetic seismograms for magnitude 9 earthquakes on the Cascadia megathrust based on 3D simulations and stochastic synthetics, Part 1: Methodology and overall results. Bulletin of the Seismological Society of America, 108(5A):2347-2369.

Fukao, Y., Hori, S., and Ukawa, M. (1983). A seismological constraint on the depth of basalt-eclogite transition in a subducting oceanic crust. Nature, 303(5916):413-415.

Fulton, P. M., Brodsky, E. E., Kano, Y., Mori, J., Chester, F., Ishikawa, T., Harris, R. N., Lin, W., Eguchi, N., and Toczko, S. (2013). Low coseismic friction on the Tohoku-Oki fault determined from temperature measurements. Science, 342(6163):1214-1217.

Furlong, K. P. and Schwartz, S. Y. (2004). Influence of the mendocino triple junction on the tectonics of coastal california. Annual Review of Earth and Planetary Sciences, 32(1):403-433.

Furumura, T. and Kennett, B. L. N. (2005). Subduction zone guided waves and the heterogeneity structure of the subducted plate: Intensity anomalies in northern Japan. Journal of Geophysical Research: Solid Earth, 110(B10).

Gao, X. and Wang, K. (2014). Strength of stick-slip and creeping subduction megathrusts from heat flow observations. Science, 345(6200):1038-1041.

Godfrey, N. J., Beaudoin, B. C., and Klemperer, S. L., M. (1997). Ophiolitic basement to the Great Valley forearc basin, California, from seismic and gravity data: Implications for crustal growth at the North American continental margin. GSA Bulletin, 109(12):15361562 .

Godfrey, N. J., Meltzer, A. S., Klemperer, S. L., Tréhu, A. M., Leitner, B., Clarke Jr., S. H., and Ondrus, A. (1998). Evolution of the Gorda Escarpment, San Andreas Fault and Mendocino triple junction from multichannel seismic data collected across the northern Vizcaino block, offshore northern California. Journal of Geophysical Research: Solid Earth, 103(B10):23813-23825. 
Goldfinger, C., Grijalva, K., Bürgmann, R., Morey, A. E., Johnson, J. E., Nelson, C. H., Gutiérrez-Pastor, J., Ericsson, A., Karabanov, E., Chaytor, J. D., Patton, J., and Gràcia, E. (2008). Late Holocene rupture of the northern San Andreas fault and possible stress linkage to the Cascadia subduction zone. Bulletin of the Seismological Society of America, 98(2):861-889.

Goldfinger, C., Nelson, C. H., and Johnson, J. E. (2003). Holocene earthquake records from the Cascadia Subduction Zone and northern San Andreas Fault Based on precise dating of offshore turbidites. Annual Review of Earth and Planetary Sciences, 31(1):555-577.

Goldfinger, C., Nelson, C. H., Morey, A. E., Johnson, J. E., Patton, J. R., Karabanov, E. B., Gutierrez-Pastor, J., Eriksson, A. T., Gracia, E., Dunhill, G., Enkin, R. J., Dallimore, A., and Vallier, T. (2012). Turbidite event history-Methods and implications for Holocene paleoseismicity of the Cascadia subduction zone. Technical report, Reston, VA.

Gomberg, J. (2018). Cascadia onshore-offshore site response, submarine sediment mobilization, and earthquake recurrence. Journal of Geophysical Research: Solid Earth, 123(2):1381-1404.

Gong, J. and McGuire, J. J. (2020). Constraints on the geometry of the subducted Gorda plate from converted phases generated by local earthquakes. Submitted to Journal of Geophysical Research: Solid Earth.

Grevemeyer, I. and Tiwari, V. M. (2006). Overriding plate controls spatial distribution of megathrust earthquakes in the Sunda-Andaman subduction zone. Earth and Planetary Science Letters, 251(3):199-208.

Groß, K., Micksch, U., and TIPTEQ Research Group, Seismics Team (2008). The reflection seismic survey of project TIPTEQ - the inventory of the Chilean subduction zone at $38.2^{\circ}$ S. Geophysical Journal International, 172(2):565-571.

Gulick, S. P. and Meltzer, A. S. (2002). Effect of the northward-migrating Mendocino triple junction on the Eel River forearc basin, California: Structural evolution. GSA Bulletin, 114(12):1505-1519.

Gulick, S. P., Meltzer, A. S., Henstock, T. J., and Levander, A. (2001). Internal deformation of the southern Gorda plate: Fragmentation of a weak plate near the Mendocino triple junction. Geology, 29(8):691-694.

Gulick, S. P. S., Meltzer, A. M., and Clarke Jr., S. H. (1998). Seismic structure of the southern Cascadia subduction zone and accretionary prism north of the Mendocino triple junction. Journal of Geophysical Research: Solid Earth, 103(B11):27207-27222.

Guo, H., Zhang, H., and Froment, B. (2018). Structural control on earthquake behaviors revealed by high-resolution $\mathrm{Vp} / \mathrm{Vs}$ imaging along the Gofar transform fault, East Pacific Rise. Earth and Planetary Science Letters, 499:243 - 255.

Guo, H., Zhu, J., McGuire, J. J., Evans, R. L., and Zhang, H. (2019). Variations in porosity and fluid content correlate with rheological transitions along the megathrust in the southern Cascadia subduction zone. American Geophysical Union Fall Meeting Abstract T13H-0334, Washington, DC. 
Han, S., Bangs, N. L., Carbotte, S. M., and Saffer, Demian M. nd Gibson, J. C. (2017). Links between sediment consolidation and Cascadia megathrust slip behaviour. Nature Geoscience, 10(12):954-959.

Han, S., Carbotte, S. M., Canales, J. P., Nedimović, M. R., and Carton, H. (2018). Alongtrench structural variations of the subducting Juan de Fuca plate from multichannel seismic reflection imaging. Journal of Geophysical Research: Solid Earth, 123(4):3122-3146.

Han, S., Carbotte, S. M., Canales, J. P., Nedimović, M. R., Carton, H., Gibson, J. C., and Horning, G. W. (2016). Seismic reflection imaging of the Juan de Fuca plate from ridge to trench: New constraints on the distribution of faulting and evolution of the crust prior to subduction. Journal of Geophysical Research: Solid Earth, 121(3):1849-1872.

Hardebeck, J. L. (2015). Stress orientations in subduction zones and the strength of subduction megathrust faults. Science, 349(6253):1213-1216.

Harper, G. D. (1980). The Josephine Ophiolite - Remains of a Late Jurassic marginal basin in northwestern California. Geology, 8(7):333-337.

Harris, R. A. and Day, S. M. (1997). Effects of a low-velocity zone on a dynamic rupture. Bulletin of the Seismological Society of America, 87(5):1267-1280.

Hartog, R. and Schwartz, S. Y. (2000). Subduction-induced strain in the upper mantle east of the Mendocino triple junction, California. Journal of Geophysical Research: Solid Earth, 105(B4):7909-7930.

Hayes, G. P. and Furlong, K. P. (2007). Abrupt changes in crustal structure beneath the Coast Ranges of northern California - developing new techniques in receiver function analysis. Geophysical Journal International, 170(1):313-336.

Hayes, G. P., Moore, G. L., Portner, D. E., Hearne, M., Flamme, H., Furtney, M., and Smoczyk, G. M. (2018). Slab2, a comprehensive subduction zone geometry model. Science, 362(6410):58-61.

He, C., Yao, W., Wang, Z., and Zhou, Y. (2006). Strength and stability of frictional sliding of gabbro gouge at elevated temperatures. Tectonophysics, 427(1):217-229. Deformation mechanisms, microstructure and rheology of rocks in nature and experiment.

Heise, W., Caldwell, T. G., Bannister, S., Bertrand, E. A., Ogawa, Y., Bennie, S. L., and Ichihara, H. (2017). Mapping subduction interface coupling using magnetotellurics: Hikurangi margin, New Zealand. Geophysical Research Letters, 44(18):9261-9266.

Heise, W., Caldwell, T. G., Hill, G. J., Bennie, S. L., Wallin, E., and Bertrand, E. A. (2012). Magnetotelluric imaging of fluid processes at the subduction interface of the Hikurangi margin, New Zealand. Geophysical Research Letters, 39(4).

Henstock, T. J. and Levander, A. (2000). Lithospheric evolution in the wake of the Mendocino triple junction: structure of the San Andreas Fault system at 2 Ma. Geophysical Journal International, 140(1):233-247.

Henstock, T. J. and Levander, A. (2003). Structure and seismotectonics of the Mendocino Triple Junction, California. Journal of Geophysical Research: Solid Earth, 108(B5). 
Henstock, T. J., Levander, A., and Hole, J. A. (1997). Deformation in the lower crust of the San Andreas fault system in northern California. Science, 278(5338):650-653.

Heuret, A., Conrad, C. P., Funiciello, F., Lallemand, S., and Sandri, L. (2012). Relation between subduction megathrust earthquakes, trench sediment thickness and upper plate strain. Geophysical Research Letters, 39(5).

Heuret, A., Lallemand, S., Funiciello, F., Piromallo, C., and Faccenna, C. (2011). Physical characteristics of subduction interface type seismogenic zones revisited. Geochemistry, Geophysics, Geosystems, 12(1).

Hole, J., Beaudoin, B., and Klemperer, S. (2000). Vertical extent of the newborn San Andreas fault at the Mendocino triple junction. Geology, 28(12):1111.

Hole, J. A., Beaudoin, B. C., and Henstock, T. J. (1998). Wide-angle seismic constraints on the evolution of the deep San Andreas plate boundary by Mendocino triple junction migration. Tectonics, 17(5):802-818.

Horleston, A. and Helffrich, G. (2012). Constraining sediment subduction: A converted phase study of the Aleutians and Marianas. Earth and Planetary Science Letters, 359360:141 - 151 .

Hsu, Y.-J., Simons, M., Avouac, J.-P., Galetzka, J., Sieh, K., Chlieh, M., Natawidjaja, D., Prawirodirdjo, L., and Bock, Y. (2006). Frictional afterslip following the 2005 NiasSimeulue earthquake, Sumatra. Science, 312(5782):1921-1926.

Hsu, Y.-J., Yu, S.-B., Song, T.-R. A., and Bacolcol, T. (2012). Plate coupling along the Manila subduction zone between Taiwan and northern Luzon. Journal of Asian Earth Sciences, 51:98-108.

Huang, Y. and Ampuero, J.-P. (2011). Pulse-like ruptures induced by low-velocity fault zones. Journal of Geophysical Research: Solid Earth, 116(B12).

Huang, Y., Ampuero, J.-P., and Helmberger, D. V. (2014). Earthquake ruptures modulated by waves in damaged fault zones. Journal of Geophysical Research: Solid Earth, 119(4):3133-3154.

Hyndman, R. D. (2013). Downdip landward limit of Cascadia great earthquake rupture. Journal of Geophysical Research: Solid Earth, 118(10):5530-5549.

Hyndman, R. D. and Wang, K. (1995). The rupture zone of cascadia great earthquakes from current deformation and the thermal regime. Journal of Geophysical Research: Solid Earth, 100(B11):22133-22154.

Hyndman, R. D., Yamano, M., and Oleskevich, D. A. (1997). The seismogenic zone of subduction thrust faults. Island Arc, 6(3):244-260.

Ide, S., Baltay, A., and Beroza, G. C. (2011). Shallow dynamic overshoot and energetic deep rupture in the $2011 \mathrm{Mw} 9.0$ Tohoku-Oki earthquake. Science, 332(6036):1426-1429.

Idini, B. and Ampuero, J.-P. (2020). Fault-zone damage promotes pulse-like rupture and back-propagating fronts via quasi-static effects. Geophysical Research Letters, n/a(n/a):e2020GL090736. 
Ikari, M. J., Ito, Y., Ujiie, K., and Kopf, A. J. (2015). Spectrum of slip behaviour in Tohoku fault zone samples at plate tectonic slip rates. Nature Geoscience, 8(11):870-874.

Ikesawa, E., Sakaguchi, A., and Kimura, G. (2003). Pseudotachylyte from an ancient accretionary complex: Evidence for melt generation during seismic slip along a master décollement? Geology, 31(7):637-640.

Ito, Y. and Shiomi, K. (2012). Seismic scatterers within subducting slab revealed from ambient noise autocorrelation. Geophysical Research Letters, 39(19).

Janiszewski, H. A. and Abers, G. A. (2015). Imaging the plate interface in the Cascadia seismogenic zone: New constraints from offshore receiver functions. Seismological Research Letters, 86(5):1261-1269.

Jurkevics, A. (1988). Polarization analysis of three-component array data. Bulletin of the Seismological Society of America, 78(5):1725-1743.

Kaneko, Y., Ampuero, J.-P., and Lapusta, N. (2011). Spectral-element simulations of longterm fault slip: Effect of low-rigidity layers on earthquake-cycle dynamics. Journal of Geophysical Research: Solid Earth, 116(B10).

Kaneko, Y. and Shearer, P. M. (2015). Variability of seismic source spectra, estimated stress drop, and radiated energy, derived from cohesive-zone models of symmetrical and asymmetrical circular and elliptical ruptures. Journal of Geophysical Research: Solid Earth, 120(2):1053-1079.

Kimura, G., Hina, S., Hamada, Y., Kameda, J., Tsuji, T., Kinoshita, M., and Yamaguchi, A. (2012a). Runaway slip to the trench due to rupture of highly pressurized megathrust beneath the middle trench slope: The tsunamigenesis of the 2011 Tohoku earthquake off the east coast of northern Japan. Earth and Planetary Science Letters, 339-340:32-45.

Kimura, G. and Mukai, A. (1991). Underplated units in an accretionary complex: Mélange of the Shimanto Belt of eastern Shikoku, southwest Japan. Tectonics, 10(1):31-50.

Kimura, G., Yamaguchi, A., Hojo, M., Kitamura, Y., Kameda, J., Ujiie, K., Hamada, Y., Hamahashi, M., and Hina, S. (2012b). Tectonic mélange as fault rock of subduction plate boundary. Tectonophysics, 568-569:25-38.

Kirkpatrick, J. D., Edwards, J. H., Verdecchia, A., Kluesner, J. W., Harrington, R. M., and Silver, E. A. (2020). Subduction megathrust heterogeneity characterized from 3D seismic data. Nature Geoscience, 13(5):369-374.

Kodaira, S., Iidaka, T., Kato, A., Park, J.-O., Iwasaki, T., and Kaneda, Y. (2004). High pore fluid pressure may cause silent slip in the Nankai Trough. Science, 304(5675):1295-1298.

Kodaira, S., Kurashimo, E., Park, J.-O., Takahashi, N., Nakanishi, A., Miura, S., Iwasaki, T., Hirata, N., Ito, K., and Kaneda, Y. (2002). Structural factors controlling the rupture process of a megathrust earthquake at the Nankai trough seismogenic zone. Geophysical Journal International, 149(3):815-835.

Kodaira, S., Takahashi, N., Nakanishi, A., Miura, S., and Kaneda, Y. (2000). Subducted seamount imaged in the rupture zone of the 1946 Nankaido earthquake. Science, 289(5476):104-106. 
Kurzon, I., Lyakhovsky, V., and Ben-Zion, Y. (2020). Earthquake source properties from analysis of dynamic ruptures and far-field seismic waves in a damage-breakage model. Geophysical Journal International.

Lajoie, K., Ponti, D., Powell II, C., Mathieson, S., and Sarna-Wojcicki, A. M. (1991). Emergent marine strandlines and associated sediments, coastal California; a record of Quaternary sea-level fluctuations, vertical tectonic movements, climatic changes, and coastal processes. In Morrison, R. B., editor, Quaternary Nonglacial Geology: Conterminous United States, Geology of North America, K-2, page 190-214. Geol. Soc. Am., Boulder, Colo.

Lamb, S. (2006). Shear stresses on megathrusts: Implications for mountain building behind subduction zones. Journal of Geophysical Research: Solid Earth, 111(B7).

Langston, C. A. (1979). Structure under Mount Rainier, Washington, inferred from teleseismic body waves. Journal of Geophysical Research: Solid Earth, 84(B9):4749-4762.

Lanza, V., Spallarossa, D., Cattaneo, M., Bindi, D., and Augliera, P. (1999). Source parameters of small events using constrained deconvolution with empirical green's functions. Geophysical Journal International, 137(3):651-662.

Lay, T., Kanamori, H., Ammon, C. J., Koper, K. D., Hutko, A. R., Ye, L., Yue, H., and Rushing, T. M. (2012). Depth-varying rupture properties of subduction zone megathrust faults. Journal of Geophysical Research: Solid Earth, 117(B4).

Levander, A., Henstock, T. J., Meltzer, A. S., Beaudoin, B. C., Trehu, A. M., and Klemperer, S. L. (1998). Fluids in the lower crust following Mendocino triple junction migration: Active basaltic intrusion? Geology, 26(2):171-174.

Li, D., McGuire, J. J., Liu, Y., and Hardebeck, J. L. (2018a). Stress rotation across the Cascadia megathrust requires a weak subduction plate boundary at seismogenic depths. Earth and Planetary Science Letters, 485:55-64.

Li, J., Shillington, D. J., Bécel, A., Nedimović, M. R., Webb, S. C., Saffer, D. M., Keranen, K. M., and Kuehn, H. (2015). Downdip variations in seismic reflection character: Implications for fault structure and seismogenic behavior in the Alaska subduction zone. Journal of Geophysical Research: Solid Earth, 120(11):7883-7904.

Li, J., Shillington, D. J., Saffer, D. M., Bécel, A., Nedimović, M. R., Kuehn, H., Webb, S. C., Keranen, K. M., and Abers, G. A. (2018b). Connections between subducted sediment, pore-fluid pressure, and earthquake behavior along the Alaska megathrust. Geology, 46(4):299-302.

Li, Y.-G., Aki, K., Adams, D., Hasemi, A., and Lee, W. H. K. (1994). Seismic guided waves trapped in the fault zone of the Landers, California, earthquake of 1992. Journal of Geophysical Research: Solid Earth, 99(B6):11705-11722.

Li, Y.-G. and Vidale, J. E. (1996). Low-velocity fault-zone guided waves: Numerical investigations of trapping efficiency. Bulletin of the Seismological Society of America, 86(2):371378. 
Liu, K., Levander, A., Zhai, Y., Porritt, R. W., and Allen, R. M. (2012). Asthenospheric flow and lithospheric evolution near the Mendocino triple junction. Earth and Planetary Science Letters, 323-324:60-71.

Liu, X. and Zhao, D. (2018). Upper and lower plate controls on the great 2011 Tohoku-oki earthquake. Science Advances, 4(6).

Liu, Y. (2013). Numerical simulations on megathrust rupture stabilized under strong dilatancy strengthening in slow slip region. Geophysical Research Letters, 40(7):1311-1316.

Liu, Y. and Rice, J. R. (2005). Aseismic slip transients emerge spontaneously in threedimensional rate and state modeling of subduction earthquake sequences. Journal of Geophysical Research: Solid Earth, 110(B8).

Liu, Y. and Rice, J. R. (2007). Spontaneous and triggered aseismic deformation transients in a subduction fault model. Journal of Geophysical Research: Solid Earth, 112(B9).

Lomnitz, C. (1982). Direct evidence of a subducted plate under southern Mexico. Nature, 296(5854):235-238.

Loveless, J. P. and Meade, B. J. (2010). Geodetic imaging of plate motions, slip rates, and partitioning of deformation in Japan. Journal of Geophysical Research: Solid Earth, 115(B2).

Magee, M. E. and Zoback, M. D. (1993). Evidence for a weak interplate thrust fault along the northern Japan subduction zone and implications for the mechanics of thrust faulting and fluid expulsion. Geology, 21(9):809-812.

Marone, C. (1998). Laboratory-derived friction laws and their application to seismic faulting. Annual Review of Earth and Planetary Sciences, 26(1):643-696.

Martin, S., Rietbrock, A., Haberland, C., and Asch, G. (2003). Guided waves propagating in subducted oceanic crust. Journal of Geophysical Research: Solid Earth, 108(B11).

Materna, K., Bartlow, N., Wech, A., Williams, C., and Bürgmann, R. (2019). Dynamically triggered changes of plate interface coupling in southern Cascadia. Geophysical Research Letters, 46(22):12890-12899.

Materna, K., Taira, T., and Bürgmann, R. (2018). Aseismic transform fault slip at the Mendocino triple junction from characteristically repeating earthquakes. Geophysical Research Letters, 45(2):699-707.

Matsuzawa, T., Kono, T., Hasegawa, A., and Takagi, A. (1990). Subducting plate boundary beneath the northeastern Japan arc estimated from SP converted waves. Tectonophysics, 181(1):123-133. Tectonics of Eastern Asia and Western Pacific Continental Margin.

Matsuzawa, T., Umino, N., Hasegawa, A., and Takagi, A. (1986). Upper mantle velocity structure estimated from PS-converted wave beneath the north-eastern Japan Arc. Geophysical Journal International, 86(3):767-787.

McCaffrey, R., King, R. W., Payne, S. J., and Lancaster, M. (2013). Active tectonics of northwestern U.S. inferred from GPS-derived surface velocities. Journal of Geophysical Research: Solid Earth, 118(2):709-723. 
McCaffrey, R., Long, M. D., Goldfinger, C., Zwick, P. C., Nabelek, J. L., Johnson, C. K., and Smith, C. (2000). Rotation and plate locking at the southern Cascadia subduction one. Geophysical Research Letters, 27(19):3117-3120.

McCaffrey, R., Qamar, A. I., King, R. W., Wells, R., Khazaradze, G., Williams, C. A., Stevens, C. W., Vollick, J. J., and Zwick, P. C. (2007). Fault locking, block rotation and crustal deformation in the Pacific Northwest. Geophysical Journal International, 169(3):1315-1340.

McCrory, P. A. (1989). Late Neogene geohistory analysis of the Humboldt Basin and its relationship to convergence of the Juan de Fuca Plate. Journal of Geophysical Research: Solid Earth, 94(B3):3126-3138.

McCrory, P. A. (1996). Evaluation of fault hazards,northern coastal California. USGS Open File Rep, 96-656, page 87.

McCrory, P. A. (2000). Upper plate contraction north of the migrating Mendocino triple junction, northern California: Implications for partitioning of strain. Tectonics, 19(6):1144-1160.

McCrory, P. A., Blair, J. L., Waldhauser, F., and Oppenheimer, D. H. (2012). Juan de Fuca slab geometry and its relation to Wadati-Benioff zone seismicity. Journal of Geophysical Research: Solid Earth, 117(B9):n/a-n/a. B09306.

McGary, R. S., Evans, R. L., Wannamaker, P. E., Elsenbeck, J., and Rondenay, S. (2014). Pathway from subducting slab to surface for melt and fluids beneath Mount Rainier. Nature, 511:338.

McGuire, J. J. (2004). Estimating finite source properties of small earthquake ruptures. Bulletin of the Seismological Society of America, 94(2):377-393.

McGuire, J. J. (2017). A MATLAB toolbox for estimating the second moments of earthquake ruptures. Seismological Research Letters.

McGuire, J. J. and Kaneko, Y. (2017). Directly estimating rupture area to remove the uncertainty in stress drop. Poster Presentation at 2017 SCEC Annual Meeting.

McGuire, J. J., Zhao, L., and Jordan, T. H. (2001). Teleseismic inversion for the second degree moments of earthquake space-time distributions. Geophysical Journal International, 145(3):661-678.

McGuire, J. J., Zhao, L., and Jordan, T. H. (2002). Predominance of unilateral rupture for a global catalog of large earthquakes. Bulletin of the Seismological Society of America, 92(8):3309-3317.

Meneghini, F. and Moore, J. C. (2007). Deformation and hydrofracture in a subduction thrust at seismogenic depths: The Rodeo Cove thrust zone, Marin Headlands, California. GSA Bulletin, 119(1-2):174-183.

Merrill, R. and Bostock, M. (2019). An earthquake nest in Cascadia. Bulletin of the Seismological Society of America. 
Merritts, D. J. (1996). The Mendocino triple junction: Active faults, episodic coastal emergence, and rapid uplift. Journal of Geophysical Research: Solid Earth, 101(B3):6051-6070.

Meunier, A. (2005). Clays. Springer Science \& Business Media.

Michel, S., Gualandi, A., and Avouac, J.-P. (2019). Interseismic coupling and slow slip events on the Cascadia megathrust. Pure and Applied Geophysics, 176(9):3867-3891.

Miura, S., Takahashi, N., Nakanishi, A., Tsuru, T., Kodaira, S., and Kaneda, Y. (2005). Structural characteristics off Miyagi forearc region, the Japan Trench seismogenic zone, deduced from a wide-angle reflection and refraction study. Tectonophysics, 407(3):165188 .

Miyazaki, S., Segall, P., Fukuda, J., and Kato, T. (2004). Space time distribution of afterslip following the 2003 Tokachi-oki earthquake: Implications for variations in fault zone frictional properties. Geophysical Research Letters, 31(6). L06623.

Moreno, M., Haberland, C., Oncken, O., Rietbrock, A., Angiboust, S., and Heidbach, O. (2014). Locking of the Chile subduction zone controlled by fluid pressure before the 2010 earthquake. Nature Geoscience, 7(4):292-296.

Morton, E. A. and Bilek, S. L. (2015). Preliminary event detection of earthquakes using the Cascadia Initiative data. Seismological Research Letters, 86(5):1270-1277.

Murray, M. H., Marshall, G. A., Lisowski, M., and Stein, R. S. (1996). The 1992 M = 7 Cape Mendocino, California, earthquake: Coseismic deformation at the south end of the Cascadia megathrust. Journal of Geophysical Research: Solid Earth, 101(B8):1770717725 .

Nakamura, M., Ando, M., and Ohkura, T. (1998). Fine structure of deep Wadati-Benioff zone in the Izu-Bonin region estimated from S-to-P converted phase. Physics of the Earth and Planetary Interiors, 106(1):63-74.

Nakanishi, A., Smith, A. J., Miura, S., Tsuru, T., Kodaira, S., Obana, K., Takahashi, N., Cummins, P. R., and Kaneda, Y. (2004). Structural factors controlling the coseismic rupture zone of the 1973 Nemuro-Oki earthquake, the southern Kuril Trench seismogenic zone. Journal of Geophysical Research: Solid Earth, 109(B5).

Nakanishi, A., Takahashi, N., Park, J.-O., Miura, S., Kodaira, S., Kaneda, Y., Hirata, N., Iwasaki, T., and Nakamura, M. (2002). Crustal structure across the coseismic rupture zone of the 1944 Tonankai earthquake, the central Nankai Trough seismogenic zone. Journal of Geophysical Research: Solid Earth, 107(B1).

Nakata, N., Chang, J. P., Lawrence, J. F., and Boué, P. (2015). Body wave extraction and tomography at Long Beach, California, with ambient-noise interferometry. Journal of Geophysical Research: Solid Earth, 120(2):1159-1173.

Nakata, N. and Shelly, D. R. (2018). Imaging a Crustal Low-Velocity Layer Using Reflected Seismic Waves From the 2014 Earthquake Swarm at Long Valley Caldera, California: The Magmatic System Roof? Geophysical Research Letters, 45(8):3481-3488. 
Nedimović, M. R., Hyndman, R. D., Ramachandran, K., and Spence, G. D. (2003). Reflection signature of seismic and aseismic slip on the northern Cascadia subduction interface. Nature, 424(6947):416-420.

Niemeijer, A. and Spiers, C. (2006). Velocity dependence of strength and healing behaviour in simulated phyllosilicate-bearing fault gouge. Tectonophysics, 427(1):231-253.

Noda, H. and Lapusta, N. (2013). Stable creeping fault segments can become destructive as a result of dynamic weakening. Nature, 493(7433):518-521.

Nowack, R. L. and Bostock, M. G. (2013). Scattered waves from low-frequency earthquakes and plate boundary structure in northern Cascadia. Geophysical Research Letters, 40(16):4238-4243.

Obana, K., Scherwath, M., Yamamoto, Y., Kodaira, S., Wang, K., Spence, G., Riedel, M., and Kao, H. (2015). Earthquake activity in northern Cascadia subduction zone Off Vancouver Island revealed by oceanbottom seismograph observations. Bulletin of the Seismological Society of America, 105(1):489-495.

Obara, K. and Kato, A. (2016). Connecting slow earthquakes to huge earthquakes. Science, 353(6296):253-257.

Obara, K. and Sato, H. (1988). Existence of an S wave reflector near the upper plane of the double seismic zone beneath the Southern Kanto District, Japan. Journal of Geophysical Research: Solid Earth, 93(B12):15037-15045.

Ohmi, S. and Hori, S. (2000). Seismic wave conversion near the upper boundary of the Pacific plate beneath the Kanto district, Japan. Geophysical Journal International, 141(1):136148.

Okada, Y. (1992). Internal deformation due to shear and tensile faults in a half-space. Bulletin of the Seismological Society of America, 82(2):1018-1040.

Oleskevich, D. A., Hyndman, R. D., and Wang, K. (1999). The updip and downdip limits to great subduction earthquakes: Thermal and structural models of Cascadia, south Alaska, SW Japan, and Chile. Journal of Geophysical Research: Solid Earth, 104(B7):1496514991.

Olsen, K. M., Bangs, N. L., Tréhu, A. M., Han, S., Arnulf, A., and Contreras-Reyes, E. (2020). Thick, strong sediment subduction along south-central chile and its role in great earthquakes. Earth and Planetary Science Letters, 538:116195.

Oppenheimer, D., Eaton, J., Jayko, A., Lisowski, M., Marshall, G., Murray, M., Simpson, R., Stein, R., Beroza, G., Magee, M., Carver, G., Dengler, L., McPherson, R., Gee, L., Romanowicz, B., Gonzalez, F., Li, W. H., Satake, K., Somerville, P., and Valentine, D. (1993). The Cape Mendocino, California, earthquakes of April 1992: Subduction at the triple junction. Science, 261(5120):433-438.

Peacock, S. M., Christensen, N. I., Bostock, M. G., and Audet, P. (2011). High pore pressures and porosity at $35 \mathrm{~km}$ depth in the Cascadia subduction zone. Geology, 39(5):471-474. 
Peč, M., Stünitz, H., Heilbronner, R., Drury, M., and de Capitani, C. (2012). Origin of pseudotachylites in slow creep experiments. Earth and Planetary Science Letters, 355356:299 - 310 .

Peng, Z., Ben-Zion, Y., Michael, A. J., and Zhu, L. (2003). Quantitative analysis of seismic fault zone waves in the rupture zone of the 1992 Landers, California, earthquake: evidence for a shallow trapping structure. Geophysical Journal International, 155(3):1021-1041.

Peng, Z. and Gomberg, J. (2010). An integrated perspective of the continuum between earthquakes and slow-slip phenomena. Nature Geoscience, 3(9):599-607.

Perfettini, H. and Ampuero, J.-P. (2008). Dynamics of a velocity strengthening fault region: Implications for slow earthquakes and postseismic slip. Journal of Geophysical Research: Solid Earth, 113(B9):n/a-n/a. B09411.

Petersen, M. D., Moschetti, M. P., Powers, P. M., Mueller, C. S., Haller, K. M., Frankel, A. D., Zeng, Y., Rezaeian, S., Harmsen, S. C., Boyd, O. S., Field, E. H., Chen, R., Rukstales, K. S., Luco, N., Wheeler, R. L., and Olsen, A. H. (2014). 2014 update of the U.S. national seismic hazard maps. USGS National Seismic Hazard Mapping Project, Reston, VA.

Petersen, M. D., Shumway, A. M., Powers, P. M., Mueller, C. S., Moschetti, M. P., Frankel, A. D., Rezaeian, S., McNamara, D. E., Luco, N., Boyd, O. S., Rukstales, K. S., Jaiswal, K. S., Thompson, E. M., Hoover, S. M., Clayton, B. S., Field, E. H., and Zeng, Y. (2020). The 2018 update of the US National Seismic Hazard Model: Overview of model and implications. Earthquake Spectra, 36(1):5-41.

Peterson, D. E. and Keranen, K. M. (2019). A high wave speed basal sedimentary layer identified from seismic imaging of the plate boundary in central Cascadia. Journal of Geophysical Research: Solid Earth, 124(7):6832-6847.

Phillips, N. J., Belzer, B., French, M. E., Rowe, C. D., and Ujiie, K. (2020). Frictional strengths of subduction thrust rocks in the region of shallow slow earthquakes. Journal of Geophysical Research: Solid Earth, 125(3):e2019JB018888.

Pimienta, L., Schubnel, A., Violay, M., Fortin, J., Guéguen, Y., and Lyon-Caen, H. (2018). Anomalous $\mathrm{Vp} / \mathrm{Vs}$ ratios at seismic frequencies might evidence highly damaged rocks in subduction zones. Geophysical Research Letters, 45(22):12210-12217.

Poli, P., Campillo, M., Pedersen, H., and LAPNET Working Group (2012). Body-wave imaging of earth's mantle discontinuities from ambient seismic noise. Science, 338(6110):10631065 .

Pollitz, F. and Evans, E. (2017). Implications of the earthquake cycle for inferring fault locking on the cascadia megathrust. Geophysical Journal International, 209(1):167-185.

Pollitz, F. F. (2019). Surface imaging functions for elastic reverse time migration. Journal of Geophysical Research: Solid Earth, 124(3):2873-2895.

Pollitz, F. F., McCrory, P., Svarc, J., and Murray, J. (2008). Dislocation models of interseismic deformation in the western United States. Journal of Geophysical Research: Solid Earth, 113(B4). 
Pommier, A. and Evans, R. L. (2017). Constraints on fluids in subduction zones from electromagnetic data. Geosphere, 13(4):1026-1041.

Preston, L. A., Creager, K. C., Crosson, R. S., Brocher, T. M., and Trehu, A. M. (2003). Intraslab earthquakes: dehydration of the Cascadia slab. Science, 302(5648):1197-1200.

Ramos, M. D. and Huang, Y. (2019). How the transition region along the Cascadia megathrust influences coseismic behavior: Insights from 2-D dynamic rupture simulations. Geophysical Research Letters, 46(4):1973-1983.

Ranero, C. R., Grevemeyer, I., Sahling, H., Barckhausen, U., Hensen, C., Wallmann, K., Weinrebe, W., Vannucchi, P., von Huene, R., and McIntosh, K. (2008). Hydrogeological system of erosional convergent margins and its influence on tectonics and interplate seismogenesis. Geochemistry, Geophysics, Geosystems, 9(3).

Reading, A. M., Gubbins, D., and Mao, W. (2001). A multiphase seismic investigation of the shallow subduction zone, southern North Island, New Zealand. Geophysical Journal International, 147(1):215-226.

Remitti, F., Bettelli, G., and Vannucchi, P. (2007). Internal structure and tectonic evolution of an underthrust tectonic mélange: the Sestola-Vidiciatico tectonic unit of the Northern Apennines, Italy. Geodinamica Acta, 20(1-2):37-51.

Rice, J. R., Lapusta, N., and Ranjith, K. (2001). Rate and state dependent friction and the stability of sliding between elastically deformable solids. Journal of the Mechanics and Physics of Solids, 49(9):1865 - 1898. The JW Hutchinson and JR Rice 60th Anniversary Issue.

Rice, J. R. and Ruina, A. L. (1983). Stability of steady frictional slipping. Journal of Applied Mechanics, 50(2):343-349.

Robert, J.-L. and Fink, M. (2008). Green's function estimation in speckle using the decomposition of the time reversal operator: Application to aberration correction in medical imaging. The Journal of the Acoustical Society of America, 123(2):866-877.

Rogers, G. and Dragert, H. (2003). Episodic tremor and slip on the Cascadia subduction zone: The chatter of silent slip. Science, 300(5627):1942-1943.

Roland, E., Lizarralde, D., McGuire, J. J., and Collins, J. A. (2012). Seismic velocity constraints on the material properties that control earthquake behavior at the QuebradaDiscovery-Gofar transform faults, East Pacific Rise. Journal of Geophysical Research: Solid Earth, 117(B11).

Rollins, J. C. and Stein, R. S. (2010). Coulomb stress interactions among Mw 5.9 earthquakes in the Gorda deformation zone and on the Mendocino Fault Zone, Cascadia subduction zone, and northern San Andreas Fault. Journal of Geophysical Research: Solid Earth, 115(B12). B12306.

Ross, Z. E., Cochran, E. S., Trugman, D. T., and Smith, J. D. (2020). 3D fault architecture controls the dynamism of earthquake swarms. Science, 368(6497):1357-1361. 
Rowe, C. D., Meneghini, F., and Moore, J. C. (2011). Textural record of the seismic cycle: strain-rate variation in an ancient subduction thrust. Geological Society, London, Special Publications, 359(1):77-95.

Rowe, C. D., Moore, J. C., Meneghini, F., and McKeirnan, A. W. (2005). Large-scale pseudotachylytes and fluidized cataclasites from an ancient subduction thrust fault. Geology, 33(12):937-940.

Rowe, C. D., Moore, J. C., Remitti, F., and the IODP Expedition 343/343T Scientists (2013). The thickness of subduction plate boundary faults from the seafloor into the seismogenic zone. Geology, 41(9):991-994.

Rubinstein, J. L., Vidale, J. E., Gomberg, J., Bodin, P., Creager, K. C., and Malone, S. D. (2007). Non-volcanic tremor driven by large transient shear stresses. Nature, 448(7153):579-582.

Ruff, L. J. (1989). Do Trench Sediments Affect Great Earthquake Occurrence in Subduction Zones?, pages 263-282. Birkhäuser Basel, Basel.

Ruina, A. (1983). Slip instability and state variable friction laws. Journal of Geophysical Research: Solid Earth, 88(B12):10359-10370.

Saffer, D. M. and Bekins, B. A. (1999). Fluid budgets at convergent plate margins: Implications for the extent and duration of fault-zone dilation. Geology, 27(12):1095-1098.

Saffer, D. M. and Tobin, H. J. (2011). Hydrogeology and mechanics of subduction zone forearcs: Fluid flow and pore pressure. Annual Review of Earth and Planetary Sciences, 39(1):157-186.

Sagy, A., Brodsky, E. E., and Axen, G. J. (2007). Evolution of fault-surface roughness with slip. Geology, 35(3):283-286.

Savard, G., Bostock, M. G., and Christensen, N. I. (2018). Seismicity, metamorphism, and fluid evolution across the northern Cascadia fore arc. Geochemistry, Geophysics, Geosystems, 19(6):1881-1897.

Schmalzle, G. M., McCaffrey, R., and Creager, K. C. (2014). Central cascadia subduction zone creep. Geochemistry, Geophysics, Geosystems, 15(4):1515-1532.

Scholl, D. W., Kirby, S. H., von Huene, R., Ryan, H., Wells, R. E., and Geist, E. L. (2015). Great $(\geq \mathrm{Mw} 8.0)$ megathrust earthquakes and the subduction of excess sediment and bathymetrically smooth seafloor. Geosphere, 11(2):236-265.

Scholz, C. H. (1998). Earthquakes and friction laws. Nature, 391(6662):37-42.

Schwartz, S. Y. and Hubert, A. (1997). The state of stress near the Mendocino Triple Junction from inversion of earthquake focal mechanisms. Geophysical Research Letters, 24(10):1263-1266.

Schwartz, S. Y. and Rokosky, J. M. (2007). Slow slip events and seismic tremor at circumPacific subduction zones. Reviews of Geophysics, 45(3).

Segall, P. and Bradley, A. M. (2012a). Slow-slip evolves into megathrust earthquakes in 2d numerical simulations. Geophysical Research Letters, 39(18). 
Segall, P. and Bradley, A. M. (2012b). The Role of Thermal Pressurization and Dilatancy in Controlling the Rate of Fault Slip. Journal of Applied Mechanics, 79(3). 031013.

Segall, P. and Rice, J. R. (1995). Dilatancy, compaction, and slip instability of a fluidinfiltrated fault. Journal of Geophysical Research: Solid Earth, 100(B11):22155-22171.

Seno, T. (2009). Determination of the pore fluid pressure ratio at seismogenic megathrusts in subduction zones: Implications for strength of asperities and Andean-type mountain building. Journal of Geophysical Research: Solid Earth, 114(B5).

Shabelansky, A. H., Malcolm, A., and Fehler, M. (2015). Monitoring viscosity changes from time-lapse seismic attenuation: case study from a heavy oil reservoir. Geophysical Prospecting, 63(5):1070-1085.

Shabelansky, A. H., Malcolm, A. E., Fehler, M. C., Shang, X., and Rodi, W. L. (2014). Source-independent full wavefield converted-phase elastic migration velocity analysis. Geophysical Journal International, 200(2):954-968.

Shiina, T., Nakajima, J., Toyokuni, G., and Matsuzawa, T. (2014). Guided wave observations and evidence for the low-velocity subducting crust beneath Hokkaido, northern Japan. Earth, Planets and Space, 66(1):69.

Shillington, D. J., Bécel, A., Nedimović, M. R., Kuehn, H., Webb, S. C., Abers, G. A., Keranen, K. M., Li, J., Delescluse, M., and Mattei-Salicrup, G. A. (2015). Link between plate fabric, hydration and subduction zone seismicity in Alaska. Nature Geoscience, 8(12):961-964.

Shiraishi, K., Fujie, G., Sato, T., Abe, S., Asakawa, E., and Kodaira, S. (2017). Interferometric OBS imaging for wide-angle seismic data. Geophysics, 82(5):Q39-Q51.

Shlens, J. (2014). A tutorial on principal component analysis.

Sibson, R. H. (1975). Generation of pseudotachylyte by ancient seismic faulting. Geophysical Journal International, 43(3):775-794.

Sibson, R. H. (1996). Structural permeability of fluid-driven fault-fracture meshes. Journal of Structural Geology, 18(8):1031-1042.

Silver, E. and Beutner, E. (1980). Mélanges. Geology, 8(1):32-34.

Silver, P. (1983). Retrieval of source-extent parameters and the interpretation of corner frequency. Bulletin of the Seismological Society of America, 73(6A):1499-1511.

Singh, S. C., Carton, H., Tapponnier, P., Hananto, N. D., Chauhan, A. P. S., Hartoyo, D., Bayly, M., Moeljopranoto, S., Bunting, T., Christie, P., Lubis, H., and Martin, J. (2008). Seismic evidence for broken oceanic crust in the 2004 Sumatra earthquake epicentral region. Nature Geoscience, 1(11):777-781.

Song, T.-R. A., Helmberger, D. V., Brudzinski, M. R., Clayton, R. W., Davis, P., PérezCampos, X., and Singh, S. K. (2009). Subducting slab ultra-slow velocity layer coincident with silent earthquakes in southern Mexico. Science, 324(5926):502-506.

Song, T.-R. A. and Kim, Y. (2011). Anisotropic uppermost mantle in young subducted slab underplating Central Mexico. Nature Geoscience, 5. 
Song, T.-R. A. and Simons, M. (2003). Large trench-parallel gravity variations predict seismogenic behavior in subduction zones. Science, 301(5633):630-633.

Spinelli, G. A. and Saffer, D. M. (2004). Along-strike variations in underthrust sediment dewatering on the Nicoya margin, Costa Rica related to the updip limit of seismicity. Geophysical Research Letters, 31(4).

Spinelli, G. A., Saffer, D. M., and Underwood, M. B. (2006). Hydrogeologic responses to three-dimensional temperature variability, Costa Rica subduction margin. Journal of Geophysical Research: Solid Earth, 111(B4).

Spudich, P. and Bostwick, T. (1987). Studies of the seismic coda using an earthquake cluster as a deeply buried seismograph array. Journal of Geophysical Research: Solid Earth, 92(B10):10526-10546.

Stephens, C. D., Page, R. A., and Lahr, J. C. (1990). Reflected and mode-converted seismic waves within the shallow Aleutian Subduction Zone, Southern Kenai Peninsula, Alaska. Journal of Geophysical Research: Solid Earth, 95(B5):6883-6897.

Stephenson, W. J., Reitman, N. G., and Angster, S. J. (2017). P- and S-wave velocity models incorporating the Cascadia subduction zone for 3D earthquake ground motion simulations-Update for OFR 2007-1348. U.S. Geol. Surv. Open-File Rept. 2017-1152, pages 3139-3156.

Takahashi, N., Kodaira, S., Tsuru, T., Park, J.-O., Kaneda, Y., Suyehiro, K., Kinoshita, H., Abe, S., Nishino, M., and Hino, R. (2004). Seismic structure and seismogenesis off Sanriku region, northeastern Japan. Geophysical Journal International, 159(1):129-145.

Tauzin, B., Bodin, T., Debayle, E., Perrillat, J.-P., and Reynard, B. (2016). Multi-mode conversion imaging of the subducted Gorda and Juan de Fuca plates below the North American continent. Earth and Planetary Science Letters, 440:135 - 146.

Tauzin, B., Reynard, B., Perrillat, J.-P., Debayle, E., and Bodin, T. (2017). Deep crustal fracture zones control fluid escape and the seismic cycle in the Cascadia subduction zone. Earth and Planetary Science Letters, 460:1-11.

Tauzin, B., van der Hilst, R. D., Wittlinger, G., and Ricard, Y. (2013). Multiple transition zone seismic discontinuities and low velocity layers below western United States. Journal of Geophysical Research: Solid Earth, 118(5):2307-2322.

Thakur, P., Huang, Y., and Kaneko, Y. (2020). Effects of low-velocity fault damage zones on long-term earthquake behaviors on mature strike-slip faults. Journal of Geophysical Research: Solid Earth, 125(8):e2020JB019587.

Thomas, M. Y., Avouac, J.-P., and Lapusta, N. (2017). Rate-and-state friction properties of the longitudinal valley fault from kinematic and dynamic modeling of seismic and aseismic slip. Journal of Geophysical Research: Solid Earth, 122(4):3115-3137.

Thorwart, M. (2006). Wavefield methods to analyze passive ocean bottom seismic dataApplication to the Tyrrhenian Sea. PhD thesis, University of Hamburg. 
Thurber, C., Zhang, H., Brocher, T., and Langenheim, V. (2009). Regional threedimensional seismic velocity model of the crust and uppermost mantle of northern California. Journal of Geophysical Research: Solid Earth, 114(B1).

Tonegawa, T., Fukao, Y., Fujie, G., Takemura, S., Takahashi, T., and Kodaira, S. (2015). Geographical distribution of shear wave anisotropy within marine sediments in the northwestern Pacific. Progress in Earth and Planetary Science, 2(1):27.

Toomey, D. R., Allen, R. M., Barclay, A. H., Bell, S. W., Bromirski, P. D., Carlson, R. I., Chen, X., Collins, J. A., Dziak, R. P., Evers, B., Forsyth, D. W., Gerstoft, P., Hooft, E. E., Livelybrooks, D., Lodewyk, J. A., Luther, D. S., McGuire, J. J., Schwartz, S. Y., Tolstoy, M., m. Tréhu, A., Weirathmueller, M., and Wilcock, W. S. (2014). The Cascadia Initiative: A sea change In seismological studies of subduction zones. Oceanography, 27(2):138-150.

Touma, R., Blondel, T., Derode, A., Campillo, M., and Aubry, A. (2020). A distortion matrix framework for high-resolution passive seismic 3D imaging: Application to the San Jacinto fault zzone, California. working paper or preprint.

Trehu, A. M. and Mendocino Working Group (1995). Pulling the rug out from under california: Seismic images of the mendocino triple junction region. Eos, Transactions American Geophysical Union, 76(38):369-381.

Tromp, J., Komatitsch, D., and Liu, Q. (2008). Spectral-element and adjoint methods in seismology. Communications in Computational Physics, 3(1):1-32.

Um, J. and Thurber, C. (1987). A fast algorithm for two-point seismic ray tracing. Bulletin of the Seismological Society of America, 77(3):972-986.

Underwood, M. B., Laughland, M. M., and Kang, S. M. (1993). A comparison among organic and inorganic indicators of diagenesis and low-temperature metamorphism, Tertiary Shimanto Belt, Shikoku, Japan. Geol. Soc. Am. Spec. Pap, 273:45-61.

Uyeda, S. and Kanamori, H. (1979). Back-arc opening and the mode of subduction. Journal of Geophysical Research: Solid Earth, 84(B3):1049-1061.

van Rijsingen, E., Lallemand, S., Peyret, M., Arcay, D., Heuret, A., Funiciello, F., and Corbi, F. (2018). How subduction interface roughness influences the occurrence of large interplate earthquakes. Geochemistry, Geophysics, Geosystems, 19(8):2342-2370.

Vandenberghe, L. and Boyd, S. (1996). Semidefinite programming. SIAM Rev., 38(1):49-95.

Vannucchi, P., Remitti, F., and Bettelli, G. (2008). Geological record of fluid flow and seismogenesis along an erosive subducting plate boundary. Nature, 451(7179):699-703.

Vannucchi, P., Sage, F., Phipps Morgan, J., Remitti, F., and Collot, J.-Y. (2012). Toward a dynamic concept of the subduction channel at erosive convergent margins with implications for interplate material transfer. Geochemistry, Geophysics, Geosystems, 13(2).

Verdonck, D. and Zandt, G. (1994). Three-dimensional crustal structure of the Mendocino Triple Junction region from local earthquake travel times. Journal of Geophysical Research: Solid Earth, 99(B12):23843-23858. 
Vidale, J. E. (1986). Complex polarization analysis of particle motion. Bulletin of the Seismological Society of America, 76(5):1393-1405.

Von Herzen, R., Ruppel, C., Molnar, P., Nettles, M., Nagihara, S., and Ekström, G. (2001). A constraint on the shear stress at the Pacific-Australian plate boundary from heat flow and seismicity at the Kermadec forearc. Journal of Geophysical Research: Solid Earth, 106(B4):6817-6833.

Wada, I., Mazzotti, S., and Wang, K. (2010). Intraslab stresses in the Cascadia subduction zone from inversion of earthquake focal mechanisms. Bulletin of the Seismological Society of America, 100(5A):2002-2013.

Wakabayashi, J. (1992). Nappes, Tectonics of Oblique Plate Convergence, and Metamorphic Evolution Related to 140 Million Years of Continuous Subduction, Franciscan Complex, California. The Journal of Geology, 100(1):19-40.

Wakabayashi, J. (2011). Mélanges of the Franciscan Complex, California: Diverse structural settings, evidence for sedimentary mixing, and their connection to subduction processes. In Mélanges: Processes of Formation and Societal Significance. Geological Society of America.

Wallace, L. M., Araki, E., Saffer, D., Wang, X., Roesner, A., Kopf, A., Nakanishi, A., Power, W., Kobayashi, R., Kinoshita, C., Toczko, S., Kimura, T., Machida, Y., and Carr, S. (2016). Near-field observations of an offshore Mw 6.0 earthquake from an integrated seafloor and subseafloor monitoring network at the Nankai Trough, southwest Japan. Journal of Geophysical Research: Solid Earth, 121(11):8338-8351. 2016JB013417.

Wallace, L. M., Ellis, S., Miyao, K., Miura, S., Beavan, J., and Goto, J. (2009a). Enigmatic, highly active left-lateral shear zone in southwest Japan explained by aseismic ridge collision. Geology, 37(2):143-146.

Wallace, L. M., Reyners, M., Cochran, U., Bannister, S., Barnes, P. M., Berryman, K., Downes, G., Eberhart-Phillips, D., Fagereng, A., Ellis, S., Nicol, A., McCaffrey, R., Beavan, R. J., Henrys, S., Sutherland, R., Barker, D. H. N., Litchfield, N., Townend, J., Robinson, R., Bell, R., Wilson, K., and Power, W. (2009b). Characterizing the seismogenic zone of a major plate boundary subduction thrust: Hikurangi Margin, New Zealand. Geochemistry, Geophysics, Geosystems, 10(10).

Wang, K. and Bilek, S. L. (2011). Do subducting seamounts generate or stop large earthquakes? Geology, 39(9):819-822.

Wang, K. and Bilek, S. L. (2014). Invited review paper: Fault creep caused by subduction of rough seafloor relief. Tectonophysics, 610:1-24.

Wang, K. and Rogers, G. C. (1994). An explanation for the double seismic layers north of the Mendocino Triple Junction. Geophysical Research Letters, 21(2):121-124.

Wang, K. and Tréhu, A. M. (2016). Invited review paper: Some outstanding issues in the study of great megathrust earthquakes - The Cascadia example. Journal of Geodynamics, 98:1-18. 
Wannamaker, P. E., Evans, R. L., Bedrosian, P. A., Unsworth, M. J., Maris, V., and McGary, R. S. (2014). Segmentation of plate coupling, fate of subduction fluids, and modes of arc magmatism in Cascadia, inferred from magnetotelluric resistivity. Geochemistry, Geophysics, Geosystems, 15(11):4230-4253.

Wech, A. G. and Creager, K. C. (2011). A continuum of stress, strength and slip in the Cascadia subduction zone. Nature Geoscience, 4:624.

Wei, M., Liu, Y., Kaneko, Y., McGuire, J. J., and Bilham, R. (2015a). Dynamic triggering of creep events in the Salton Trough, Southern California by regional earthquakes constrained by geodetic observations and numerical simulations. Earth and Planetary Science Letters, 427:1-10.

Wei, M. and McGuire, J. J. (2014). The Mw 6.5 offshore Northern California earthquake of 10 January 2010: Ordinary stress drop on a high-strength fault. Geophysical Research Letters, 41(18):6367-6373. 2014GL061043.

Wei, S., Barbot, S., Graves, R., Lienkaemper, J. J., Wang, T., Hudnut, K., Fu, Y., and Helmberger, D. (2015b). The 2014 mw6.1 south napa earthquake: A unilateral rupture with shallow asperity and rapid afterslip. Seismological Research Letters, 86(2A):344-354.

Wells, R. E., Blakely, R. J., Sugiyama, Y., Scholl, D. W., and Dinterman, P. A. (2003). Basincentered asperities in great subduction zone earthquakes: A link between slip, subsidence, and subduction erosion? Journal of Geophysical Research: Solid Earth, 108(B10).

Wessel, P., Smith, W. H. F., Scharroo, R., Luis, J., and Wobbe, F. (2013). Generic mapping tools: Improved version released. Eos, Transactions American Geophysical Union, 94(45):409-410.

White, J. C. (2012). Paradoxical pseudotachylyte - fault melt outside the seismogenic zone. Journal of Structural Geology, 38:11 - 20. Physico-Chemical Processes in Seismic Faults.

Williams, T. B., Kelsey, H. M., and Freymueller, J. T. (2006). GPS-derived strain in northwestern California: Termination of the San Andreas fault system and convergence of the Sierra Nevada-Great Valley block contribute to southern Cascadia forearc contraction. Tectonophysics, 413(3):171-184.

Wilson, D. S. (1989). Deformation of the so-called Gorda Plate. Journal of Geophysical Research: Solid Earth, 94(B3):3065-3075.

Wirth, E. A., Frankel, A. D., Marafi, N., Vidale, J. E., and Stephenson, W. J. (2018). Broadband synthetic seismograms for magnitude 9 earthquakes on the Cascadia megathrust based on 3D simulations and stochastic synthetics, Part 2: Rupture parameters and variability. Bulletin of the Seismological Society of America, 108(5A):2370-2388.

Zhang, H. and Thurber, C. H. (2003). Double-Difference Tomography: The Method and Its Application to the Hayward Fault, California. Bulletin of the Seismological Society of America, 93(5):1875-1889.

Zhu, L. and Rivera, L. A. (2002). A note on the dynamic and static displacements from a point source in multilayered media. Geophysical Journal International, 148(3):619-627. 